\title{
Epic Television - Music and Sound in Ramayan and Mahabharat
}

\author{
Dissertation \\ zur Erlangung des philosophischen Doktorgrades \\ an der Philosophischen Fakultät der Georg-August-Universität Göttingen
}

vorgelegt von Britta Lesniak

aus Detmold

Göttingen 2017 


\section{Zusammenfassung}

\section{Epic Television: Music and Sound in Ramayan and Mahabharat}

In der vorliegenden Dissertation untersuche ich die Musik der zwei Hindisprachigen indischen TV-Serien Ramayan und Mahabharat, die von 1987 bis 1990 auf Indiens damals einzigem TV-Sender, Doordarshan, ausgestrahlt wurden. Leitend ist dabei die Frage nach dem, was Musik und Klang im Format der Fernsehserie tun und bewirken können. Mit dieser Fragestellung erweitere ich die bisherige Erforschung von Fernsehmusik, in der bislang ausschließlich Produktionen aus dem nordamerikanischen und europäischen Raum berücksichtigt wurden, um einen entscheidenden Beitrag, indem ich die Diskussion über Serienformate aus anderen Regionen mit anderen kulturellen Selbstverständnissen und Erzähldynamiken eröffne.

Die Serien, die in der vorliegenden Dissertation untersucht werden, haben ein Stück indische Fernsehgeschichte geschrieben: Sie gehörten nicht nur zu den ersten in Indien produzierten televisuellen Unterhaltungsformaten, sondern sie waren darüber hinaus auch die ersten Sendungen, die mythologische, Hindu religiöse Inhalte ins indische Fernsehen brachten - und dort auch etablierten. Die Geschichten, die Ramayan und Mahabharat, benannt nach zwei gleichnamigen Epen bzw. Stofftraditionen, erzählen, drehen sich maßgeblich um zwei Hindu-Gottheiten. Da die Serien die beliebten Stoffe erstmals ins Fernsehen überführten, lösten sie einen beispiellosen Ansturm auf das Medium aus, der die Dynamiken des öffentlichen Lebens während ihrer Ausstrahlung am Sonntagmorgen spürbar veränderte. Die beiden Serien polarisierten die indische Öffentlichkeit und wurden auch in wissenschaftlichen Diskursen kontrovers diskutiert. In jedem Fall waren Ramayan und Mahabharat populärkulturelle Meilensteine, die das nunmehr im indischen Fernsehen florierende Genre der (Hindu) mythologischen Serie begründeten.

Die Klänge der Serien befinden sich also an einer einzigartigen historischen Schnittstelle, in der das indische Fernsehen seine eigene Stimme findet und dabei zugleich (religiöse) Stoffe aufarbeitet, die seit Jahrhunderten in vielen verschiedenen Formaten mit eigenen Ästhetiken überliefert wurden. Die Musik der Serien ist damit also nicht nur beispielhaft für klangliches Erzählen im indischen Fernsehen, sondern zeigt zudem die Anfänge einer eigenen medialen Ästhetik auf. 
In der Arbeit stelle ich zunächst diesen Kontext der Serien sowie meine Fragestellung vor und positioniere die Arbeit in den Diskursen um die Serien sowie in der bestehenden Forschung zu Fernsehmusik. Ich erläutere meinen methodischen Ansatz, der ethnografische Methoden (zwei Feldforschungsaufenthalte in Neu Delhi und Mumbai, Indien) und close readings des Serienmaterials vereint, gebe einen Überblick über die Forschungsliteratur zu den Serien und zu Musik im Fernsehen und stelle anschließend kurz die Produktionsprozesse der Serienmusik vor.

Nachdem ich in die Hintergründe und die spezifische Ausrichtung meiner Fragestellung eingeführt habe, umreiße ich in Kapitel 2, 'Music in Television Serials', die konzeptuellen und theoretischen Grundlagen meiner Analysen der Musik und Klänge in Ramayan und Mahabharat. Ausgehend von der Prämisse, dass Musik ein erzählendes Element in Fernsehserien ist, erarbeite ich unter Bezugnahme auf intermediale Erzähltheorie, Filmmusikforschung und Fernsehmusikforschung einen konzeptuellen Rahmen für die Narrativität von Musik im audiovisuellen Kontext. Die Wirkung von Musik in Fernsehserien geht über das Vermitteln von Inhalten und formalen Rahmen hinaus und beinhaltet eine tiefgreifende emotionale, körperlich fassbare Dimension. Damit, so meine Behauptung, lässt sie sich nicht allein mit dem Konzept der Narrativität erfassen, das mehr die strukturellen Effekte des Erzählens von Musik bezeichnet aber nicht erfasst, wie Musik und Klang ohne den konkreten semantischen Gehalt von Worten erzählen. Daher zeige ich auf, dass es die Materialität von Klang ist, die ihm seine erzählenden Funktionen verleiht. Ich verstehe Klang als Atmosphäre, die die Zuhörenden umspült, durchdringt, auf diese Weise kulturelles Wissen mobilisiert und das Publikum auf zutiefst körperlich spürbare Weise bewegen kann. Vor diesem Hintergrund skizziere ich dann die analytischen Kategorien, die sich aus diesem konzeptuellen Rahmen ergeben und gebe eine Übersicht über die Klänge, die Formen und Ästhetiken der Musik in Ramayan und Mahabharat.

Im dritten Kapitel, 'Amalgamated Narrations', gehe ich auf die Zusammensetzung der Serien(musiken) vor dem Hintergrund ihrer vielfältigen Überlieferungs- und Stofftraditionen ein, die über ganz Südasien verbreitet sind. Ich fasse zusammen, welche dieser Traditionen und Ästhetiken für die Klänge der Serien besonders maßgeblich waren und analysiere dann exemplarisch die Vorspann-Sequenzen von Ramayan und Mahabharat, an denen sich die Schwerpunkte und Textur dieser Verschmelzung von Erzähltraditionen besonders illustrativ zeigen. Dabei gehe ich nicht nur darauf ein, wie 
die Sequenzen spezifische Lesarten der Stoffe suggerieren, sondern auch auf ihre zentrale strukturgebende Funktion für das Format der Fernsehserie.

Kapitel vier, das die Überschrift 'Sonic Dimensions of Normativity, Moral, and Religion' trägt, ist - wie der Titel erahnen lässt - dem verwobenen Komplex von Religion, Moral und sozialen Normen, der in Mahabharat und Ramayan vorherrschend ist, gewidmet. Ich erarbeite, wie dieser Komplex klanglich konstruiert und evoziert wird. Dabei betrachte ich zunächst, wie in den Serien Hindu religiöse Praxis klanglich dargestellt wird, und diskutiere das besondere Potenzial von Klang nicht nur als Mittel zur Repräsentation religiöser Praxis, sondern als eigenes Medium religiöser Praxis. Die Darstellung von religiöser Praxis ist eng verwoben mit dem moralischen Gerüst, das die Serien entwerfen, und das sie mit universalistischem Anspruch kommunizieren. In Mahabharat und Ramayan sind Klang und Musik zentrale Elemente dieses moralischen Rahmens, da sie moralische Kategorien durch ihr atmosphärisch-narratives Wirken und etwa durch die Darstellung von Figuren und Handlungselementen mitkonstruieren. Die klanglich vermittelte Normativität, die so entsteht, analysiere ich hier exemplarisch anhand der klanglichen Konstruktion von Geschlechternormen in Ramayan und Mahabharat.

Im fünften Kapitel, 'Fighting, Roaring, Screaming: The Sounds of Violence' befasse ich mich mit einem weiteren Aspekt, der beide Serien zentral prägt: Gewalt. Ich erarbeite hier, wie die audiovisuelle Repräsentation von Gewalt in den Serien ästhetisiert wird und wie diese Darstellungen den Fluss und Verlauf der beiden seriellen Narrative prägen. Dabei argumentiere ich, dass Klang nicht nur ein unerlässliches Mittel für die verständliche, für das Publikum nachvollziehbare Darstellung von Gewaltszenen ist, sondern dass er die Intensität der gewaltsamen Begegnungen der Figuren auf einzigartige Weise spürbar machen kann. Ich verdeutliche, wie die Klänge die Dimension des Körperlichen in die körperlos-ästhetisierten Gewaltdarstellungen von Ramayan und Mahabharat einbringen und es dem Publikum so ermöglichen, diese Szenen als intensiv wahrzunehmen und den komplexen Empfindungen gewaltsamer Begegnungen nachzuspüren. Zudem zeige ich auf, wie Klang und Musik in Repräsentationen von Gewalt dazu dienen, die Vorstellungen von Moral und geschlechtlicher Normativität der Serien zu übermitteln, wodurch sich Schnittstellen zu Kapitel 4 ergeben.

In Kapitel 6, 'Epic Television: TV-Frenzy, Legends, and Nostalgia' gehe ich abschließend auf den legendären populärkulturellen Status der Serien ein. Während ihrer 
Erstausstrahlung zogen die Serien ein Massenpublikum nie dagewesenen Ausmaßes an. Die Ausprägungen und Dimensionen dieser Begeisterung wurden nicht nur damals in der Presse diskutiert, sondern fanden ihren Weg auch in den wissenschaftlichen Diskurs über die Serien und werden bis heute im Reden über die Serien herangezogen. Ich analysiere, wie diese Erzählungen das Bild und die Erinnerungen an die Serien prägen, wie die Klänge der Serien heute, beinahe 30 Jahre nach ihrer Ausstrahlung, als Anker für nostalgische Erinnerungen dienen und zeige auf, wie die Serien selbst, sowie auch visuelle und klangliche Fragmente aus ihnen, bis heute nachhaltige Strahlkraft auf indische Populärkultur ausüben. 


\section{TABLE OF Content}

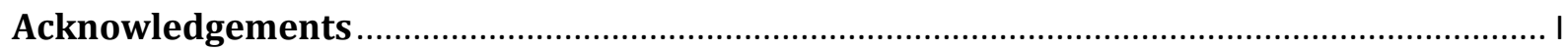

List of Characters in Ramayan and Mahabharat .................................................................. III

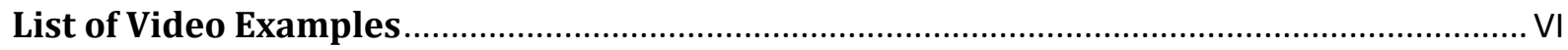

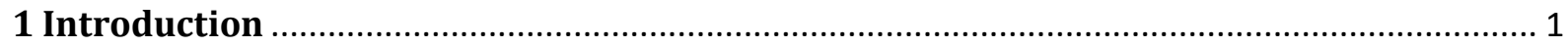

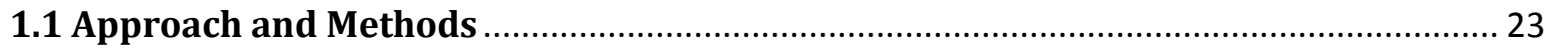

1.2 Overview - Research on Ramayan, Mahabharat, and Music in Television................. 32

1.3 Ensounding Mythological Worlds: Music Production for Ramayan and Mahabharat

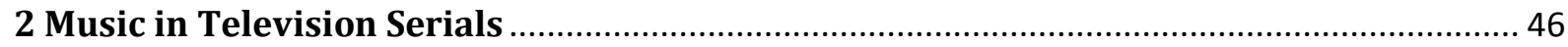

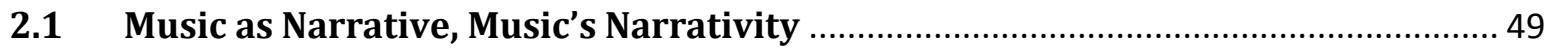

2.2 Music as a Narrative Device in Ramayan and Mahabharat .................................... 72

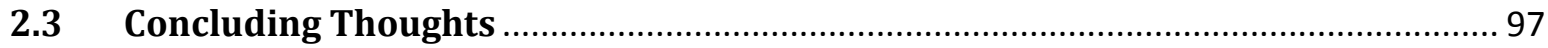

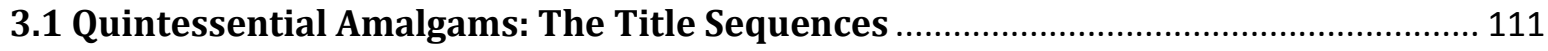

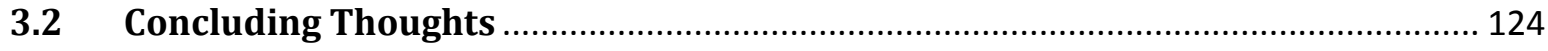

4 Sonic Dimensions of Normativity, Moral, and Religion ................................................... 126

4.1 Yajna, Bhakti, Puja: Religious Practice as Music, Religious Practice and Music ....... 132

4.2 Dharm-Adharm and Subtler Nuances: Creating Morality and Normativity through

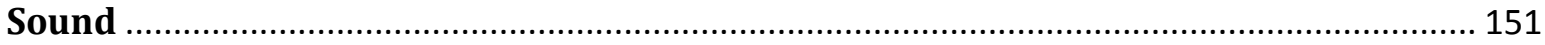

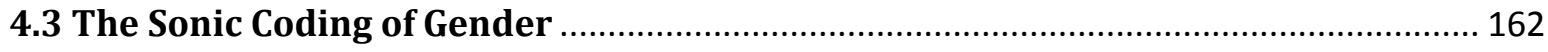

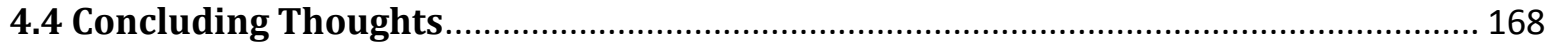

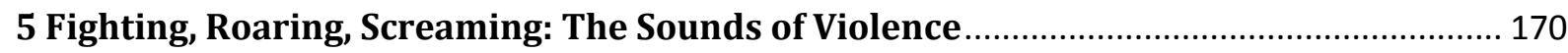

5.1 The Sounds of Violence and the Rhythms of the Narratives....................................... 179

5.2 Audio-Visual Conventions and Aesthetics of Violence in Mahabharat and Ramayan

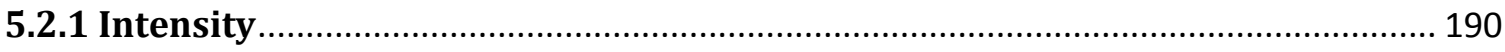

5.3 Aural Valorization of Violence: Norms, Moral and Gender......................................... 200

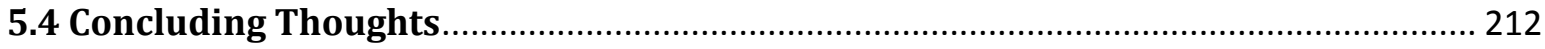

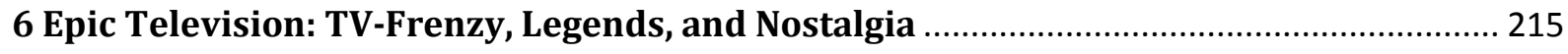

6.1 Perspectives on Mahabharat and Ramayan - Now and Then .................................. 217

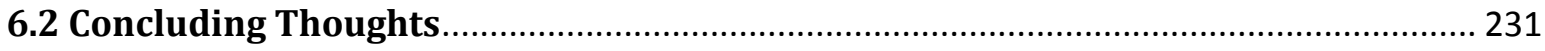

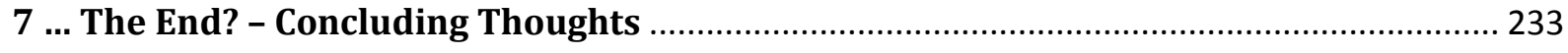


Filmography

Bibliography .

Online Sources 



\section{Acknowledgements}

First of all, I want to thank my first supervisor Prof. Dr. Birgit Abels. Besides her extreme patience with me, she has encouraged me over and over to find my own path during the research and throughout the writing of this dissertation. With her constructive feedback and her constant support, she has the capacity to always ground me and to bring me back to the core of the work. My second supervisor, Prof. Dr. Patrick Eisenlohr I want to thank for his interest in my work far beyond the boundaries of his own discipline. His feedback was invaluable and always gave me impulses to think my work further. Prof. Dr. Andreas Waczkat I thank for his willingness to be a third reader of this dissertation, and his helpful feedback during earlier presentations. I want to thank Frank Kelleter and every member and associate member of the entire DFG-Research Unit Popular Seriality: Aesthetics and Practice for including me in this fantastic group for three years and for all the input and exchange during this time, from which I benefited immensely.

For financing my research and writing with scholarships and funding, and for the substantial ideational support I want to thank the Studienstiftung des deutschen Volkes and the Graduiertenschule für Geisteswissenschaften Göttingen.

My research in New Delhi and Mumbai, India, in 2015 and 2016 would have been impossible without the help from several people. I want to thank Prof. Dr. Philip Lutgendorf for providing me with the material from which I got my first contacts, and Dr. Shubha Chaudhuri at the Archives and Research Center for Ethnomusicology in Gurgaon for her help with my work there and her input. Minnie Vaid and Nitish Bharadwaj were especially helpful when I was trying to get my research started. They generously provided me with contacts and sacrificed their time to meet me, be interviewed by me and spend time with me. Thank you very much. I further want to thank (in alphabetical order) all those people who spent their spare time talking with me and answering my many - and often weird - questions:

Aashish, Abhay, Ajay G., Ajay S., Arjun, Ashwin, Atul, Bhavdeep, Darryl, Gaurav, Gufi Paintal, Inder, Irfan, Jai, Kanika, Kavita, Lucille, Maithili, Naresh, Omar, Palak, Poorva, Prem Sagar, Raju, Rathna, Ravindra Jain, Rohit, Shailaja B., Shailja K., Shubhra, Sudhish, Sunny, Surya Raj Kamal, Sushil, Uttank, and Vinay. 
Especially the fantastic women who opened their doors to accommodate me, took me under their wings and helped me to get set and oriented in India during the first phases of the research, were lifesavers. Their voices have been of immense value to my research. Thank you! Akshay and Tapas have helped me with great enthusiasm. Without their help I would not have gotten anywhere with my research. Not only the content of their ideas were incredibly valuable, but their willingness to give me their time and provide me with further contacts, was incredible. The friendships that developed out of our time together are an extra bonus. I also want to thank Divya and Deepak for both their support in the research as well as their friendship. Laura and Philipp, thank you for so generously giving me a home away from home during my second stay and for being awesome friends. Those weeks with you were the best!

The help and encouragement I received from all of you, and the friendships that evolved from my time in India, are very important to me.

My colleagues Christine, Gerlinde and Charissa, I thank for being a constant source of exchange, of learning, of constructive feedback, invaluable input, emotional support and tons of fun (and places to sleep). Rasika, thank you for your quick help during the final days of writing this dissertation. Especially Eva I want to thank for sharing the intensity of this period, during which you calmed me down, helped me, cheered me on, practically sub-let your apartment to me and became one of my best friends - I can't thank you enough.

Last but not least, I want to thank my parents, my sister, and my partner, who have dealt with my emotional turmoil and frequent absence for the last four years, traveled around the world to be with me, and gave me all the love, space, courage, and time that I needed to write this dissertation. You had superhuman patience with me! Thank you so much, I could not have done it without you. 


\section{List of Characters in Ramayan and Mahabharat}

\section{$\underline{\text { Ramayan }}$}

Ahalya, cursed woman

Bali, brother of Sugriv, rival to the throne of his kingdom

Bharat, Brother of Ram, Lakshman and Shatrugn, prince of Ayodhya

Dasharath, king of Ayodhya, father of Ram, Bharat, Lakshman and Shatrugn

Hanuman, monkey god, ally and helper of Ram

Indrajit (Meghnad), eldest son of Ravan

Janak, king of Mithila, father of Sita

Jatayu, the king of vultures

Kaikeyi, (youngest) wife of Dasharat, mother of Bharat

Kaushalya, (eldest) wife of Dasharat, mother of Ram

Lakshman, brother of Ram and Bharat, twin brother of Shatrugn

Mandodari, wife of Ravan

Manthara, waiting maid of Kaikeyi

Ram, protagonist, prince of Ayodhya, brother of Bharat, Lakshman and Shatrugn

Ravan, demon king of Lanka

Shatrughn, brother of Ram and Bharat, twin brother of Lakshman

Shurpanka, sister of Ravan, demoness

Sita, wife of Ram, daughter of king Janak of Mithila

Sumitra, wife of Dasharat, mother of Lakshman and Shatrugn

Sugriv, monkey king, rival of his brother Bali

Swayamprabha, guardian of the magical cave who transports the monkeys to the shore

Tadaka, demoness

Vibhishan, brother of Ravan, devotee of Ram

Vishwamitra, sage 


\section{Mahabharat}

Duryodhan, the eldest

\section{Dushasan}

98 brothers
The Kaurava brothers, princes of Hastinapur, sons of Dhritarashtr and Gandhari

Arjun, supreme archer

Bhim, the strongest

Nakul, twin brother of Sahadev

Sahadev, twin brother of Nakul

Yudhishthir, eldest brother, later righteous king

The Pandava brothers, princes of Hastinapur (and later Indraprasth), sons of Kunti, nephews of Dhritarashtr

Amba princess of Kashi, abandoned by Bhishm, seeks revenge, later reborn as Shikhandi

Ambalika, princess of Kashi, sister of Amba and Ambika, mother of king Pandu

Ambika, princess of Kashi, sister of Amba and Ambika, mother of king Dhritarashtr

Balram, Krishna's older brother, cousin of the Pandavas

Bharat, ancestor of Kauravas and Pandavas, king of Hastinapur

Bhishm (Devavrat), son of king Shantanu of Hastinapur, former heir to the throne, half-greatuncle to the Kauravas and Pandavas

Chitrangad, son of Satyavati and Shantanu, dies childless

Devki, mother of Krishna

Dhritarashtr, king of Hastinapur, father of the Kauravas

Draupadi, princess of Panchala, wife of the five Pandavas

Dron, archer, warrior, teacher of the Kauravas and Pandavas

Eklavya, tribal prince, illegitimately learns from Dron

Gandhari, wife of Dhritarashtra, queen of Hastinapur, mother of the Kauravas, sister of Shakuni

Ganga, river goddess, first wife of Shantanu, mother of Devavrat/Bhishm

Jarasandh, king of Magadh, enemy of the Pandavas

Kansa, uncle of Krishna

Karn, illegitimate son of Kunti and the sun god, loyal friend of Duryodhan

Krishna, divine cousin of the Pandavas, Arjun's charioteer during the war

Kunti, wife of Pandu, mother of Yudhishthir, Arjun and Bhim

Madri, second wife of Pandu, mother of Nakul and Sahadev 
Nanda, foster father of Krishna

Pandu, brother of Dhritarashtra, father of the Pandavas, short-time king of Hastinapur

Satyavati, second wife of king Shantanu of Hastinapur, mother of Vichitravirya, mother of Vyas, grandmother of Dhritarashtr and Pandu

Shakuni, king of Gandhar, brother of Gandhari, uncle of the Kauravas

Shantanu, king of Hastinapur, father of Devavrat/Bhishm, and of Víchitravirya

Shikhandi, brother of Draupadi, was Amba in a former life, seeks to kill Bhishm

Vasudev, father of Krishna and Balram

Vichitravirya, son of Satyavati and Shantanu, dies before he has children

Vidur, half-brother of Pandu and Dhritarashtr, wise minister of Hastinapur

Virat, king of Matsya at whose court the Pandavas hide during exile

Vyas, sage, illegitimate son of Satyavati

Yashoda, foster mother of Krishna 


\title{
List of Video Examples ${ }^{1}$
}

\author{
Chapter 2, Music in Television Serials
}

2.1 Mahabharat E 58 (11:35 - 27:28), plan for and execution of Keechak's death

2.2 Mahabharat E 19 (24:20 - 25:34), Shakuni's passage

2.3 Mahabharat, E 1 (00:00 - 00:43), narrator Samay

2.4 Mahabharat, E 34 (41:36 - 42:07), sung summarizing section

2.5 Ramayan, E 43 (24:06 - 24:56), singing narrator's shifting focalization

2.6 Ramayan, E 4 (04:05 - 04:23), swarmandal passage

2.7 Ramayan, E 45 (24:33 - 24:58), morphing, pulsating synthesizer

2.8 Ramayan, E 9 (12:16 - 13:04), 'soft' instrumental - sitar, bansuri

2.9 Ramayan, E 38 (03:23 - 04:19), swirling orchestral music

2.10 Ramayan E 30 (13: 15 - 13:42), noisy synthesizer

2.11 Mahabharat E 9, (33:09 - 33:25), divine encounter

2.12 Mahabharat E 3, (07:30 - 07:58), blend melodic synthesizer

2.13 Ramayan E 56 (01:25 - 01:33), tutari

2.14 Mahabharat E 59 (27:18 - 27:25), conch

2.15 Mahabharat E 51 (16:15 - 16: 34), women dancing

2.16 Mahabharat E 39 (05:36 - 06:06), Om Jai Jagdish Hare

2.17 Ramayan E 10 (06: 54 - 30:23), musical mosaic Ram and Sita's wedding

2.18 Ramayan E 57 (10:41 - 11:18), singing narrator paraphrases dialogue

\section{Chapter 3 - Amalgamated Narration}

3.1 Mahabharat E 14 (07:43 - 14:16), Krishna bhajan I and arti

3.2 Mahabharat E 14 (19:20 - 25:17), Krishna bhajan II

3.3 Mahabharat E 14 (38:45 - 42:27), Krishna submits Kaliya

\footnotetext{
${ }^{1}$ All of these video examples, which are the base of the analyses in this thesis, are sequences from two DVD-sets with digitally remastered versions of the serials Mahabharat (B.R. Chopra, Ravi Chopra, Arrow Films 2009) and Ramayan (Ramanand Sagar, Asian Video Movie). They were the base of the research process going into this thesis and unless otherwise marked are sources of the examples mentioned throughout the texts. 
3.4 Mahabharat E 1 (02:41 - 03:09), festive intradiegetic music

3.5 festive music from Babubhai Mistri's Mahabharat movie (07:52 - 08:24)

3.6 Ramayan title sequence

3.7 Ramayan closing sequence

3.8 Mahabharat title sequence

3.9 Mahabharat closing sequence

Chapter 4 - Sonic Dimensions of Normativity, Moral, and Religion

4.1 Ramayan E 6 (13:02 - 13:49), Sita and her sisters

4.2 Ramayan E 6 (14: 41 - 16:09), Sita and Gauri darshan

4.3 Ramayan E 6 (16:10 - 29:19), remainder episode, Ram and Sita in love

4.4 Ramayan E 4 (12:48 - 13:18), yajna, chanting with pre-recorded chant

4.5 Ramayan E 19 (29: 38 - 30:11) yajna, chanting without pre-recorded chant

4.6 Mahabharat E 43 (00:22 - 01:43) Yudhishthir's rajasuya yajna

4.7 Ramayan E 3 (23:05-29:12) Shiva puja

4.8 Ramayan E 53 (01:25 - 08:10) bridge building, devotional songs, puja

4.9 Mahabharat E 28 (06:50-10:39) Rukmini Parvati puja-song

4.10 Mahabharat E 14 (13:41 - 14:31) puja Krishna's family

4.11 Mahabharat E 71 (13:22-15:00) Arjun summons Durga

4.12 Ramayan E 30 (27: 40 - 29:17), Shiva tandav stotram

4.13 Mahabharat E 7 (06:09 - 10:01), Bhishma asks for Gandhari's hand, Gandhari agrees

4.14 Ramayan E 15 (06:18 - 07:38), Ram hears of his banishment

4.15 Mahabharat E 23 (03:23 - 05:59), Dron asks for Eklavya's thumb

4.16 Mahabharat E 46 (entire episode), match of dice and assault on Draupadi I

4.17 Mahabharat E 47 (entire episode), match of dice and assault on Draupadi II

4.18 Mahabharat E 46 (22:04 - 22:34), intradiegetic sounds match of dice

4.19 Mahabharat E 46 (21:10 - 21:24), the villains' laughter

4.20 Ramayan E 32 (23:03 - 23:45), Sita's abduction

4.21 Ramayan E 4 (30:55 - 31:29), Tadaka

4.22 Mahabharat E 58 (17:43 - 18:12), Draupadi singing 


\section{Chapter 5 - Fighting, Roaring, Screaming: The Sounds of Violence}

5.1 Mahabharat E 42 (01:11 - 10:38), fight Bhim and Jarasandh

5.2 Mahabharat E 69 (01:38 - 12:15), maha yuddh-song

5.3 Ramayan E 30 (14:38 - 15:37), fighting against demons, synthesizer sounds

5.4 Ramayan E 67 (10:20 - 11: 30), battle song I

5.5 Ramayan E 70 (29:38 - 31:47), battle song II

5.6 Mahabharat E 77 (02:53 - 04:06) flying arrows

5.7 Ramayan E 45 (16:17 - 16:44), Hanuman fights in Lankan garden

5.8 Mahabharat E 47 (27:17 - 28:51), Draupadi's disrobing

5.9 archery duel from Babubhai Mistri's Sampoorn Ramayan, (01:45:17 - 01:45:23)

5.10 Ramayan E 71 (19:03 - 19:42), Indrajit's death

5.11 Ramayan E 63 (27:56 - 29:28), orchestral and synthesizer sounds when fighting demons

5.12 Mahabharat E 77 (02:19 - 03:19), fanfare-like synthesizer sounds in battle

5.13 Mahabharat E 1 (27:02 - 28:11), Ganga drowns her son

5.14 Mahabharat E 6 (15:15 - 16:07), Vyas niyoga I

5.15 Mahabharat E 6 (18:10-19:30), Vyas niyoga II

5.16 Mahabharat E 52 (16:39 - 16:50), encounter with benevolent god

5.17 Mahabharat E 24 (04:05 - 04:51), sparring of the grown-up princes

5.18 Mahabharat E 11 (04:25 - 05:19), Kansa kills his nephew

5.19 Mahabharat E 1 (13:18 -14:17), Ganga's passage

5.20 Ramayan E 4 (31:15 - 32:32), Tadaka

5.21 Mahabharat E 12 (28:45 - 30:11), Putana abducts baby Krishna

5.22 Mahabharat E 78 (24:33 - 26:24), Shikhandi (with Arjun)

5.23 Mahabharat E 58 (23:44 - 24:49), fight Bhim and Keechak, Brihannala plays the drum

Chapter 6 - Epic Television: TV-Frenzy, Legends and Nostalgia

6.1 Mahabharat E 3 (35:15 - 36:25), what D thought was Devavrat's oath

6.2 Mahabharat E 3 (37:27 - 38:55), Devavrat's/Bhishm's oath

6.3 Metal Bharat 1 
6.4 Metal Bharat 2

6.5 Metal Bharat 3

6.6 Dipraj Jadhav, Mashup of Nucleya feat. Diving, Scene Kya Hai 



\section{Introduction}

I sit down on the couch, perhaps a little rushed, but glad to have made it just on time. I switch on the TV, take a sip of my drink or a bite of a snack. The show starts. I feel excitement and anticipation at the first sounds of the familiar title track, and briefly try to recollect the last episode's cliffhanger. I relax as I get into the mood for the show. The familiar sounds gradually pull me into the fictional world they frame. The title track is over, the episode starts. Over the next 20 to 60 minutes, suspense grips me tightly as rumbling subliminal droning sounds endow scenes with a threatening mood while the show's villain is scheming. Through sudden, startling spikes of shrill sounds, I feel deep in my gut the heroine's shock upon realizing she has been betrayed. The rapid burst of gun shots, the thumping of punches and hectic, fast-paced music of a fight scene make my heart race as I root for the hero to defeat his enemies. My eyes well up as the hero and the heroine tearfully part ways under the thick, voluminous sounds of strings. I laugh at the montage sequence in which the jokers of the story goofily prepare for a quest, the images ironically charged by the music, which also temporally compresses the scene. I feel relief and a sense of security when, accompanied by mellow music and featuring calm conversation, the heroes return home after their quest and tuck their children in to bed. The episode is over: the credit sequence starts rolling and brings me back to the real world, allowing me to digest the events of the episode and reclaim a distance from the fictional world in which I have so pleasantly lost myself.

While the genre, the plot, the setting and the style may differ, this is an everyday experience that serial viewers around the globe can relate to ${ }^{2}$. This experience illustrates several aspects of this study: most importantly, that watching a television show can be a highly immersive experience, and that music and sound design play a vital role in creating that experience. In other words, music does something in television shows. That 'something' is, in fact, many things: Music creates atmospheres, it evokes emotion and often palpable sensations, it produces settings and turning points of plots, it frames the story, and as such, it is an essential element of audiovisual storytelling. Furthermore, the

\footnotetext{
2 In the days of internet streaming, the reference to the rush the television schedule can cause appears a little anachronistic. However, readers probably remember how the relentless progression of the daily programming schedule once used to dictate the engagement with the medium television and the stories it used to tell, how individual narratives were (and actually still are) integrated in a never ending flow of sounds and images, and how seemingly endless blocks of commercials were (are) endured.
} 
sounds and musics of TV shows and the ways in which they are employed in televisual storytelling are so thoroughly conventionalized that the above description is sufficient to seem so familiar to us. However, although music and sound conventions are common by definition, they are far from universal, and the ways in which sound works in a given show requires specific attention to its exact context and to its structures.

But what exactly is it that sound does in television shows? How can the intense, often palpable effects of music and sound effects be grasped and understood? It is these questions that this thesis primarily addresses, and I will and offer answers by studying two Hindi TV serials that aired in India between 1987 and 1990: Ramayan and Mahabharat.

Even though television music has been studied since the 1970s, there are considerable gaps in the existing research. In part, this might be due to the slow pace at which the topic was adopted by researchers. While there are publications from the 1970 s, only relatively few studies were published before the 1990s, when the topic started to draw increasing attention in musicology. While research on TV music is still growing, it is still a somewhat niche topic compared to the plethora of publications on music in film. Research on sound and music in audiovisual media is thriving, and today covers an enormous spectrum of theoretical approaches, perspectives, epistemological interests, medial configurations, and cultural particularities. Recent publications such as The Oxford Handbook of New Audiovisual Aesthetics (2013) or the Routledge Music and Screen Media series incorporate studies on television and partly address the wide range of approaches taken to music in audiovisual media ${ }^{3}$. This thesis seeks to address some of the substantial gaps in existing research.

The most problematic gap concerns the very audiovisual material that is being studied. As far as I am aware, there are no academic publications that analyze the music of television shows that have not been produced in either Europe or North America. While the music of Indian cinemas, most notably and prominently that of the commercial Hindi cinema (popularly known as 'Bollywood'), has become the subject of many academic, and particularly musicological publications since the 1990s, the music of India's major television industry has received absolutely no scholarly attention. In this study of the

\footnotetext{
${ }^{3}$ See John Richardson's and Claudia Gorbman's introduction of The Oxford Handbook of New Audiovisual Aesthetics (2013: 3-35). 
music of Ramayan and Mahabharat, I wish to draw attention to the ways in which sound and music are employed in these two specific serials - serials that were produced at a specific moment in time, under specific circumstances, through specific means, governed by specific aesthetics, politics, and structures of representation. I aim at challenging some of the assumptions that have been taken for granted in previous research on television music by introducing the sounds of serials that were produced outside of the North Atlantic ${ }^{4}$ axis and impacted not only a mass audience, but Indian televisual aesthetics more generally.

Another gap in research on television music is located at the intersection of sound and medium. The range of epistemological interests and theoretical lenses through which music in television is approached is diverse. However, within this proliferation of approaches the specificity of the televisual formats in which the sounds are embedded is barely addressed analytically ${ }^{5}$. This creates a mosaic of perspectives and (often brilliant) analyses of the sounds of television shows without providing in-depth insights into the ways in which format and sound are specifically interlinked. In this thesis, I will contribute to filling this gap with heightened awareness of the music's formal background in Mahabharat and Ramayan. I will approach the sounds of these serials explicitly in their function as sounds of television serials - as aspects of the specific medial configurations of this format. I will do so by exploring how the employment of sound and music correlates to the different formal entities and levels of the serial narrations - from individual episodes to the serials in their entirety - thereby also considering the circumstances of the music's production and links to other media, whether formally or aesthetically.

\footnotetext{
${ }^{4}$ I use this term in the sense of Abels (2016) to describe the cultural and regional axis comprising Europe and North America in order to avoid the flawed notion of 'the West'.

${ }^{5}$ Some publications, for instance by Robynn Stilwell $(2003 a, 2011)$ are a notable exception to this.
} 


\section{Ramayan, Mahabharat and Television in India}

Ramayan, spanning 78 episodes broadcast between January 1987 and July 1988 and Mahabharat, spanning 94 episodes broadcast between October 1988 and June 1990, were telecast on India's only television channel at the time, the state-run Doordarshan (which translates to distant sight or vision). The two serials were milestones in Indian television history in more than one way. They narrated mythological stories rooted in Hindu devotional bhakti-traditions, which revolve around, or include, the life stories of Ram and Krishna, two avatars of the god Vishnu. Reciting parts of any vernacular, epic version of Ramayan is considered a (Hindu) devotional activity (Lutgendorf 1989: 53-54) and a section of the Mahabharata 6 epic, the Bhagavad Gita, circulates independently as a central and popular piece of Hindu philosophy. Integrating Hindu doctrine and the serial format, Ramayan and Mahabharat were the first shows to bring mythological content to television. The two serials are televisual re-narrations of stories, or rather of narrative traditions, that have grown and sprawled all over South Asia for millennia. As epics in Sanskrit and other vernacular languages, and through performative traditions such as dance, film, comics, oral recitation, and musical narration, the stories of Ramayan and Mahabharat are a part and parcel of the stock of cultural knowledge in India ${ }^{7}$. In addition to contrasting considerably with the rest of Doordarshan's content at the time, Ramayan and Mahabharat were unprecedented in popularity. Over the course of two and a half years, they mobilized a mass audience whose extent was unmatched by previous shows aired in India. Both hyped and criticized, Ramayan and Mahabharat changed not only public life during their broadcast on Sunday mornings, but also permanently transformed Indian television.

Mahabharat's and Ramayan's outstanding success and the medial shift they represented 8 are best understood against the backdrop of the history of television in India. First introduced in India in 1959 and established in the context of a program sponsored by the UNESCO, television was initially exclusively employed as a tool for promoting

\footnotetext{
6 In this study, I will mostly employ the Anglicized form of transliterations of terms and names from Hindi and Sanskrit, such as Bhagavad Gita or yajna, omitting most diacritical marks except when quoting a text in which they are used. In this, I will omit the 'a' inherent in Hindi syllables and Hindi version of originally Sanskrit words, for instance dharm instead of dharma. For the sake of clarity, I will furthermore refer to the serials as Ramayan and Mahabharat and to the narrative traditions on which they were based as Ramayana and Mahabharata, thereby alluding to the inherent 'a' of syllables in Sanskrit.

${ }^{7}$ Beyond these narrative traditions, the stories and their individual episodes pervade everyday life in India - as parts of school curricula, as proverbs, as elements of some forms of Hindu religious practice and so on. ${ }^{8}$ Which would be followed by further profound shifts shortly after their broadcast.
} 
development (Mitra 1993: 11; Rajagopal 1993; Gupta 1998: 19-20; Mankekar 1999: 5; Kumar 2006: 24-25; Roy 2008: 30-31). With its developmental agenda, Doordarshan was a governmental institution, directly connected to the Ministry of Broadcasting and Information. This government patronage of television, with Doordarshan as the only network, would continue until the early 1990s, when programming was opened to a free market in the wake of India's economic liberalization. Beyond its developmental agenda, television was employed as a means of nation building. As media scholar Abhijit Roy points out, Doordarshan was set to "homogenize" its increasingly vast audience "as part of the nationalist drive of conjuring a standardized citizenship" (2008: 29; cf. Rajagopal 1993).

At first, television in India was limited to a few transmitters in the agglomeration of Delhi, and broadcast only a few hours per week. The scale of distribution was widened slowly but steadily during the following decades: further transmitters were installed in the country's urban centers, and transmission was later advanced to satellite technology, so that distribution and the quality of transmission gradually improved. For the first two and a half decades of Doordarshan's existence, the content broadcast on the network strictly adhered to developmental principles, with shows on agriculture, hygiene and family planning, as well as on the process of nation building (Lutgendorf 1990: 132-33; Mankekar 1999: 5-6; Kumar 2006; Sen and Roy 2014: 3). Entertainment content only emerged in India's television programming in the early 1980s, which most academics attribute to India's hosting of the 1982 Asian Games. Broadcasting the games provided an internationally visible platform for the Indian government to demonstrate the state's modernity (Mankekar 1993: 545; Rajagopal 1993; Kumar 2006: 31-32; Sen and Roy 2014: 3). Indologist Philip Lutgendorf offers a different perspective, ascribing this shift to improving VCR technology, which became a competitor that Doordarshan needed to keep up with (1990: 133)9. In the early phase of this shift, television's original developmental agenda was combined with entertainment, most prominently in the pro-development soap opera Hum Log (1984-1985). Hum Log was "the first commercially sponsored

\footnotetext{
${ }^{9}$ Mitra (1993), Gupta (1998) and Mankekar (1999) also recount this phase with slightly different emphases of events and turning points than the majority of authors writing about Indian television's shift toward entertainment.
} 
entertainment serial" (Rajagopal 1993: 103) on Indian television (cf. Roy 2008: 37-38). It was very popular, but primarily due to its entertaining qualities rather than its developmental messages (Rajagopal 1993: 104). Hum Log's success initiated a phase of almost playful experimentation in Indian television. A variety of Indian-produced fictional serials were broadcast in combination with imported international content that was either in English or dubbed/subtitled in Hindi ${ }^{10}$. The Indian-produced serials were commissioned by Doordarshan, and their development and production executed by experienced film makers. The outcome of this initiative was a variety of serial productions such as Buniyaad by Ramesh Sippy, Bharat Ek Khoj by Shyam Benegal - and Ramanand Sagar's Ramayan and B.R. Chopra's Mahabharat.

The first shows to bring the well-known mythological stories and a specific cinematic aesthetic to the small-screen, Ramayan and Mahabharat created a cesura that marked "the birth of popular television in India" (Roy 2005: 9; cf. Sinha 2014: 114). Both set audience records, boosted Doordarshan's revenues, and quickly became a matter of widespread and enduring public interest. Even though they generated an enormous, enthusiastic following, Ramayan and Mahabharat polarized the Indian public because of their connection to Hindu religion and dogma, which was perceived by critics as conflicting with the state's explicitly secular agenda in a time of rising communal tensions. Therefore, Ramayan and Mahabharat also became the topic of heated debates about the government's stance toward religion (see Lutgendorf 1990: 165; Mankekar 1999: 16566). However, these debates were mostly limited to intellectual and leftist social spheres, academic discourse, and the cultural criticism of particular news outlets, and had no impact on the serials' broad popularity. In academic literature on the serials, Ramayan and Mahabharat are frequently framed as aiding the rise of Hindu nationalism because they normalized the spread of Hindu religious symbols (visual as well as aural) in Indian public space and blurred the lines between Hindu and Indian culture (Mankekar 1999; 2002; Rajagopal 2001; Ohm 2007; Sinha 2014). In this sense, authors describe the two serials as contributing to the deteriorating communal dynamics that ultimately erupted in multiple violent outbreaks throughout India during the 1990s.

\footnotetext{
${ }^{10}$ As far as I am aware, the diversification of languages on television happened at a slightly slower pace than the expansion of Doordarshan's entertainment niche so that, initially, the Indian-produced shows were broadcast in Hindi.
} 
Ramayan and Mahabharat established the now thriving genre of the mythological serial in Indian television. In transferring the mythic stories onto the small screen, the serials drew on a range of traditions of telling the epic stories (see chapter 3 ). They fused these narrative styles in a way that rendered the stories as full-blown melodramas. As Anna Morcom points out, the "term melodrama literally refers a drama accompanied by music, melo- coming from the Greek melos for music" (2007: 14). As a predominant form of Indian cinemas, melodramas used "a hyperbolic rhetorical mode" (Mazumdar 2007: 8) to combine "heroism with sensational excitement, violence, and cosmic ambition" (ibid.), while "focusing on issues of loss, the suffering of the innocent, the importance of the family and the domestic sphere" (Vasudevan 2011: 9). It is this "overload of emotional and moral import in melodrama" (Morcom 2007: 14) that makes "music [...] crucial to the understanding of the melodramatic mode" (ibid.) due to the ways in which music makes or allows the audience to empathize, to indulge in the intensity of the narrative. As this suggests, studying the music of Ramayan and Mahabharat not only allows deep insights into the serials because of their melodramatic texture. More so, understanding the serials as melodramas underlines their affiliation with the corresponding melodramatic cinematic mode. Given the prior careers of Ramayan's director and producer, Ramanand Sagar, and Mahabharat's director and producer, B.R. Chopra, were in Hindi cinema, it is not surprising that the serials, too, had cinematic characteristics.

The outstanding popularity of Ramayan and Mahabharat during their initial broadcast ${ }^{11}$ can be traced back to structural factors such as their primetime slots on Sunday mornings and the fact that, with only one existing channel, there was no competition for viewers. Just as crucial for their popularity, though, were their content and aesthetics - the fact that they brought extremely popular and well-known mythological stories to the medium using a specific aural and visual means of narration ${ }^{12}$. The flashy aural and visual style of Mahabharat and Ramayan combined cinematic, popular iconographic, and regional theatrical aesthetics. It furthermore approximated the lively cinematic styles of movie

\footnotetext{
11 Both serials have since been repeatedly telecast.

${ }^{12}$ In the wake of India's economic liberalization, Doordarshan gave up on its televisual monopoly and opened the medium to the market shortly after Mahabharat's broadcast ended. The first private channel started broadcasting in 1992 (Sinha 2014: 114). From that point, the Indian television market kept growing constantly and now ranks among the largest television markets of the world (Sen and Roy 2014: 2).
} 
reruns on TV and of imported serials while remaining decidedly distinct. In this sense, Ramayan and Mahabharat were also aesthetic landmarks in Indian television. Thus, studying the music of Ramayan and Mahabharat allows not only to comprehend how vital sound is for the televisual re-narrations of the stories, but also to apprehend their role as a platform of experimentation with the potential, and limitations, of narrating through sound in the new medium.

\section{Orientation I - the Stories}

The serials are extensive, with 78 35-minute episodes for Ramayan and 94 episodes of 40-45 minutes for Mahabharat. The stories they tell are, however, even more extensive. As Philip Lutgendorf points out, Sagar's serial version of Ramayan is "far from being the longest" re-narration of the epics, and is regularly overshadowed by narrative formats such as the Ramlila in the north Indian town of Ramnagar, or by oral recitations that may last as long as 700 hours (in comparison to the serial's 45 hours) (1990: 142). Similarly, the Mahabharata epic is routinely labeled the world's longest epic poem and is notorious for its complexity - in terms of narrative techniques, events and characters portrayed. In order to help orient the reader in the chapters that follow, I will now provide synopses of both of the serials. ${ }^{13}$

\footnotetext{
13 These only pertain to the renditions of the stories as they are told in these particular televisual renarrations. Beyond these serial renditions, there are countless other versions of both stories, many of which differ significantly from Ramayan and Mahabharat, but these versions cannot be accounted for in the context of this thesis.
} 


\section{Ramayan}

Ramayan tells the story of Ram, prince of Ayodhya, seventh incarnation of the god Vishnu. The serial begins with the gods pleading with Vishnu to help them free the earth from the tyranny of the demon-king Ravan of Lanka. Due to boons granted by the gods Brahma and Shiva for his outstanding piety, Ravan cannot be killed and overthrown by the gods. Vishnu agrees to send a human avatar of himself to earth to vanquish Ravan.

In the town of Ayodhya, the childless king Dasharath holds a yajna ritual $^{14}$ and in this begs the gods to grant him sons by his three wives. His plead is successful and his wives give birth to four sons: Kaushalya, the eldest queen, gives birth to the first son, Ram, Kaikeyi gives birth to Bharat, and Sumitra gives birth to the youngest brothers, the twins Shatrughn and Lakshman. The princes spend their childhood in the ashram of the sage Vashisht, where they receive their (spiritual) education. Grown up and fully educated, the princes return to their father's palace. They have only spent a brief time there before the sage Vishwamitra arrives. He reports that a group of demons has recently been terrorizing his ashram and have been disturbing the pious lives of the sages living there. Vishwamitra asks Dasharath for Ram's help in combatting the demons. Dasharath reluctantly agrees and lets Ram, accompanied by his brother Lakshman, go with Vishwamitra. On their way to the ashram, Ram kills the horrifying demoness Tadaka and receives divine weapons as a reward from Vishwamitra. At the ashram, Ram kills the two demons responsible for the disturbances. When Vishwamitra hears that king Janak is having a swayamvar, a ritual for finding a husband for his daughter Sita, he decides to take Ram and Lakshman there. The swayamvar consists of a contest: the challenger who is able to lift Shiva's bow will be worthy of the bride. Ram and Lakshman agree. On their way to the swayamvar, Ram frees a woman, Ahalya, who had been turned into a stone by a touch of her husband's foot. At king Janak's palace in Mithila, Ram and Sita briefly see each other in the garden before the swayamvar; they are instantly mesmerized by each other and fall deeply in love. At the swayamvar, Ram succeeds with flying colors and not only is he the sole contestant able to lift the bow, he even breaks it when he tries to bend it.

\footnotetext{
${ }^{14}$ Yajna rituals are a form of Vedic fire sacrifices (see chapter 4).
} 
When Ram's family is informed of his impending marriage, they decide to go to Mithila together to join the celebration. In Mithila, the parents of the bridal couple decide to not only marry Sita and Ram, but also Sita's sisters to Ram's brothers. The princes and princesses marry in a splendid ceremony. After the return to Ayodhya, the princes, their new wives, the queens and the king live together happily until Dasharath decides to abdicate. Dasharath decides to make Ram, the most virtuous of his virtuous sons, his successor. The entire court assembly agrees with this obviously correct decision and the people of Ayodhya are overjoyed at the prospect of having Ram as their king. However, the maid of Dasharath's second wife Kaikeyi, Manthara, is jealous that Kaikeyi's son Bharat is not announced as the future king. She manipulates Kaikeyi into jealousy and persuades her to redeem two boons that Dasharath had promised her years before. When she demands that he withdraw his promise of the throne to Ram in favor of Bharat and, furthermore, that he banishes Ram into exile to the forest for 14 years, Dasharath is bound by his promise and has no choice but to agree. The king is devastated by this betrayal but Ram agrees to the ban without resentment. Sita and Lakshman decide to accompany Ram. Kaushalya, Sumitra and Dasharath are initially bitterly resentful of Kaikeyi.

Escorted for a time by the people of Ayodhya, who are devastated to lose their future king, Ram, Sita and Lakshman depart into exile. They head towards Chitrakut, where they plan to settle for the first months of their exile. Meanwhile, in Ayodhya, Ram's family suffers from Kaikeyi's betrayal. Bharat, who had been visiting their grandfather's court with his brother Shatrughn, returns and is appalled to learn of his mother's actions. Dasharath dies of grief over Ram's banishment. Bharat rejects the throne of Ayodhya because he considers Ram the righteous king. After performing the funeral rites for their father, Bharat and Shatrughn take their mothers to go retrieve Ram so that he may ascend the throne of Ayodhya. However, when they arrive in Chitrakut, Ram refuses to return to Ayodhya since it would mean disobeying his father's order. Still, he accepts the throne under the condition that Bharat acts as substituting regent until the 14 years are over. Bharat returns to Ayodhya with Shatrughn and their mothers and, following Ram's wishes, rules Ayodhya.

After some time living in Chitrakut, Ram, Sita and Lakshman move on and start traveling from ashram to ashram in the Dandaka forest, which is infested with demons. The brothers kill the demons and in turn receive teachings and divine weapons from the sages living in the ashrams there. One day, as they settle in a new hut, a demoness named 10 
Shurpanka sees the three ascetics and instantly falls in love with Ram. She approaches the three and expresses her desire for Ram, who rejects her. She then sees Lakshman and desires him, too. When he also rejects her, she threatens to eat Sita. She is about to attack when Lakshman intervenes and cuts off her nose. She leaves enraged, threatening with revenge.

Shurpanka does indeed get her revenge, although she needs two attempts. First, she convinces her brother Khar to mobilize his army and fight Ram, but Ram kills every single one of the demons. Shurpanka then goes to Lanka, to ask her brother Ravan, the demon king, for help. Ravan, introduced not only as a brutal tyrant, but also as a scholar and great devotee of Shiva, agrees to avenge his sister. He comes up with a plan to kidnap the beautiful Sita. Having lured Ram away from the hut where the three are staying, Ravan magically makes Lakshman believe hears Ram cry for help and, when he goes to his brother's aid, abducts Sita. When Ram and Lakshman realize what has happened, they immediately start following the trace Sita has left for them. A friend, who has witnessed the abduction and had tried to help Sita (Jatayu, the ancient king of vultures), tells Ram and Lakshman what happened. Meanwhile, Ravan and Sita have reached Lanka, where Ravan keeps her in a garden, guarded by demonesses. He urges her to become his wife, but she furiously rejects him.

Following a suggestion by a monster they encounter during their search for Sita, Ram and Lakshman seek help from the exiled monkey king Sugriv. On their way, they meet the monkey god Hanuman, who tests their intentions to determine if they are worthy to meet Sugriv. Hanuman, who will later be their most important helper in the quest to rescue Sita, then recognizes Ram as his predestined, divine companion and patron. In exile, Sugriv is hiding from his brother Bali, who has occupied Sugriv's throne and has taken his wife. Sugriv agrees to help Ram rescue Sita, but Ram first insists on helping Sugriv fight Bali in order to reclaim his kingdom. After Sugriv fails to defeat Bali on his own, Ram decides to help him during the second fight. Sugriv and Bali meet again and in this second fight, too, Bali is superior. Ram shoots Bali from behind a bush. Bali dies, questioning Ram's moral integrity and Sugriv ascends the throne of his empire, Kishkinda. 
After some time, Hanuman and the monkey army head out in search of Sita, but they struggle and suffer from hunger and thirst. They find a magical cave whose guardian, Swayamprabha, allows them to satisfy their hunger and thirst before magically transporting them to the sea shore, only a short distance over the sea from Lanka. Hanuman, who has magic powers, flies over the water to find Sita in Lanka, overcoming a number of obstacles and opponents on the way. When he finds Sita, he assures her that Ram is on his way to rescue her. She refuses to allow him to simply carry her back to her husband because she does not want to be touched by another man. After he has talked to Sita, Hanuman wreaks havoc in Lanka but gets caught by Indrajit, the eldest son of Ravan. Hanuman announces Ram's war against Ravan. As a punishment, Ravan's henchmen set Hanuman's tail on fire. Hanuman, however, escapes, sets fire to the city with his burning tail, and flies back to the shore. He and his army go back to Kishkinda to retrieve Ram and Lakshman. Meanwhile, in Lanka, Ravan's wife Mandodari and his brother Vibhishan, who is a devotee of Ram, warn Ravan not risk war with Ram and try to convince him that he is doing wrong.

After some consultation, including with the god of the sea, Ram and his counsellors decide to build a bridge in order to cross the sea to Lanka with their entire army. With the help of the gods, the army completes the bridge quickly and arrives on Lanka's shore soon after. When Ravan hears of their success, he becomes angry and tries to trick Sita into marriage by claiming that Ram has died. Following the advice of her demoness friend, she does not fall for Ravan's ruse.

Ram and his army ponder strategy and provoke Ravan in a first confrontation, in which he is attacked by Sugriv. Ram decides to have Vibhishan advise him on battle strategy due to his knowledge of Lanka. Ram gives Ravan one last chance to end things peacefully by sending Bali's son Angad to Ravan. Ravan refuses the final peace offering despite being urged by some of his advisors, and so the war begins.

One by one, Ravan's sons, brothers, and other heroic warriors fall, and Ram's army even retains the upper hand when Ravan uses unfair - magical - means of fighting. At one point, however, Lakshman is seriously injured by Ravan's eldest son and finest warrior, Indrajit. Hanuman abducts a healer from Lanka and then flies to the Himalayas, bringing back with him an entire mountain on which grows a magical plant that can heal Lakshman (and by coincidence meets Bharat on his way). Even though he almost dies, Lakshman is 
ultimately saved and Ram can continue the war. Their victory is briefly in danger when Indrajit performs a ritual to gain ultimate strength for the final battle, but the ritual is disturbed and as a result Indrajit dies in battle. Ultimately, Ram kills Ravan in battle and thereby conquers Lanka. Ram crowns Vibhishan the new king of Lanka. Sita is freed and undergoes a fire ordeal which not only proves her chastity during the time of captivity, but also brings back the 'real' Sita: the Sita abducted by Ravan was only an illusion, while the real Sita stayed in the realm of the fire god Agni. Together with Sita, Lakshman and Hanuman, Ram returns to Ayodhya where he - much to everyone's joy - finally ascends the throne and begins his righteous reign.

\section{Mahabharat}

Mahabharat is a complex and winding story about an intra-familial conflict of two sets of cousins, the Kauravas and the Pandavas, for control of the state of Hastinapur. This conflict culminates in an apocalyptic war with devastating losses on both sides. Nevertheless, justice is restored, as Yudhishthir, the eldest of the Pandava brothers, ultimately ascends the throne. The serial's narrative begins a few generations before the war, introducing king Bharat of Hastinapur as the founder of a just system of rule. Bharat realizes that neither of his sons is worthy of the throne and therefore appoints another non-related candidate to succeed him. Bharat's decision is framed as the first instance of ideal just rule in Hastinapur, which future kings of the realm strive to equal. Generations later, king Shantanu falls in love with the goddess Ganga who marries him on the condition that he will never question any of her actions. As a result of this promise, Shantanu must powerlessly watch Ganga drown seven of their newborn sons. When she sets out to kill their eighth son, Shantanu interferes. Ganga explains that she had in fact not killed the infants, but rescued them from a curse from their earlier life. She spares their eighth son from this destiny, but leaves Shantanu for breaking his promise. Sixteen years later, Ganga returns and brings along their son, Devavrat, who is now perfectly trained for the duties of a king. She leaves again, but Shantanu is delighted to have Devavrat with him and, after his son has proven worthy, appoints him crown prince. 
One day, Shantanu falls in love with Satyavati, the daughter of a fisherman, and is overcome with lovesickness when the fisherman refuses to give his daughter's hand to the king. The fisherman will only agree to let Satyavati marry Shantanu if one of her sons will one day become king of Hastinapur. Since he has already promised the throne to Devavrat, Shantanu cannot agree to the fisherman's request. When Devavrat, who cannot bear to see his father so desperate, learns of the fisherman's request, he renounces the throne and takes an oath never to marry or have children. This oath, which earns him the name Bhishm (which refers to the terribleness of this oath), allows Shantanu to marry Satyavati. For his self-sacrifice, the gods grant Bhishm the boon of choosing the time of his own death. Shantanu marries Satyavati, but dies of guilt for his actions. Bhishm, who is deeply committed to the good of Hastinapur, takes care of Satyavati's sons, Chitrangad and Vichitravirya. Chitrangad succeeds Shantanu as king of Hastinapur, but dies young and childless, so Vichitravirya becomes king. In order to find a wife for his half-brother, Bhishm interrupts the swayamvar of the three princesses Amba, Ambika and Ambalika, to which he has not been invited, and abducts the princesses. Ambika and Ambalika agree to the marriage, while their sister, Amba, rejects it. Ambika and Ambalika live with Vichitravirya, but he dies before he has fathered a son to follow him to the throne. Therefore, Vyas, an illegitimate son of Satyavati, is ordered to impregnate Vichitravirya's wives.

Dhritarashtr, a blind but strong boy, and Pandu, a weak, unhealthy child, are born to the queens. Even though Dhritarashtr is the older brother, he is deemed unfit for the throne due to his blindness. Therefore, Pandu is announced king - a decision that displeases Dhritarashtr. Bhishm, also looking out for this generation of Hastinapur's rulers, arranges that Dhritarashtr marries princess Gandhari of Gandhar. Her brother Shakuni is enraged that his sister is to marry the inferior Kuru brother, who will not ascend the throne. Gandhari, however, agrees to the arrangement and voluntarily blindfolds herself to experience the world the same way as her husband does. Pandu is married to the princess Kunti, who already has an illegitimate son with the sun god. Because she abandoned the child, a boy named Karn, who is raised by a charioteer and his wife, no one knows about him. Pandu's second wife is princess Madri. When Pandu accidentally kills a sage and his wife, they curse him to never be able to sleep with his wives again. Pandu is remorseful, abdicates the throne and goes to exile with his wives. Because of his forced abstinence, he urges Kunti to employ her magical mantra in order to have any offspring at all. She does 
as she is told and gives birth to three children: Yudhishthir, son of the god Dharma, Arjun, son of Indra, the king of gods, and Bhim, son of the god of wind. She passes her mantra on to Madri, who gives birth to the twins Nakul and Sahadev, sons of twin gods. Meanwhile, in Hastinapur, Gandhari is pregnant as well and claims to have conceived before Kunti. Gandhari gives birth to 100 sons, the eldest of whom is Duryodhan.

Meanwhile, in the kingdom of Mathura, the evil Kansa dethrones his father and marries his sister Devki to king Vasudev. When he hears a prediction that he will be killed by Devki's eighth son, he incarcerates his sister and her husband. In prison, Devki repeatedly conceives, but the first six of her children are killed by Kansa, who each time grabs the newborns and smashes them against the prison wall. When Devki notices her seventh pregnancy, Vasudev's other wife magically takes over the pregnancy during a visit and gives birth to Krishna's elder brother Balram outside of captivity. When Devki gives birth to her eight child, Krishna, the eighth avatar of Vishnu, a divine intervention allows Vasudev to take the child, walk out of the prison, and take him to a nearby village where he is raised by Vasudev's friends. During his childhood and youth, Krishna is the star of the village, playing tricks, stealing butter, and revealing his divinity already at a very early age. He plays the flute, flirts with the cow herder girls and occasionally even saves the villagers from external threats. At one point, Kansa invites him to Mathura, because he has suspected that this miracle performing boy might be the nephew from the prophecy. Kansa plans to have Krishna and his brother Balram killed in an arena, but is instead himself killed by the adolescent Krishna.

The story of Krishna's childhood is followed by the narration of Pandu's death. In exile, Pandu cannot resist the temptation of his second wife, Madri, and dies in her arms. Because Madri burns herself on Pandu's funeral pyre, Kunti adopts her children and moves back to Hastinapur, where they are welcomed by Bhishm and Dhritarashtr's part of the family, except for Duryodhan. The cousins, the five Pandavas and the 100 Kauravas, are now raised and educated together. Duryodhan is encouraged in his jealousy and hatred of the Pandavas by his uncle Shakuni, who is still offended by his sister's marriage. Dhritarashtr, too, is worried that the Pandavas will surpass his sons, so he makes sure that his own sons are always given advantage. When Duryodhan is still a child, Shakuni incites him to poison Bhim, who survives the assault and gains exceptional physical 
strength as a result. Even though the Pandavas know that Duryodhan attempted to kill Bhim, they keep it to themselves. The adults are aware of the slowly simmering conflict between the cousins and that, in contrast to the ill-tempered, jealous and selfish Duryodhan, the wise and fair Yudhishthir is a better suited successor to the throne.

The princes receive their military education from the sage Dron. Quickly, Arjun turns out to be the best archer and warrior of the princes and he becomes Dron's favorite student. Over the course of the princes' education, Dron rejects two students because of their heritage: Karn, who is raised by a charioteer and isn't aware of his royal heritage, and Eklavya, a tribal prince, who had secretly been listening to Dron's teaching without asking for permission. At the end of their education, the princes demonstrate their skills to their family and the people of Hastinapur by fighting against each other in a stadium. Karn joins in and claims to be a better archer than Arjun. He is mocked for his allegedly common birth and is not allowed to challenge Arjun. Duryodhan realizes that Karn is a potentially powerful ally against the Pandavas. He immediately gives Karn the kingdom of Anga, thereby making him king and equal to the Pandavas.

Only because of immense pressure by the wise minister (and half-brother of Dhritarashtr and Pandu) Vidur, other ministers and the people of Hastinapur, does Dhritarashrtr appoint Yudhishthir crown prince instead of Duryodhan. Duryodhan is furious with envy. Together with Shakuni, he plots to kill the Pandavas and Kunti by burning them in a house made from wax in which they are supposed to sleep during a travel. The Pandavas learn of the ruse and dig a tunnel out of the house. They escape, but still allow Duryodhan to think that they have died, so the news of their death is spread in Hastinapur. Vidur later informs Bhishm that they have escaped. The Pandavas, meanwhile, decide to stay away from Hastinapur for a while and take exile disguised as Brahmins, protecting the people of the cities they travel through from demons.

On their journey, the Pandavas decide to go to a swayamvar held for princess Draupadi, who has also attracted the interest of Karn and Duryodhan. The Pandavas turn up there disguised as Brahmins, and only their cousin Krishna, who is also there, recognizes them (but doesn't reveal their true identity). Arjun is the only competitor who accomplishes the swayamvar's task because Draupadi rejects Karn for his alleged lowly origin before he can participate. The brothers take Draupadi to their mother. Kunti, who is busy when her sons arrive and does not turn around to see that, in fact, they have brought home Arjun's future 
wife, tells them to share what they have brought home. Since the brothers are morally bound to obey to each of their mother's orders, the five brothers now share Draupadi as their wife. Dhritarashtr learns that the Pandavas are still alive and, following is minister Vidur's advice, welcomes them and their new bride in Hastinapur. Duryodhan, Shakuni and Karn are furious. In order to make peace between the Kauravas and the Pandavas, Dhritarashtr gives a (barren, demon-infested) part of his kingdom to the Pandavas, so that both Yudhishthir and Duryodhan can rule over their respective kingdoms. Yudhishthir is crowned king of his realm, Indraprastha, and the Pandavas turn their kingdom into a beautiful oasis with a magical palace. In a joined effort, Yudhishthir and his brothers establish (military) predominance among the neighboring states, so that Yudhishthir can conduct a rajasuya ritual, which makes him emperor.

After the ritual, when Duryodhan wanders through the halls of the Pandavas' palace, he falls into one of the indoor ponds which he had mistaken for a carpet. Draupadi witnesses the scene and laughs at Duryodhan. Enraged and humiliated, not only by Draupadi but also by the rajasuya ritual, Duryodhan longs for revenge. Shakuni, master of the dice, suggests inviting the Pandavas to Hastinapur for a game of dice. Yudhishthir accepts the invitation, even though he has been warned that it is a trap. Yudhishthir indeed loses again and again and - with the stakes rising ever higher - eventually loses everything he owns, including his status as king and his brothers. Ultimately, he stakes Draupadi. The queen, who is menstruating and therefore in seclusion, is dragged by Duryodhan's brother Dushasan to the assembly hall where the match of dice is taking place under the eyes of the elders and the king. Draupadi appeals to Yudhishthir, doubting his right to stake her, and to the elders to intervene and stop her humiliation. Nevertheless, she is insulted by Duryodhan and Karn before finally Dushasan starts to disrobe her. Draupadi prays to Krishna who, although not being present, intervenes by magically making the fabric of Draupadi's sari endless, so that Dushasan is unable to expose Draupadi and is forced to give up.

Draupadi demands justice and the court's elders appeal to Dhritarashtr to intervene and bring his son to reason. Dhritarashtr declares the dice match invalid so that the Pandavas gain back everything and go back to Indraprastha. The brothers resent Yudhishthir for his failure. Duryodhan pressures Dhritarashtr into inviting the Pandavas for another match. 
Yudhishthir loses again. Agreeing to what he originally staked in the game, he, his brothers and Draupadi have to go into exile for 13 years, of which they have to spend the last year in disguise and unrecognized by other people.

The first twelve years of the exile pass. For its last year, they go to the court of king Virat of Matsya, disguised as servants. Yudhishthir is courtier to the king, Bhim a cook, Nakul and Sahadev stable hands, and Draupadi is a maid of the queen. Arjun, due to a curse he had previously received, is a transvestite ${ }^{15}$ called Brihannala and teaches singing and dancing to princess Uttara. The queen's brother assaults Draupadi in front of the court assembly. She demands revenge from Bhim, who this time does not bear his wife's humiliation passively, and kills Keechak. The news of Keechak's brutal death spread and when they reach Hastinapur, Duryodhan suspects that the Pandavas are responsible for it. He attacks Matsya in order to provoke the Pandavas, reveal their disguises, and then, according to their agreement after the game of dice, send them into exile for another 13 years. Brihannala decides to help the prince of Matsya, who would on his own lose a battle against Duryodhan and thereby reveals the Pandavas' identity to his cousin.

The Pandavas make an effort to solve their conflict with Duryodhan peacefully, their negotiations led by Krishna. Duryodhan, however, is not willing to compromise and the parties must prepare for war. Krishna agrees to be Arjun's charioteer. While the Pandavas and Kauravas assemble their armies and gather their allies, Krishna tells Karn about his true identity. Nevertheless, Karn remains loyal to Duryodhan, although Kunti urges him not to fight against his brothers. As the parties prepare for war, Dhritarashtr's charioteer Sanjay gains the ability to see everything happening on the battlefield. Therefore, he can report the events of the battle to Dhritarashtr, with whom he is staying in Hastinapur.

Just when the war is about to start, Arjun drops his weapons, unable to fight his own family. Krishna delivers the Bhagavad Gita to him, teaching Arjun about his moral duties and the higher meaning of his actions, after which he reveals his divine form to him. The Pandavas receive blessings from the elders who have to fight them due to their obligation towards Hastinapur and the war of Kurukshetra begins.

The war lasts for 18 days, wreaking havoc among each of the armies. Both sides employ ruses and unfair attacks (even off the battlefield) to eliminate unbeatable enemy warriors.

\footnotetext{
15 In fact, Brihannala's gender remains ambiguous throughout the serial and in the Sanskrit epic version of the story (Custodi 2007: 211). 
The Pandavas lose all their sons and most of their allies, while all of the Kauravas and Karn die, as do most of their allies. The Pandavas win the war, but they realize that, although necessary, the struggle for justice was not worth the loss of so many lives. Ultimately, Yudhishthir justly ascends the throne of Hastinapur.

\section{Approaching Sound in the Serials, Approaching Popular Culture}

In studying the sound and music of Ramayan and Mahabharat, I expand the existing perspectives on music in television serials. I do so by understanding sound and music as crucial components of the serial narratives - by asking what it is that music and sound do in these narratives, how it is that they narrate - and by linking these questions to the specificities of the serial format. Furthermore, by focusing on the sounds of Ramayan and Mahabharat, I am also complementing the perspectives of existing research on the two serials, in which, as stated above, the aural dimension has been entirely neglected. Understanding sound and music as essential narrative elements of Mahabharat and Ramayan helps to flesh out and explain their representational, structural and aesthetic qualities. Bound up with these structural characteristics, and yet exceeding them, I understand sound's effects in the audiovisual serials as resulting from its particular material, resonating capacities, which touch the audience on an emotional and visceral level. As such, it mobilizes feelings and cultural knowledge in a complex way which is specific to sound, and which differs from the ways in which language and images - as the other narrative elements of audiovisual media - engage the audience.

The topics of the individual chapters in this thesis point towards both the overarching themes that have been prominent in existing research on the serials as well as towards aspects that have received little attention in research, either on the serials or on TV-serial music in general. The study integrates musicological perspectives on Ramayan's and Mahabharat's aural construction of religion, morality and norms, their amalgamation of aesthetics and narrative conventions, and the ways in which they audio-visually construct violence. Thus, with a focus on an aspect of narration that has been routinely underestimated and overlooked, it provides an alternative perspective on the serials and explores less-trodden paths of television music research more generally. 
Not only is research on the music of television serials culturally and regionally biased. So too is the young field of research on the cultural phenomenon of popular seriality (Kelleter 2012), which is mainly occupied with North Atlantic serials and perspectives. That is not to say that there is no research on (TV) serials outside of this cultural, geographic context ${ }^{16}$. Rather, it is the concept of popular seriality which is conceptualized as inherently North Atlantic. Therefore, particular serial formats, such as the television serial, are usually understood as North Atlantic by default. It is certainly true that the principles, formats and conventions of popular cultural serials from North America and Europe continue to have a massive influence on serial narrations in other parts of the world. Popular seriality, here understood as a principle that not only relates to narrative structures, but also to dynamics of production, reception, and distinction of serial narrations, which are explicitly oriented at commercial success (Kelleter 2012), does certainly resonate with Ramayan and Mahabharat on several (but not all) levels. However, differences to such an overarching concept of seriality, as formulated by Kelleter, become evident upon closer examination of the premise on which this concept is built, namely his notion of popular culture.

Kelleter defines popular culture as "field of practice of modernity, which [...] emerged during the first half of the $19^{\text {th }}$ century" and which, "since the late $20^{\text {th }}$ century" works as an "epochal field of cultural change" (Kelleter 2012: 16, my translation). Kelleter considers self-consciousness and reflexivity as constitutive of popular culture and a feature by which it actively distinguishes and delimits itself from other cultural fields and aesthetics (ibid.: 13-14). Popular cultural serial narratives are explicitly commercial and originate from structures of quasi-industrial production, which is possible only since industrialization has created the means for mass-production (ibid.: 15-16, 18-19). In a way, this implies a sort of cultural segregation by which popular serials, as quintessential formats of popular culture, cannot be mistaken as anything other than popular cultural. Here, I argue, it is vital to consider the heterogeneity of popular cultures in the (postcolonial) context of India: the overlaps between, for instance, religion and the popular; between the 'high' cultural value of the stories on which Ramayan and Mahabharat are based and their demonstratively popular form as television serials; and between regional,

\footnotetext{
16 I do not only mean the research on Ramayan and Mahabharat here. Obviously there is a lot of research on serial narratives other than North Atlantic ones apart from the works that I am quoting in this story. 
so-called 'folk' aesthetics, 'high brow' aesthetics, and the flashy aesthetics of commercially-produced forms of expression.

I propose to complement and expand Kelleter's notion of popular culture in a way that does justice to the specific, post-colonial context of India. Vijay Devadas and Chris Prentice point out that in postcolonial contexts specifically, "mediated popular cultural practices" intersect with "everyday lived experiences" such as, amongst others, "food, sports, and religious practices and performances", and do so across cultural fields (2011: 690) . They thereby provide a more inclusive notion of popular culture as a field of practice that allows for encompassing the heterogeneous manifestations of popularity that accompany different orders of knowledge, perceptions of the world, and cultural hegemony (Devadas and Prentice 2011). This more inclusive notion of popular culture, which in fact blends a number of cultural fields, is better suited to the cultural setting of 1980 s postcolonial India and to the textures and the particular position of Ramayan and Mahabharat at a specific historical juncture of the medium television. The ways in which cultural fields such as to stay with an abovementioned example - religion and commercial mass media intersect, especially in postcolonial contexts (Meyer and Moors 2006), illustrate the heterogeneity of these cultural settings. This heterogeneity, caused by the "unevenly dense" times (Chatterjee 1999: 131-32) that are the texture of India's postcolonial modernity, makes categorical distinctions between religion and popular culture obsolete. This is neither to say that there is no such thing as popular culture in India, nor that North Atlantic notions of seriality and popular culture did not or do not impact the forms of seriality and dynamics of popular culture in India. Rather, it is to point out how music, serial formats and the popular are powered by distinct cultural dynamics in their specific settings.

It is against this backdrop that Mahabharat's and Ramayan's sounds and musics, and their particular constitution need to be considered. Exploring the aural storytelling of these two serials contributes to expanding the horizon of existing research on TV serial music and at the same time offers a perspective on the shows' particular takes on the serial format. It is through music and sound that the blurry boundaries between different traditions and aesthetics of expression are negotiated in Ramayan and Mahabharat. 


\section{Orientation II - This Study}

In the rest of this chapter, I will further clarify my epistemological interest in this study and position my approach by discussing the methods of my research and my understanding of my role and background as a researcher (section 1.1). In section 1.2, I provide a brief overview of the academic literature on music in television (serials) and on the two serials in question, thereby contextualizing my research questions and further positioning them within the academic discourse. Following this, in section 1.3, I briefly outline the processes of production of Mahabharat's and Ramayan's music.

In chapter 2, I first outline the conceptual and theoretical groundwork for the following analyses of the study. By getting into the intersection of (intermedial) narrative theory, film music studies, and television music studies, I flesh out the conceptual understanding of sound's and music's narrativity in Ramayan and Mahabharat, as well as the analytical categories that emerge from this framework. This understanding of music's narrative functions in audiovisual media, and moreover its emotional, visceral, impact cannot be explained as a purely structural effect. As I will outline, this understanding draws attention to sound's materiality, which I describe by drawing on the concept of atmosphere. This is followed by an overview of the sounds, the diverse aural aesthetics, structures and forms of sounds employed, and narrative-structural functions of the diverse manifestations of music and sound-effects over the course of the two serial narratives.

Against the backdrop of this broad structural overview, in chapter 3, I explore the serials and their music in terms of the histories of and rich traditions around the stories they tell. I first give a brief outline of how performance traditions and written versions of the stories have been incorporated into the serials. Then I examine the title sequences of both serials, which I will explore as epitomes of their amalgamated narrations. I analyze these sequences in terms of how they integrate narrative traditions and suggest specific understandings of the serials, as well as in terms of their structural functions with regard to the narrative form of the television serial.

Chapter 4 revolves around the complex of religion, morality and social norms that is so prominent in the two serials, and explores the ways in which these issues are constructed aurally in Ramayan and Mahabharat. It considers how Hindu religion is represented aurally and how, over the course of the serials, sounds time and again evoke Hindu 
religious settings more or less subtly. Likewise, the construction of morality - the rendering of moral judgments towards characters and their actions - prominently takes place through sound and is tightly interwoven with Hindu religion. Similarly entangled with morality and Hindu religion, norms are constructed aurally in the serials. In my analysis, I focus specifically on how normative ideas of gender are constructed through music and sound in Ramayan and Mahabharat.

In chapter 5, I address another nexus of topics that is prominent in Mahabharat and Ramayan and that partially overlaps with the issues in focus in chapter 4: the audiovisual representation of violence in the serials, and their entanglement with morality, normativity, and gender. I explore how violence, as a crucial mode of character interaction in both serials is aestheticized in its representation through images and sounds. I will analyze how sounds, by virtue of their particular material qualities and the visceral impact they can have, are a crucial means through which the intensity of violent encounters is rendered. I furthermore look into the ways in which music and sound are employed to enforce the moral framework of the shows by aurally delineating legitimacy and transgression of norms.

Chapter 6 addresses the popularity of television that Ramayan and Mahabharat unleashed in India, which heavily shaped the discourse on the two serials. Along with their outstanding popularity, the serials developed into pop-cultural phenomena. Even now, almost three decades after their broadcast, they are still considered a landmark in Indian television. I address the ways in which a generation of their initial audience interlace the serials into popular culture and how, for many of my interlocutors, the sounds of the serials function as aural anchors for nostalgia and embodied memory. I will conclude my findings in chapter 7.

\subsection{Approach and Methods}

In this study, I explore how music and sound effects function as narrative agents in Ramayan and Mahabharat. I examine how (musical) sound's impact in these audiovisual narratives is unique because of its particular textures, which resonate with the audience 
and mobilize their cultural knowledge in distinct - sonic - ways. My take on the two serials' music intends to carry forward existing perspectives on Ramayan and Mahabharat in general, and on music in the narrative format of the television serial in particular. In fleshing out and pursuing my interest in the serials' sounds, I have drawn on impulses from existing research in musicology on sound in audiovisual media, but also from social and cultural anthropology, religious studies, Indology, narratology/literary and film studies, television and media studies, and philosophy.

Methodologically, not all of these impulses were relevant. As a cultural musicologist, I am interested in how music and sound function as culturally meaningful practices, as cultural modes of orienting, belonging, of acting, interacting, of "making sense of the world with your ears" (Abels 2016: 11). In this sense, it would not have made sense to analyze the serials from afar, based on the audiovisual material, academic literature and newspaper articles. At no point of this research was the necessity of fieldwork in question, of talking to people who had once already 'made sense of the world' through the sounds of the serials, either by listening to them or by producing them, and who could help me make sense of these sounds myself. Approaching the sounds of Mahabharat and Ramayan through anthropological methods was thus indispensable. This approach also meant that I had to define or delimit a 'field' through which I could get this access to the sounds of Ramayan and Mahabharat.

\section{Delimiting 'the Field'}

This delineation of the 'field' and, ultimately, my entire research process as well as the questions that I would be able to ask and find answers to, were most strongly influenced by the fact that I started my research 26 years after Ramayan first aired. It was obvious from the beginning that my questions and my general approach would need to be adapted to this massive temporal gap. I needed to consider that, for instance, the ways in which audience members and production staff would remember the serials, the (dynamics of) their reception, details about the production and so on, would be distorted by almost 30 years of consumption (and production) of media that had taken place since the initial airing. Potential informants would have a natural distance to the serials and would locate their specific aesthetics in meta-narratives. Moreover, the zeitgeist of the late 1980s, and the political topicality of the serials, would have long faded. By the time of my research, 
Ramayan and Mahabharat were but a memory - idealized or not - of a distant past for their audience, producers, and critics. My approach, and my questions, regarding the serials' impact and people's experience of their music, would thus have to be framed precisely against the backdrop of the 26 years that had passed. This points toward the overarching question in planning and conducting my research stays in India: what exactly was my 'field'? Studying the music of two mass mediated audiovisual narrations hardly pointed to one specific, geographically enclosed space that would sufficiently constitute the site of my research - even though some places were more promising than others, for instance India in general, and Mumbai, the hub of the Hindi film and television industries. Rather, my site would be defined by people and their particular perspectives on the serials and their music, and frequently also by the ways in which my interlocutors' professions informed these perspectives and their knowledge of music.

When preparing for my fieldwork by watching Ramayan and Mahabharat and reading up on the two shows, a number of highly political perspectives on the serials (see section 1.2) strongly shaped my understanding, and thus also my initial ideas for the direction of my research. These perspectives revolved around issues of modernity, religion, communal tensions and the rise of the Hindu right, the nation state and television's role within this political construct, the specific political and social ideologies promoted by the serials, and the particular versions of the stories that formed the serials. This was the path I first wanted to follow to inquire how these aspects - modernity, nation state, regionalism, Hindu religion - might resonate with the music of the serials. I planned to talk to those who had actively contributed to the discourse on the serials. Furthermore, I planned to find out about more about the actual production process of Ramayan and Mahabharat, specifically of their music, the latter of which was barely covered in the texts on the shows. To better understand how people actually experienced the music of the serials - now, decades after their broadcast - I also planned to watch episodes of Mahabharat or Ramayan with as diverse a range of informants as possible. I planned to spend roughly half of my (first) stay in Delhi, hoping to learn more about Doordarshan's policies for commissioning the serials and about the ways in which the serials were embedded into the programming schedule - how they interlaced with commercials, and the like. I decided to spend the second other half of my stay in Mumbai, at the heart of the Hindi TV and film 
industries, in order to find out more about the production of the serials' music. Getting access to an industry, to a professional culture that is as "abstract, diffuse, and unmanageably large in scale" (Ganti 2012: 27) as the entertainment industry in Mumbai, initially seemed to be an overwhelming challenge.

\section{Fieldwork}

Ultimately, however, it was precisely this industry that turned out the least problematic group to access. Undergoing a typical fieldwork experience, disoriented by encounters and opinions of the serials and their music, my plans for the further course of the research and its thematic priorities shifted during and after my first stay in India. Not being able to get a hold of people, blunt rejection of both me and my questions, confusion and frustration arising from miscommunications, and deep insecurities instilled by sometimes harsh questioning of my work and my right to conduct it, were very much part of this experience. These moments brought latent doubt to the fore, repeatedly reminding me that "there are dangers involved in speaking for others, particularly if these are members of a group that we do not belong to" (Scharff 2010: 85). Overall however, these encounters, and the discomfort and self-doubt they instilled in me, ultimately cautioned me to remain aware of my position as a researcher ${ }^{17}$. And even as they blatantly reminded me of the closed doors of my inquiry, they simultaneously opened up new doors, revealing new potential directions and other questions to pursue. Aside from these negative encounters, I had countless positive and encouraging encounters, too. A large number of my interlocutors were open, if not enthusiastic, with regard to the topic of my research, and willingly spent their time with me.

My first stay in India lasted from early March to late July 2015, and my second from midFebruary to mid-March 2016. Over the course of these two stays, the first one in New Delhi and Mumbai, the second one in Mumbai only, I conducted 50 semi-structured or unstructured interviews ranging in length from 30 minutes to more than two hours. I also

\footnotetext{
${ }^{17} \mathrm{And}$, as addressed in a constantly growing body of publications on the issue, is an inherent part of the ethnographic research process, which, as Hume and Mulcock exemplify with regard to the method of participant observation, creates a "socially anomalous identity" for the researcher (2004: xii). See also van Straaten (2017) for an in-depth account of and engagement with these dynamics in the process of conducting musicological fieldwork. 
had several informal conversations concerning the topic my research ${ }^{18}$. All interviews were conducted in English as my Hindi had not reached a sufficient level. My first contacts during my first stay in India were journalists and writers who had been active as commentators on Ramayan and Mahabharat during their initial broadcast and/or were currently commenting on them or newer serial versions of the stories. These contacts were easily acquired through the platforms of their publications, and many of them eagerly connected me with further interlocutors, so that I was able to establish a network of interlocutors through snowballing mostly from these first initial contacts. However, these interviews also made it clear to me that music was not among the elements that professionally motivated people who had watched Ramayan and Mahabharat decades ago remembered (unless they were musicians themselves). My inquiry in the archives of Doordarshan and the Archives and Research Centre for Ethnomusicology in Gurgaon in Delhi's periphery, even though the latter yielded some material and a helpful, important encounter, also did not turn out as fruitful as I had previously imagined.

These initial obstacles were however compensated by some interviews I conducted in Delhi and by most of my encounters in Mumbai. As Anna Morcom points out, research in the music/entertainment industry requires "access to a highly privileged sector of the population" (2007: 21). That I was able to obtain this access, enabled by contacts I already had, was without a doubt significantly facilitated by my position as a European researcher ${ }^{19}$, by the curiosity I might have sparked not only with my particular interest, but also as a white woman in her mid-twenties. I assume that my position also facilitated many of my other contacts outside of this particular professional context. In Mumbai, I interviewed music producers and composers currently active in the television industry, actors of Mahabharat, one of which belonged to the show's production staff, a son of Ramayan's producer Ramanand Sagar, who also worked on the show, I met singers who recorded songs for the serials, as well as Ramayan's music director and the son of

\footnotetext{
${ }^{18}$ Over the course of this thesis, I will refer to most of my interlocutors, with the exception of public figures or people who are publicly known for their work and are quoted by me in this function, through anonymized initials.

${ }^{19}$ Ganti (2012: 28-29) describes the reverse side of this power dynamic.
} 
Mahabharat's music director, who was in charge of recording and producing the background score of the serial.

Beyond these interviews in a professional context, there were several contacts that I heavily relied on during my research and from whom I received precious input, and invaluable ideas and impulses for my study. This heterogeneous assemblage consisted of people who were recommended to me as musicians and experts on music, or who were colleagues, friends and acquaintances of initial contacts. In these interviews, which were conducted at their workplaces, in their or my homes, or in cafés, we talked about their memories of the serials. When we watched episodes or clippings of the serials, we discussed their re-experiences of viewing and of the music. These interviews turned out to be invaluable for my understanding of the shows' music, and about conventions and the meanings my interlocutor ascribed to the aural aesthetics.

While these interviews were particularly helpful, especially the interviews combined with serial-watching, they were originally planned differently. Initially, I had wanted to watch episodes with as diverse a group of informants possible. At first, this was not possible due to my limited access: early on in my fieldwork I barely had any personal contacts in India and I primarily relied on the women who hosted me - and who generously agreed to help me, not only watching episodes of the serials with me and allowing me to interview them, but also providing me with further contacts. It was probably the format of these interviews that made it difficult for me to initiate contacts myself. After all, sitting down for several hours with a complete stranger, perhaps even at one's home, is an intrusion into privacy and a significant sacrifice of time. After a few attempts to diversify this group $^{20}$ did not turn out quite the way I had hoped, I realized that those informants with whom I had so far watched episodes of the serials had something in common - namely, they had watched the shows as children and still had distinct memories of their experiences $^{21}$. This became my target group and I consciously worked with such people for the rest of my time in India. These informants were also quite homogeneous in other

\footnotetext{
20 These attempts consisted of one episode watching-plus-interview with an elderly couple in their 70s in which I experienced considerable problems in communication and clear signals of their discomfort and incomprehension for my request as well as of several attempts for scheduling more interview-meetings, which got cancelled.

${ }^{21}$ While most of these interlocutors were in their mid-30s to early 40s, some of them were slightly younger than this. But since they had watched the serials in their re-runs in the early 1990s, they also had childhood memories of watching Ramayan or Mahabharat - with limitations regarding the specificities of the initial broadcast.
} 
respects: they mostly grew up in urban environments, many of them in Delhi; and they were middle to upper-middle class and (highly) educated, but differed, for instance, in terms of their religious backgrounds. This composition of the group generated a bundled perspective on the shows, enriched with very personal and in-depth insights into (musical) childhood memories, and the reflective positions of adults towards their experiences with, and knowledge of, audiovisual media. Further informants with whom I talked about the serials' music expanded this target group in terms of age but still remained within the confines of the educated (upper) middle class.

The range of perspectives, information and impulses I gathered during my stays in India caused significant shifts in the direction of my thesis, moving its initial focus away from politically charged topics. My frequent attempts to engage my informants in conversations about these political issues usually failed as most of them were not aware of the serials' political dimensions and implications. Other topics proved to be fruitful, so that the conversations gravitated more towards the serials' audiovisual aesthetics and the experiential dimension of remembering, watching and listening to Mahabharat and Ramayan. My interlocutors' knowledge of and opinions about the serials and their music were essential for me to orient myself in the musical worlds of Ramayan and Mahabharat, in the complex dynamics of the shows' aesthetics. They helped me to make sense of what I heard and saw, and to understand the processes and dynamics of their production and reception. This knowledge formed the indispensable basis for writing this thesis, even though the topics that I analyze in depth were not necessarily talked about (in detail) in the interviews. Occasionally, it would be casual remarks by an interviewee that would inspire an entire chapter. Overall, however, though intersubjectively enriched by my ethnographic research, the orientation and foci of this study are a result of my subjective perception and my close readings (Richardson 2016) of the serials and their sounds.

\section{Speaking About Music}

My informants' knowledge of music, the ways in which they talked about sound, and the understandings of music their descriptions conveyed, were invaluable for me to make sense of the serials and their music. The wide range perspectives I encountered facilitated 
approaching the music from different angles: through structural features which referenced particular culturally meaningful forms, through textures my interlocutors felt evoked emotions and moods, or through the ways in which they related sounds to (medial) conventions. However, communicating about music often did not function smoothly. My interlocutors and I encountered one of the typical challenges of musicology, which is putting what we hear and how it makes us feel into words. Many of my interlocutors had difficulties talking about the music. Some, for instance, were inhibited because they felt that their lack of musical training meant they could not "really" say anything about the sounds, while others resorted to catchphrases and (music theoretical) categories without elaborating on them. Sometimes, my interlocutors lacked words to describe music because the thorough conventionality of the sounds in a given scene made them seem so "typical" or "normal" that they could not discern any structural features or particularities to explain to me. And very often, frankly, my questions about sound were simply not posed in a way that made sense to my interlocutors.

Despite these communicative obstacles, my interlocutors and I did manage to talk about sound and music, and did so in a variety of ways. In my study, I try to include the variety of approaches to, and verbal conceptualizations of, music in my analyses. These analyses, the ways in which I understand and entangle effects, functions and meanings of music and sound in Ramayan and Mahabharat, are best understood as 'close readings' John Richardson's (2016) sense of the concept, thereby aligning with the predominant approaches to music in audiovisual media. My descriptions, analyses and interpretations of the music and sounds of Ramayan and Mahabharat result from processes of closely listening to and watching the serials, and insofar as they are informed by my fieldwork, also include "the experiences of cultural actors" (Richardson 2016: 115). These descriptions will integrate the visual and the aural dimension of these sequences, attempting to highlight not only their sounds, but the (dynamics of the) interaction of images and sound that is so vital to the audiovisual format (see Chion 1994). Due to the eclectic aural character of the serials that combines vastly different styles, textures and systems of sound, this study contains no visual representations of the sounds in this study, either through staff notation or any other form of visual representation. Any attempt to do so would not, in my opinion, do justice to the subtle ways in which sounds function in the audiovisual context: first, because sound design and music are often not analytically separable from each other, and second, because the complexity of sound's structural 
features in the serials - instrumentation, texture and timbre, volume, melodies, rhythms, meter - could not possibly be represented in one picture or graph and would thus not facilitate orientation for the reader. Instead, I use video clips from the scenes in question, extracted from the DVD sets of Ramayan and Mahabharat on which I base all of my analyzes.

Richardson points out how close reading approaches to music rely on the dynamic of framing, as understood in Mieke Bal's (2002) sense of the term. Framing sounds, approaching them through a specific perspective - with a specific question or in terms of a particular structural feature (Richardson 2016: 120) - allows making sense of sounds while not excluding potential other meanings. Bal emphasizes the processual nature of framing (2002: 134-36), which, for the duration of the framing act, "produces an event" (ibid.: 135). This processual nature of framing points to "the unstable position of knowledge itself" (ibid.: 136), which not only means that what is framed may be understood differently at other points of time, where it is subjected to different frames, but also that "frames are embedded within one another and the levels are fluidly interdependent" (ibid.: 121). It is this fluidity implied by the concept that makes it so interesting for musical analysis. The sounds of two different scenes can have entirely different effects, evoke different experiences and mobilize different nuances of cultural knowledge, even if they are similar. This calls for interpretive openness, and close reading, as Richardson points out, is characterized precisely by staying "responsive to the object at hand rather than imposing a priori assumptions" (ibid.: 128).

The music and sound effects of the serials are highly eclectic, which is reflected in the terminology I employ in the descriptions and analyses below. Analyzing the music and sounds ${ }^{22}$ of Ramayan and Mahabharat with only one set of terms originally derived from European conceptions of art music would be as insufficient as employing only the concepts derived from Indian art musics. Both serials combine sounds organized according to principles of Hindustani classical music and based on structural features such as rag and tal, orchestral film music that bears traces compositional principles and

\footnotetext{
22 In my analyses, I focus on music and sound effects and also include the sounds of voices. The lyrics of songs, however, will not be analyzed in-depth as this would go beyond the scope of this thesis. Instead, if required by the analytical context, I will briefly summarize the lyrics of a given sequence.
} 
aesthetics from both European art music and Indian musics, they combine folk musics, Hindu devotional music, and a plethora of sound effects and synthesized musical passages that defy classification. Thus, I resort to varying sets of terms to refer to music depending on what I feel best describes the particular structural and textural features of the sounds in question. In doing so, I employ descriptive vocabulary which captures my experiences of the sounds and/or those of my interlocutors, as well as terms that derive from North Atlantic art music, Hindustani classical music, Hindi film music, or popular musics. Using words and concepts that belong to either one of those musical traditions, even though it might seem inconsistent at first sight, is supposed to minimize confusion, and enable capturing particular qualities of musical passages, such as playing techniques, without creating an entirely new terminology. This way, speaking about the musics of Ramayan and Mahabharat not only reflects my particular understandings, but also occasionally links back to and integrates the ways in which my interlocutors described and explained the serials' sounds and related their experiences of the music.

\subsection{Overview - Research on Ramayan, Mahabharat, and Music in Television}

In this section I give a brief overview of two fields that are most relevant to this thesis: the musicological study of music in television, and academic publications on Ramayan and Mahabharat from different disciplines that illuminate the two shows and their political and medial contexts.

Most of the academic work on Ramayan and Mahabharat was published approximately during the first 15 years after their initial broadcast ${ }^{23}$. Coming from a range of disciplines, the epistemological interests of those works are diverse. Nevertheless, a number of topics and issues appear frequently enough that they shape the (scholarly) discourse on the serials. In these works, the authors focus on at least one of the following aspects: the exceptional scale and social side-effects of the audience's response to Ramayan and Mahabharat during their initial broadcast; the relation of the serialized versions of the stories to other traditions and formats of narrating or performing them; the factor of Hindu religion - especially in the context of the controversial airing of the serials on a

23 The serials have since been repeatedly telecast again. 
government-controlled TV channel; and, closely related to this, the political undertones, implications and consequences of Ramayan's and Mahabharat's broadcast. The serials' broadcast coincided with a new rise of Hindu right wing movements, increasing political tension in India. Ultimately, this tension resulted in multiple violent outbreaks of communal conflict all over the country in the early and mid 1990s. In some publications, the serials are loosely connected to the Hindu nationalist upswing in the sense that they were instrumentalized by the Hindu right's agenda. Ramayan and Mahabharat, it is argued, normalized the permeation of India's public space with Hindu religious symbols as well as the telecast of religious content through a government-owned channel (see Mankekar 1999; 2002; Rajagopal 2001; Kumar 2006; Ohm 2007; Cusack 2012).

Philip Lutgendorf's extensive paper "Ramayan: The Video", although also engaging with political discourse surrounding the serial, mostly addresses the aesthetic and formal features of the serial. The paper was published as early as 1990, while Mahabharat was still running and the audience's enthusiasm for mythological serials was still at its peak. Critically engaging with the extraordinary modes and extent of the audience's response to Ramayan, Lutgendorf traces the processes and dynamics of the serial's production in alignment with the development of television in India. He analyzes the specificities of the serial in relation to the diversity of the traditions of transmitting the story, focusing on a selection of traditions from the north of India. As such, he not only explains the religiously tinted modes of reception, but also the textual and structural characteristics of the serial which directly link to cinematic and specific performative conventions. Lutgendorf furthermore addresses the hype around Ramayan's broadcast. He analyzes the religious responses to the serial and rebuts the fears of cultural homogenization that the broadcast provoked.

In his monograph Television and Popular Culture in India: A Study of the Mahabharat (1993), Ananda Mitra, too, mentions sound, but only in brief descriptions. Overall, he investigates the role of the medium of television in shaping and contributing to popular culture in India. Locating his work within the intellectual tradition of British cultural studies, Mitra focuses on Mahabharat as a case in point for television's potential in shaping and regulating hegemonic discourses on pressing social issues. He considers the constitutive features of Mahabharat, such as its serial structure, its cast, its sets, the 
specific story told and its sounds, as the elements by which hegemonic images of religion, language, regionality, caste and class are disseminated in the televisual medium (1993:119-120).

In Purnima Mankekar's seminal study Screening Culture, Viewing Politics: An Ethnography of Television, Womanhood, and Nation in Postcolonial India (1999), analyses of Ramayan and Mahabharat are conducted in two separate chapters, each of which pertains to a specific socio-cultural issue. The study, approaching Doordarshan more broadly by examining a variety of fictional serials is, as Mankekar puts it, "about the role of a popular mass medium - state-run television, Doordarshan - in the ideological construction of nation, womanhood, identity, and citizenship" (1999: 4). The two chapters on Ramayan and Mahabharat focus on the construction of the main female characters of the serials, Sita and Draupadi, and the ways in which viewers relate to them through their own experiences and ideas of appropriateness regarding the role of women in Indian society. As is the case in most studies on the two serials, Mankekar pays close attention to the hype surrounding the programs and to the exceptional extent and modes in which the audience engaged with them. Similarly, Mankekar focuses on the political implications of Ramayan and Mahabharat, critically engaging with the powerful dynamics of communalism and nationalism which the serials fed. For example, she points out the casual, routine conflations of Indian culture and Hindu culture in both serials. Mankekar's analysis of Ramayan focuses on the serial's relation to religiosity and religious practice and its construction of an idealized and explicitly Hindu Indian past, which she reads as promoting an idealized image of Indian society that is heavily casteist, patrimonial and hierarchical (cf. Mankekar 2002). In analyzing Mahabharat, she focuses on the idea of Indian womanhood represented in the figure of Draupadi, first comparing the (exclusively male) producers' intentions in constructing this character with the way it was perceived by female viewers, and then relating those positions to nationalist discourses. She critically engages with television as a politically potent medium, and approaches it mostly in terms of the viewer's engagement with the content of broadcast. In this sense, she attributes it with enormous potential to shape major social dynamics as they are negotiated in the serials. She argues that even though "televisual signs [...] are polysemous, this polysemy cannot be equated with pluralism: the connotations of these signs are not "equal" among themselves, but are mediated by hegemonic discourses" (1999: 253). 
Like Mankekar's work, Arvind Rajagopal's monograph Politics after Television: Religious Nationalism and the Reshaping of the Indian Public (2001) is not focused on the serials per se, but rather includes Ramayan in its analyses. Politics after Television mainly revolves around the interconnectedness of mass media with the rise of Hindu nationalism at the specific point in time during which Ramayan was broadcast. Rajagopal demonstrates how mass media - in this case, television and printed press - each imply specific dynamics of consumption, of everyday use and conventions, so that they differ in terms of their relations to powerful institutions and in reach and coverage. Rajagopal points out how the Ramayan's depiction of a "sanitized version of the ancient society" (2001: 118) was originally intended by the Congress (India's then-ruling party) to secure the uncommitted Hindu vote for the upcoming elections, but then turned out to promote Hindu nationalist movements. Rajagopal argues that the staging of Ramayan as the rediscovery of an ancient and forgotten truth concealed the power exerted by the structural implications of the medium itself (ibid.: 72). His analysis of Ramayan thus considers not only its textual specificities, but also the ways in which the interplay of editing and narrative aspects, such as camera positions, music and the construction of its characters, support the reception of the show as religious text (ibid.: 93,109, 112). Rajagopal argues that it was the specific rendering of the story which, by constructing the epic past as at once traditional and advanced and modern while also rewriting "women's and caste oppression [...] as benevolent protection" and presenting "a patriarchal ordering of society [ ] in somewhat casual guise" (2001: 118), naturalized and legitimized persistent social structures.

Beyond these publications, there are numerous others in which the serials are mentioned, sometimes briefly, sometimes more extensively, which assert and expand the perspectives dominantly shaped by the abovementioned publications. For example, Prabha Krishnan's and Suddhabrata Sen Gupta's articles on the two serials critically assess Ramayan's and Mahabharat's construction of gender and approach the serials with a highly political view. In her feminist semiotic analysis, Krishnan argues that the shows promote a specific image of North Indian casteist hegemony, and construct a black-andwhite picture of the stories and their characters in order to convey an unambiguous morality (Krishnan 1990: 106). She frames the serials as promoting a worldview of fundamental inequality, especially in terms of gender. Notably, and in contrast to most of 
the other authors writing on the serials, she includes music as a discursive element of the shows in her analysis and considers it just as significant as the dialogues. Similarly, Sen Gupta describes Ramayan and Mahabharat as state-funded promotion of Hindu nationalism and thus, of communal conflict. The serials constitute, as he puts it, "the material for a popular culture of Hindu fascism" (1991: 2559), which he mainly illustrates in terms of the patriarchal social order oppressive towards women he understands them to promote. Similar to Lutgendorf, in the introductions to her edited volumes on the Ramayana traditions $(1991,2001)$, Paula Richman frames Sagar's televisual rendition in terms of its position among the multiple and diverse versions of the narrative and looks at the serial in terms of its medial constitution. She addresses the intense audience reactions to the broadcast (1991), and, in the latter volume, argues that the serial is an authoritative telling of the story due to the medium used, the corresponding scale of its distribution, and its particular version of the story. Carole Cusack (2012) approaches Ramayan in terms of the shows' religious appeal, attributing the audience's religious interaction with it to the intersection of the story's bhakti background, the particular aesthetics of the serial, and its medial constitution. In this, she also touches upon the political dimension of Ramayan's particular design and of its broadcast, locating it in the broader context of the rise of Hindu nationalism. In Nilanjana Gupta's monograph Switching Channels: Ideologies of Television in India (1998), Mahabharat is considered to be a government-sanctioned narrative of India's historical and cultural heritage with its own integrative powers. She characterizes Mahabharat as a state-controlled narrative that was supposed to offer orientation during a time of perceived rootlessness by combining narrative and filmic conventions and borrowing from older traditions of telling the epic. In Rachel Dwyer's monograph Filming the Gods: Religion and Indian Cinema (2006) the serials are aligned with another medial 'tradition', namely the genre of the mythological film. Here, Dwyer also focuses on the serials' aesthetics and medial constitution. She sketches out the similarities and differences between Ramayan and Mahabharat and the filmic genre of the mythological which they so heavily draw from. In the epilogue of his monograph on the Mahabharata epic (2012), James Hegarty, representative of the more textual approaches to the serials, briefly compares the televisual rendition of the story to the narrative particularities of the Sanskrit epic.

As this overview shows, existing research on Ramayan and Mahabharat has mainly focused on two sets of intersections. The first addresses political issues, especially the 
tension between the shows' Hindu religious content and the secular institution of their distribution, communalist conflicts, the rise of Hindu nationalist political groups, and nation-building. The second intersection concerns what may be broadly described as textual approaches, contextualizing the serial versions within in the spectrum of performance traditions. Studies of this kind analyze the implications of the televised versions regarding socio-cultural issues such as the position of women, casteism or the implications of the dominant display of Hindu symbols. These two approaches overlap at various points, rendering diverse insights into the contextures of the shows with the narrative traditions they spring from and the medial, political, cultural setting in which they were produced and perceived. This relatively stable frame of perspectives on Ramayan and Mahabharat highlights the relevance of studying these issues. To a degree, this frame might even be considered as integral to the texts: as Paula Richman points out, "Rama's story is inherently political" (2001: 6).

The trends in literature on music on television are obviously more diverse. While the comparatively small but steadily growing body of work on music in television embraces a wide range of approaches and epistemological interests, the majority of the studies acknowledge the specific character of televisual mediality - the set of structural implications and specificities that arise from the fact that music broadcast on, perceived through and sometimes produced for the medium of television. Many studies relate the music analyzed to the technological, material features of the medium, the practices of production and reception it affords and, in my view, give these aspects a more central position than studies of film music tend to do.

This emphasis on the televisual medium, especially in the earlier studies on television music, spring from the relatively low cultural value attributed to television, especially in relation to film, which is considered more of an art form. The critical position towards television, as for instance formulated by the Frankfurt School theorists, shines through in some publications on television music, which seem to portray television as a mass medial catalyst of the public's collective stultification ${ }^{24}$.

\footnotetext{
${ }^{24}$ Of course this outline grossly oversimplifies things. The range of perspectives and opinions on television is large and the cultural value(s) ascribed to television and film have shifted and changed. However, conceiving of cinema as a potentially artistic medium and in contrast of television as more of a threat to the
} 
While the study of TV music, of either televisual format, has grown significantly over the past 15 years, it was of musicological interest a lot earlier than this. As James Deaville points out, Adorno's interest in television music sparked a downright "German flow of literature about television music during the 1970s" (2011b: 13). A case in point is Hans Christian Schmidt's edited volume Musik in den Massenmedien Rundfunk und Fernsehen (Music in the Mass Media Radio and Television, 1976). The articles of this volume, written from musicological, journalistic and music pedagogical perspectives, approach the music of a range of televisual formats in terms of its functionality and pedagogical or cultural value, sometimes very critically so (cf. Deaville 2011b: 12-13). Philip Tagg's PhD dissertation (1979), a book-length study of the title sequence of the detective series Kojak, was exceptional in focusing on such a brief musical, or rather audiovisual, fragment in such depth, and did so from a semiotic and affect-theoretical angle, positioning the music among classical and pop musical aesthetics and structural conventions. In his essay “Television/Sound" (1986), Rick Altman uses Raymond Williams' notion of the flow to provide a media theoretical analysis of music in the US-American televisual schedule. As such, the text foreshadows other publications that analyzed music, not of individual shows, but with regard to a cross-section of (a given country's) programming schedule. For the following decades, the body of work on television music grew slowly before speeding up starting in the early 2000s. The majority of this newer research covers the music of the wide range of televisual formats, but - as far as I am aware, solely - in the US and a few European countries. Some publications give a broad overview of the ways in which music is built into the flow of programming and interacts with the continuity of the programming schedule. Other publications focus on specific genres or individual shows, ranging from Sci-Fi serials, detective shows, cartoons, documentaries and news magazines to casting shows, music television, or commercials. It is noteworthy that many of these publications conceptualize television music primarily as popular music (see Negus and Street 2002: 245) especially in the Anglophone literature (see Deaville 2011b: 14-15). This is most evident in publications such as the special issue of the journal Popular Music on 'Music in Television' (2002), whose articles cover popular music in live music shows (Frith, Stahl), in TV-serials (Donnelly), as element of the musical socialization of children (Lury), or part of the branding of television stations (Brownrigg and Meech).

public's common sense was definitely a tendency not only within scholarly discourse over an extended period of time. 
Robynn Stilwell's article on music in The X-Files (2003a) is included in an edited volume on the analysis of popular music (even though it does not actually emphasize this dimension of the serial's music, but instead, quite a lot like her article on Dr. Who (2011), focuses on, and precisely captures, the specificity of televisual (serial) structures and their interlinking with music). As the title indicates, in his article "Nip/Tuck: Popular Music" (2013), Ben Aslinger similarly approaches the music of the serial Nip/Tuck in terms of its popular aesthetics.

Among the more comprehensive studies of US-American televisual sound is Ron Rodman's Tuning In: American Narrative Television Music (2010). As the title indicates, Rodman approaches music in a range of formats - including series and serials ${ }^{25}$, commercials, network jingles and music television - from a narratological angle. In his semiotic approach, Rodman connects Raymond Williams' notion of the televisual flow, which describes the ceaseless stream of audiovisual material of a televisual schedule, with narratological concepts from literary and film scholars such as Barthes, Chatman and Genette. He suggests distinguishing between what he calls three "semiotic spaces" (2010: 53 ) - the extradiegetic, intradiegetic and diegetic - in which music can be located. While his comprehensive account offers thorough (narratological) analyses informed by indepth theoretical semiotic groundwork in combination with a chronological reconstruction of American television's development, his structuralist account maintains an exclusively textual focus that barely extends beyond the concrete audiovisual material he analyzes.

Alternatives to such 'text'-centric analyses include Robynn Stilwell's articles on TV serial music (2003a; 2003b; 2011). Rather than focusing on a strict narratological perspective, she this conceptual approach (of music as narrative element) selectively, interlinked with explorations of the specific medial dynamics of the TV-serials she studies, such as the infrastructural background, budgets and personnel resources, or the conditions of production, such as time frames, as well as televisual aesthetics in comparison to cinematic aesthetic. Other texts that particularly emphasize how music is vital for

25 These two terms are usually employed to distinguish between episodic and continuous serial narratives (see chapter 3). 
storytelling in the TV-serial format are, for instance, Charles Fairchild's "Flow amid Flux: The Evolving Uses of Music in Evening Television Drama" (2011). Here, the author regards music as vital for intra-narrative continuity within individual episodes and for creating an aural contrast between the serial and the televisual flow. Similarly, in her article "Storytelling in Song: Television Music, Narrative and Allusion in The O.C." (2013), Faye Woods demonstrates how the employment of popular music in The O.C. contributes to connecting story arcs and strengthening inner-episodic coherence within the serial narrative.

In recent years, the topic of television music has led to the assemblage of several edited volumes, which represent both the tendency of research in this field to either take a very broad approach, covering the diversity of formats and genres, or to particularize and specialize. The volumes Musik im Fernsehen: Sendeformen und Gestaltungsprinzipien (Music on Television: Formats and Principles of Composition, ed. Peter Moorman 2010) and Music in Television: Channels of Listening (ed. James Deaville, 2011a) are representative of the former tendency. Moormann's book on German television comprises contributions not only by musicologists but also from within the industry itself. The essays cover a wide range of televisual formats and genres, and furthermore feature a special focus on music television: five of the 10 essays are about non-fictional programs staging and displaying (live) performances of music. The volume edited by Deaville (2011a) confirms the prevalence of research on television in North America and the UK, assembling essays that exclusively focus on those countries. Within this framework, the authors either present case studies on a variety of genres and formats - from detective and science-fiction serials to live music-broadcasts and documentaries - or present a more overarching outline of the dynamics and specificities of televisual music.

In contrast, the edited volume Music, Sound, and Silence in Buffy the Vampire Slayer (ed. Attinello, Halfyard and Knights, 2010) is the first book-length musicological publication focusing exclusively on one single TV serial. The authors approach the aural dimension of the serial from a range of mostly text-centered perspectives, investigating the construction of characters, the complex of meaning, or identification through sound or its absence. In the volume's chapters, music is understood as vital to the narrative and to the construction of the "Buffyverse", providing a rich texture of points of identification for its audience. As the title suggests, the edited volume Music in Science Fiction Television: Tuned to the Future (Donnelly and Hayward, 2013) focuses not on an individual show but rather 40 
on a specific genre. It comprises essays on the music of Science Fiction serials from the USA, the UK, and Germany. Most of the contributions elaborate in detail on the institutional background of the respective show's music, or on the composers and producers/directors responsible for the sound track. In this, they analyze the specific conditions of producing music for television and, more specifically, address the specific challenges posed by the Science Fiction: producing aural imaginations of the serials' futuristic settings, of a (fictional) time that has not yet happened.

As this brief outline suggests, even though the study of television music has grown, and continues to grow, it still occupies a relatively minor niche within musicology. Similarly, in television studies, music is not yet routinely considered an essential element, either of the medium in general or the serial format in particular, so that publications that acknowledge sound are still rare ${ }^{26}$. In my view, however, what particularly stands out is the lack of perspectives on shows from outside the US or Europe. In studying the sounds of Mahabharat and Ramayan, I take a first step in the process of diversifying the academic perspectives on television music ${ }^{27}$.

As this overview indicates, asking what sound and music do in Ramayan and Mahabharat promises a new viewpoint on these particular serials. Furthermore, asking how the aural contributes to not only the universes of the stories but also provides sonic anchors of orientation and empathizing for a mass audience, how it evokes religion, and permanently influences the ways in which the audience perceives and remembers the show, also allows to better understand the functions of music in the medium of television.

\subsection{Ensounding Mythological Worlds: Music Production for}

\section{Ramayan and Mahabharat}

The further analyses in this study of the sounds and music in Mahabharat and Ramayan will mainly focus on the actual audiovisual material and will not dwell on the processes of

\footnotetext{
${ }^{26}$ Edited volumes on television with media- or cultural studies-background that feature musicological contributions include, for instance, Ethan Thompson's and Jason Mittell's How To Watch Television (2013), featuring Aslinger's essay on Nip/Tuck or Kim Akass' and Janet McCabe's Reading Six Feet Under: TV to Die For (2005), featuring an article by Peter Kaye on the serial's music's aesthetics.

27 I consider further, and even more vital steps in this diversification to complement the discourse on television music with voices that are not located in European and North American academia.
} 
production. In order to provide a more thorough context, a production-frame if you will, which adds another dimension to comprehending the music of the serials, I will now briefly deal with these processes of production, and outline them as they were described to me by my interlocutors ${ }^{28}$.

During my first stay in Mumbai, I conducted semi-structured interviews with musicians involved in and critically leading the production of Mahabharat's and Ramayan's music. I talked to Ramayan's music director Ravindra Jain, who sadly passed away later that same year, and I met composer Surya Raj Kamal, son of Mahabharat's music director Raj Kamal, who was responsible for the serial's background score. Moreover, I conducted interviews with two singers of Ramayan's songs. One of them, a renowned playback singer highly successful in the Hindi film industry, also sang for Mahabharat. In further interviews with music directors/composers who are currently active in the Hindi and Marathi television industry, and one television producer, I gained an impression of the unsurprisingly massive shifts in the conditions and dynamics of television music production in the decades after Ramayan and Mahabharat. From these interviews I got the impression that, beyond the vastly different musical aesthetics of today's televisual serials and the technological shifts of music production, it is especially the processes of decision-making and the timeframes of production that have shifted ${ }^{29}$.

From what I learned in the interviews, the processes of music production for Mahabharat and Ramayan were distinct from each other. The accounts of the production of Ramayan's music all affirmed Sagar's image as tireless devotee of Ram, for whom the serial's production was a mission and labor of love - an image that was also employed in the show's marketing ${ }^{30}$. Moreover, for the singers with whom I spoke as well as for music director Ravindra Jain, creating and producing the music for Ramayan was a moving, devotional experience as well. They fondly recalled the recording sessions, the dedication of the decision makers, and the quality and devotional character of the songs themselves.

\footnotetext{
${ }^{28}$ While I got a rough overview of the processes and particular dynamics of the music production during the interviews I am referencing here, this overview is rather sketchy. For instance, I could not find out anything about the post-production and the adding of background music or the recording processes of the instrumental music. Despite these gaps, however, this part of the serials' production has so far been entirely ignored by authors.

29 Of course, a thorough study of the televisual music industry would be required here for a more differentiated assessment of these shifts and dynamics.

30 This image, prominent in the newspaper articles surrounding the serials' broadcast (e.g. Vaid-Fera 1987), was also affirmed by Sagar's son Prem in our interviews in June 2015 and February 2016 as a genuine trait of his father.
} 
Sagar undoubtedly was the ultimate authority in all decisions surrounding the serial, and he closely worked together with Jain, weighing in on style, aesthetics and song lyrics. This is not necessarily uncommon in the production process of Hindi film songs (see Morcom 2007), and as such continued the procedures of the film industry, which both Sagar and Jain were familiar with. However, according to my interlocutors, Sagar's involvement exceeded the usual degree of involvement of a director. As Jain and the singers recalled, Sagar would often be present during the recording sessions of the songs and sung passages of the serial to discuss and calibrate them together with Jain.

According to my interlocutors, Sagar's most important criteria for the show's music were the impression of antiquity - it was supposed to correspond to the setting of the story and the devotional quality of the music and the lyrics. As Jain told me, both criteria influenced not only the choice of instruments (he mainly employed what he called "traditional Indian" acoustic instruments such as sitar, bansuri and manjiras), but also structural parameters such as rag and tal and, for the songs, the singers' intonation and vocal techniques. Sagar's input on the music during the recording sessions was strongly oriented towards the main source of the serial, Tulsidas' Ramcaritmanas (a version of the Ramayana epic in a Hindi dialect), and he judged not only the lyrics, but also expressive aspects of the music against this template. For the singers I talked to, Sagar's perfectionism in terms of the musical production and Jain's dedication appeared to be especially fond memories. To illustrate the intensity of Sagar's commitment, Jain recounted anecdotes of Sagar calling him in the middle of the night, asking for songs, or that Sagar would not even spare his own health, planning new songs with Jain even when hospitalized.

While these anecdotes illustrate and maybe even romanticize Sagar's commitment to his serial, and round off the picture of an outstanding production process painted by the musicians involved, they also point toward a formative factor of the music's production process that is also predominant in today's production of serial music: time pressure. Also similar to the way TV serial music is commissioned today ${ }^{31}$, in the case of Ramayan the

\footnotetext{
31 Usually, the title songs, the music for the promotional clips and the background music are produced by different composers.
} 
sounds were not entirely in the hands of the music director. A large portion of the show's background music - the swirling orchestral passages and the gloomy, otherworldly synthesizer sounds, both of which shape the overall sound of the serial so considerably were not produced by Jain, and not even selected by him, but taken from a tune bank and added in post-production.

As alluded to above, the production of Ramayan's music roughly seemed to correspond to the typical process of film music production, in which the recording of individual songs takes place before the shooting of the film and background music and sound-effects are added after shooting (Morcom 2007: 26-27). However, from what I could conclude from the interviews - my interlocutors remained rather vague on this issue - in the case of Ramayan these processes seemed to be closely interlocked due to the time pressure of the production (and broadcasting) schedule.

Overall, the production of Ramayan's music as recalled by my informants neatly matches the show's religious flavor and Sagar's image as committed devotee. The comprehensiveness of this image - the fact that Sagar was not just interested in televising Ramayan, but made his fervor for this labor of love pervade every aspect of the production - reminds me of the dynamics of the marketing of Hindu devotional (cassette) music that Manuel describes. As he points out, it was expected of "commercial bhajan singers" that their lifestyle "conform to certain standards" (1993: 113) - those of a pious and modest Hindu life. While I have no reason to doubt the accounts of my interlocutors, this coherence of the show's and Sagar's image that their accounts complemented and matched, is remarkable.

The production of Mahabharat's music was similar, but in some respects clearly distinct from Ramayan. Similar to Ramayan and the Hindi film industry, the music's planning and recording and the shoot of the show were interlocked. Unlike Ramayan, though, these processes were scheduled far in advance so that the music's production was not affected by time pressure. The show's famous title track was even recorded one year before the show aired. Furthermore, Mahabharat's music production, too, was divided: music director Raj Kamal composed and produced the show's songs while his son Surya was responsible for the background music and played significant parts of it himself with his Yamaha 100 synthesizer. At least parts of the show's instrumental background music 
were recorded especially for the show $\mathrm{w}^{32}$ and the recording sessions for the songs were no different from those of film songs, as the singer working for both shows told me. However, the heavy use of synthesizer music for Mahabharat's background score can, aside from its particular aesthetics, probably also be attributed to financial restrictions of the show.

As Surya Raj Kamal told me, his father and he were involved in the processes of planning and deciding about the further course of the show, including the aesthetics of its music. Unlike the case of Ramayan, my interlocutors ${ }^{33}$ told me that while the ultimate decisions were B.R. Chopra's, overall the serial's conceptualization, planning and production were a team effort. Still, the joint effort of B.R. Chopra, his son Ravi Chopra, who directed the serial, and the renowned script writer Rahi Mazoom Reza was marketed as a token of the show's origin in expert culture, or rather discussed as such in the discourse on the show. My interlocutors' accounts affirmed this thinktank image of dedicated pundits meticulously adjusting even musical details to the epic template.

Mahabharat's and Ramayan's position between film and television - produced by film makers, but among the first productions for the new televisual medium - comes to the fore through the processes and dynamics of their music production. Drawing on film's glamour through its famous voices, referencing film music's aesthetics while simultaneously introducing televisual aural aesthetics - which in turn were a result of the conditions of production - building on established procedures of production and structures of decision making while adapting them to the particularities of the new medium: they indicated some of the structural characteristics of the emerging industry that would establish themselves in the following decades.

But beyond these operational frameworks, which sounds, exactly, did this interim state of the medium produce? How is sound employed in these two television serials, what does music do in them? What do Mahabharat and Ramayan actually sound like?

\footnotetext{
32 Surya Raj Kamal told me that all of the show's background music was freshly recorded, but I am familiar with one musical passage from the show that was drawn from an older movie.

${ }^{33}$ Apart from Surya Raj Kamal and the singer who worked for both Mahabharat and Ramayan, with whom I talked about the process of music production, I also conducted an interview with Gufi Paintal, who played Shakuni in Mahabharat, was the show's casting director and belonged to the stable team of associates with whom Chopra worked on many of his films.
} 


\section{Music in Television Serials}

(Example 2.1) ${ }^{34}$ In the 58 th episode of Mahabharat the Pandavas are in the last year of their exile, which they spend in disguise as servants at the court of Virat. In a repetition of the abuse by Duryodhan and Dushasan at the court of Hastinapur after the game of dice, Draupadi, hiding at the court as maid, has just been assaulted by the Queen's brother Keechak in front of the entire court assembly. A mid-frequency synthesizer-tone with a soft, muffled timbre that had started in the previous scene builds a loopy, circulating pattern with the pitches a fifth and a major third below it on a diachronic scale. A second and a third layer of synthetic sounds come in a few seconds later, one of them chromatically circling around a set of close pitches. The timbre of this second layer of differs from that of the first layer, vaguely resembling deep-pitched brass winds. The third layer of sound consists of deeppitched, hollow sounding irregular percussive beats.

Against the backdrop of these sounds, the kitchen of Virat's palace is shown. Bhim, who hides in Virat as a cook, is sleeping on the floor. The music is unmetered, the slowly circling melodic fragments with their fizzing texture dominate the sound, while the percussive strikes create rhythmic irregularity. The volume alternatingly swells up and down, while the high density of the overall sound remains the same the entire time. After a few seconds, a tinkling sound illustrating the sound of jewelry moving indicates the arrival of another person. Draupadi enters and wakes up Bhim, demanding that he avenge her humiliation through Keechak. The wash of sound created by the chromatic clashing synthesizer-layers constantly hovers over the entire scene, albeit now at a lower volume so that the dialogue is the aural foreground. Draupadi and Bhim discuss her demand and develop a plan for killing Keechak.

Four minutes 45 seconds into the sequence introduces an entirely new setting: along with a panning camera movement through a picturesque garden-setting, a quickly descending passage caused by swiping over the strings of a sitar is heard. Draupadi appears, the blood from Keechak's assault still on her face, roaming through the garden seemingly lost in daydreams. The sitar plays a descending heptatonic scale, thereby introducing the tonal frame of the ensuing song. Draupadi starts singing (obviously playback) an unmetered,

\footnotetext{
${ }^{34}$ As mentioned in footnote 1 , the video examples given and analyzed throughout this thesis are drawn from two DVD-sets of the serials. At the time of writing, the serials can, however, also be watched on YouTube. 
slowly ascending and descending ornamental scale in sargam, of which fragments are repeated by the sitar, thus complementing the initial exposition of the scale ${ }^{35}$.

Draupadi then sings the phrase which forms the melodic core and the almost entire melodic material of the song, repeated over and over first by her, then by the sitar. Draupadi's playback-voice is at a significantly deeper register than the falsetto so predominant in Hindi film songs' female voices. She is accompanied by single restrained strokes of the sitar and a slow tabla-rhythm. Keechak appears on the scene, hooked by her singing. He approaches her in the garden while she pretends to be oblivious to him, lost in her reverie, singing the line "the mirror of my eyes reflects the face of my handsome beloved"36 over and over again. After a few repetitions of the phrase the (off-screen) sitar picks up on it, accompanied by the steady pace of the tabla, and is then again replaced by Draupadi's singing. The music abruptly comes to a halt when Draupadi sees Keechak stepping up next to her. To the sounds of chirping birds, Draupadi and Keechak arrange a meeting at the dancehall later that night. When Keechak agrees to the meeting with a smug smile on his face, the phrase of the song is heard again, played by sitar and tabla.

A cut nine minutes into the sequence introduces the nightly setting of the dancehall. Contrasting with the abrupt change of the visual track, the music continues from the previous scene. The sitar and tabla maintain the melody and rhythmic pattern without any rupture or glitch, thus creating a smooth transition. Keechak is anticipating an erotic encounter and identifies the sari-clad silhouette sitting in the middle of the hall with its back turned towards him as Draupadi. In fact, however, it is Bhim in disguise, who is waiting for him. Keechak enters the room, casually without his crown, evidently drunk. Draupadi herself hides behind a pillar, speaking to Keechak, who approaches the disguised Bhim. The music, now played only by the sitar, starts to accelerate and moves to higher pitches the closer Keechakgets to Bhim. As soon as Keechak reaches Bhim-as-Draupadi and touches him, Bhim turns around and punches Keechak, which is emphasized by a loud smashing sound. At the same moment, the sitar music stops and is replaced by a combination of fast drumming and synthesizer sounds.

\footnotetext{
35 While the song is based on $\mathrm{rag}$ Megh, the melody mostly revolves around five pitches of $M e g h$ 's scale. ${ }^{36}$ As translated in the subtitles.
} 
The drumming, as is shown in a medium shot one second after the punch, comes from Arjun, who lives at Virat's court as dance teacher Brihannala. He plays the pakhawaj loudly to cover up the swelling sounds of Bhim and Keechak's fight. The synthesizer-sound, which starts at the same moment, has a hissing, swooshing quality that makes it impossible to determine a pitch, as is so characteristic for the synthesizer-sounds of the serial. The synthesizer hovers in the aural background while the dense, fast and loud drumming and the sounds of the fight (grunting, punching, bodies falling and tumbling) aurally dominate the setting. Visually, fast-paced shots alternate between a wider frame of the two fighters getting increasingly bloody and sweaty, shots of Draupadi watching them from behind the pillar, and Brihannalla tensely playing his pakhawaj, staring straight ahead. The scene builds up to a climax with swiftly alternating shots, the synthesizer-sounds swell in density and volume, the pace of the drumming is rapid, and Keechak roars and grunts as Bhim keeps him in a headlock. Almost 15 minutes into the sequence (at 14:53), Bhim snaps Keechak's neck, while Brihannala simultaneously (shown in a succeeding shot) smashes the drumhead in a final beat. Against a soundwall of white noise, images of Keechak's falling body, Brihannala's upset face and a delighted Draupadi are seen. The scene ends with a freeze-frame of Draupadi's relieved face and the melody of the famous arti 'Om Jai Jagdish Hare' played by a synthesizer, a vibraphone and manjiras to which a male voice sings a couplet on the lesson of the preceding sequence 37. As the description of this Mahabharat-sequence illustrates, the densely layered and stylistically diverse sounds in Chopra's version of the epic story create a powerful (narrative and atmospheric) presence. The same goes for Ramayan, which is filled with sound just as lavishly as Mahabharat. Not only do both of the shows integrate a wide range of aural aesthetics and musical styles, this aural diversity also covers a range of functions at structurally diverse points in the audiovisual narratives. I argue that conceiving of sound and music in TV-serials as a narrative component does justice to their vital contribution to audiovisual narratives. Likewise, it allows us to grasp the multifarious effects of sound and music in audiovisual narratives - that is, what they do in this medial context. In this chapter, I elaborate on this contention, arguing for music's narrative properties in Ramayan and Mahabharat by conceptually unraveling notions of (audiovisual) narrative and narrativity, as well as providing thoughts on the dynamics of sound's unique impact in the context of televisual narratives. In this, I argue that while

\footnotetext{
${ }^{37}$ As translated in the subtitles: "Keechak lost his life because he played with fire / Draupadi's tears have got back their honor". 
understanding music as narrative agent provides a conceptual grip of its relevance in the televisual format, the concept of narrativity alone is not sufficient for grasping the intensity and uniqueness of sound's effects. Therefore, I argue that it is sound's and music's atmospheric materiality that is so crucial to its powerful effects in the audiovisual narrative.

Putting this thesis in perspective with existing research on music and narrative, in section 2.1 I discuss the relationship between music, narrative and narrativity by exploring narratological and musicological positions on this issue. Next, I consider the medial setting of the serials by exploring perspectives on music in film and television. Expanding on these ideas, I then discuss the intersection of sound's materiality, its ability to create atmospheres, and its signifying properties, arguing that they are the basis of sound's narrative potential. In section 2.2, I elaborate on the notion of sound's power by outlining the styles, structural features, functions and positions of music in Ramayan and Mahabharat.

\subsection{Music as Narrative, Music's Narrativity}

To explore the narrative impact of sound and music in Ramayan and Mahabharat, it is first necessary to step back from the specificity of the televisual serial context and to consider the more fundamental question of music's relationship to narrative and narrativity. Exploring music's potential narrativity in television serials touches upon a number of entangled issues: the fact that music does not have fixed, inherent meanings; music's particular material qualities that are so distinct from those of images and language; the relation of image and sound in $\mathrm{TV}$, the composition and structure of audiovisual narratives; and finally the impact of the format-specific serial structure on music's narrativity. I will approach this cluster of layered and interrelated questions step by step. Narratology has been a sprawling academic field for decades, which is why it cannot possibly be covered here in its entirety. Drawing on selected contributions to this field, I will first present notions of narrative and narrativity that include media other than written texts. Seeking an understanding of narrative that captures music's specific 
expressive and material qualities, I discuss models of narrativity that have been developed for North Atlantic instrumental art music, as well as the approaches of film music scholars. This will be followed by a reflection on the intersection of sound's significatory and atmospheric material qualities, which are central to sound's strength in televisual narratives.

\section{Narrative and Narrativity}

For decades, the scope and limits of the twin concepts of narrative and narrativity have been the subject of debate in an increasing number of disciplines (see Prince 2005: 372). Among the vast range of contesting perspectives, it is necessary to find a definition of narrative and narrativity that does justice to music in particular, and the multimedial context of the television serial in general. Beginning with the assumption that music and sound are narrative elements in television serials, I need to flesh out how music and sound can function as narrative elements - in principle and as elements of the multimedial framework of the television serial.

Even though narratology originated in the study of written stories, its transmedial relevance has always been obvious (Ryan 2004: 1), and has culminated in the narrative turn and the employment of narratological perspectives in various disciplines. A symptom of narratology's spread are countless (re-)definitions of narrative to account for all of its potential manifestations. As intermediality scholar Werner Wolf points out, this trend has resulted in an increasing fuzziness of the concept. This conceptual dilution complicates working with the term, especially with regard to media whose narrative properties are ambiguous, such as sounds or images (2002: 23-26) ${ }^{38}$. The definition Wolf proposes himself allows for a cross-medial application without favoring some media over others. Wolf defines narrative as a cognitive scheme - a culturally and historically contingent nexus of patterns of communication, expectations and understanding. It can be evoked in different media and is open to an almost indefinite range of contents and forms (ibid.: 29). Against this backdrop, Wolf defines narrativity as the quality of a cultural text of evoking

\footnotetext{
${ }^{38}$ Wolf illustrates this dilution by drawing on two definitions of narrative by Mieke Bal and Gerald Prince. According to these definitions, narrative is "'the representation of events in temporal sequence"' (Bal), or "the representation of at least two real or fictive events or situations in a time sequence, neither of which presupposes or entails the other'" (Prince) (2002: 34). While these notions are broad enough to capture a wide range of the manifestations of narrative, they are too vague for an actual conceptual grip. 
the narrative scheme through the smallest textual units (narremes) that mark narrative content (ibid.: 29-30, 44-51).

By emphasizing the cultural dimension above the textual, Wolf's definition allows for integrating the perspectives of producers and recipients in the analysis of a given narrative, and moreover offers a conceptual frame for narratives in different media. Narratologist Marie-Laure Ryan proposes a very similar cognitive approach to defining narrative and narrativity. This definition integrates two layers that emerge from a general understanding of narrative as a cognitive scheme: the textual ${ }^{39}$ layer of the narration, and the perception of this text as narrative. While Ryan intentionally leaves the type of medium constituting the "textual act of representation" (2004: 9) open, she deems language to be the best suited medium to "make explicit the logical structure of narrative" (ibid.: 15). For Ryan, however, language is not the only narrative medium since a narrative is not only a text but also "a cognitive construct, or mental image built by the interpreter in response to the text" (ibid.: 8). Based on these two layers (or as she puts it: modalities) of narrative, she suggests distinguishing "between [an expressive format] 'being a narrative' and 'possessing narrativity"' (ibid.: 9). According to Ryan, a narrative is "any semiotic object produced with the intent of evoking a narrative script in the mind of the audience", while objects that are "able to evoke such a script [...] without being narratives in a literal sense" (ibid.) may be understood as possessing narrativity. For Ryan, music is among the latter media due to its non-denotational character. Whether a 'text' is a narrative or not, is not a matter of arbitrary assessment, but is bound to a set of (culturally contingent) requirements, which Ryan defines as follows:

“1. A narrative text must create a world and populate it with characters and objects. [...]

2. The world referred to by the text must undergo changes of state that are caused by nonhabitual physical events. [...] These changes create a temporal dimension and place the narrative world in the flux of history.

3. The text must allow the reconstruction of an interpretive network of goals, plans, causal relations, and psychological motivations around the narrated events. This implicit

\footnotetext{
${ }^{39}$ Ryan repeatedly uses the term text while at the same time making explicit that she also refers to media other than written text, which is why I understand her usage of the term text in a broad, Geertzean sense.
} 
network gives coherence and intelligibility to the physical events and turns them into a plot" (ibid.: 8-9).

Given the two modalities of this definition - narrative as textual representation and cognitive scheme, and narrativity as a corresponding quality - it lends itself to analyzing cross-medial configurations such as TV-serials, but at the same time does not allow every cultural expression to be defined as narrative. In this sense, it is evident that music can be understood as a narrating agent in the multimedial context of the television serial, but not as a narrative in itself. Here, music is not self-sufficient and does not fulfill the textual criteria listed by Ryan. It does, however, possess narrative qualities (narrativity), which, together with the other narrating elements, constitutes the televisual serial narrative. This dependence on other narrating agents, however, does not mean that music's narrative capacities are merely supplementary. Sounds, due to their specific materiality, are a distinct "modality of creating meaning and knowledge" (Eisenlohr forthcoming: 9) within the narrative that goes beyond what images and language can express.

An understanding of music and sound in television serials as possessing narrativity corresponds with recent trends in narratology, where the term 'narrativity' has slowly started to supersede narrative as a descriptive category. Narratologist H. Porter Abbott attributes this popularity to the term's inherent dynamic qualities that arise from its "grammatical status as a reference to a property or properties rather than to a thing or class", thereby describing "a felt quality, something that may not be entirely definable or may be subject to gradation" (2011: Paragraph 3). The term 'narrativity', although rarely defined precisely, generally refers to a quality either considered to be inherent in a text, or arising from the perception of the audience. It thus accounts for the audience's agency in reading and processing the narrative's impulses, and in understanding it as narrative. It makes sense to assume that the narrativity of sound and music in television serials arises from being identified as such by the audience. After all, narrativity needs to be perceived to function. At the same time, to be perceived as possessing narrativity, an expressive format requires structural elements that encourage a narrative perceptual mode. These, in turn, are also dependent on the (cultural) setting of the format. The fact that the perception of a text as narrative is culturally contingent, which is so vital to this thesis, is thus also accounted for in this model of narrative and narrativity. 
Against this conceptual backdrop, television serials can be understood as multimedial narratives. Music, as one of the constitutive elements of these narratives, isn't a narrative in its own right but vitally contributes to them by virtue of its narrativity - its qualities that enable the audience to perceive the narratives as such.

\section{Music and Narrative}

The narrative potential of music has not only been of interest in film-and television-music studies, but also in historical musicology. In this section, I discuss these musiconarratological approaches in order to better come to terms with music's narrative qualities in the televisual context.

While conceiving of instrumental music as narrative is in some ways related to the notion of absolute music and has surfaced in musicological discourse time and again, it only gained popularity in Anglophone musicology about thirty years ago, in the wake of the narrative turn (Reyland 2014). Here, various authors argue(d) that pieces of North Atlantic art music - purely instrumental or opera - could be conceived of as self-contained narratives and be analyzed accordingly (see Maus 2005; Almén 2008; Reyland 2012, 2014).

As Nicholas Reyland points out, two main positions emerged in the debate sparked by this approach, which were analogous to "literary narratology's approaches to the play and the novel" (2014: 205). Accordingly, music was either understood "to represent agents and their activities [...] as a real-time imitation of events" (ibid.), or conceived as a "narrator to recount a plot involving agents and their activities" (ibid.). Overcoming the discrepancy between verbal modes of narration and the structural and non-denotationality of instrumental music is the biggest challenge in these approaches. One example of how authors deal with this problem can be found in Byron Almén's monograph A Theory of Musical Narrative (2008). Here, Almén develops a model of musical narrative that circumvents the structural divide between notions of verbal and musical narration. Like Wolf, Almén argues that any theory of musical narrative derived from theories of literary narrative condemns the former to being a mere modular adaptation of already existing 
theories in which language is privileged. According to Almén, this inevitably results in theoretical shortcomings, since musical formats can never entirely meet the requirements of narrative as defined with regard to verbal formats (2008: 12). He therefore suggests a definition that "separates narrative universals from those arising from specific media". Of course, this model focuses on what he regards as narrative universals: "the dynamics and possible outcomes of conflict or interaction between elements, rendering meaningful the temporal succession of events, and coordinating these events into an interpretive whole" (ibid.: 13). These alleged core features of narrative are, I argue, far from universal but rather are specific to North Atlantic instrumental music. For example, the factor of "temporal succession" is not only a central structural element of this kind of music, but it also presumes the universality of a paradigm of linearity and causality in storytelling. However, as I will elaborate below regarding the narrative structures of Hindi films, this neither applies to all narratives nor to all musical structures. Almén's model ascribes the narrative properties to three aspects of North Atlantic instrumental art music: its capacity to evoke embodied responses, from which, as a second aspect, results "the experience of narrativity itself, rather than specific stories" (Reyland 2014: 210), as well as its temporality, which matches narratology's preoccupation "with the transformation of ideas over time" (ibid.: 213).

As these approaches suggest, understanding North Atlantic instrumental art music as narrative requires a massive remodeling of the predominantly literary notions of narrative (even though not necessarily of narrativity), which then lose their conceptual grip when it comes to narratives in media other than music. Originating from a structuralized understanding of music, several of the 'narrative' approaches to North Atlantic instrumental music seek to legitimize music as a form of narrative expression by strongly adapting existing definitions of narrative towards the specific structural qualities of the music in question, instead of embracing more inclusive - intermedial - models of narrative. It is questionable whether these approaches serve a purpose other than to substitute for other formalist perspectives, as Lawrence Kramer argues (1991: 142-43) a position aligned with more general critiques of structuralist narratological analysis as an end in itself that does not grant insights beyond the textual form (for instance Bal 1997: 220-21). 
The musico-narratological take on instrumental music springs from a perspective deeply rooted in the European Romantic history of thought ${ }^{40}$ and directly related to the aesthetic paradigm of absolute music. It presupposes that 'music' inherently consists of a structure of aural negotiation between (at least) two harmonic/melodic entities. The dynamic resulting from this negotiation is the element of change - analogous to the harmonic and melodic shifts in the elaboration of musical material in North Atlantic art music - that is then considered the essence of what makes music a narrative. In a sense, this claim essentializes music by presuming it possesses a fixed set of meanings. The element of change is translated from structural musical characteristics into an abstracted meaning that can be deciphered correctly by the (educated) listener. Conceptualizing instrumental music as self-contained narrative thus inevitably becomes a self-fulfilling prophecy when exclusively applied to a very small corpus of music. As soon as these concepts are confronted with other sounds, other musics that have not emerged from the traditions that lie at the heart of these specific approaches, or even other notions of narrative, they appear misplaced.

Despite the vast differences between these approaches and my own notions of music and narrative, I still find it useful to draw on what Reyland sums up as their "overarching tendencies", all of which relate to music's materiality: the ability to grasp us viscerally, to "invoke embodied responses" (2014: 210), the factor of experience (of experiencing the music), and music's temporality, which points as music's inherent dimension of movement. It is these elements which, even though I do not consider them sufficient to form a self-sufficient narrative, are vital for music's narrativity.

\section{Narrative (and) Film Music}

As these considerations make clear, it is imperative to investigate music's narrative properties in audiovisual narratives in this medial and cultural context. That is, it is necessary to consider the material, structural and theoretical implications of sound's location in a multimedial context - a context from which it cannot be analytically

\footnotetext{
40 This is also pointed out by Reyland (2012: 56 ).
} 
isolated $^{41}$. In what follows therefore, I approach the medial nexus of Ramayan's and Mahabharat's sounds by first turning to research on film music, exploring how its narrative qualities have been prominently conceptualized. While I am fully aware that film and television are different media whose particularities need to be considered separately, there are obvious reasons why research on the narrativity of film music is relevant to this study of television serial music. Primarily, there is the structural similarity of the two media; the audiovisual narration via screen follows very similar aesthetics and conventions, which has led to frequent interchange between studies of music in film and television. Moreover, film music has been studied within a narrative conceptual frame for roughly three decades. The theoretical complexity resulting from this extensive research is not yet matched in the study of television music, which has historically been motivated by different sets of questions. To manage the breadth of this material, I will limit the following exploration primarily to a few select positions.

Perspectives on film music as a narrative component are themselves based on established concepts of narration. Earlier works on narrative film music generally drew more on literary notions of narrative (such as Genette's), while newer approaches also draw on specific filmic models of narrative (such as Chatman's). These conceptual shifts acknowledge that filmic narration works differently than literary narration, that it is governed by different dynamics than written narratives due to its entirely different medial configuration. Through this shift in focus, the authors conceptually account for the significantly non-verbal functioning of filmic narration. Overall, these approaches share a central occupation with music's relation to the other narrative components and music's position as a structural and content-determining factor within the whole narrative. Different positions here mainly result from diverging perspectives on whether film should be best understood as a primarily visual or audiovisual medium, and thus whether music serves more as a decorative addition, or as a constitutive element of the narrative (and how exactly it functions as constitutive element).

I consider it essential to acknowledge that the audiovisual narrative is created not only through language and moving images, but also through sound and the interplay of these three elements. In his Film Narratology (2009), Peter Verstraten proposes an 'egalitarian' idea of filmic narration. He argues that the filmic narrative is composed by three

\footnotetext{
${ }^{41}$ Unless, of course, when studying a separately marketed soundtrack.
} 
narrators: the filmic, the visual, and the auditive narrator (2009: 7-10). These narrators are not to be understood as anthropomorphic figures with authorial intention (as promoted in some models), but rather as the channels through which images and sound are transmitted and shaped. The visual narrator, as the term suggests, is responsible for "the sequence of images" in a film, while the auditive narrator "controls the auditive track, which contains external and internal voice-overs, dialogue, voices, music, and all other kinds of sound" (ibid.: 130). Sound and music, therefore, do narrate within the filmic narrative. Both these narrators operate individually, not aware of what the other narrator does, but are instead coordinated and controlled by the third, hierarchically superior, filmic narrator (ibid.: 7; 130).

The coordination by the filmic narrator ensures that the audiovisual framework makes sense, resulting in a relation of image and sound that Claudia Gorbman describes as "mutual implication" (1987: 15). In fact, even though the relation of sound and image is complex and at times might seem mismatched or independent from each other, Michel Chion emphasizes that the audience only perceives them as one (multisensorial) unit, which is, consciously or not, "distributed in the spectator's perceptual apparatus according to the relation each bears" to each other element (1999: 3).

Assuming that sound and images are complexly intertwined in constituting the audiovisual narrative, the question still remains how sound relates to the broader structural components of the narrative, and how to grasp and describe its concrete narrative effects. In her groundbreaking monograph Unheard Melodies: Narrative Film Music (1987), which established the idea of music as a narrative element of film ${ }^{42}$, Claudia Gorbman approaches these questions through a combination of narratological, semiotic and psychoanalytic perspectives. While she proposes to understand music as a narrative filmic component, she clearly subordinates music to the other narrative elements, and to the story itself, due to its lack of autonomous representational capacities (Gorbman 1987: 31). Gorbman locates music's narrative power mainly in its capacity to mediate between apparently disparate visual elements of the narrative (ibid.: 30), thus smoothing over

\footnotetext{
42 I am aware of her paper "Narrative Film Music" from 1980 in which she already sketches this concept. Still, it was her book-length study from 1987 that has achieved seminal status in the study of music's narrative properties in audio-visual media.
} 
ruptures and providing a sense of continuity and even causality. These functions are enabled by music's capacity to exert a visceral influence on the audience - providing a "bath of affect" (ibid.: 6) and a point of suture for the audience (ibid.: 55) - which facilitates immersion in the story. In a similar vein, she emphasizes the commenting functions of music regarding the events shown on screen, its ability to set a mood to a visual setting, the continuity it provides through repetition, and, most importantly, the fact that it affects the audience subconsciously. Analytically, Gorbman grasps music's position towards the 'underlying' narrative by adapting Genette's notion of narrative levels and distinguishing between diegetic and nondiegetic music ${ }^{43}$. According to this distinction, diegetic music is music issuing from within the filmic narrative world, while nondiegetic music refers to what is commonly termed background scoring: music that is heard but the source of which is not visible on screen. Gorbman suggests the term nondiegetic music, because she perceives it as "narrative intrusion upon the diegesis" (ibid.: 22). This set of terms is arguably the most influential (and controversial) element of Gorbman's work in the study of music in audiovisual media, in which it is now is a conceptual staple.

While Gorbman's understanding of music as a narrative element of film did (at least initially) receive enthusiastic responses among film music scholars (for instance Kalinak 1992), some voices have also criticized perceived insufficiencies of the approach (e.g. Brown 1994 and 2005; Levinson 1996; Kassabian 2001; Donnelly 2005; or Goldmark, Kramer and Leppert 2007), even though they do not necessarily reject the basic idea of music's narrativity in film. Despite focusing on the narrative qualities of music, Gorbman ascribes it a relatively marginal role within the filmic narrative. While it is undeniable that filmic narratives are not (always) dependent on music and can in principle function without it, in those films that do contain music, it is an important narrative device with unique expressive potential resulting from its specific materiality.

The gaps in Gorbman's model resulting from the marginal role she attributes to music and the inflexible concept of two narrative levels explaining music's structural role, are in part filled by Ben Winters. Explicitly positioned as a modification of Gorbman's model,

\footnotetext{
${ }^{43}$ To be accurate, Gorbman also introduces a third category: that of metadiegetic film music. Corresponding with Genette's concept of the term metadiegetic as the level of narration "pertaining to narration by a secondary narrator" (1987: 22), she explains it as those musical instances that function as a commentary on the plot or a given situation in a film from a higher, detached level of narration (26). This category, however, appears to play only a marginal role in her analyses and is mostly irrelevant in the academic perception of Gorbman's work.
} 
Winters' concept of musical narration in film proposes a different understanding of the filmic diegesis and an alternative set of terms for describing music's relations to the filmic narrative. Overall, this model allows for a more inclusive understanding of musical narration in film. Central to Winters' approach is his critique of Gorbman's adaptation of literary notions of diegesis for analyzing music in the filmic narrative (2010: 225). Winters argues for an understanding of diegesis that is common in film studies, which acknowledges the potential fantastic elements of a narrative and accounts for the fact that most North Atlantic films rarely contain different levels of narration. He suggests that by conceiving of narrative spaces instead of an opaque notion of narrative levels enables an understanding of music as inherent part of the narration (ibid.: 226-228). Winters traces the central criterion for classifying music as nondiegetic - whether the characters in the scene are able to hear it or not - back to Adorno's and Eisler's extremely influential notion of film as an inherently realistic medium. As Winters points out, however, this concept is unable to grasp the worlds of film, which are fantastical more often than not (ibid.: 228, 236). He instead suggests categorizing music based on whether it belongs to the same narrative space as the other elements of the narrative (ibid.: 236-37) - that is, the same fictional universe in which the plot is located - because this acknowledges music's vital contribution to the construction of this universe (ibid.: 225). To this end, Winters proposes a modification of Gorbman's terminology, distinguishing between diegetic ("for continuity's sake", ibid.: 237) 'realistic' sounds within the diegesis, intradiegetic sounds beyond the unambiguously realistic ones that are however still in the narrative space of the diegesis, and extradiegetic sounds that are clearly outside of this space, on a potential separate level.

Despite urging for an understanding of the importance of music for the filmic diegesis, Winters does not grant music the power to actually narrate in film. Even though he criticizes Gorbman's use of Genette's notion of diegesis, he ultimately draws on Genette's distinction between narration and narrating himself, arguing that music is merely a "product of narration" (ibid.: 228) and not a narrative instance in its own right. According to Winters, the reason for music's inability to narrate lies precisely in its close entanglement with the diegesis. In order to actually narrate, so Winters, music would have 
to "occupy an extra-diegetic level that is removed both temporally and spatially from the characters" (2012: 40), as is for example the case with a voice-over.

At this point I disagree with Winters: as pointed out above in the context of Verstraten's concepts of filmic narrative, the act of narration does not require a detached and explicitly verbalizing (anthropomorphic) agent. Instead, narration in film takes place through the interplay of images and sound and their joined evocation of the cognitive scheme of the narrative, their ongoing construction of fictional worlds, characters, events, and moods. The ways in which sound contributes to relating the story by giving orientation, focalizing, referencing, repeating alluding, evoking and emotionally engaging, are clearly acts of narration because they communicate aspects of the story. While most film music scholars describe the functions of sound and music in film as supplementary to an already existing filmic narrative, most of them acknowledge that music and sound are vital for creating moods and atmospheres. As detailed below, I argue that this creation of atmospheres addresses the specific agency of sound in film (see Goldmark, Kramer, Leppert 2007), and is a crucial element of sound's narrative functions in film.

The studies of film music I have drawn on so far are exclusively focused on the products of the Hollywood and European film industries and do not take into account the rich diversity of other narrative cultures and film industries. However, the Hindi film culture, which is of utmost importance for both Mahabharat and Ramayan, urgently needs to be considered here. There is a plethora of texts on Indian cinema - academic and nonacademic - that covers topics ranging from production and reception, to the star system, the cultural dynamics of generic or performative traditions in film, to detailed readings of filmic texts. While a vast number of publications have emerged from the expert cultures centered on Indian cinema, the scholarly study of Hindi film music has only been firmly established in the academic canon in the past two to three decades. Next to musicological (for instance Ranade 2006) and media- and film studies-perspectives (such as Jhingan 2011, 2013) on film music, ethnomusicological approaches (such as, for instance, Arnold 1992; Morcom 2007; Booth 2008a, 2008b and Beaster-Jones 2015) are formative here.

The majority of the (ethno-)musicological studies of Hindi films focus on one salient musical feature that significantly shapes 'typical' commercial Hindi movies ${ }^{44}$ : the songs,

44 I am well aware that there are commercial Hindi films without these sequences. However, these sequences have become a characterizing feature defining Hindi films, also in a structural way. 
and song-and-dance-sequences, which have become emblematic of this filmic culture ${ }^{45}$. In fact, songs are so central to the study of Hindi film music that Morcom's monograph (2007) is one of the rare publications that considers background scoring in some detail. Overall, scholarly musicological works of Hindi film music do not conceptualize music's narrative role very differently from how it is understood in North Atlantic films. The songand-dance-sequences are either positioned within the dominant film musical paradigm, or in an extension of its formative notions of narrative levels. Before I give a brief overview of how song sequences, background score and their narrative functions is predominantly conceptualized in research on Hindi films, I will go into the more general aspect of narration in Hindi film. This is important with respect to the cultural contingency of narrative, which accordingly impacts the ways in which music and sound narrate in the medium film.

As film theorist M. K. Raghavendra (2006) points out, generally speaking, Hindi films are not necessarily governed by the principle of time-compressed causality as most (mainstream) Euro-American films are. Rather, they are mosaics of narrative and generic fragments that are drawn together in each single film. This does not mean that films, or at least parts of plots, are never based on causally motivated stories. Nevertheless, causality is not the central motivator of film narratives (Raghavendra 2006: 26, 31). The ways in which the narratives of Hindi films evolve are, according to Raghavendra, not based on an understanding of progression and change, as is paramount in most North Atlantic film narratives ${ }^{46}$, but on an episodic model of narration. In this respect, Hindi filmic narratives are not about creating suspense, but rather about conveying fragments of a story or multiple stories, the structure and outcome of which are generally known to the audience (ibid.: 26, 33). The films can, for instance, dwell on a tableau-like status quo of situations or on specific constellations of characters and their relation to each other, which are sometimes drawn directly from mythology (ibid.: 31-33). Raghavendra argues that this is connected to a fundamentally different conception of time as non-linear, which is deeply

\footnotetext{
45 Ranade even goes so far to say that film songs should not be considered as part of a larger filmic whole, but studied as a separate entity (2006: 432). While I disagree with Ranade, I think his point is in a way representative of the special status attributed to film songs.

46 In fact, this criterion not only applies to North Atlantic filmic narratives, but is defined as central to the concept of narrative in general by Ryan (2004: 8-9).
} 
embedded in Indian cultural knowledge, philosophy and history of the arts ${ }^{47}$. In Hindi cinema, this leads to favoring relations and dynamics that are perceived as universal and timeless over disruptive elements such as change and surprise. A case in point is the strong impact of mythological fragments on Hindi cinema. Prominently drawn from the Ramayana and Mahabharata traditions, such fragments are frequently and subtly interwoven into the main narrative of films, for instance through analogies and parables (Booth 1995: 173-176).

Shaping narratives on a different level than actual narrative structures, the genres of Hindi cinema are "notoriously fuzzy" (Dwyer 2006: 15) and often bleed over into each other in individual films (see Booth 1995). The fuzziness of generic categories notwithstanding, an umbrella term frequently employed to describe Hindi films is that of the melodrama (Ganti 2004: 137; Morcom 2007:14; Vasudevan 2011). This term not only incorporates the diversity of generic features of Hindi films, but also emphasizes the "emotional realism and moral struggle", which, according to Morcom, is of higher relevance in Hindi film "than psychological realism" (Morcom 2007: 14). In addition, as outlined in the introduction, the term 'melodrama' indicates the eminent importance of music for Hindi films ${ }^{48}$.

As vital elements of their melodramatic film format, song-and-dance-sequences occupy a range of functions in Hindi films (Booth 2000; Morcom 2007; Beaster-Jones 2015). They provide a platform for the expression and evocation of feelings that cannot be expressed otherwise (Beaster-Jones 2015: 7) and they "propel plot development" (Ganti 2004: 80) by giving information on "the development of narrative situations and characterisations" (Booth 2000: 127). Booth remarks that "the vast majority of music scenes are devoted [...] to the nonverbal, non-synchronic [...] portrayal of all shades and aspects of the romantic relationship" (2000: 128), even in films which are not primarily about love (Ganti 2004: 80-81). They are equally important for creating "feeling[s] of separation" and "the sentiment of grief" (Ranade 2006: 426), for evoking religious practice and feelings, or indicating places and situations that are becoming relevant for the plot development (Beaster-Jones 2015: 5-6). The song-and-dance-sequences of Hindi films occupy

\footnotetext{
47 Dwyer also points to this conception of time as vital factor in the genre of the mythological film in India (2006: 15).

48 The central position of Hindi film songs in the filmic narratives originates from a diversity of folk and urban theatrical performance traditions (Dwyer 2006: 2, 12; Morcom 2007: 3). 
prominent positions within the narrative due to their stylized aesthetization: with the elaborate dancing, obvious lip-synching of the actors and frequent changes of (exotic) scenery, the sequences are supposed to be perceived as larger than life. Morcom points out that this aesthetic is "encapsulated in the Hindi term filmi" (2007: 85). This prominent position within the narratives has made the structural relation of the song-sequences to the rest of the narrative subject to discussions. While some authors understand film songs as self-contained elements inserted into the film without being narratively embedded, others have argued for the thorough embeddedness of the song-sequences into the filmic narratives (see Morcom 2007: 10-14). Anna Morcom convincingly argues that the melodramatic mode of Hindi films requires the song sequences as vital parts of the narrative (2007: 14-15). Given their relevance for the overall filmic narratives, in line with the terminology proposed by Winters, I suggest treating them as intradiegetic, since they essentially take place within, or closely relate to, the diegesis of the film. This also emphasizes that, despite their prominent structural positions and aesthetics, they contribute to shaping the filmic universe just as the background scoring does.

Music, be it in Hindi or North Atlantic films, is a substantial narrating element. It not only corresponds to the respective narrative principles of the film, but actively shapes them in addition to its 'typical' functions of co-creating the filmic universe, the characters and their relations to each other, and propelling the plot. Throughout spaces and levels, sound and music narrate by framing, positioning, and guiding the storyline(s), and, essentially, they narrate in a way that is specific to sound - by involving the audience emotionally and viscerally.

\section{On Analyzing (Narrative) Sound and Music in Television}

While the numerous parallels between film and television are obvious and their vicinity is even more evident in medial overlaps, as when re-runs of movies are broadcast on TV 49 ,

\footnotetext{
${ }^{49}$ This points to the crucial aspect of media practices and the shifts of medial distinctions through emerging practices such as video on demand and online streaming. Given the main questions of this study and the fact that the internet obviously wasn't a factor in late 1980s India, I will not follow up on this issue here.
} 
it is still necessary to mention the differences between them in order to account for the specificities of televisual music.

As Robynn Stilwell points out (2003b, 2011), the institutional, technical and infrastructural conditions of television strongly impact its formats and content, and accordingly also the music and sounds that are heard in it. Television often is connected to (and initially brought about by) national governments - a relation still evident in many countries in the segmentation of channels and networks, or in the structure of broadcasting slots (Stilwell 2011: 120). This governmental connection was a vital factor in the production of Ramayan and Mahabharat, which were commissioned by the Indian Ministry of Broadcasting and Information. The impact of these institutional frameworks is not only felt on macrostructural levels, but trickles down to the details of individual programs, such as the targeting of shows and advertisements, the length of programs, and the distribution of timeslots. Likewise, the (inner-episodic) timing of shows and serials with regard to advertising breaks result from the commercial, political and institutional structures of television (ibid.: 121). The individual composition of television shows is equally affected by these structures: the target audience, budgets and conditions of production (such as the time frame for production) are among the elements involved here. It is at this level that differences between the media of television and film manifest significantly. Generally, films have longer timespans and a bigger production budgets than television shows, resulting in higher production value and a corresponding visual and aural aesthetic. Before large sections of televisual audiences could afford high-tech home theater systems, shows produced for TV needed to be watchable on small screens with low resolution and inferior speakers, which limited sound and visual design as aesthetic options (Stilwell 2003b: 60). Due to the continuous schedule of television, especially the frequent blocks of advertising, individual programs are designed to stand out from the rest of the programming. The need to capture the (potential) audience's attention against intense competition significantly affects the aural aesthetics of shows. The music of a given program is closely interwoven with its structures, which in turn are contingent on overarching televisual structures: music forms arcs of suspense, needs to be adapted to the rhythms of commercial breaks, and is required to establish recall value. Rarely, especially in the context of current Indian television, do budgets and other general conditions allow for a TV-show's music to sound like that of a high-value cinematic production (see also Stilwell 2003b: 60-61). Similarly, several televisual formats are not 
found in cinema, for instance reality TV or the various narrative structures of TV-serials with their (aesthetic) implications, such as the close grid of repetitions. These differences and similarities between film and television do however not need to massively impact the methods for analyzing television music. In the case of this study, the structures and rhythms of Ramayan's and Mahabharat's narrations resulting from their medial setting can easily be accounted for without outlining an entirely new conceptual framework. The same goes for the serials' specific aesthetics: Since they were produced by former film directors at a point in time when India's television had not yet developed its own, distinct aesthetics, the premises of music's functioning in the multimedial setting, as well as the methods for grasping its effects, can principally be transferred to this context. It is important, however, to bear in mind the specificities of the medium, as well as the Indian context and mythological backdrop of the serials, in order to adapt the approach and its underlying assumptions flexibly when demanded by the material.

So far in this chapter, I have fleshed out the structural implications and features of music's narrating capacities in filmic and televisual narratives. What I have not yet addressed, however, is the question of how exactly I consider sound and music to narrate without words, and thus the substance of what music does in audiovisual media.

\section{The Materiality of Musical Narration - of Signs and Atmospheres}

This question of the mechanisms of music's narrating capacities, of what it actually does, lies at the heart of the debate on musical narrativity. Most scholars writing on the issue only deal with it in passing, vaguely bringing up semiotics, often treating it more as a catchphrase than a central concept in their work. Understanding music as sign provides a handy explanation for its efficiency in audiovisual narratives, accounting for the fact that large, heterogeneous audiences are able to perceive music and sound in similar ways. This approach, however, fails to account for the mysterious intensity of sound's effects - the often emotional and viscerally felt impact music and sound are able to instill in an audience. This contribution of sound to the narrative is usually described as mood or atmosphere by scholars of film or television music attempting to grasp musical effects that are notoriously difficult to put in words (see for instance Gorbman 1987; Kalinak 
1992: 93 and 2010: 2-4; Kassabian 2001: 56; Ranade 2006: 430; Rodman 2010: 21). As stated above, Claudia Gorbman describes sound's gripping, immersive power as "bath of affect" which "rounds off the sharp edges, masks contradictions, and lessens spatial and temporal discontinuities" as well as "awareness to the frame" and thereby draws "the spectator further into the fantasy-illusion suggested by the filmic narrator" (1987: 6). As Goldmark, Kramer and Leppert point out, music in audiovisual narratives is more than "a scarcely noticed background [...] that sometimes delivers ideological messages while creating mood or atmosphere, but [...] an agent, a force [...] engaged in ongoing negotiations with image, narrative, and context" (2007: 3). However, most authors tend not to follow up on this conceptual lead. To grasp these nuances of music's functions in Ramayan and Mahabharat, I propose to understand music and sound both in terms of their signifying capacities, and as immersive, atmospheric forces.

The fact that music and sound are understood in similar ways by the members of heterogeneous mass audiences can be traced to their signifying potential and their conventionality in multimedial contexts. Sound has been conceptualized as sign in research on television music for decades: landmark publications on TV-music such as Philip Tagg's thesis on Kojak's title sequence (1979) and Ron Rodman's monograph on American television music (2010), for instance, approach music as part of a semiotic framework. An especially promising approach for grasping music's signifying capacities is the semiotic model of Charles Sanders Peirce. Jayson Beaster-Jones considers Peirce's semiotics particularly useful because it captures "the ways in which music [...] can have manifold significances for audiences without reifying these meanings or resorting to linguistic analogies" (2015: 14). With the versatility of its notions of signs and signification, Peirce's semiotics, so Beaster-Jones, "acknowledges the contingency of meaning" (ibid.) as well as the varying degrees to which associations and meanings are connected to signs for the individuals in the audience.

Accounting for the contingency and potential multiplicity of meanings as well as the openness of the process of signification is crucial in a concept of musical signification. After all, musical signification is never stable. Which meanings are ascribed to sounds is highly variable, depending on numerous factors such as (historical) time, the cultural setting, and the individual perspectives of the people perceiving them. Peirce's model of semiosis is complex. It combines multiple triadic constructs that describe the different types of signs as well as their relations to each other, to the things they signify, and to the 
agents for whom they function as signs. Not only does this allow for acknowledging the complexity of sound's signifying dynamics, but it also does justice to the social dimensions of signification. This is crucial because, as anthropologist Patrick Eisenlohr writes, "semiosis has an inbuilt tendency to propel chains of social action, as signs will always beget new signs and actions. Semiosis thus understood not only appears as irreducibly social, but also generative and processual" (Eisenlohr forthcoming: 21). This generative quality of semiosis in the Peircean sense explains a vital aspect of music's efficiency in audiovisual narratives: apart from those sounds whose material qualities create unambiguously comprehensible atmospheres, highly generic, abstract sounds also function effectively in audiovisual narratives. They can accordingly be understood as the result of aural signification as processed through the conventions and aesthetic stylizations of their use in film (as symbols according to Peirce's taxonomy of signs).

Peirce's fundamental notion of signs is broad: "A sign", he states, "is something which stands to somebody for something in some respect or capacity" (Peirce 1955: 99). It does so by creating the interpretant, which is "an equivalent [...], or perhaps a more developed sign" of what it signifies for the person it signifies it to. The interpretant, in turn, "stands for something, its object" (ibid.). This triadic concept of the sign - its specific manifestation, the object it stands for and the intepretant it creates in the mind of the perceiving person - forms a conceptual basis. Beyond this, Peirce further triadically distinguishes between the characterizing aspects of the sign itself, as well as between the relations between sign, interpretant and object (Turino 1999). Peirce's probably most well-known triad - the concepts of icon, index and symbol - "specifies three ways that the sign and object are related in a perceiver" (Turino 1999: 226). As musicologist Thomas Turino poignantly summarizes: "icon refers to a sign that is related to its object through some type of resemblance between them" (ibid. original emphasis). The term index "refers to a sign that is related to its object through co-occurrence in actual experience" (ibid.: 227) which is most commonly illustrated by the example of smoke's indexical relation to fire. The third object-sign relationship, the symbol, "is related to its object through the use of language" (ibid.), and thus inherently a result of convention (Peirce 1955: 112). While these categories describe only a fragment of Peirce's nuanced taxonomy of signs, they precisely comprise the aspect of signification that is relevant here. 
The categories of signs most relevant for music and sound are those of index and icon. As Turino points out, icons and indices are "signs of identity (resemblance, commonality) and direct connections" (1999: 228). Understanding sound and music as indexical and iconic signs makes sense, given that sounds frequently resemble their source or point towards the specific social conditions of their existence ${ }^{50}$. The sounds of chanting and temple bells are not only actual performance of Hindu religious practice, but also indexically relate to Hindu religion, thereby signifying it. Crucially for this notion of musical sign, the dynamic of signification is neither unilateral nor essentialized or naturalized, but acknowledges the (inter-)subjectivity and contingency of perceiving music. This dynamic element is inherent in the structures of icons and indices, which are rooted in the (embodied) experience of the perceivers (see Turino 1999: 227). Thus, Peirce's model not only suggests multilayered, flexible notions of signs, but also provides a "highly differentiated" (Eisenlohr forthcoming: 20) perspective on the social dynamics of signification.

This perspective is so compelling because Peirce's semiotic model is "thoroughly integrated with materiality, causality and embodiment" (ibid.: 170-71). This aspect makes conceptual room for the significatory and material specificities of sound, which work and narrate so very differently from images and words. This way, "signification", as Eisenlohr puts it, "is not arbitrarily imposed on sonic movement", but "is inherent to its processual forms" (ibid.: 21), to the constant movements of sound and the multifarious shifts in knowledge it mobilizes through these movements.

Sound's significatory capacities in audiovisual media however only account for a part of its impact in this medial setting. Its often-mystified (and just as often analytically bypassed) capacity as "force" (Goldmark, Kramer, Leppert 2007: 3) cannot be explained simply by processes of signification ${ }^{51}$. The term atmosphere is frequently used - albeit usually in a colloquial sense - to describe the emotional, sometimes almost palpable effects of sound in audiovisual media. Therefore, I suggest that engaging with the term of atmosphere will yield a promising grip on these mystified qualities. The concept of atmosphere has been defined in different ways in philosophy and cultural theory and has

\footnotetext{
50 Sound can also function as a symbol. Especially in the context of audiovisual narration, the use of sound is highly determined by conventionalization, which is a central mechanism of how symbols signify.

51 There are of course studies which thoroughly analyze the inherent visceral effects of sound and music without getting into the issue of signification, for instance Chion 1994, Cheng 2013 and Coulthard 2013. 
been employed in a correspondingly wide range of epistemological interests (Anderson 2009: 78, Abels 2013: 220-21). As musicologist Birgit Abels and anthropologist Patrick Eisenlohr demonstrate, the notion of atmosphere, as employed in the context of (German language) new phenomenology, is productive for the analysis of sound and music.

The colloquial use of the term already gives a sense of the concept's fundamental idea and indicates its productivity for musical analysis. We experience atmospheres as moods, as ambience or presence (Anderson 2009: 78; Abels 2013: 222) that exists in a space (even if that space is outside or virtual) or between persons. This presence manifests as a blend of often indescribable feelings or sensations that touch us deeply, as happens so often when watching a film or a television show. The weather, frequently evoked to explain the concept of atmosphere, illustrates how the perception of atmospheres can be described neither as exclusively emotional, nor as purely bodily. According to the new phenomenologists, the somatic perception of atmospheres not only happens through the physical body, but also through the felt-body (German: Leib), which "can extend beyond the boundaries of the physical body", thus absorbing and feeling "sensations" that result from "phenomena outside the limits of the physical body" (Eisenlohr forthcoming: 127). Atmospheres, therefore, are felt presences that surround us, that even pervade us, as we experience them through our felt-body.

Atmospheres fill and create spaces, as does sound. Phenomenologist Gernot Böhme understands atmospheres as "object-like emotions, which are randomly cast into a space" (2000: 15), which also exist as entities beyond human individuality (see also Eisenlohr forthcoming: 22). Abels, however, warns that the idea of quasi-objective feelings (2013: 222) harbors the danger of essentialization. I agree, not least because assuming quasiobjective emotions would nullify the flexibility of the concept of atmospheres. However, Böhme's definition points to the spatial dimension of atmospheres and to the fact that they enclose those inhabiting that atmospheric space. The factor of spatiality is especially illustrative of why sound can be understood as atmosphere. As Abels points out, Schmitz understands music as a surfaceless phenomenon (forthcoming: 10), which creates spaces through its fluid textures, enveloping everyone who is located within them. Likewise, Böhme describes music as "expanded corporeal space, i.e. a physical reaching out into the domain which the music concurrently moulds and articulates" (2000: 16). Sound and 
music thus create and pervade spaces as atmospheres do - or rather because they are atmospheres.

Sound is a vital factor for orientation in our environment. The timbres and textures of sound provide information about a space but can also confuse our perception of space by manipulating our aural orientation in space. For instance, in the designed aural atmosphere of an audiovisual medium, staggered echoes of voices and noises can create the illusion of a large, but enclosed space. By the same mechanism, sonic impulses affect the entire body and make it resonate, for instance through the rhythmic thumping of an amplified electronic bass, or those screeching noises in horror movies that give us goosebumps. This visceral dimension of experiencing sound can be traced to its physical fundamentals: sound, as vibration, is not exclusively perceived by ear, but pervades the entire body and "transcends the notions of inside and outside by way of its primarily corporeal experiential quality" (Abels forthcoming: 5). As Abels and Eisenlohr suggest, this mechanism by which sound, or sound-as-atmosphere, so thoroughly gets a hold of us, can be understood through the concept of transduction, "the transmutation and conversion of signals across media" (Helmreich 2010: 10). Transduction, as the momentum of translating vibrations into sound that makes sense to us, is the point where "structured sound leverages both felt-bodily and cultural frames" (Abels forthcoming: 11). We make sense of sound as we are pervaded by it. This viscerality of atmospheric sound also explains how sound is able to create a sensation of intimacy in audiovisual narratives despite their highly technical, mediated setting. Here, sound directly taps into the paradox of remediation as elaborated by Bolter and Grusin (1999: 5-15), according to which impressions of immediacy are heightened the more elaborately and complexly they are mediated. The ways in which the sonic atmospheres of a TV-serial draw us in, touch us, obscures the fact that they rely on complex machineries of mediation.

Music and sound, by virtue of their omnidirectional proliferation in space (see Eisenlohr forthcoming: 121), create atmospheres that touch us individually as well as collectively when in shared spaces. In this capacity, the concept of atmospheres accounts for intense sensations of collectivity and belonging when groups of people are similarly permeated and moved by the textures of sound and understand them similarly (Abels 2013: 231; forthcoming: 10). Another phenomenon that results from their materiality is the ephemerality of sonic atmospheres. As Ben Anderson puts it, atmospheres "are perpetually forming and deforming, appearing and disappearing, as bodies enter into 70 
relation with one another. They are never finished, static or at rest" (2009: 79). Thus, beyond their spatial fluidity and impact as space, sounds-as-atmospheres are processual, dependent on the course of time, which in turn changes them as they morph and shift. Likewise, despite the intensity with which sound sometimes engages us, immersion into aural atmospheres is dependent on a willingness to give into them. The artificially designed aural atmospheres of audiovisual narratives can only make an offer of immersion to the audience, but they are dependent on the audience's willingness to give in to them (Abels 2013: 227).

In audiovisual narratives, sound functions simultaneously as atmosphere and as sign. Its significatory potential is inherently tied up with its materiality, which in turn is the basis of its atmospheric quality. While acknowledging its potential subjectivity, this notion of aural signification accounts for the conventionality of sounds in audiovisual narratives, which is a necessity given that they need to be understood by a large audience. Sonic signification thus draws on conventions as well as common life experience and resonates on a visceral level by virtue of its materiality. This visceral impact of sound can be best understood as atmosphere in the phenomenological sense of the term. The atmospheric and semiotic take on sound are closely entangled. As Patrick Eisenlohr points out, "the movements atmospheres suggest to the felt-body are suffused with semiosis, principally indexicality and iconicity" (forthcoming: 171), just as "the meaningfulness of [...] sound is not the product of an imposition of mental representations on an essentially asignifying sonic materiality. Instead, such meaningfulness is internal to the processual nature of its material forms" (Eisenlohr forthcoming: 172). The felt-bodily impact of sound in audiovisual narratives thus can also be considered in semiotic terms. Conceiving of sound as atmosphere, thereby acknowledging the intersubjectively perceiveable, immersive spaces that are richly layered complexes of information and orientation created by sound, as proposed by Abels and Eisenlohr, allows the bridging of the gap between the perception of a sound and the intense emotional impact it can have - something not possible using the concept of signification alone.

The signifying and atmospheric capacities of sound are at the heart of its narrative qualities in audiovisual media. While sound does convey and enhance what images indicate, its narrative powers go beyond these supplemental functions. Sound's 
atmospheric qualities mobilize cultural knowledge and thereby narrate in their own specific way. Sound relates to images and language in all sorts of ways, emphasizing and steering, subverting and ironically negating what might be read into the images. This endows sound with a specific narrative agency.

\subsection{Music as a Narrative Device in Ramayan and Mahabharat}

In what follows, I will inquire into how these theoretical aspects actually play out in Ramayan and Mahabharat. To do so, I will delve into the structural specificities of music and sound in the serials, providing an overview of their aesthetics and styles as well as their narrative properties. This will be followed by a brief reflection on the sonic categories of music, noise, sound effects, and the voice. Subsequently, I will address the different nuances of aural narration employed in Mahabharat and Ramayan. Finally, I will outline and describe the different musical elements in both serials, such as background scoring from stock and songs and singing, as well as their respective functions as constituents of Ramayan's and Mahabharat's serial structures and story worlds.

Both Mahabharat and Ramayan contain a lot of music, quantitatively speaking as well as in terms of stylistic variety. Their extended title tracks are complemented by rich layers of background scoring 52 , occasional songs ${ }^{53}$, sung passages of varying lengths, sometimes by diegetic music and a range of sound effects. The musics of both shows assemble an eclectic range of idioms, combining voluminous orchestral sounds, Hindu devotional songs, dense layers of synthesizer sounds, occasional fragments played by folk instruments, as well as passages played by instruments typically conceived of as Indian, such as sitar, bansuri, tabla, pakhawaj, dholak and harmonium. This blend of styles is typical for the soundtracks of Hindi films as described by Manuel (1993), Morcom (2007), Booth (2008) or Beaster-Jones (2015). In the episodes, "large orchestras, especially with large string sections playing unison melody lines and rapid passage work" (Booth 2008:

\footnotetext{
52 Nondiegetic music in Gorbman's terms. While I am in principle subscribing to Winters' terminology for positioning music in relation to other narrative elements of the show, I will also occasionally draw on terms such as background scoring in reference to Kassabian (2001) when foregrounding other functions of the music. I consider these terms to be more conceptually innocuous, thus allowing for also understanding the sounds in a different light than an exclusively narrative one.

53 The term 'song' does not capture the variety of formats of singing in Mahabharat and Ramayan. While I will get back to this terminological issue below, for the time being I will stick to the term 'song' for the sake of simplicity.
} 
85) are arranged in wildly cut-and-pasted passages that create a "huge wash of sound" (ibid.). These passages are either alternated or layered (and thus melted) with passages light in texture, played by melodic instruments such as sitar, santur and bansuri, often in combination with vibraphone and tabla or pakhawaj, or with unmelodic and unmetered, often noisy, ambient layers of synthesizer sounds. In addition to these instrumental sounds, songs and sung passages are an important part of the serial narratives, complementing the aural aesthetics described above with those of voices singing in the styles of Hindi film songs and North Indian Hindu devotional songs.

By heavily drawing on the aesthetics of Hindi film music, Hindu devotional genres, and the musical traditions surrounding the Ramayana and Mahabharata traditions (see chapter 3), Ramayan and Mahabharat operated fully within the conventions of the (mythological) Hindi film. The serials were filled with sounds that resonated with their recipients' knowledge of cinematic sounds, of the cultural practices around the stories, and of Hindu religion more generally ${ }^{54}$. Through this composition, Ramayan and Mahabharat did not revolutionize the sound of audiovisual narratives on Indian screens, but nevertheless, especially in comparison to other early Indian serials such as Buniyaad (1986) or Hum Log (1984), Ramayan and Mahabharat stood out for their extensive use of music.

\section{Music and Sound, Singing and Song: Aural Categories of the Serials' Soundscapes}

So far, I have been referring vaguely and alternatingly to either music or sound without clearly delimiting their semantic territory. It is neither possible nor sensible to define music and non-musical sound in audiovisual media as separate and exclusive concepts, given that both are aestheticized elements of the audiovisual narratives. However, for the sake of analytic clarity it is important to address this terminological divide.

Even though my approach to the serials is a decidedly musicological one, limiting the analysis of the serials' sounds to music would miss a vital part of the aural narration. In

\footnotetext{
${ }^{54}$ In the interviews I conducted, several of my informants pointed out how the serials' sounds reminded them of Hindi cinema, Hindustani classical music and North Indian devotional music (interviews with PS UV, 28 Mar 2015; with DV and PK, 8 Apr 2015; with VJ, 30 May 2015; with RV, 19 Jul 2015).
} 
addition, it would necessarily fail given the fragile, ambiguous, and often non-existent lines between musical and non-musical sounds. Especially given the thoroughly aestheticized nature of filmic sound worlds, artificially separating noise and music misses the point of their integrative aesthetics. In an article on Quentin Tarantino's films, Lisa Coulthard states that

"sound effects and noise work in conjunction with dialogue and music to create multivalent soundscapes that make it difficult to determine whether any sound can be classified only as an effect or musical cue. [...] rock and pop beats interact with rapid-fire dialogue and the noise of car engines, sword hits, punches or gun shots." (2012: 166)

This holistic concept of sound in audiovisual narratives, which certainly is at an extreme in the audio-visual worlds created by Tarantino, is promoted also by Chion and Verstraten. In his elaboration of the temporal and spatial contributions of sound to audiovisual narrative, Chion (1994) does not discriminate between music and sound effects in terms of their structural functions in film. Rather, he points out how all sounds heard in an audiovisual narrative have an impact on the way the narrative is understood, no matter their structural composition. Verstraten, too, emphasizes the (narrative) relevance of non-musical sounds when explaining his concept of the auditive narrator. The example by which he illustrates this narrator's role highlights the spatial dimension of sound's function in film. The combination of images with the sounds of talking voices (especially their volumes and textures, which vary depending on the characters' distance to the camera or to each other) and ambient sounds such as footsteps creates a sense of spatial perspective (Verstraten 2009: 146). Verstraten frames these spatial functions of sounds - all sounds - as strategies of focalization, by which the auditive narrator filters information and thereby creates a specific perspective from which the audience perceives the action in the scene.

In a similar vein, Lisa Coulthard (2013) and William Cheng (2013) base their analyses of European new extremism-films and a horror-video game on the aesthetic coherence of the respective format's noises, sound design, and music. Both authors demonstrate how all these aural factors create atmospheres of fear and discomfort. The elements of the soundscapes - music, droning sounds, ambient noises - are essential in their entirety to creating these atmospheres, thereby gripping the audience/player, immersing them into the nightmarish scenarios they co-create, and penetrating them with fear and nausea. 
While these examples have their respective generic and media-specific conventions, they are still relevant to a discussion of the sounds of Ramayan and Mahabharat. In both serials, sounds of various structural manifestations - be it sound effects, ambient noises, voices or melodic passages - are aestheticized elements of the fictional serial worlds and shape them in ways that defy categorization into either 'music' or 'sound'. Sound effects, noises, voices and musical passages frequently bleed and transition into each other, or are layered and combined. Accordingly, even though I will continue to speak of music, noise, sounds, and sound effects throughout this thesis when it is analytically sensible to do so, I do not differentiate between them categorically.

One category of sound that is nevertheless exceptional and deserves individual attention is the voice. As Chion points out, the voice usually receives relatively little attention in film (music) studies because it generally is confused with speech - with the semantic dimension of what it conveys (1999: 1) - as long as it isn't singing. As for the speaking voice, its materiality - its texture or timbre - is usually analytically neglected. As anthropological research of the past decades has shown, the voice is a complex field of culturally and historically contingent negotiations of identity and can be perceived as a "marker[...] of class, race, geographic origin" (Weidman 2014: 40). The specific material, embodied qualities of voices are always also connected to cultural, philosophical, political and ideological dynamics. As Eisenlohr (forthcoming: 17-21; 111-117) outlines, the voice is a potent nexus of embodied materiality, of performative potential that combines signifying complexity and somatic anchorage. Given its characteristic paradox of being embodied while at the same time detached from its source, the voice furthermore contains "features of an autonomous object" (ibid.: 113). Analyzing the sounds of voices in the serials - their pitch and timbre while speaking and singing, or whether they yell, whisper, or are allowed to speak at all - opens up another level of sound's meaningfulness and its atmospheric potential in narrative audiovisual media.

In the following analyses, I will focus on the aestheticized sounds of Ramayan and Mahabharat which prominently impact the sequences in question, thereby embracing the blurred boundaries between noises and musical passages. The verbal side of utterances will however not be element of the analyses, since that would go beyond the scope of this work. 


\section{Narrative Spaces, Narrative Levels and Musical Acts of Narration}

Music and sound effects are an essential part of the narrative spaces in which audiovisual narratives are created. I would like to return to the issue of narrative space specifically with regard to Mahabharat and Ramayan. Drawing on the serials' audiovisual texts, I will illustrate how music's relation to the other elements of narration is better conceptualized as occurring within the same space rather than on a different level.

As discussed above, in "The Non-Diegetic Fallacy”, Ben Winters rejects Claudia Gorbman's notion of nondiegetic music on the grounds that it "threatens to separate it from the space of the narrative, denying it an active role in shaping the discourse of onscreen events" (2010: 224). This assessment is based on Gorbman's oft quoted definition of the diegesis as "the narratively implied spatiotemporal world of the actions and characters" (1987: 21, original emphases), which limits diegetic music to "music that (apparently) issues from a source within the narrative" (ibid.: 22). Accordingly, other music that does not obviously issue from the diegesis would be defined as nondiegetic, and thus per definition as outside of this spatiotemporal world, operating on an alleged separate level of the narration. Winters opposes this separation of music from the filmic narrative on the grounds that it is based on a problematic transfer of literary notions of diegesis to the medium of film (2010: 225-228). As an alternative, he proposes conceiving of the filmic narrative as a narrative space in which music and sound effects can occur as part of the narrative and not as a separated elements alien to the realistic world of the diegesis.

I consider Winters' proposal to replace the notion of narrative levels with that of a potentially inherently unrealistic narrative space to be crucial for an inclusive analysis of audiovisual narratives. In particular, the songs of the serials indicate the limits of Gorbman's concept while simultaneously elucidating the usefulness of Winters' approach. That is, while clearly being parts of the plots, performed within the diegesis, songs do not apply to Gorbman's criteria for diegetic music. Through the use of obvious playback singing, or the voluminous aural textures of numerous virtuously played instruments that are clearly not issuing from a 'real' source on the screen, songs in the serials expose their "larger-than-life, showy, glittery, glamorous" (Morcom 2007: 85) filmi-aesthetic ${ }^{55}$ while at the same time being vital to the narrative. Using their atmospheric potential, the sounds emotionally and somatically engage the audience, making them empathize with the

\footnotetext{
55 This also applies to the instrumental sounds in the serials.
} 
current situations and emotional states of the characters. In this sense, the sounds are inherent parts of the diegesis and vital for understanding the course of the story.

Likewise, the background scoring - intradiegetic music in Winters' terms - is a mode of musical narration that shares the same narrative space as the diegesis. Take, for example, the passage associated with the character of Shakuni in Mahabharat. Starting with his introduction in episode 7 and ending with his death on the battlefield of Kurukshetra in episode 90, Shakuni, the scheming uncle of the Pandavas and Kauravas, is constantly linked to this specific passage ${ }^{56}$ (example 2.2). It is heard in most of the scenes in which he makes an appearance, thereby not only creating an immense recall value, but continuously accumulating associations along with the character's development, thus adding to his thoroughly negative image ${ }^{57}$. The potency of this pattern is especially striking in scenes in which he does not actively scheme and would appear harmless if not for the music. It is through the atmospheric effect of the music, the tension and suspense created by the sounds, that even unremarkable scenes are imbued with a sense of threat. When played in total, the passage lasts slightly over one minute and can be roughly divided into three parts, which stylistically bleed into each other but are sometimes also heard separately or in varying succession. The sequence is so particularly tied to the character of Shakuni that even when heard only in fragments, his malevolence is immediately present. The passage combines clashing textures of synthesizers, a lowpitched, oscillating string pattern, and sometimes Shakuni's smug voice. The tensions created by these textures play a large part in stirring sensations of unease brought about by the character's appearances ${ }^{58}$. The passage usually starts with a long-held synthesizertone in a mid-frequency range with a timbre resembling an electronic organ, which is combined with a rattling, wooden-sounding rapid and high-pitched ascending pattern (as if caused by a fast sweep over a xylophone) starting two octaves above the steady tone.

\footnotetext{
56 The strong connection of Shakuni's character to his own musical passage has been noticed by other authors as well, for instance Mitra (1993: 109).

57 To do justice to the complexity of the Mahabharata story, the character of Shakuni is constructed in a differentiated way and not as inherently evil in many renditions of the story.

58 Sound is not the only means through which Shakuni is constructed as villain. His invariably black clothing, or the ways in which actor Gufi Paintal creates Shakuni through facial expressions, posture and gestures such as the rubbing of the dice between his palms, suggest a certain reading of the character. Ultimately, the audience's previous knowledge of the character also influences the way he is perceived.
} 
After the sweep fades out, a creaking sound comes in together with another layer of synthesizer-sound that quickly moves up an octave in a swiveling motion, providing a distorted echo of the xylophone-sweep. This unmetered part of the passage is then complemented by a higher-pitched, amorphous hissing sound. After ten seconds, another layer of synthesized sound comes in with the timbre of the first steady tone, playing a slowly stretched out succession of four tones on pitches close to each other. This is followed by the threefold structure of a twice-repeated small pattern consisting of three whistling synthesizer-tones. An initial high-pitched tone is followed by a leap toward an even higher pitch and a very small step down from that second pitch. This is accompanied by chords or single tones (sometimes not clearly discernible) on the pitch of the tone initiating the pattern at a lower octave. This is repeated twice, with each repetition played at gradually lower pitches so that the whole threefold structure forms a chromatic downward movement. The entire section is then repeated by a set of string instruments at the same pitches an octave lower. The repetition of the downwards movement in interspersed with the hissing noises from the beginning and the xylophone-streak. The passage is closed by a string-pattern consisting of two pitches played alternatingly in short succession. In total, the passage is heavily shaped by the mixture of whistling and organ-like synthesizer-sounds, creaking, hissing noises, a scale that operates with alternations of big and very small intervals, and a lack of a consistent meter and distinctly rhythmic sounds. The otherworldliness of the timbres accounts for an overall sense of eeriness.

Despite this inclusive conception of sounds in the narrative space, in both serials there actually is more than one level of narration. In Mahabharat, a second, aurally marked level of narration frames every single episode: Samay, the disembodied voice of time, guides the audience through the narration. Samay's deep, male voice, heavily booming with reverberation and backed by singular staggered and high-pitched synthesizer tones, introduces every episode's setting and announces the main points of the plot (example 2.3). $\mathrm{He}^{59}$ guides the audience by explaining characters' backstories and by teleologically framing the events of episodes in light of the impending apocalyptic battle of Kurukshetra. Samay is aurally and visually separated from the settings of the episodes. His voice is

\footnotetext{
${ }^{59}$ While I am not aware that the concept of samay is commonly anthromorphized in mythology or ascribed a specific gender, for the sake of convenience, I will refer to Mahabharat's Samay with a male pronoun due to the qualities of Bhimani's voice whose stereotypically male features are most certainly not coincidental. 
almost always heard together with computer generated images of a deep blue starstudded space-panorama through which occasionally the Earth can be seen to float by. Usually the space-panorama is complemented by the image of a slowly turning chakra positioned mid-screen, white outlines of the silhouette of a sage and wads of smoke. Even though the silhouette is a type of visualization of this narrator, it remains faceless and vague throughout the serial. With his invisibility, Samay is an illustrative example of what Chion (1999) calls the acousmêtre: a recurring, disembodied and therefore mysterious voice in an audiovisual narrative.

Samay often explicitly verbalizes his distance from the events he narrates by mobilizing his own infinity in contrast to the story's fixed location in time. This complete detachment from the narrative space of the plot reinforces the idea that Samay is narrating from a distinct level60. The notion of level is more apt here than that of space, because even though Samay is clearly detached from the diegesis of Mahabharat, treating him as situated in a distinct narrative space would imply a certain self-containment, or an autonomy of this space. However, Samay does not have a separate story on his own but refers to the diegesis and plots of Mahabharat in every utterance. Samay is thus detached from the narrative space of the plot(s) and at the same time inherently linked to it. Besides, the hierarchization implied in the notion of level better describes the relation of Mahabharat's diegesis and this narrating agent: the omniscient Samay is in a superior position in relation to the diegesis, the plot and the characters.

In contrast to Samay's introductory sequences, the sections that close the episodes of Mahabharat do not feature an elaborate anthropomorphized narrator. Instead, in brief sung sections, the lesson that is supposed to be drawn from the respective episode is summarized by the disembodied singing voice of playback singer Mahendra Kapoor, who also sings Mahabharat's title and credit sequences (example 2.4). These summarizing lines are invariably sung to the same melody, although the lyrics differ from episode to episode, and are always combined with a tableau-like freeze-frame of a key scene from the given episode. The melody of these segments is closely aligned with the music of the

\footnotetext{
60 See Sarah Kozloff's Invisible Storytellers: Voice-Over Narration in American Fiction Film for a detailed study of voice-over narrators (1988: 45; 74).
} 
credit and title sequences of the show, featuring the same scale and the familiar voice of Kapoor. The heavily synthetic timbre, however, differs from the credit and title sequences, which establish a distance to the narrative by authoritatively summarizing the events. Furthermore, the combination of music and the freeze-frame disrupts the fictional world of the episodes, contributing to the distanced position ${ }^{61}$ of these segments.

Similar but distinctive, a separate narrative musical level shapes the episodes of Ramayan. While in contrast to Mahabharat there is no Samay-like narrating figure or concept in Ramayan, the narrating - singing - voice of the show's music director Ravindra Jain accompanies the individual episodes. Jain's voice is often only accompanied by a vibraphone or a harmonium, and usually dwells on the details of the characters' actions or feelings, sometimes paraphrasing what they would be saying if the situation was conveyed through dialogue. For instance, in episode 45, Hanuman flies over the sea to Lanka and explores the city and its inhabitants at night. In a long sequence, interrupted by a few scenes with dialogue and without music, Jain's singing voice, combined with various instrumentation and melodic setups, describes Hanuman's quest. When Hanuman flies through Lanka, he peaks into the chamber of Ravan. Here, the singing narrator's focalization shifts perspectives from outside to inside, moving from describing Hanuman's actions to paraphrasing his thoughts upon seeing Ravan asleep (example 2.5).

Often, these narrating sequences are followed by a song sequence with a distinct song structure (more on that below), a greater set of instrumentation, and additional or entirely different singers. Especially in conjunction with song sequences, the narrative status of these sequences is ambiguous, since the songs are mostly intradiegetic, within the same narrative space as the other elements of the diegesis. The narrating sequences, in contrast, are mostly outside of this space, describing events from an omniscient, superimposed perspective. The resulting momentum of oscillation between narrative levels permeates the serial.

Even if sound depends on the interaction with images and language in these instances of musical narration, it is not just a supplement. On the contrary, the material qualities of

\footnotetext{
61 There is, however, an ambiguity about how these sequences relate to the show's narrative levels. On the one hand, they are clearly detached from the narrative space of the story, separated by the frozen image and the distanced perspective adopted and conveyed by the singer. Furthermore, the sequences build an aural bridge to the credit-sequences through their stylistic proximity to them. On the other hand, they still are linked to the diegesis by explicitly referring to the events of the plot, just as the visuals of the freezeframe are directly drawn from the diegesis.
} 
sound are the essence of these modes of narration in the serials, determining not only their structural composition and relation to the overall narrative, but also providing a frame for them - a material backdrop that subtly draws on our cultural knowledge of these sounds. Sound, here, does something that images and language cannot, proving once more that it, to quote Eisenlohr, "is a separate modality of creating meaning and knowledge" (forthcoming: 9).

\section{$\underline{\text { Instrumental Music, Gods, Space and Time }}$}

Sound's ability to create atmospheres that captivate the audience, evoke visceral responses, and afford empathy with the characters, is a vital part of the narrative setup of Ramayan and Mahabharat. As already mentioned, the narrating qualities of sound in North Atlantic audiovisual narratives have mainly been described in terms of orientation or comment. To briefly recap, Robynn Stilwell emphasizes music's ability to characterize setting and space of the plot (2003b: 63), its commentary function (ibid.: 67), and its function as "mediator of the visual experience" (ibid.: 79) in The X-Files. Gorbman, apart from highlighting music's importance as bonding agent between audience and film ${ }^{62}$, emphasizes its function of providing clues for the interpretation of scenes (1987:55). In existing research, these orienting functions are usually conceptualized separately from sound's immersive powers and its ability to create moods. While providing orientation through referencing is a vital element of music in Ramayan and Mahabharat, I would argue that a separation of sound's immersive/atmospheric capacities from its orienting functions is not helpful since these capacities don not contradict each other. To the contrary, I contend that they are inherently intertwined: the atmospheric impact of sound directly results from its materiality, as do its commentary functions. Therefore, when music or sounds comment on, say, a character, they do so as atmospheres, or through the same dynamics by which they create atmospheres.

\footnotetext{
${ }^{62}$ Ranade actually argues the opposite with regard to instrumental background music, claiming that it is "distracting and distancing the spectator from the visual narrative" (2006: 430). He does not, however, elaborate on this thought at all, which makes it less persuasive.
} 
In Ramayan, these material-narrative capacities of music are strictly connected to the situations narrated, while in Mahabharat they are also linked to individual characters (most notably to Shakuni and Ganga). In both serials, the sounds co-construct settings and occasions, for instance through ritual sounds or festive music. Music and sound create the sensation of a scene's gravity, of shock, terror, sadness or relief through conventional aural structures such as stingers or the use of scales or instruments charged with associations, thereby using its materiality to draw on the audience's sono-cultural knowledge. This is especially illustrative with regard to three aspects: space/setting, time and divinity/miracles.

Music is vital for establishing the space and situational context of narratives and single scenes. Filtered by cinematic convention, sounds draw connections to the audience's reallife experiences - the ringing of a temple bell will immediately position a scene in a Hindu religious context - and to their imaginations of places and eras. The serials are located in northern India through the actual geographical location of the stories, but also through language, props, rituals, and, of course, sounds and music. The formats of devotional songs and musical aspects such as instrumentation or the intonation of the singers' voices differ from southern Indian formats ${ }^{63}$ (see Mitra 1993: 108-112). Likewise, the repertoire of pre-existing songs employed (without exception Hindu devotional) are suggestive of the North of India. Likewise, sound design and music are vital factors for constructing spatial settings, be it through reverberations that create a sense of wide but enclosed spaces such as big halls, through the wash of ambient noises evoking the chaos of a battlefield, or through sounds that are indexically tied to religious or festive settings.

Beyond this, sounds are also vital for creating the imagined historical settings of the narrations. The ancient settings of the stories are complexly intertwined with claims to authority made on their behalf, with their credibility, and with their religious gravitas. Connected to this, and more important for their re-creation in the televisual context, is the question of the stories' actual historical location. This, in turn, is tied to what might be conceived as the tension between the historicity and fictionality of the events narrated. As it would go too far to further delve into this issue, it suffices to state that irrespective of (alleged) historical realities, the periods in which Ramayan and Mahabharat are located, and which are re-created in their televisual renditions, are imagined mythological

${ }^{63}$ Interview with DV, 8 Apr 2015. 
pasts in which miracles are an everyday-experience and gods and demons populate the earth. Creating this imagined, mythological time meets the same challenges as the genre of science-fiction, which, in the words of Guido Heldt, is required to create "a time that is not (yet), with a music that is not yet either" (2013: 87). Likewise, the music employed in the serials faces the challenge of creating the impression of an ancient setting while at the same time being compatible with a modern audience. That way, the historicity of the music, too, is an imagination. In our interviews, both composers of Ramayan and Mahabharat who I met during my first stay in India emphasized their aim of creating an aural world for their respective serial that would credibly construct the ancient setting. Therefore, they consciously chose to employ instruments which have long traditions in classical or folk genres ${ }^{64}$. The sounds of sitar, bansuri and tabla, of manjira, veena, conch, ravanhatta and the like are thus endowed with the authority of age and have the power to create ancient settings, even though their modern versions are heard in the serials. However, the modern musical structures played by these instruments and generously blended with an array of synthesizer sounds and orchestral filmi music, are still able to evoke the stories' indeterminate ancient setting due to the associations of age with which the instruments' timbral qualities are charged.

Intradiegetic sounds are not only essential for aurally crafting the stories' (imagined) historical settings. They are equally important for creating the impression of the passing of time within the narrative space of the narration. As Chion (1994) elaborates, audiovisual narration is dependent on sound for fundamental dynamics such as causality, temporalization, or the creation of (diegetic) space. Chion especially highlights sound's temporalizing capabilities: Since on the visual track "shots do not always indicate temporal succession" (1994: 13), this dimension is complemented by sound due to its inherent temporal qualities. Sound, for its emergence as well as perception, is dependent on the passage of time. This, in turn, has a linearizing, or vectorizing (ibid.: 17-20) effect on moving images, especially with continuous sounds such as conversations, lasting (background) noises, sound effects and music. Chion emphasizes how sound enables orientation for viewers in passages of quick successive images, such as fight scenes, by

\footnotetext{
${ }^{64}$ Interviews with Surya Raj Kamal, 17 Jun 2015, and with Ravindra Jain, 27 May 2015.
} 
"spotting" them with "rapid auditory punctuation, in the form of [...] bangs" (ibid.: 11) that highlight, and at the same time aestheticize, the significant moments of a given sequence. Noises, musical passages and voices thus produce not only the spatiotemporal settings of an audiovisual narrative, but also determine the pace of the narration. On the one hand, intradiegetic music may accelerate the story time or conceal leaps in time, for instance in montage sequences. On the other hand, sounds are also able to slow down a scene or force a realistic speed on images by virtue of their vectorizing quality - for instance sounds with an intrinsic speed or rhythm such as speaking voices, heartbeats, ticking clocks and the like. The narrated pace of a scene is therefore inherently tied to the temporal fabric imposed by the sounds. Sound's linearity, imposes itself on the scenes it pervades, does however not force a linear sense of narration onto the stories. Instead, I argue that the recall value of sound effects and musical passages equally matches linear as well as the discontinuous, episodic narrative structures as found in Hindi cinema. In the rather linear narrative structures of the Ramayan and Mahabharat serials, recurring passages can either point back to past events within the stories or smooth over temporal leaps in the narration.

In the construction of a mythological world located in a magical yet timeless past, the creation of the divine is an important function of the sounds of Mahabharat and Ramayan. Likewise, the sounds need to make the audience accept that these otherworldly phenomena are familiar to and taken for granted by the serials' characters. While for the most part the divine protagonists Ram and Krishna, as well as Ram's demonic antagonist Ravan, are aurally constructed just like the human characters, other divine and demonic apparitions are usually go along with thick layers of synthesizer sound or prolonged swarmandal-sweeps. This latter type of sound is characteristic for blissful, auspicious moments and divine apparitions in Ramayan: staggered sweeps across the chords of a swarmandal covering its entire ambitus are looped, reverbed and repeated, thereby producing a wash of high-pitched, unmetered sound with delicate and airy timbre - like a warm pleasant aural shiver (example 2.6). Divine or supernatural actions performed by rishis, sadhus or demons in both serials are ensounded by synthesizer-sounds. Details of these sounds vary from instance to instance, but they are structurally and stylistically similar. Unmetered and without a distinguishable rhythm, the passages are usually comprised of several layers of synthesized sounds with muzzy timbres - the result of broad overtone spectrums with portions of noise that sometimes prevent the distinction 
of specific pitches. These sounds often seem to morph or pulsate through timbral shifts, whose occasional irregularities create the sense that they are organic (example 2.7). Many of these passages do not sound pleasant, not even if the ensounded phenomena are clearly benevolent. Especially in Mahabharat, the sounds of divine phenomena are often almost machinic - hissing, swirling and rumbling with only occasional melodic parts. It is these material features of the synthesizer sounds that are vital for creating the magical element of these phenomena since they build a stark contrast to the sounds of the acoustic instruments and to the way mechanically produced sound behaves. These 'unnatural', otherworldly sounds are therefore ideal vehicles for evoking a sense of the supernatural.

The Abundant Soundscape of the Mythical World: Stock music, "Indian" Sounds and the Synthesizer

Against this backdrop of structural qualities and functions of sound and music in Ramayan and Mahabharat, I will now go into the ways in which instrumental music and sound effects are woven into the serial narratives. As already described, Ramayan and Mahabharat each integrate a range of musical styles. Given the high number of episodes and the long timespan of their runs, both serials accumulate a large and diverse amount of music. However, despite this broad range of sounds, music is also an important means of providing stability and coherence to the audience. Over the course of their respective broadcasts, both Ramayan and Mahabharat have relied on a stable set of musical styles, down to specific passages that remain consistent over the course of their entire runs.

Within the aural eclecticism of the serials, their instrumental intradiegetic music can be divided into three broad types. In the first type, a melody is played by a single instrument at a time - usually either santur, sitar, bansuri or shenai - accompanied by vibraphone or a drone. (example 2.8) Like other instrumental intradiegetic music, passages of this first type are constructed modularly from several alternating elements. One element of alternation is the irregular change of the instrument playing the melody. In longer passages, the instruments alternate in varying successions, but still jointly construct one coherent melody through the use of the same scale, tempo, and similar melodic patterns that are repeated in numerous variations. Coherence may also be achieved through the 
use of continuous percussive layers. Curiously, this structure also creates an impression of variety, which results from the modular, sometimes seemingly random, constitution of these passages. The modular structure allows for re-employing a fixed set of musical segments in a wide range of combinations, thereby creating familiarity and recall-value while at the same time presenting the audience with a certain amount of variation. Due to this technique of assemblage - and to the way they are positioned in the serial narrative - these passages vary greatly in length, from just a few seconds to several minutes at a stretch. This in turn entails that it is not possible to determine a 'definite' or default length or form of these passages.

The aesthetic of this type of intradiegetic music is targeted at creating a specific historical 'Indian' sound 65 matching and shaping the stories' mythological settings. The fact that a limited number of musical parameters is sufficient for evoking a sense of ancient 'Indianness' points to the efficiency of aesthetic conventions in audiovisual media. The parameters through which this sense of Indianness is created in Mahabharat and Ramayan can be broken down to the use of a specific range of instruments (most prominently sitar, sarod, shenai, bansuri, santur, veena, ektara, ravanhatta, pakhawaj, tabla, chenda, duff, and manjira); rags and their particular associated melodic structures; characteristic rhythmic and metric structures, such as the often frequented bhajani theka; and the melodies of devotional songs and other widely shared repertoires.

In both serials, the melodic layer of this first type of instrumental intradiegetic music is frequently backed by harmonies played by a vibraphone, or by the drone of a tanpura. Percussion instruments are not employed in this style of music. The passages invariably have a mellow sound caused by the combination of instrumentation, pace, scales employed, and the style of playing: there are no harsh breaks or strokes or attacks, no great leaps of interval or abrupt movements, the music just ripples smoothly, revolving around the melodies. The passages, either backing up dialogue or standing on their own, create clouds of sound that are immersive through their regularity. Their aural movements mostly spring from the revolving melodies and the alternation of instruments. The melodies, based on pentatonic, hexatonic or heptatonic scales, usually progress according to the principles of Hindustani classical music, systematically proceeding from pitch to pitch of the respective scale. While there are occasional brief,

65 Interview with Ravindra Jain, 27 May 2015, and with Surya Raj Kamal, 17 Jun 2015. 
rapidly ascending or descending melodic fragments, overall the passages are not agitated. The lack of percussion instruments and sudden, eruptive aural impulses, the solid consistency of the rich texture of the tanpura, and the slow, ascending chords of the synthesizer with its fuzzy timbre combine to produce a smooth envelope of sound. The lack of low pitches, the soft volume and the instrumental timbres make the passages sound light and airy. Corresponding to these smooth musical structures, these passages are never heard in scenes of agitation. The sensations of serenity, sublimity or deep tragedy the passages create are equally heard in scenes in which the characters are either blissful or sad - provided they are not agitated. Overall, the scenes in which this music is heard have a relatively slower narrative pace. The music provides the medium for the audience to immerse themselves in the emotional situation of that scene. The combination of long dialogues, extended reverse-shots of faces and reactions with extended musical passages enable the audience to properly empathize with the characters, to thoroughly 'marinate', as Birgit Abels jokingly puts it (2015: 61) in a given situation. The atmospheric presence of the music alone reveals the full (emotional) intensity of a character's situation.

The second main type of instrumental intradiegetic music is played by a full orchestra and heavily contrasts with the first type (example 2.9). This type always has a voluminous, monolithic sound. Even if specific groups of instruments are singled out, the sound does not become more delicate but only changes timbre. Apart from the orchestration, the thickness of the sound is strongly related to the quality and specific (technical) aesthetics of the recording. The orchestral sequences of music were in part recorded for the serials, and in part drawn from tune banks. As is the case with the first type of intradiegetic music, the segments of orchestral sound in both serials are combined in a modular way, played in fragments, and merged alternatingly.

Also like the first type of music, yet aesthetically distinct, the second type of music is structurally focused on melodies. Without exception, the passages are built around singular melodic lines played in unison by several instruments, accompanied by harmonies played by the rest of the orchestra. This accompaniment in turn is closely 
adapted to the course of the melody ${ }^{66}$, thereby clearly positioning the music within the musical conventions of Hindi film ${ }^{67}$. Structurally, the harmonies serve as a textural filler for the melodies. In this context, despite the superficial aesthetic similarities with North Atlantic romantic orchestral (film) music, the structural functions of harmonies diverge greatly. The passages build a stark stylistic contrast to the first type of music. They are not only played by entirely different instruments, creating dense textures of sound, they are also often rapidly paced, featuring different melodic structures with "heavy chromaticism, diminished sevenths, augmented scales, tritones, unmelodic lines with large, awkward leaps, tremolo strings and loud, accented playing in brass" (Morcom 2007: 144) as well as "sudden, loud, accented chords" (ibid.).

This second type of intradiegetic music, too, is an (atmospheric) instrument of immersion that keeps the audience engaged in the scene. With its eruptive, erratic and dense aesthetics that incessantly give intense sonic impulses (stingers, leaps, rapid passages), agitation is deeply engrained in its constantly moving structures. Through their heavy use of this musical style, the serials unambiguously position themselves within a cinematic framework of meaning making, mobilizing the audience's learned embodied reactions to these highly conventionalized sounds. As in Hindi film, music of this type generally has negative connotations and is employed in scenes of shock, violence, or disturbance. As Morcom points out, these segments usually "express sudden shock, such as when a character hears some appalling news" (2007: 144). Given the dramatic nature of both stories, it makes sense that they are pervaded by this style of music.

The third type of instrumental intradiegetic music revolves around the numerous timbres and textures produced by synthesizers. Overall, these sounds are much more present in Mahabharat than in Ramayan. In Ramayan, blends of synthesizer sounds are sometimes combined with a vibraphone or instruments like the santur. Sometimes, these blends create short melodic patterns, while sometimes they are blaring, pulsating noisy tones (example 2.10). While these passages are not as intense as the music of the second type in terms of the erratic aural impulses and rapidity, they frequently create aural tension through unmetered, long-held clashing tones and the morphing, extremely artificial sonic

\footnotetext{
66 Beaster-Jones describes the harmonies in Hindi film music as typically "laminated" onto the melody (2015: 18).

${ }^{67}$ As mentioned before, Hindi film music served not only as a stylistic template for these passages, but, since much of the intradiegetic music of the serials is drawn from tune banks, also quite literally as a source. 
textures of the synthesizer. In Mahabharat, this element of tension is much more present: the synthesizers' dense, noisy layers of sound create blurry sonic textures that are often also harsh, grating and machinic. They fabricate atmospheres of looming threat over the course of the show. The aesthetic contrast to Ramayan is especially evident in how (most) outstanding encounters with divine characters are created aurally: the pleasant and sugary shivers of the swarmandal heard in Ramayan take the shape of rattling, metallic, cacophonously pulsing soundwalls in Mahabharat (example 2.11) In Ramayan, the countless self-sacrifices of the characters are valorized through mellow sounds. In Mahabharat, by contrast, the agony of the characters' countless dilemmas, and the aggression, envy and hatred that motivate the plot so centrally, are co-created and intensified by the harsh sounds of its music. Of course, there is soft, mellow music in Mahabharat as well, just as there are moments and sounds of despair, violence and battle in Ramayan. However, between the two shows, Mahabharat focuses more on evoking the negativity of the story by means of the visceral, bodily impact of sound.

Most often, the types of music are heard separately from one another, creating distinct moods for distinct situations in the narratives. Nevertheless, in both serials, they are also sometimes combined, in Mahabharat more than in Ramayan. In Ramayan, this usually happens by interlocking segments of the first type of music with segments played by the orchestra, smoothly transitioning through a similar pace, use of scale, and melodic movements. In these cases, the orchestral segments are not as loud and explosive as they usually are, but still contrast significantly with the music of the first type. In Mahabharat, the mixing of musical types is usually more of a thorough fusing. For example, in episode 3, the intradiegetic music heard during King Shantanu's and Satyavati's first encounter structurally corresponds to the first type of music (a high-pitched characteristically meandering melody played by a single instrument) but is played by a synthesizer with corresponding distinct timbre and texture (example 2.12). Shakuni's passage (example 2.2) is another illustrative example which fuses fragments of different types of music and different aesthetics into a nexus of aural tension.

The sounds of both shows demonstrate how the line between intradiegetic and diegetic sound is fragile since all the sounds are so thoroughly aestheticized. Some dramaturgically relevant sounds which are positioned in the diegesis differently than intradiegetic sounds 
blur the line between these two aural modes through their stylization. An example is the sounds of the conch and the tutari, which are blown in the context of important announcements and especially before battle (examples 2.13,2.14). The conch is always heard as a loud, long held single airy, yet densely textured tone that varies in intensity. The tutari is heard as one or two instruments playing a single tone at the same high pitch with a piercing timbre at a rapid pace, varying the length of the single tones' duration. These sounds are unambiguously diegetic. Yet their actual sounds are so polished, with such a larger-than-life aesthetic that they could pass as intradiegetic. This, in turn, affects the ways in which intradiegetic sounds are perceived. The stylized use of diegetic sounds in a sense naturalizes this aesthetic, thus embedding the larger-than-life intradiegetic sounds more thoroughly into the fictional space.

Diegetic music in Mahabharat and Ramayan is heard most frequently in the context of dancing. With the exception of Arjun, who learns to dance during his time at Indralok, the dancers are always female and serve the stories' kings, princes and gods with their dancing. Sometimes, these dances turn into extended song-and-dance sequences, while sometimes the music remains instrumental (example 2.15). The diegetic (dance) music, also heard as the backdrop for festive occasions, is played by acoustic instruments such as sitar, bansuri, and percussion instruments. Like the other types of music, it is constructed around the melody - often played by several instruments at once - and is stylistically clearly located within the 'Indian' aesthetic targeted by the composers.

The intradiegetic music of the serials is modular. Passages are heard in fragments and cut, pasted and combined in a multiplicity of ways. Given that a significant portion of the serials' intradiegetic instrumental music is drawn from tune banks, not all segments that are combined over the course of the serials really 'match' in the sense of being adapted to each other in their employment of scales, melodic structures or other structural features. When such 'mismatching' passages are combined, the effects are aesthetically disruptive because they crack the coherence of the fictional space created by images and sounds. Likewise, the intradiegetic musical backdrop is sometimes abruptly stopped at points in the music where a sudden silence cannot be anticipated structurally and therefore somehow sounds 'off', is followed by intradiegetic silence, or by a cut into another scene. Occasionally, there are technical glitches that cause the intradiegetic music to slur, slipping down a few pitches only to drift back up to its original pitch shortly afterwards. These glitches are clearly unintentional, likely resulting from errors during post90 
production. However, all of these irregularities create fissures in the narrative façade, disturbing the aesthetic coherence of the very world constructed by images and sounds. In this, they briefly make the audience aware of the fragility of the immersive envelope. While on the one hand these glitches expose the artificiality of the fictional setting, on the other hand they may be paradoxically understood as contributing to the immersion. Disruptions of an immersive envelope expose the artificiality of the atmosphere and make us tilt between awareness of the illusion and consciously giving into it. The moments of awareness allow us to fully acknowledge the material constitution of the immersive frame and to decide whether to be moved by the sounds or to perceive them with a more distanced perspective (see Abels 2013: 226; Bieger 2011).

\section{Ramchandra, Baby Krishna, and Emotional Rollercoasters: Songs and Singing in \\ Mahabharat and Ramayan.}

The range of forms and styles of instrumental music in Ramayan and Mahabharat constitutes only one of two major modes of musical narration in the two serials. Sung passages and song sequences are equally vital elements of the shows. Narrating the stories through song and singing appears to be almost a formal necessity for several reasons: numerous formats of narrating the stories incorporate or are based on song and singing, the serials were based on the mythological film format, and Chopra and Sagar both had previous careers in Hindi cinema. In both serials, the forms of singing go far beyond the typical song-structure prevalent in Hindi cinema. The term 'song' is therefore unsuitable as an umbrella term for all the musical passages that involve singing. Overall, songs and sung passages are more prevalent in Ramayan than in Mahabharat and are more fluid in their structures.

In Mahabharat, there are just above 30 songs in the serial's 94 episodes. The songs are distributed irregularly over the overall narrative. For instance, the six-episode stretch between episodes 12 and 17, which are about the birth, childhood and youth of Krishna, contain a total of 10 songs. This contrasts with the 22 episodes from 72 to 93 dealing with the Bhagavad Gita, the epic battle and its aftermath, which contain not a single song. Within the episodes, the placement of songs is highly variable as well, ranging from songs 
opening the episodes (of course only after Samay's introduction) to songs closing episodes. In the episodes containing two songs, their placement is not as highly varied. In these cases, the first song usually starts within the first ten minutes of the episode and the second one is placed in the second half. Even though integrating either one or two songs in an episode does shape its narrative pace, the placing of songs generally does not appear to be strategically coordinated. The songs are rarely obviously aimed at enhancing narrative climaxes, moments of suspense, or pacing the episode's narrative, but are instead positioned at points of the narrative in which the emotional state of the characters lends itself to be explored through singing.

Structurally, most of the songs roughly correspond to what Morcom (2007: 62) and Beaster-Jones (2015) describe as the predominant form of Hindi film songs. Following the terminology used by music directors, which is in turn rooted in Hindustani classical music, Beaster-Jones refers to this song-structure as "the mukhrā-antarā form" (2015: 33). This term points to two of the three structural parts of the songs, the third being instrumental interludes. Beaster-Jones describes the typical progression of a song as follows:

"Most film songs begin with some sort of non-lyrical musical introduction [...]. The instrumental melody of this introduction is [...] recognizable [...] and is [...] frequently the music used to end a song. [...] The mukhrāa (literally "face") begins the sung portion of most film songs. It is a long refrain that contains the memorable melodic information that is repeated throughout the song in whole or in part [...]. Most film songs follow the first instance of a mukhrā with an instrumental interlude [...]. This interlude is followed by a structure that begins with an antarā, which is a section containing lyrics with a melody that is distinct from the mukhrā. [...] The melody at the end of the antarā contains material found in some part of the mukhrāa. Most songs have two or three [antaras] and vary in length from three to six minutes, depending upon the length of the interludes" (2015: 33-34).

The alternating succession of mukhra, antara and interludes is the structural frame of most of the songs in Mahabharat and often reaches a duration of roughly five minutes. One example is the song Draupadi sings to lure Keechak into the trap she set up with Bhim and Arjun in episode 58 (see example 2.1). It does not contain any antaras but has the aesthetics and structural function (within the episode) of a song. Most of the songs are stylistically coherent and are composed of a balanced blend of the characteristically fuzzy synthesizer and vibraphone timbres, percussion instruments such as tabla, pakhawaj, dholak or manjiras (the latter found in devotional songs), and melody instruments like 
sitar, bansuri, santur or sarod. The melodic structures and the ornamental - in the case of female voices, characteristically high-pitched - style of singing, contribute to the decidedly "Indian" sound of the songs, which is supported by the timbres and textures of the melody instruments and percussion. Regarding their (lyrical) contents and dramaturgical contexts, the songs all move within the range of topics that Morcom, Beaster-Jones and Booth describe. Many of them address aspects of romantic relationships, most often from a female perspective. The mainly positive frame of reference for the songs (with some exceptions) results from the interplay of structural and aesthetic factors. The specific qualities of the instruments employed give the songs a coherent aesthetic; they often have dense rhythmic frames, their melodies - alternatingly played by instruments and sung - have animate melodic structures and a vivid pace. As Beaster-Jones points out, and as briefly mentioned earlier, songs usually focus on crucial narrative junctures that are related to the emotional state of characters. They narrate, for instance, "the development or reinforcement of social bonds and the act of falling in love" or "the transition of the hero from childhood to adulthood" (2015: 5-6). Furthermore, in Ramayan and Mahabharat, popular periods of the protagonists' lives get extra narrative attention through songs. In both serials, the childhoods of Ram and Krishna are extensively narrated through songs and even feature well-known devotional repertoires. By addressing such junctures of emotional and religious significance through a musical mode of expression, the songs allow the audience to thoroughly empathize with the characters and emotionally explore the sensations involved in these situations. Here the notion of music as atmosphere is again helpful: songs, as a mode of narration focused on feelings, create an immersive cloud that fills the space of hearing with aural structures that trigger specific culturally learned responses. The audience has the chance to dwell in these atmospheres and, linked to their location in the narrative, comprehend them on a deep emotional level.

Beyond the songs, two passages of sung music (apart from the title and credit sequences) in Mahabharat occur more or less regularly throughout the show, thereby providing continuity and creating seriality. The first, as already mentioned, is the section at the end of each episode that summarizes its events and thereby acts as a musical bridge into the credit sequence. The other is a less regular rendition of the well-known arti 'Om Jai 
Jagdish Hare', a devotional song frequently sung in North Indian Hindu rituals of worship ${ }^{68}$. In the context of Mahabharat, the arti is always rendered with lyrics adapted to the respective context, which comment on the meaning of the preceding scene (similar to the concluding sequences) (example 2.16). The placement of the 'Om Jai Jagdish Hare' sections throughout the serials does not follow a pattern. The sequences are always sung by Mahendra Kapoor, are always accompanied by vibraphone, synthetic glockenspiel and manjiras at the same pace, and are always on the same pitch, varying in length only insofar as there are sometimes two repetitions of the melody. The sequences therefore establish familiarity through the invariability of their sound as well as through the audience's acquaintance with the arti itself 69 . As the sung closing sections, these renditions of ' $O m$ Jai Jagdish Hare' are structurally different from the songs and can therefore be understood as a further mode of sung narration. As previously mentioned, they are explicitly detached from the diegesis. In describing, recapitulating and evaluating actions and plot developments, these sections open up a meta-perspective that differs from the narrative mode of the songs' lyrics, which usually represent the perspective of a character. More salient, however, is the cultural baggage of 'Om Jai Jagdish Hare': the arti is a sounding evocation of Hindu ritual, unambiguously positioning the respective sequences within Hindu moral frameworks. Its structural composition - the melody, the instrumentation, the sound of Kapoor's voice - powerfully positions such sequences in a quasi-religious setting, atmospherically penetrating the space shared by the audience and the narrative.

As in Mahabharat, the narrative instance in the countless passages of sung music in Ramayan is enigmatic and acousmetric. Without ever being introduced, as Samay is in Mahabharat, singing voices, most notably that of the show's music director Ravindra Jain, lead the audience through Ramayan's 78 episodes, thereby providing an aural continuity that contrasts with the structural fluidity of the passages. Overall, sung music is much more ubiquitous than in Mahabharat, but it is distributed just as irregularly, both over the course of the serial and within the micro-structures of single episodes. The sung passages only partially correspond to the structure of film songs, with most deviating from this structure to varying degrees: some are shortened to only one antara, others repeat brief melodic sequences with different constellations of singers (for example Jain would sing a

\footnotetext{
${ }^{68}$ Arti can be either a ritual in itself or the concluding part of a larger worship ceremony such as puja (Manuel 1993: 108).

${ }^{69}$ I will go into the implications of the Hindu religious context on this passage (and others) in chapter 4. 94
} 
few lines and a group of male voices would repeat these exact lines), or similar. The sequences in which Ravindra Jain's voice - accompanied by a vibraphone or a harmonium - describes the situation on screen at lengths varying from a few seconds to several minutes are another structural model of sung narration. Given the high degree of formal variation and the fact that these structures often bleed into or succeed each other, it would be pointless to fix them in structural categories. It makes more sense to conceive of the song and singing formats in Ramayan as a spectrum ranging from the grid of the filmi git structure to the brief sequences of sung commentary.

The sung musical passages are often clustered in individual episodes of Ramayan, combined into long musical passages evidently consisting of disparate elements. This practice of combining several sung sequences contributes to the irregularity of their distribution over the serial narrative. Some episodes are entirely without singing while others contain stretches of ten to fifteen minutes of song and singing in different formats. In these longer stretches of music, clearly audible ruptures indicate that they are composed of several smaller pieces instead of one extensive monolithic musical block, thereby endowing these sequences with a wide expressive array. Ramayan's episode 10, for instance, narrates Ram's and Sita's wedding and surrounding events through an almost uninterrupted stretch of songs and sung passages over the course of almost 25 minutes (example 2.17). The musical passages change with significant shifts of rhythm, melody, instrumentation and scale (even though there are melodic segments that return throughout the episode). First, a group of high pitched female singing voices is accompanied by flute, manjira, sitar, santur and shenai. This is superseded by a fast-paced passage sung by female voices in a call-and-response-pattern, accompanied by vibraphone, sitar and a swift percussive pattern. Next, after a slow-paced, unmetered instrumental sitar-passage, another passage of singing ensues, sung first by female voices, later also by a male voice. Accompanied by a sedate percussive layer, flute, santur and vibraphone, this passage is itself interrupted by a segment of a ritual, backed by chanting in Sanskrit and so on. If songs are considered atmospheric manifestations of a specific range of emotions and interpersonal dynamics, these combined sequences can be understood as the extended exploration of the range of feelings accompanying a given situation. Each of the segments delves into a specific nuance of the rush of emotions, 
constituting a mosaic of feelings created by the changing blocks of musical structure and their individual dynamics. This extensive acknowledgment of the nuances of a given situation slows down the story time, allows the audience to thoroughly bathe in the cloud of the music and be moved by the shifting musical atmospheres. Despite some differences between individual segments, the overall style of the sung sections and songs in Ramayan is consistent. They feature instruments like sitar, bansuri, santur, manjiras and tabla as well as vibraphone and synthesizer, and combine stylistic idioms from film songs, Hindustani classical music, and devotional and folk musics. Many of the songs draw on classical structural principles such as rag and tal, or on the melodies of famous devotional songs and synthesizer-harmonies, thus assembling an altogether eclectic idiom.

Like the songs in Mahabharat and the long sequences comprising shorter sung segments, the songs of Ramayan usually focus on moments - on short timespans and the feelings connected to them. These detailed explorations create a dimension of depth in the development of the character who is singing, or in the feelings elaborated by the song. As such, the songs rarely propel the action forward but rather slow it down without entirely bringing it to a halt. This is often different in the narrating sung passages of Ramayan, when the singer explains the visual action (or vice versa, when the visuals mirror the lyrics of the sung passage) and replaces the dialogue by paraphrasing the characters' words (example 2.18). In these episodes, sung commentary and dialogue complement each other. Here, the sung sections just as often deal with mundane events as with moments of outstanding emotion, and massively emphasize both, the mundane and the emotional, through the atmospheric layers of sound that grab the audience's attention.

In both Mahabharat and Ramayan, songs and sung passages are vital elements of the serial narration. Formally, they reflect the influence of Hindi cinema by partially corresponding to the song structures prevalent in that medium. At the same time, they assert their medial distinctiveness through a range of highly variable formats that idiosyncratically lead the way through the long and winding televisual narratives. The lyrical formats and the versatile expressive potential of the music makes songs and sung passages an indispensable part of narrating the epic stories, especially the emotional extremity and moral cornerstones of Mahabharat and Ramayan. 


\subsection{Concluding Thoughts}

In this chapter, I have explored the notion of sound's and music's narrativity in audiovisual media, with a focus on Ramayan and Mahabharat. Adopting the multimedial concepts of narrative as a cognitive scheme constructed by Wolf and Ryan, I have argued that music and sound possess narrativity. They are able to evoke a narrative script within the wider narrative but cannot be self-contained narratives in their own right. A narrative, according to Ryan, must fulfill certain conditions, such as the creation of a (fictional) world and characters populating this world, which clearly cannot be achieved by sounds and (instrumental) music alone. Their narrativity, their narrative-ness, however, allows us to grasp how sound and music are vital to audiovisual narration. Winters' conceptualizing of music not as an intrusion into audiovisual narratives but as an aspect of an inherently unrealistic narrative space - in which music can occur as a 'normal' element of the world created - allows for an inclusive grasp of music's role in audiovisual narratives.

Music and sound contribute to audiovisual narratives both at the level of content as well as in the actual process of narrating - by commenting, providing information, establishing moods, and through their ability to generate sensations of time, speed, space, and atmosphere. To this end, sound and music employ a vast set of conventions from various formats. Given the efficiency of sonic conventions in audiovisual media, it makes sense to conceive of sound in audiovisual narratives in semiotic terms. A Peircean understanding of music and sounds as signs that are related indexically and iconically to the sounds of the audience's real-life experiences helps to explain this efficiency, but only up to a point. What a semiotic perspective fails to grasp is the emotional, often visceral intensity with which sound and music make us feel along with the characters and events of a television serial. The extent to which we are moved by sounds, the way they make us feel suspense, fear, excitement or joy, cannot be matched by images or language. I have argued that the intensity and structures of these sensations are rooted in sound's materiality - as soundwaves that not only surround us, but penetrate us. Accordingly, I have proposed an understanding of sound in audiovisual media as atmosphere in the new phenomenologist sense of the term. This notion of atmosphere captures sound's ability to create and fill 
spaces, to pervade and move everyone in these spaces, and to create moods by mobilizing cultural knowledge.

Against this theoretical backdrop, I presented the sounds that shape Ramayan and Mahabharat, introducing the styles, instruments, structures, functions and formats of music in the serials. I illustrated how music and sound narrate by manipulating the perception of spaces, time, and the dynamics between characters, through instrumental (intra-)diegetic sounds, as well as through the numerous songs and sung passages that combine musical narration with verbal narration. Both serials integrate a variety of musical aesthetics, ranging from noise over devotional music to orchestral layers of sound. Sound and music in Mahabharat and Ramayan are highly conventionalized, drawing on mythological film as well as other performative traditions (see chapter 3). In the following chapter, I will more closely examine this eclecticism and explore how it informs the aesthetics and cultural self-positioning of the serials. 


\section{Amalgamated Narrations}

(Example 3.1) In Mahabharat's 14th episode, Krishna's foster mother Yashoda catches the boy red-handed stealing butter. In the village of Vrindavan, where they live, Krishna has previously gained notoriety as a butter thief, but Yashoda never believed her neighbors' accusations. Accordingly, Yashoda is disappointed. Krishna wants to appease her and tries to convince her that he did not actually steal the butter. He breaks into a song, the wellknown bhajan 'Maiya Mori Main Nahi Makhan Khayo' ('mother I did not steal the butter'), the lyrics of which were written by the poet-saint Surdas. The singing (adult) male voice is accompanied by swarmandal, sitar, santur, sarangi, bansuri, tabla, manjira. The song fits the mukhra-antara-structure with long instrumental interludes alternatingly played by varying instruments. The percussive instruments create a solid rhythmic frame for the song with an initially sedate and light pace, which speeds and up towards the end. The melody, based on a heptatonic scale, consists of swift movements, intervallic leaps and quick passages that are heavily shaped by the relatively high pitches of the melody, the light timbres of the instruments, and the reverberating voice of the singer. The roughly six minutes of song are combined with a montage of sequences in which Krishna kids around, dances and snuggles up to Yashoda, seeking her forgiveness. Krishna does not move his lips to sing the lyrics of the song in playback, which enhances the sense of detachment between the adult voice of the singer and the child actor.

The scene following the song (at the end of which, of course, Yashoda has forgiven her son) shows Krishna's family gathered in front of the family's shrine. Nanda, Krishna's foster father, performs an arti to which an intradiegetic rendition of 'Om Jai Jagdish Hare' is heard, the lyrics metaphorically describing the importance of, to put it plainly, being a good person in order to live a pious life ${ }^{70}$. This is sung by the same singer as in the previous song and is accompanied by vibraphone and hand cymbals to which heavy reverberation has been added.

(Example 3.2) In the subsequent sequence, Krishna is teased by his friends, after which he seeks consolation from Yashoda. The ensuing sequence of a song of roughly five minutes is

\footnotetext{
${ }^{70}$ Literally, the lyrics here describe that the lamp for the ritual only burns in ghee and not in other dairy (translation, as the others referenced in this chapter, by Rasika Ajotikar). While these lyrics can be understood as a reference to the religious practice itself, they are not the original lyrics of the arti.
} 
an obvious parallel to the previous song-sequence: on the visual track, the characters enact the singer's words through movements and gestures, without synchronizing the lyrics. The music, too, is very similar to the first song: 'Maiya Mohi Dau Bahut Khijayo' (Krishna complains to his mother that he is teased by the other children) is also a well-known bhajan written by Surdas, and despite slight differences in instrumentation and scale, the music its melodic outline, timbre, pace, and structure - is strikingly similar to the first song sequence.

At the end of the episode, Krishna tries to retrieve a ball his friends dropped into the river while playing and encounters the serpent Kaliya in the river. Upon realizing Krishna's divinity, Kaliya surrenders and promises to leave the riverbanks around Vrindavan. The underwater scene is infused with visual special effects and synthesizer sound effects. Rumbling and synthetically seething, throbbing sound layers create the setting's otherworldliness. (Example 3.3) When Kaliya agrees to leave Vrindavan, dense and fast drumming starts and is soon complemented by a layer of synthesizer sound resembling an electronically amplified santur repeatedly playing a single tone in close succession so that one rapidly accented tone emerges. On the visual track, Krishna lands on the serpent's head. The serpent starts to rise to the surface of the water with Krishna, who has started to play the flute, on its head. The high-pitched, rapidly meandering melody of the flute now dominates the aural track. Krishna emerges from the water on the serpent's head and the music increases in density and pace. Watched and cheered on by the people of Vrindavan, Krishna dances on the serpent's head. With the sound of a conch, the music changes to an entirely percussive intradiegetic track. Drums, bells and cymbals play a dense and rapid rhythmic structure. Until the end of the sequence, a male (intradiegetic, acousmetric) voice rhythmically chants along taranas with the percussion, in sync with Krishna's dancing, in a loud, reverberating voice ${ }^{71}$.

These extracts from episode 14 of Mahabharat are representative of how both serials integrate the diverse range of aesthetics, versions, and (performative) traditions associated with the stories that they narrate. Mahabharat's episode 14 is among the episodes narrating the childhood of Krishna, cousin of the Pandavas. Krishna grows up in the idyllic pastoral village of Vrindavan, where he and his friends rollick and play pranks on the village people, and during which he occasionally grants glimpses of his divinity.

\footnotetext{
${ }^{71}$ The lyrics are a blend of taranas, syllables that guide the drummer, and verses describing the serpent's surrender or referencing the Tandav, the dance of Shiva. 100
} 
Krishna's butter stealing and his victory over the serpent Kaliya are both staples of the corpus of stories and performative traditions surrounding Krishna-worship, found mainly in the Braj-area around Vrindavan. Integrating these fragments about Krishna into the narrative shows the extent to which these serials integrate narrative and performative traditions, since Krishna's childhood is not actually part of the Mahabharat epic but is drawn from the tenth book of the Bhagavata Purana (see Bryant 2007: 111, and Hegarty 2012: 194). This popular corpus of stories is not only rendered in their written version, but also in numerous performative traditions. One of these is Raslila, "a devotional dancedrama" (Swann 1993: 177) that is performed around the area of Vrindavan. In Raslila, the stories of Krishna's childhood and adolescence are created through song, dance, "dialogue and mimetic action" (ibid.: 185) in order to evoke the presence of Krishna (ibid.). When I watched episode 14 together with two informants, they pointed out to me that they knew the episode's songs from the celebrations of Krishna-related holidays from the Vrindavanarea $^{72}$. Thus, the episode integrates not only a storyline from the Bhagavat Purana into its narration of the Mahabharat epic, but also the aesthetics and performative conventions of Raslila, devotional songs, the representation of a Hindu ritual of worship (the family's arti), as well as televisual or cinematic aesthetics and modes of representation. Similar to Mahabharat, Ramayan, too, draws on a range of formats of telling and performing its story, thereby creating diverse audiovisual aesthetics that versatilely combine conventions and codes.

The serials' amalgamating textures have received attention in academic discourse because they provide many insights into the serials' (self-)positioning in cultural frameworks. Pursuing a range of epistemological interests, and with different emphases, Lutgendorf (1990), Rajagopal (2001), Mankekar (1999, 2002) and Sengupta (2017) all explore the constitution of the serials. The combination of aesthetics and conventions also occasionally surfaced in the interviews I conducted during my stays in India. During the joint watching of episodes, my interlocutors would point out when elements of the episodes reminded them of other performative settings of the stories (since I asked

\footnotetext{
72 Interview with Mr and Mrs D (11. Apr 2015).
} 
specifically for input on the music, they mainly pointed out the musical intersections of the serials with other traditions to me).

The amalgamating strategies used in Ramayan and Mahabharat are highly relevant for their (aural) aesthetics, their structural-narrative frame, and their cultural selfpositioning. In the following, I explore these strategies with a focus on sound and their deployments in the TV-serials. To do so, I first provide a brief overview of the histories of the serials' underlying stories and story traditions. This is followed by an overview of how the serials incorporate elements of the performative traditions and story versions they draw on. Afterwards, I briefly discuss the televisual serial format and how Sagar and Chopra drew on a number of narrative conventions to incorporate the stories into it. The stories underlying Ramayan and Mahabharat have always been told and re-told in different media, so that their adaptation into television was a logical step in their medial history and provides insights into the process by which television developed a distinct mode of (aural) expression and aesthetic in India. By channeling the aesthetics and conventions of other traditions, Ramayan and Mahabharat made the first step in establishing a voice for mythological television serials. Finally, I complement this exploration with an analysis of the title and credit sequences of Ramayan and Mahabharat, which are representative not only of the shows' amalgamated narrations, but also of their new serial guise.

\section{Ramayana and Mahabharata - Diverse Traditions}

Ramayan and Mahabharat were the first televised versions of two narrative traditions/epics whose stories have been popular all over South Asia for centuries. Both of the stories have been compiled and repeatedly re-invented over the centuries and can be traced back several millennia ${ }^{73}$. The underlying stories are so relevant not only to Hindu, but also to Indian culture that they are commonly referred to as "national epics" (an expression which resonates prominently in the press coverage of the shows, see Bhargava 1987; Vaid-Fera 1987; Deshpande 1988; Desai and Nair 1988, Manwani 2013). They infuse the structure and content of many performative and narrative traditions, and

\footnotetext{
${ }^{73}$ See for instance Hudson (2013: 9) and Lutgendorf (1989: 3) for elaborations on the estimations on the age of the story corpus. Overall, the development of both story traditions and the constitution of the epic versions over the course of centuries has been a central topic of research in Indology. 102
} 
they suffuse everyday life in India, pervading popular culture, Hindu religion, public spaces, schoolbooks (and curricula), and language ${ }^{74}$. Both the Mahabharata and Ramayana traditions have been passed down throughout the ages not only as epics, but via countless vernacular performative and narrative practices. Specifically, the Ramayana tradition is notorious for its diversity. As Indologist Philip Lutgendorf puts it:

"the ancient tale of Prince Ram of Ayodhya [is] a story that exists in countless variants both within and beyond the Indian subcontinent and represents one of the world's most popular and enduring narrative traditions. The Ram legend has not only given rise to hundreds of literary texts, including several that rank among the masterpieces of world literature, but has also flourished for at least two millennia - and still flourishes today - in oral tradition. The most influential early text of this tradition is the one called Rāmāyaṇa; indeed, in India this name has come to be used as a sort of genre name for all texts of the tradition and even as a colloquial label for any long narrative" (1989: 3).

Lutgendorf thus understands Ram's story as a narrative tradition that also includes an epic form. Paula Richman terms this approach, which acknowledges each version in its own right, and sees each of them equally legitimate, the "'many Ramayanas' approach" (Richman 2001: 5).

Given the vast area of distribution and the age of both stories, it should be obvious that the differences between their various renditions are not limited to language and performative style, but also to the actual content of the stories. In fact, with regard to the Ramayana tradition, Rajagopal points out that the differences between the countless versions are so great that "no coherent textual influence can be claimed. What we have in common are certain names, characters, and plot-elements, in a symbolic repertoire of sorts" (2001: 89). This remark puts into perspective the monumental nature of Sagar's and Chopra's task of producing one version of Ramayan and Mahabharat to be aired nationwide to a mass audience. It was a risk for Sagar and Chopra (and in a way also for Doordarshan) which required a delicate balancing of options ${ }^{75}$. Responding to this

\footnotetext{
${ }^{74}$ In our interview in February 2016, RK, a woman in her thirties who had watched the serials as a girl and had especially fond memories of Ramayan, told me about how the Ramayana and the Mahabharata serve as backdrops or sources for a number of common phrases.

75 Expectedly, the versions of the narratives represented in the serials were contested repeatedly over the course of their airing. Mankekar (1999) elaborates on the contestation of Ramayan in detail.
} 
challenge, Chopra and Sagar both made an effort to more or less subtly legitimate their respective versions of the story. Chopra surrounded himself and his production with authorized versions of the story and with writing staff that was (presented as) endowed with particularly authoritative knowledge of it. Sagar presented the serial as the outcome of his dedicated study of all written versions of the story - not only in marketing for the show, but also in the first episode of the show, as well as in the credits. Moreover, the versions he relied on most heavily were themselves hegemonic (Richman 2001: 9-10) ${ }^{76}$. Regardless of the fact that the televisual renditions of the stories were nevertheless contested, these legitimizing strategies demonstrate how important the idea of authoritative scriptures was for the stories' transition to the small screen. In any case, the effort paid off and the serials became authoritative versions of their respective traditions in their own right (see ibid.).

Among the different versions and performative traditions integrated in Ramayan, the strongest influence was the Ramcaritmanas, Tulsidas' vernacular epic in a dialect of Hindi, and the performative and musical traditions in which this version is usually rendered (see Lutgendorf 1990). As Lutgendorf elaborates, these influences pertain to the content and style of the serial, evident in the way the epic text is treated with liberty; adding parts (such as the elaboration on Ram's childhood, see Lutgendorf 1990: 147-49), or arranging the characters in tableau-like stills in order "to evoke mythic scenes" (ibid. 143). The close alignment of the show with the Ramcaritmanas traditions is also evident in its musical style. The most striking example of this is found in the serial's title sequence (see chapter 3.1). Furthermore, throughout most of the serial the singing narrator constantly evokes (specifically North Indian) folk traditions while explaining and elaborating on situations and inner states of the characters (see chapter 2.2). As Gregory Booth points out, this is also common in Hindi cinema (1995: 174) 77 . The lyrics of these narrating sequences are usually set in the meter chaupai, as are Tulsidas' Ramcaritmanas, and sometimes quote the epic directly ${ }^{78}$. Ramayan is interspersed with devotional songs, a significant share of which are popular bhajans. This reference to musical and theatrical traditions of

\footnotetext{
${ }^{76}$ See also Dwyer (2006: 16) for observations on the dynamics of hegemony, caste, and gender with regard to the versions of the stories represented in Ramayan and Mahabharat.

${ }^{77}$ Booth does not explicitly relate this convention to formats of narrating Ramayan and Mahabharat, but to other "oral epics" (1995: 174).

${ }^{78}$ This was pointed out to me by Ravindra Jain in our interview (27 May 2015). 
rendering the story also surfaces in Mahabharat, as illustrated above in the description of episode $14^{79}$.

Sagar's son Prem explained the integration of these popular folk formats in Ramayan to be the result of targeted market research in rural areas, an attempt by his father to cater to the taste of the broad majority of his audience ${ }^{80}$. Yet another way to frame the adaptation of these performative and sonic conventions would be to understand them as televisual versions of the mythological movie, a genre that has shaped cinema in India since its inception (see Dwyer 2006; Mankekar 1999). This perspective also resonates with other commentaries on the serials that have highlighted Ramayan's and Mahabharat's reliance on pop-cultural formats. For instance, Mankekar points out that the two serials integrated "the modes of address and performative traditions of Hindi film melodrama, the use of background music and song, the narrative rhythms of U.S. soap operas, and the iconography of religious calendar art" (1999: 228). Lutgendorf, too, emphasizes the aesthetic proximity of the serials with other mass mediated visual representations of the stories' characters and events, such as calendar art (chromolithographs) and Amar Chitra Katha-comics (1990: 168). As Dwyer explains, Ramayan and Mahabharat both draw heavily on the conventions of the mythological film (2006: 52), both visually, through the style of special effects, costumes, and appearance of the actors, and aurally through the use of prerecorded music and sound effects, and by means of songs, singing and the background score to provide sonic structure for the narrative. In fact, one sequence of Mahabharat's background score that occurs frequently in festive or celebratory contexts is copied without any modification from the background score of Babubhai Mistri's 1965 movie Mahabharat (examples 3.4 and 3.5 ${ }^{81}$ ). Other performative formats not directly referenced in Ramayan and Mahabharat but which strongly shaped mythological film, for instance Yakshagana and Nautanki (see Dwyer 2006: 18), had an indirect impact on the serials.

\footnotetext{
79 Peter Manuel (1993: 119) points out how the success of the two serials, with their distinct regional flavors, sparked a revival of other regional performance traditions of the stories.

${ }^{80}$ Interviews with Prem Sagar, 24 Jun 2015 and 19 Feb 2016.

81 Mistri's full movie is available on YouTube: https://www.youtube.com/watch?v=p-.wcExIbNw [view date 02 Dec 2017].
} 
Against this backdrop, Ramayan and Mahabharat can be understood as amalgamations of a range of popular cultural formats and conventions of telling the stories, constructing their characters, and depicting their iconic moments. This amalgamation creates compatibility of the serials with a wide range of understandings of the epic stories. Employing the standardized aesthetics of these formats is vital for creating a high recall value - of characters, of famous episodes, of relationships between characters - for a very heterogeneous audience. This allows viewers with a less intricate knowledge of the characters and plots, or who are more familiar with other versions of the stories, to identify them. Marie Gillespie elaborately illustrates this dynamic. In her ethnography on watching mythological movies and Mahabharat with a Hindu family of Indian descent in London, she describes how the visual representations of characters with their established attributes (for instance Krishna's display with the peacock-feather and his flute) and characteristic behavior are vital for audience recognition (1995). This was also pointed out by several my informants whose knowledge of the myths prior to watching the serials sprang from schoolbooks and Amar Chitra Katha comics ${ }^{82}$. The conventional representation of the stories and their characters made them relatable to a heterogeneous audience with widely varied prior contact with the stories. Despite the inclusivity of the serials' amalgamated constitution, I do not wish to gloss over the fact that their specific versions of the stories did, in fact, imply massive mechanisms of exclusion, too. By favoring authoritative tellings of the stories, specific regional aesthetics, and a strong Hindu ethos, they did not offer anchors of identification for masses of people. This reinforcement of hegemonic power relations is discussed in the (academic) discourse on the serials (see especially Mankekar 1999 and Rajagopal 2001), but it also surfaced in conversations during my stays in India, usually with non-Hindu interlocutors, some of whom were from the south of India.

Despite heavily relying on schematic conventions, both Chopra and Sagar also brought a level of individuality into their serials. Chopra, for instance, repeatedly criticized the inheritance of power throughout the serial. At a time when Rajiv Gandhi, as descendant of the Nehru-Gandhi-dynasty and prime minister of India was involved in the Boforscorruption scandal, this was perceived as an open political statement (Manwani 2013).

\footnotetext{
82 Interviews with PS and UV, 28 Mar 2015, with PK and DV, 8 Apr 2015, with DP 5 Jul 2015, with DK 24 May 2015, and with BA 18 Jun 2015. Also see Lutgendorf (1989: 3). 106
} 
Sagar, for his part, expanded the story by adding details about Ram's childhood and education that are not part of existing Ramayana traditions ${ }^{83}$ (Lutgendorf 1990).

\section{Epics or Soap Operas?}

In research on Ramayan and Mahabharat the stories' shift into the new medium of television has received considerable attention, mainly in terms of the political implications of their broadcast and the dynamics of reception. While it would be an oversimplification to describe the medial transition of Ramayan and Mahabharat as a move from epic to soap opera, it does capture the seeming incongruence between the serial format and the stories' broad public perception as epics. On the most obvious level, this apparent incongruence relates to the textual level of the two narrative forms. As Rajagopal points out, a soap opera is "usually defined in terms of its open-ended narrative, one that can potentially be stretched on forever" (2001: 92) - which evidently contrasts with the closed format of the epic. However, the stories of Ramayan and Mahabharat go beyond their epic versions and serials are not limited to the soap opera format. Thus, the switch to television is not as conflicting as it might initially seem. Beyond this textual aspect, the medial shift also implies a change in the dynamics of production and reception, and in the aesthetics and modes of address. Looking again at how Ramayan and Mahabharat turn a range of narrative templates into a serial - switching from epic to soap opera, so to speak - is also insightful for understanding the role of music and sound in these serial narrations.

Serials come in many forms and in many media. While the breadth makes it difficult to find a universal definition of the television serial, media scholar Tanja Weber and media journalist Christian Junklewitz (2008: 15-17) distill four characteristics that capture the common thread of televisual narrative formats: Serials always consist of multiple pieces. They are broadcast regularly. The individual segments are linked in one way or another (be it through cast, through narrative links, a continuously employed setting or formal features). And, last but not least, they are presented as serials, which implies that their

${ }^{83}$ As Lutgendorf (1990) elaborates, this corresponds with the conventions of Ramlila, which allow for individual embellishment of the story during performance. 
formal status changes when they are framed as something other than a serial. These characteristics also suggest that it is possible to turn an epic into a television serial through a number of formal changes, such as splitting the story into several parts, regularly broadcasting, and including repetitive elements such as title and credit sequences. The closed format of the two epic narratives - their well-known fixed endings - which some have regarded as problematic for their transformation into serials (see Rajagopal 2001: 92), does not conflict with this taxonomy (after all, all serials have to end at one point anyway). Thus, Ramayan's and Mahabharat's serial manifestations can already be understood as serials on the basis of their medial framing and presentation alone. At this point it is also salient how the use of music - which offers a set of repetitions and a regular sonic framing through the title sequence, as well as cinematic aesthetics and narrative qualities - contributes considerably to this medial transfer.

Within this broad understanding of the serial, distinctions are usually made between the specific formats of televisual serial narration. Two main types are commonly distinguished: the serial and the series. Serials have extensive, continuously developed storylines, often making abundant use of suspense and a narrative intensification towards the end of episodes through cliffhangers. The soap opera is a typical serial. Series, by contrast, are episodic: each episode starts from the same initial situation and the incidents that are subject of the episodes are ultimately resolved so that the original equilibrium is reinstated before the next episode (Weber and Junklewitz 2008: 19-20). Usually, sitcoms are series. This binary taxonomy is, however, a simplification of the complex morphology of serials (Allrath, Gymnich and Surkamp 2005: 5-6). Therefore, scholars have proposed understanding these two types as the ends of a spectrum on which a show is located according to its degree of narrative continuity (Allrath, Gymnich and Surkamp 2005: 6-7; Weber and Junklewitz 2008: 23). Against this backdrop, Ramayan and Mahabharat, with their expansive stories that are however continuously told, can be understood as serials with a pre-determined ending, which are interspersed with occasional episodic segments. Given the immense scope of both stories, Sagar and Chopra obviously had to be selective during production, even though the long run of both serials allowed for re-telling the stories in some detail. The required splitting up of the narrations into pieces for the weekly broadcast was not a revolutionary act in the histories of the stories' traditions. On the contrary, splitting them into smaller pieces and narrating or performing them episodically has always been a feature of these traditions. In many performative 108 
traditions, an installation or performance focuses on one specific section of the story, as for example most mythological films do (Dwyer 2006:16). Alternatively, the narrative may be enacted or recited episodically over the course of several days, nights or events, as for instance in Ramlila (Lutgendorf 1990: 142-43) ${ }^{84}$. Because of these episodic modes of telling the stories, not only do individual episodes from the Mahabharata and Ramayana traditions also circulate separately, but a modular telling of the stories is also possible, if not common. Accordingly, throughout both Mahabharat and Ramayan, extant episodic fragments repeatedly serve as templates for structuring the televisual episodes. However, these episodic fragments did not account for the entire televisual re-structuring of the stories. As Gufi Paintal, casting director of Mahabharat, actor of Shakuni and regular member of Chopra's production team told me, factors influencing the assemblage of the single episodes of Mahabharat included the relation of narrative fragments to the entirety of episodes, episode-length, the distribution of incidents over the course of an episode, and advertising breaks ${ }^{85}$.

Overall, both serials revolve around one main, continuous storyline, which is largely driven by causal motivation and generally focuses on one set of characters. Occasionally, both serials diverge from their respective main storyline to incorporate backstories of characters (more extensively so in Mahabharat) if they relate to the main plot in some way ${ }^{86}$. In contrast to stringently clocked television serials like soap operas, the narrative pace and the episodic structures of Ramayan and Mahabharat appear more irregular and are, in comparison, narrated more slowly. The extensive display of certain events can appear disproportionate compared to other events that would be of roughly equal length within a setting of realistic time: In Ramayan, for instance, the death of the monkey king Bali spans roughly 35 minutes over the course of two episodes (38 and 39), whereas the rescue of Ahalya takes up a mere 6 minutes of episode 5 . At these points, the serial's indebtedness to preceding formats of telling the stories - and how these overpower the

\footnotetext{
${ }^{84}$ In this context, Lutgendorf does not fail to mention that Sagar's televisual Ramayan does not even remotely range among the longest running episodic re-narrations of the story.

85 Interview (26 May 2015). See also Newman 2006 on the common structures of American TV-serial episodes.

86 This does not really apply to the extensive narration of Krishna's childhood. It is obvious that this fragment was incorporated in order to enhance the serial's appeal to a religious Hindu audience (which was also pointed out to me by KT during our interview in April 2015).
} 
'standardized' narrative rhythms of TV-serials - is obvious. Lutgendorf points out that the north Indian performative traditions that were formative for Ramayan commonly use a free and individualizable treatment of the story time (see 1990: 141-42). The episodic and temporal structure of Ramayan and Mahabharat was also influenced by Hindi film. As elaborated earlier, Hindi films often construct time as discontinuous and static (Raghavendra 2006: 32-35) ${ }^{87}$. In the serials, this idea of time manifests in the extensive emotional scenes, the musical sequences revolving around a feeling or an encounter, the tableaux of the song sequences (see Raghavendra 2006: 30), and not least by the narrator of Mahabharat, who is both time and timeless. It is at this point that the crucial role of music once again comes to the fore: The extended duration of individual scenes is tailored to evoking a range of emotions according to the respective situation and thus for creating an emotionally deep experience for the audience, which is prominently created through music and song (see chapter 2).

Another feature of seriality is repetition. While seriality can also manifest on a narrative level, it is also a formal issue, a matter of a fundamental modality (Kelleter 2012). In the case of Ramayan and Mahabharat, which lend themselves to being serialized as continuous narratives due to the vastness of their stories, seriality does in fact mainly play out on this formal level. The framing of Mahabharat's episodes by Samay and the sung closing segments, as well as the general framing of both serials' episodes by title and closing sequences make a decisive contribution to the seriality of both shows. The constant repetition of these sequences, the distinct aural aesthetics of the shows, the repetition and re-iteration of similar sounds and passages, and the strategies of interweaving music with images provide continuity and create seriality over the course of the narratives.

Ramayan and Mahabharat are neither epic nor soap opera, but continuous serialized narratives focusing on one main story each but hinting at the countless stories branching off from their narrative trunks. Their seriality is created by a segmentation of the continuous narratives that integrates or occasionally revolves around episodic fragments, thereby presenting a new version of two highly schematized narratives. Sound is an

\footnotetext{
${ }^{87}$ In his monograph The Spectre of Sound: Music in Film and Television, K.J. Donnelly suggests that in contrast to film, television (even though he does not specify this, it is quite obvious that he is referring to Anglophone North Atlantic television) generally rather displays "momentary dramatic instants" (2005: 111) instead of causally motivated plots and alternations of suspense and release - a position that I consider highly questionable.
} 
essential factor in this. It provides a framework of repetition and orientation as well as variation within this framework. Likewise, sound is a vital element of amalgamating the rich traditions of narrating the stories which are told in Mahabharat and Ramayan. It draws together the aesthetics, structural peculiarities, and modes of rendering the stories by virtue of its materiality. In this sense, next to its narrating and immersive, atmospheric functions, sound serializes and fuses traditions and versions of narrating the stories. These latter two of sound's functions are especially apparent in the title- and creditsequences of Ramayan and Mahabharat.

\subsection{Quintessential Amalgams: The Title Sequences}

The relevance of title and credit sequences can hardly be overestimated in their relevance for the serial format and, in case of Ramayan and Mahabharat, for their amalgamating functions. In the small body of academic work on TV-serial music, this importance is usually acknowledged. It also resonated with those of my informants working in the film or television industries. The relevance of these sequences manifests on different levels and through a range of functions. One of these is the fundamental function of creating a sense of seriality through repetition. Even though other musical elements of TV-serials are also repeated over the course of a serial's run, the title sequences occupy a prominent position. Bridging the gap from the televisual flow of the programming schedule to the specific setting of a given serial, they are have a prominent position in a way that other musical elements of a show do not. The fact that they do not need to compete for attention against dialogue or narrated events, as does music within the narratives, makes them easily recognizable anchors for serial repetition (see also Mitra 1993: 104-5.).

A feature of title sequences that was mentioned frequently in the interviews with members of the television music industry is their function as a type of alarm ${ }^{88}$. The sound of a title sequence, so my interlocutors said, is supposed to alert potential viewers to the beginning of the show, make them stop whichever activity they were engaged in, and watch the show. This aspect is also mentioned prominently in the academic literature on

\footnotetext{
88 Interviews with LK, 30 Jun 2015, Prem Sagar, 19 Feb 2016, BG, 1 Jul 2015 and ST, 3 Jul 2015.
} 
TV-serial music (Tagg 1979: 61-62; Donnelly 2005: 113; Rodman 2010: 30; Davison 2013: 147-48). The alerting function is closely tied to a specific media practice in which the schedule of the television program determines the interaction with the medium and its programs, and thus to a certain extent the daily rhythms of its viewers. While this mode of interaction with televisual content is now declining, it was still prevailing when Mahabharat and Ramayan were broadcast in the late 1980s. Title sequences, as Davison and Tagg point out, offer an opportunity for the viewer to attune to what they are about to watch and listen. Thus, engaging with the title tune of a show "may also become ritualized, born of anticipation and excitement for a planned period of escapism and/or engagement" (Davison 2013: 148; see also Tagg 1979: 62).

Closely connected to alerting viewers, a function of title sequences is the establishment of recall value. Given the audience's high exposure to them, title sequences are more likely to create an association with the show than other (musical) elements of a show. Their extraordinary memorability is perfectly illustrated in the example of Mahabharat's title sequence, or rather in the reaction many of my interlocutors displayed during first conversations: when I would first explain my research topic or ask about their (musical) memories of the shows, many of them, usually those who had watched the shows as children, would burst into a melodic exclamation of the word "Mahabharat", imitating the beginning of Mahabharat's title sequence, which has become so iconic over the years ${ }^{89}$. While my interlocutors' reactions were infused with nostalgic childhood memories (see chapter 6) and borne out of the specific memory of a musical experience from decades ago, the impulse to sing along - the somatic reaction to the memory of sound - is not exclusive to Mahabharat and Ramayan. The sounds of a title sequence introduce the upcoming show to the audience. They give a preview of a show's overall style and content and communicate a range of "serial- and episode-specific information" (Davison 2013: 147). In this, to paraphrase Davison, they generate and convey a brand identity for their show (ibid.) ${ }^{90}$. In their capacity as atmospheres, they create in the audience a strong sensation of connection to the show that they announce. This musical, or rather audiovisual, atmosphere powerfully frames the respective show by virtue of its high

\footnotetext{
${ }^{89}$ Some of my informants with whom I watched episodes of Ramayan also sang along to Ramayan's title sequence.

${ }^{90}$ In the case of Ramayan and Mahabharat, I would contend that given the institutional state of television in India at the time of their broadcast the competitive dimension of creating a brand identity was probably not a priority of Doordarshan or the producers.
} 
frequency of repetition. Title sequences allow the viewers to (mentally) prepare, to get excited for the start of the show, and they offer an almost ritualized frame for getting into the mood and mindset that viewers connect with the show.

Beyond these atmospheric and emotional aspects, title sequences are tools for the cultural self-positioning of the respective serial and a platform to communicate a preferred reading of the televisual text. By creating a distinct audiovisual aesthetic and thereby highlighting specific features of the serial, title sequences frame a show in terms of, for instance, genre, the fundamental moral categories underlying the show, the target audience, or the cultural aspirations of the show. The title sequences of Ramayan and Mahabharat are illustrative examples of these capacities and demonstrate how the balance between the newly adapted format of the TV-serial and the other narrative formats was achieved.

\section{$\underline{\text { Ramayan }}$}

The title sequence of Ramayan has a duration of one minute and nine seconds, if the Sagar Arts-jingle is excluded, as I do in this analysis ${ }^{91}$. (Example 3.6) The title sequence starts with a pattern that has a sharp and metallic timbre and reverb, possibly a glockenspiel. The pattern consists of three single notes alternating at a slow pace. The first two times this pattern is played, a swarmandal comes in on the second note, playing a very brief ascending passage that sounds like a sweeping across the strings and leads from the second to the third note. This combination is played twice. It is combined with semi-static visuals: a beige background with a drawn image of a blue-hued Ram, bending a bow, on the left third of the screen. The remaining two thirds of the screen show blue and redcolored lettering: first "Sagar Enterprises presents" and then the word "Ramayan", first

\footnotetext{
${ }^{91}$ As with the other material I have analyzed from the serial, I originally intended to conduct the analysis of the title sequence based on the DVD-box of Asian Movie Video, which I also used to watch material from the serial with my informants. There are other versions of the title sequence available on YouTube, in which the visuals of the sequence diverge from those in the DVD-version I am working with, while the music is the same. Even though during my fieldwork none of my interlocutors remarked that the visuals in the title sequence that I watched with them was different from what they remembered, I assume that the title sequence from the DVD-box is a remastered version and does not represent what was actually shown on television during the initial broadcast.
} 
shown written in Devanagri script, then in Latin script ${ }^{92}$. During the third repetition, instead of the swarmandal, a drone and a pakhawaj come in, followed by a set of manjiras. With these aural changes, the visuals of the sequence change as well: now, white lettered credits set against a bright blue background screen appear, alternatingly in Devanagri and Latin scripts ${ }^{93}$. The percussion instruments establish the sequence's rhythm and meter an 8-beat tal that is also known as bhajani theka, as I was told by some informants ${ }^{94}$ which points to its prevailing use in Hindu devotional music. Accordingly, it is an efficient means of creating a north Indian Hindu devotional musical atmosphere. The sedate pace of the pakhawaj is steadied by the manjira, which is heard on every beat, adding its metallic, piercing, high-pitched tone to the musical arrangement. When the tal is established after a few beats, singing replaces the pattern of the three alternating pitches. The glockenspiel-like instrument now only adds barely discernable harmonies every few beats, thus emphasizing the melody. A male and (at least two) female voices sing the melody in unison, the male voice an octave below the female voices. This creates an impression of fullness of the melody since the individual voices' textures complement each other - an effect that is especially salient when the female voices change to a very high register later in the song. They sing softly, not at the top of their voices, and identically sing even the smallest bit of melodic ornamentation together. The sung part of the title sequence is divided into two segments, which correlates with the meter of the lyrics, the chaupai ${ }^{95}$. The lyrics describe the story of Sita and Ram as so sweet and pure that one wants to listen to it over and over again.

The course of the melody, which is created from a heptatonic scale ${ }^{96}$, is closely aligned with the structure of the lyrics: The first and the third line each start at a higher pitch, and each move downwards to the first and lowest pitch for the second half of the line (variably starting with the last or penultimate word, depending on the number of syllables), in

\footnotetext{
92 This pertains to the televisual version, as can be seen here: https://www.youtube.com/watch?v=R9g7kiK cCg [view date 30 Nov 2017]. The remastered version of the sequence from the DVD-box show has a different beginning - a separate Sagar Arts jingle that is added to these first sounds and visuals.

${ }^{93}$ Again, the visuals of the DVD-version differ slightly: the screen shows a dark blue, star-studded night sky with wafting clouds in the foreground of the lower fifth of the screen. The credit roll - in yellow letters, exclusively in Latin script - seems to emerge from these clouds and traverses the screen from the bottom up.

94 Interview with AK, 25 Feb 2016 and with SK 16 Feb 2016. See also Bor 1999: 7.

${ }^{95} \mathrm{~A}$ detailed description of the meter and the intricacies of its use in the Ramcaritmanas is conducted by Lutgendorf (1989: 14-15).

${ }^{96}$ As was pointed out to me by an informant, the melody is based on rag Khamaj, but is not a pure rag (interview with AK, 25 Feb 2016). 
which the same melodic pattern, a movement ascending from the lowest to a higher pitch and then back to the lowest again over the course of four beats, is sung. The regularity of the melodic movement emphasizes the metric structure of the lyrics. Similarly, the second and fourth line are the same. Both start on different pitches than the first and the third line, but close with the same melodic pattern as the other lines. This invariable small ascend-descend pattern at the end of every line imparts the overall melody with a repetitive character. The two segments of the chaupai are separated by a break of eight beats, in which the pattern of three alternating pitches from the beginning of the sequence is heard alongside the percussion and the drone. The pattern is also played again after the singing ends, now together with the ascending sweep of the swarmandal, and is repeated four more time until the sequence ends on the lowest pitch of the melody.

When discussing this sequence, many interlocutors identified or remembered the music as either a "folk tune" or a bhajan ${ }^{97}$. Others were familiar enough with the melody to identify it as the melodic contour used for reciting (passages from) the Ramcaritmanas ${ }^{98}$. In employing a melody that is closely connected to recitational practices of the serial's main source, the title sequence of Ramayan positions the serial unambiguously within these north Indian textual and performative traditions of the story. In the title sequence, the music and the credit rolls emphasize the relevance of Tulsidas' narration for the serial: the Ramcaritmanas are listed among the serial's main sources, the lyrics are in the same meter as Tulsidas' epic, and the melody references a specific, regional mode of reciting the text ${ }^{99}$. The connection to Tulsidas is even more explicit in the closing sequence, in which the lyrics directly quote the Ramcaritmanas to the same melody as in the title sequence. Apart from the regional dimension, the sequence evokes Hindu devotional practices through a number of musical parameters and thereby suggests a religious understanding of the serial. While parameters like the melody, known for its use in (devotional) recitation, the tal, typically employed in devotional music, and the measured pace are important for this association, timbre is equally relevant here. A case in point in Ramayan's title sequence is the use of the manjira. The high-pitched, metallic sound of the

\footnotetext{
97 Interview with VJ 30 May 2015, SK 19 Feb 2016, PS in an informal conversation March 2015.

98 PS in an informal conversation March 2015, Interviews with RK 2 Mar 2016, SB 26 Jun 2015, AK, 25 Feb 2016.

${ }^{99}$ Interview with Ravindra Jain, 27 May 2015.
} 
hand cymbal stands out during most of the title sequence and several informants characterized it as a vital instrument for Hindu devotional rituals ${ }^{100}$.

The importance of timbre for understanding the serial's music particularly struck me when I was watching an episode of Ramayan with DV and PK. Both identified as South Indian. DV grew up a Brahmin family in Maharashtra, PK grew up in a catholic household in North India, whereas her parents were from Kerala. They were not aware of the origin of the sequence's melody in North Indian traditions of reciting the Ramcaritmanas. Neither of them had musical training. Both identified the sound of the manjiras in conjunction with the timbre and intonation of Ravindra Jain's voice in the title sequence as constitutive of creating an air of particularly North Indian Hindu piety and morality 101. For both PK and DV, the singers' intonation and manipulation of their voices communicated a specific musical aesthetic that they firmly associated with a geographical region. The sequence's moderate, steady pace, and the timbral quality of the singing, the specific intonation of the singers and the glockenspiel's reverb, the low volume of the pakhawaj and the high, metallic pitches of the glockenspiel, the swarmandal and the manjiras - all create an atmosphere of North Indian Hindu religious devotion. They thereby frame the serial as more devotional than worldly escapist entertainment.

The closing sequence of Ramayan (example 3.7) reinforces this devotional character. As mentioned above, apart from some details, it is a replication of the title sequence. Different from the title sequence are a slight melodic variation at the very beginning and the fact that it starts with Ravindra Jain's singing instead of a short instrumental introduction. It employs the exact same instrumental track and for the second half of the sequence, and even the same lyrics as the title sequence. The lyrics of the first section of the closing sequence are a well-known quote from Tulsidas' Ramcaritmanas. As one informant told me, it is usually recited for seeking protection or encouragement in everyday life ${ }^{102}$. The similarity of the title and credit sequences establishes a cohesive frame around the individual episodes of Ramayan.

This frame creates seriality on different levels. On one level, its cyclical nature lends itself to unlimited repetition; the melody's provenance in Ramcaritmanas recitation alludes to

\footnotetext{
100 For example, during the interviews with PS and UV, 28 Mar 2015, with DV and PK, 8 Apr 2015, with Surya Raj Kamal, 17 Jun 2015 and AK, 25 Feb 2016.

101 Interview with DV and PK, 8 Apr 2015.

102 Interview with SB, 26 Jun 2015.

116
} 
the seriality of its continuous and countless intonations. On another level, the weekly repetition of this frame itself creates seriality. On yet another level, the sequence's music is anchored in the serial narrative; the melody surfaces repeatedly in the sung commentary and the specific musical aesthetic of the sequence shapes the music of the whole serial, which is characterized by the presence of instruments like manjira and swarmandal, as well as by the voices of Jain and Krishnamurthy. This draws a connection between the framing sequences and the paradigmatic axis of the serial's (musical) narration.

The musical evocation of a North Indian devotional practice (and aesthetic) in the title sequences not only positions the serial within the traditions and formats of narrating the epic, but also establishes television as a new, legitimate medium for re-narrating the story of Ram.

\section{Mahabharat}

The title sequence of Mahabharat integrates a range of aesthetic conventions and narrative and performative traditions through different stylistic means. This not only pertains to the aural, but also the visual dimension of the sequence, which contains two different styles of (animated) images. Including the jingle of the production company B. R. TV103, Mahabharat's title sequence spans three minutes and five seconds divided into four segments (example 3.8). The first segment - the B.R. TV-jingle - takes up the first 30 seconds of the sequence. With a washed-out sound quality, a male voice melodically recites a Sanskrit verse from Bhagavad Gita (chapter 2, verse 47), supported by the drone of a tanpura. Visually, from an originally dark screen the silhouettes of two bodies standing on a globe in front of a dark background emerge. At 00:23, a sharp and metallic sounding stroke of a gong and the blaring, static tone of a conch are heard. This is accompanied by a black screen, on which a white star rapidly expands until it almost fills the screen. At the center is the logo "BR TV presents" in dark red fonts (Latin script). In

103 Which I do here because I am not aware of any discrepancies regarding the material similar to the case of Ramayan's title sequence. 
00:29 a second stroke of the gong and an emphasis on the blown conch are heard, terminating the section.

At 00:32, the second section - the actual title sequence of Mahabharat - begins. A sound that resembles a swarmandal but may be produced by a synthesizer initiates this new section with a rapid, descending pattern like a sweep across the strings. This is immediately followed by two layers of synthesizer sound at staggered intervals (at 00:33 and 00:38). The first layer is an amorphous swooshing that combines a descending pitch over the course of a few seconds and a sound with indeterminable frequency resembling brown noise. At 00:38, the second synthesizer layer is heard for close to two seconds, replacing the first layer with a higher-pitched, but similarly noisy swooshing. These synthetic sounds heavily contrast with the textures of the sounds heard directly before, thus producing an aural tension. These sounds are combined with visual material from the serial: different shots from the battlefield of Kurukshetra depicting the clashing of the opposing armies are seen in the background. In the foreground, an orange-brown colored, frayed frame, fading into black, contracts around the images of the battlefield until they depict the logo "Mahabharat", written in black Devanagari letters on a black background (readable through the light fringes of the letters, through which the images of the battlefield are visible) at 00:40. At the same point, the dense, swooshing sound carpet is replaced by a tanpura and a singer exclaiming the famous melismatic "Mahabharat" over a duration of six seconds. The occurrence of the synthesizer sounds coincides with the morphing and shrinking of the Mahabharat emblem, so that it appears as if the swooshing sounds are caused by the morphing emblem ${ }^{104}$. The "Mahabharat" call employs the same pentatonic scale as used in the melodies of the remaining sections of the sequence. It starts with a short initial syllable "Ma". The syllable "Ha" is extended, allowing for a melismatic movement descending from its initial pitch, which was slightly above that of the "Ma" via four steps. The melody swiftly ascends again on the syllable "Bha", arriving on a higher pitch than the "Ha" before. The syllable "Rat", then, is held steadily for a few seconds. In addition to the tanpura, a vibraphone comes in on this last syllable, playing a few single ascending pitches from the pentatonic scale employed in the singing. This portion of the sequence - the swooshing synthesizer sounds merging into the tanpura and vibraphoneaccompanied "Mahabharat"-call accompanied by the shrinking and morphing frame that reveals the "Mahabharat"-emblem - is repeated twice more with slight variations. The

${ }^{104}$ An effect discussed in detail by Chion (1994). 
second time, the emblem is shown in Latin script and the third time in Urdu. There are also slight musical variations: in each repetition the "Mahabharat"-call is set on a lower pitch, thus gradually descending. Apart from this, the calls remain identical in terms of their melodic or ornamental structure, the pace and timbre, and specific intonation of the singer.

At 01:09, the third section of the sequence begins, lasting one minute until 02:10. This section strongly contrasts with the preceding section on both the visual and aural levels. While it employs the same scale as the previous section ${ }^{105}$, the instrumentation and other structural features change considerably. A group of singers - male and female voices start intoning a descending scale on the vowel ' $a$ '. The melody descends over three sets of pitch sequences consisting of three pitches each, and lands on a rhythmically accented oscillation on the lowest pitch (at 01:15). A drum accompanies the singers, probably a dholak, playing a slow pattern of beats that alternate between a sharper and a deeper pitched, voluminous sound. The pattern of the dholak and the singers together emphasizes the 7-beat meter of the section (123 1234). The descending melody is then repeated by a sitar and a flute in unison and combined with slight variations in the percussion (and the addition of another percussion instrument). At 01:24, a male voice starts singing, accompanied by the percussion. His singing introduces the show thematically. The first two lines are repeated by the male and female voices heard at the beginning of that section. The melody starts at a deep pitch, then initially revolving around this pitch before continuously ascending during the course of the section. During the sung passages, the instrumentation is reduced to the percussion, repeating the pattern from the beginning of the section while the flute, sitar and voices repeat smaller patterns from the sung melody in brief interludes. The final lines of this section (referring to the truthfulness of the Bhagavad Gita) are sung in a melodic pattern that spans one line and is repeated three times. Rhythmically, the singing is closely aligned with the strong accents of the percussion instrument, which provide virtually the only instrumental accompaniment. The singing here is non-melismatic and strongly shaped by the accented

105 In fact, as was pointed out to me during an interview, it is the same rag, Madhyamad Sarang (interview with AK, 25 Feb 2016). 
percussion layer. The singer's intonation gets more and more vigorous towards the end, so that the final lines serve as the climax of a preceding progression of intensity.

This section also contrasts visually with the preceding section. From 01:09 onwards, the animation of the "Mahabharat"-emblem is replaced by a range of still, chromolitographstyle printed pictures that alternate irregularly, at durations of a few seconds each. The pictures constitute the background of the credit rolls. In total, five different pictures are shown here, whereas three of them are only shown in one shot and two are shown in total and then with alternating close on the characters depicted in it. With one exception (the image of Sanjay, the charioteer, reporting to King Dhritarashtr about the events on the battlefield), all the images depict the moment in which Krishna renders the Bhagavad Gita to Arjun and manifests in his divine form. The images are all roughly in the same style, depicting the characters with the typical attributes of their standardized (pop-cultural) representation, such as the crown and mustache of Arjun, the many heads of Krishna's divine form, his blue complexion, and the peacock feather in his crown ${ }^{106}$. The lyrics in this section announce the serial as 'the story of Mahabharat', which is about divine truth, and alludes to the Bhagavad Gita as manifestation of this truth.

The fourth and final section of Mahabharat's title sequence begins at 02:10 and concludes the sequence at 03:05. It begins with yet another aural contrast: the loud, forceful sound of a conch is heard, sustained for seven seconds and emphasized with a rumbling drum roll. The sound of the conch is accented towards its end and the drumroll increases in volume and density. This creates the impression of yet another dramatic intensification, which is further heightened by the reverb that extends the sound of the conch for another second after it has already faded. Starting at 02:17, a vibraphone plays slow ascending progressions based on the pentatonic scale of the previous segments. At 02:18, the male singer starts reciting two shlokas from the Bhagavad Gita (chapter 4, 7-8) in Sanskrit. In the verses, Krishna announces his return to earth in times of injustice at a slow pace. In reciting the verses, the singer initially alternates between two relatively low pitches. His voice is amplified with reverb, the pace of his recitation slow. Initially, the vibraphone is the only instrument in this section. Its scattered, ascending sounds, which are heard during the brief pauses between words, appear to be unmetered. When the singer proceeds to the second part of the first shloka, the pitch of the recitation rises stepwise,

${ }^{106}$ According to the credits, the source of these pictures is the ISKCON Bhaktivedanta Book Trust (01:1501:19). 
now alternating between three pitches. At the beginning of the second shloka, he first moves back down to the lower pitches and then ascends again, further than the first time. At 02:46, a sharp-sounding, high-pitched percussive instrument is added to the singer and the vibraphone, successively followed by two more percussion layers. They complement the first drum's sharp timbre with a deep, resonant duff and a high-pitched, piercing cymbal. The percussion instruments all play the same fast succession of beats, thereby creating a loud, dense, full sound. Simultaneously, the vibraphone shifts from playing single strokes to creating a carpet of sound in which the single strokes are blurred. Corresponding with this increasing intensity, the singer's intonation changes at around 02:50, becoming louder and increasingly forceful, and ascending further and further in pitch. The title sequence ends on the word "yuge" after which the percussion instruments and the vibraphone fade out. The last sounds heard are scattered strokes of the vibraphone, which builds a smooth transition to the sounds of the episodes following this introduction, since Samay's voice is always accompanied by scattered, echoing synthesizer sounds.

The visuals accompanying this last segment of the title sequence continue the display of pictures of Arjun and Krishna. The last image (02:52-03:05) shows Krishna's divine form. Despite the continuity of this visual element throughout the last segments, overall Mahabharat's title sequence is shaped by its strong aural and visual contrasts. Its individual elements allude to a range of media and traditions and firmly position the serial among them. Visually, the animation of the Mahabharat logo from the beginning of the title sequence contrast with the images displayed in the remainder of the sequence. Both can be understood as a reference to cinema: the former by exhibiting the potential of cinematic animation and reiterating the cinematic convention of displaying a film's title in different languages ${ }^{107}$, the latter by invoking cinematic techniques of creating title sequences. A second reference implied in the display of the images is the standardized portrayal of the mythological characters in chromolithographs, comics, and other printed mass media. The entirety of the final section of the title sequence strongly suggest a religious understanding of the epic and its televisual re-narration. The recitation of well-

\footnotetext{
107 VJ pointed this out to me during our interview on 30 May 2015.
} 
known shlokas von the Bhagavad Gita - the part of the epic of utmost relevance for Hindu religion - in combination with the images of Krishna rendering the Gita to Arjun, make this connection explicit. Here, the aural level is particularly potent in producing a religious and sublime atmosphere through the slow, solemn recitation of the Sanskrit verses by Kapoor's booming, deep, and reverberating voice, accompanied by the ethereal tones of the vibraphone. The combination of these elements unambiguously signals which part of the notoriously complex story is considered most important by the director.

Apart from these allusions to Hindu religion, the aural elements of the whole sequence point to film music just as the visual elements reference cinematic conventions. An example of this is the futuristically swooshing synthesizer sounds (which simultaneously express the serials' claim to modernity ${ }^{108}$ through their use of modern technology) or the classical style of the middle segment with its employment of rag and tal109. Contrast, as a stylistic element, is a particularly formative factor for Mahabharat's title sequence. One informant, himself a composer with experience in advertising, described this structure as an "advertising approach". As he pointed out, this combining of aesthetically disparate elements, as is also customary in advertisements, shows that in the sequence "the importance is not [the] flow of the song" but rather the "flow of the story"110. It squeezes as much information as possible about the upcoming serial into the short sequence. This was an unusual structure for serial title sequence in late 1980s television in India and can therefore be understood as an act of self-positioning within the new televisual medium.

In conjunction with the credit sequence, Mahabharat's title sequence creates an atmospheric serial frame around the show, a sort of audiovisual bracket. It not only provides information about the serial but also seeks to create sensations and feelings in the audience that then become associated with the show. Furthermore, this bracket is aurally constructed in a way that interlocks the episodes and the title sequences. The fixed settings at the beginning and end of each Mahabharat-episode - the space-setting with Samay, and the sung moral of the story - are compatible with the sounds of the title and credit sequences. The softly fading vibraphone at the end of the title sequence is in a sense picked up by the scattered vibraphone strokes that invariably start the Samay sections,

\footnotetext{
108 Interview with Surya Raj Kamal, 17 Jun 2015.

109 One informant perceived the particular choice of rag in that sequence as debatable, since it is not usually associated with vir ras, the rasa conveyed in the sequence (interview with AK, 25 Feb 2016).

110 Interview with SK, 16 Feb 2016.
}

122 
which have a similar timbre. The sung morals that conclude the individual episodes similarly connect with the credit sequence by employing the same pentatonic scale as the latter, ending on a pitch close to the one that begins the credit sequence, and through some similarities of the melodic outline.

The closing- or credit sequence of Mahabharat (example 3.9) lasts about one minute fifteen seconds and can, despite some obvious differences, be understood as a structural mirror of the title sequence. It employs the same rag, similar melodic structures, mostly the same instruments (changes mostly pertain to the percussive instruments), as well as the same combination of singing voices. Apart from its shorter duration, it is also structured differently than the title sequence, lacking the latter's clear segmentation. It starts with a brief drum pattern which then turns into a steady-paced, accented accompaniment of the voices singing a stretched-out melody that descends in regular intervals from a very high initial pitch. It is sung in unison by the male and female voices. After twelve seconds, Kapoor starts singing, first alone, then alternating with brief interludes by the voices, which intonate on ' $a$ '. This is complemented again by the percussion layers playing the pattern from the beginning of the sequence and brief instrumental interludes (flute, sitar) later on. The lyrics reference the age and wisdom of the story, as well as its timeless validity ${ }^{111}$. Stylistically, the music of the credit sequence is quite close to the third part of the title sequence. The visual track of the title sequence combines different elements similarly found in the title sequence. The credits (white letters in Devanagari and Latin script) are displayed over a background of alternating stills from the respective episode, which is a reference, as well as alternation, of the images of Arjun and Krishna in the title sequence. At 1:13, Kapoor and the other singers conclude by repeatedly and alternatingly singing "Mahabharat" out loudly and stretchedout, but not as melismatic as in the title sequence. Also, this "Mahabharat"-call is part of the song, a seamless continuation, accompanied by the same instruments as before, and not as singled out like the call in the title sequence. On the visual track, the "Mahabharat" singing is combined with the Mahabharat-emblem, alternatingly shown in the scripts of nine Indian languages. Similar to the first visuals in the title sequence (minus the

111 Continuity is also given through the lyrics, which provide closure to the episode. They refer to the episode as ancient story of Bharat (India), as river of knowledge and eternal teaching. 
morphing), the letters are silhouettes cut out of a black screen, allowing for a peek on the video running 'behind' it, which again appears to be footage from the scenes on the battlefield. The sequence ends after the last "Mahabharat" call with the brief sound of a conch.

The closing sequence mirrors the title sequence through references on the aural and the visual level as well as structurally by beginning respectively ending with the "Mahabharat" call and emblem. Through these similar aesthetic elements and their lyrics, the sequences create a distinctive and cohesive frame around the single episodes. Likewise, they provide a point of intersection that connects the title and closing sequences to the single episodes. Thereby, they link the individual episodes to the wider frame of the broadcast's steady unfolding while at the same time framing the episodes as distinct units. This applies to the title and credit sequences of Ramayan as well. Those aural connections between the title sequences and the paradigmatic axis of the serial are also established through other fragments that create aesthetic coherence, such as the voices of Ravindra Jain and Kavita Krishnamurthy in the title sequence of Ramayan, which are heard throughout the serial, or the swooshing, distorted sounds of the synthesizer in the first segment of Mahabharat's title sequence, which anticipates a considerable amount of the show's background score.

\subsection{Concluding Thoughts}

Ramayan and Mahabharat fuse a range of narrative and performative traditions in transferring the stories onto the small screen and into the serial format. Sound and music are essential elements of this process of amalgamation. As easily recognizable parts of the traditions and aesthetics incorporated in the serials they provide anchors of identification, while at the same time they create a formal framework for the medial setting of the television serial. The way the serials incorporate performative and narrative traditions is insightful in terms of their cultural self-positioning. Drawing on devotional music, recitational practices, cinematic conventions, and performative traditions such as Ramlila and Raslila, they favore North Indian, hegemonic readings of the stories that emphasize their Hindu religious dimensions. Sound and music integrate and amalgamate elements of all these traditions' aesthetics while co-narrating the stories according to the 
conventions of the televisual medium. Thus, they are crucial elements of structuring the stories as serials in the new medium.

The title sequences of Ramayan and Mahabharat quintessentially represent the amalgamation of, and negotiation between, the formats used in the serials. They do so not only on a musical level, but through the interplay of visual and aural elements. As vital formal elements of TV-serials, they are central for transporting the epic narrations into the new format. They do so by establishing an audio-visual frame that: 1) sets the respective serial apart from the flow of televisual programming and alerts the audience; 2) introduces the content and the setting of the respective serial, 3) contributes to the selfpositioning of the serial and suggests ways in which the respective serial should be perceived and understood and 4) represents the momentum of seriality by nature of its continuous reiteration and connections to the audio-visual serial text.

The understandings of the serials suggested through the constitution of the title sequences and the entire soundtrack of the serials emphasize their strong claims to moral and Hindu religious authority. Because this dimension is essentially (co-)created by the sounds of the fictional worlds of Ramayan and Mahabharat, I will approach this cluster of sound, religion, normativity, and morality in the following chapter. 


\section{Sonic Dimensions of Normativity, Moral, and Religion}

In episode 6 of Ramayan, Ram and Sita meet for the very first time at her father's palace. Vishwamitra has taken Ram and his brother Lakshman to Mithila so that Ram can participate Sita's swayamvar, the ceremony in which princes and kings compete for Sita's hand by trying to lift Shiva's bow. Sita's mother sends Sita and her entourage to the temple in order to perform a puja, a ritual of worship, for the goddess Gauri and to pray for a successful swayamvar (example 4.1). Softly, plucked string instruments, first a santur, later a sitar, are heard, playing a winding successions of notes in mid-to high-pitched frequencies. The music, evolving unmetered over a few pitches in a meandering way so that a melodic structure is undeterminable, is heard for one minute before it fades out. The passage moves swiftly but is not rushed, with the light timbre that is characteristic of the instruments playing. Sita is shown amongst an entourage of sisters, aunts and her mother. The women, all clad in shiny, glamorous garments and sparkling jewels, are positioned in a row with Sita in their middle, plates with offerings for the puja in front of them. Bright, warm colors in different shades of red dominate the scenery. The meandering music with its soft volume and light timbre, submerges the setting in a warm and peaceful atmosphere. The queen explains the benefits of the specific puja, which promises the benefits of a happy marriage, in a soft, calm voice, accompanied by the music and the irregular clinking sounds of the jewelry with every movement of the women's bodies. Sita smiles and lowers her head humbly.

Later, Sita and her entourage are accompanied into the garden, shown in a receding shot on their way to the temple. The music picks up simultaneously with the shot (example 4.2). Stylistically, it is similar to the music from the previous scene with the women. First, a sitar is heard, soon followed by a tabla which sets a moderate pace at a soft volume, as well as a tanpura and a vibraphone playing at very low volume. Even though the tabla is playing in a very restrained way, it provides a cohesive frame to the music. The sitar plays a brief pattern that is looped and repeated and used as underlying melodic material of the sequence. After a few seconds, a set of high-pitched female voices comes in, duplicating the sitar's circulating melody, repeating the same brief pattern again and again over the course of almost one minute, albeit with continuous and not repetitive lyrics. The employment of only a small range of pitches that are close to each other, the circular repetition of the pattern, and the intonation of the singers at a relatively low register compared to the 'typically' high filmi register create a strong resemblance with chanting. The lyrics, however, are not (only) a prayer but mainly describe the women's procession to the temple. A bansuri plays a high- 
pitched melody along to the singing and the sitar. Its great leaps between pitches and the swift, irregular rhythm contrast with the circulatory character of the pattern played by the sitar and sung by the intradiegetic voices. The women walk through the garden carrying prasad plates. Even though none of them is visibly moving their lips, the singing appears to be emanating from the group. The music continues until the women have positioned themselves in front of the statue of Gauri in the temple. The camera zooms in on the adorned statue. At that point the music is replaced by the sound of repeated, fast-paced and ascending passages of a swarmandal that sound like sweeps across the instrument's strings, which is complemented by equally swirling ascending and descending vibraphone scales. This flickering, swirly sound coincides with a lengthy zoom and close-up on the murti112 of the goddess, and thus with the instance of darshan - a blessing, visual interaction with a deity, granted to the women and the audience. This particular musical sound at this point of the serial has already become associated with divine encounters and blissful situations. This sweeping-pattern sounds like an unstructured swooshing, a tinkling wash of sound that owes its intensity - despite its timbral and textural softness - to the continuous stream of rapidly ascending and descending pitches of the swarmandal and the vibraphone. However, the pattern is not entirely unstructured, but is built around tightly paced repetitions of a pentatonic scale that are grouped and amplified with reverberation in a way that creates the impression of a sparkling, hazy wave of sound that submerges the listener.

The swarmandal passage bleeds over into a new set of intradiegetic music, which is another regularly used musical staple of the serial. A sitar, manjiras and tabla play another short, repeating pattern in a heptatonic scale with a mid-range tempo and a light and springing dynamic and timbre, stylistically very close to the other musical passages heard before. A high-pitched intradiegetic female voice is layered over the music, chanting a brief prayer to the goddess on three alternating pitches. The combination of these components - the intradiegetic music and the prayer - causes a clash because neither the melodic movements of the two elements, nor their respective rhythms or employed scales, match. Apparently, the

\footnotetext{
112 As Christopher Fuller puts it, "the term murti is widely employed to denote a deity's form [...] as well as a deity's image" (Fuller 2004: 61), in this case the statue in the temple. The relation between murti and deity is, however, more complex, since this image in not only a mere representation of the deity, but is inhabited by it, is "a "bodily" form of the deity, made concrete and visible in mundane time and space" (ibid.). It is with this visible manifestation of the deity that the benedictory visual interaction of darshan is shared.
} 
music and the chanting are emanating from the characters: Sita is kneeling and offering flower petals to the goddess, while her sisters and entourage assemble around her in a semicircle, some of them playing drums. In congruence with the musical mismatch, Sita does not move her lips, nor do the percussion instruments played by her consorts match those heard on the soundtrack. The music is replaced by the sweeping pattern of swarmandal and vibraphone, which is combined with a close-up shot of the murti, panning upwards from her feet to her face, thus enabling another moment of darshan.

The remainder of the episode (example 4.3) is similarly filled with music. Ram and Lakshman go to the garden to pick flowers, which is described by two intradiegetic singers, and later accompanied by intradiegetic instrumental music. Sita's consort spots Ram and Lakshman in the garden. The intradiegetic music merges into a passage of singing, accompanied by santur and bansuri, as Sita's friend tells her about the princes. Sita's entourage persuades the reluctant princess to go to the garden to take a peek at the beautiful princes. They are accompanied by intradiegetic instrumental music, which changes into a passage of intradiegetic sung commentary on what turns out to be Sita's and Ram's first encounter. For a few minutes, the visual track consists mostly of alternating shots of Sita, shyly standing behind a bush, and Ram, picking flowers, gazing at each other, love stricken. A male and a female intradiegetic voice sing about their mutual enchantment, accompanied by sitar and percussion. When Sita's friends notice how lost she is in her admiration of Ram, they pull her away. The music changes again into another passage of sung commentary on how overwhelmed the two are by this encounter, the singers' descriptions mirrored on the visual track. Sita runs back to the temple, praying to Gauri through another song, which is framed by the swarmandal-sweeps, which is followed by a sung blessing by the goddess in the (slightly varied) melody of the show's title sequence. This is sung by a very high-pitched female intradiegetic voice and accompanied, among other instruments, by manjiras and temple bells. The goddess grants Sita her deepest wish and promises that Ram will be her future husband. The episode is almost entirely musicalized, with sung commentaries or instrumental music in almost every scene, shifting and changing irregularly. Despite these numerous shifts, the many musical passages are similar in that they employ mostly the same instruments (producing coherent textures and timbres), similar scales and melodic structures, a steady pace framed by softly played percussion instruments, and the same voices. 
What happens in this part of Ramayan's episode 6? It has at its center the first encounter between the predestined, divine couple Ram and Sita and focuses on Sita's perspective. It presents receiving an ideal spouse as divine blessing bestowed on Sita by the goddess Gauri as a reward for her exemplary devotion. Sita's portrayal as ideal woman (analyzed thoroughly by Mankekar 1999) here is expressed in her piety and devoutness towards her destiny as future bride. In this, the segment captures how the three intersecting ideological mainstays of the serials - Hindu religion, morality and $\operatorname{dharm}^{113}$, as well as normativity - are constructed in the serials, and how music and sound are essential to this. These three elements form a closely entwined nexus; Ramayan and Mahabharat relate moral messages regarding a wide range of manifestations of human (and divine) coexistence. As "dharmic serials"114, explicitly and implicitly judging over right or wrong in terms of their characters' actions is a central feature. Their moral propositions are always normative and these norms are in turn articulated in terms of morals, for instance with regard to gendered social roles (such as: morally appropriate behavior for a woman), or they pertained to Hindu religious practice, forms of worship and to piety (for instance, a pious life is represented as morally good and therefore as a desired norm). Religion, in turn, served as legitimizing source and backdrop for the moral messages of the shows, in which, in turn, pious conduct was framed as a matter of moral duty. This way, the nexus of normativity, religion and morality almost inseparably pervades and shapes every aspect of the serials, from the construction of characters over the course of the plots, to aesthetic elements of the narrations.

Sound and music are essential to this tripartite nexus. Hindu religious practice, for instance, is represented in the serials as thoroughly ensounded. Whether it is recitation, prayer, worship or darshan, not to mention those forms of religious practice that are music, without exception, every act of worship in Ramayan and Mahabharat is constituted by a rich soundtrack. Likewise, the establishment of the serials' moral frameworks heavily relied on sound and music. While, for instance, evaluations of characters and situations

\footnotetext{
${ }_{113}$ Dharm, a derivative from the Sanskrit dharma, here is probably best understood as moral conduct. The term is notorious for its complexity and cannot be translated by one single English word. In the Sanskrit epics, its complexity is played out in its entirety, shifting the nuances of meanings repeatedly and intricately (see Brockington 2004; Fitzgerald 2004; Hudson 2013).

114 They were mainly designated with this label by the Hindi press (Rajagopal 2001: 92).
} 
are made on the visual track and are often explicitly verbalized, aural aspects such as the sound and intonation of a character's voice and the intradiegetic music, effectively and atmospherically position the situation within the serials' moral spectrum. In the part of episode 6 described above, norms are related in terms of social expectations regarding high-caste, high-status Hindu women and their religious conduct; the women speak with soft voices, while Sita does not speak at all. Even her singing when praying to the Goddess is stylized and intradiegetically detached from her body as she is not moving her lips. The almost constant music in all of the excerpt's scenes is equally soft and unobtrusive, without harsh attacks, played by instruments with light or hazy timbres and with meandering melodies that mostly lack distinct or memorable melodic contours - all of which makes the setting decidedly harmless and pleasant. Sita is introduced in the serial only as Ram's future bride and not as an independent character with goals and motivation on her own, thereby foregrounding her dharm as a wife. This highest social purpose of hers is closely connected to her idealized piety, represented by her prayers for divine assistance for her marriage. The women's religious practices are thoroughly musicalized. The sung worship in the temple, the darshan with its hypnotic showers of swarmandal and vibraphone, and finally the deity's sung blessing illustrate how (Hindu) religious practice in the serials takes place through music.

The segment of episode 6 only exemplifies a fraction of the ways in which Mahabharat and Ramayan create images of social norms, Hindu religion and dharm through sound and by mobilizing the cultural status of the stories they narrate. This dynamic of moralism, religion and normative claims has been a central point in most of the academic works on them (see Mankekar 1999, 2002; Rajagopal 2001; Ohm 2007), highlighting how vital these issues are to an understanding of the two shows. ${ }^{115}$ Given the centrality of these issues, and the centrality of sound to them, in this chapter I explore how Ramayan and Mahabharat brought the nexus of religion, morality and normativity - and specifically how this was represented and created by music and sound -to Indian TV-screens for the first time.

\footnotetext{
115 Even though the serials capitalized on the moral authority of the stories they narrated, Ramayan and Mahabharat were not unanimously perceived as morally or religiously authoritative by their audience. During my stays in Mumbai and Delhi, a number of my interlocutors pointed out that they had perceived the serials as entertainment and not as a moral guideline or as religious in any way. Others were aware of the serials' religious and moral frame but did not feel affected by the norms expressed in the shows. While these opinions give an impression of the variety of perspectives on the serials, they are obviously not representative of how the mass audiences perceived the two serials.
} 
Precisely because of their (atmospheric) materiality, sound and music are powerful means of creating religious sensations and relating moral evaluations and normative ideas. Their capacity to grasp the audience on a visceral and deeply emotional level is again crucial here. Aural markers of religious practice, such as the chiming of temple bells, provide aural anchors for sensorially and emotionally charged memories of the audience's own experiences. Sounds are essential in molding scenes of divine encounters - moments of devotion to and interaction with the divine - as for instance illustrated by the swarmandal-pattern described above. They build on and afford modes of religious experience that devout Hindu viewers are familiar with from their everyday lives. This way, they not only connect to their audience's "emotional ecologies", to quote Abels (2015: 62), but create audiovisual spaces for religious experience. This also pertains to the way that sound atmospherically communicates norms and values. The characters' decisions and acts, the ways in which they relate to gendered social dynamics and expectations, are not only judged and categorized, but also created by music and sound, through the effectiveness of cinematic musical conventions. Exploring the sonic creation of this node of morals and norms is all the more pressing when considering that the dynamics between the characters in terms of gendered moral norms are a major motivating force behind the stories of both serials. Inquiring into the aural construction of the nexus around (gendered) norms, morality and religion can therefore also be understood as a different take on the narrativity of sound and music in Mahabharat and Ramayan.

I will approach this complex by splitting it into three sub-chapters. In the first sub-chapter, I analyze the representation of Hindu religious practice through (the interaction of images and) sound in both serials. In the second sub-chapter, I shed light on the issue of morality and explore how the nuances of good and bad - of dharm and its transgressions - are negotiated through sound in Ramayan and Mahabharat. In the third and final part of the chapter, I explore the question of normativity by focusing on how gender is articulated aurally in the serials and how this contributes to the serials' claims to authority. 


\subsection{Yajna, Bhakti, Puja: Religious Practice as Music, Religious Practice and Music}

Hindu religion is a central element of both Ramayan and Mahabharat. Beyond the stories' obvious centrality to Hinduism (and vice versa), the serials are pervaded by omnipresent metaphysical Hindu concepts, divine characters and religious practice, and rituals and devotional acts. While sound has been neglected in previous analyses of Hindu religion in Mahabharat and Ramayan, it is in fact a vital element of creating and mediating religious acts and experiences. Moreover, in both serials, religious practice often is music, for instance in chants and devotional songs. Analyzing religious sounds in the serials thus allows to capture a major strategy the serials use to evoke their audience's cultural knowledge of Hindu religious practice and which at the same time affords emotional and visceral engagement. In turn, analyzing sound in Ramayan and Mahabharat as religious will allow me to come to terms with how Hindu religion is represented in the serials, and how normative views of religion are constructed through sound.

The relevance of Hindu religion to or in the serials has significantly shaped the way Ramayan and Mahabharat were perceived by the audience and analyzed in academic discourse. In those academic publications on Mahabharat and Ramayan that address religion, the concepts that are usually discussed are those of bhakti and darshan. Bhakti, a mode of religious understanding and experience that roots in the idea of a personal relation with a given deity, is characterized by total devotion and love toward the deity (see Mankekar 1999: 165-204; 2002; Rajagopal 2001: 109-113; Cusack 2012). Often in these texts, the serials' abundant opportunities for darshan - the blessing visual interaction between deity and devotee - are considered the prime vehicles for enabling bhakti, or a (Hindu) religious reception of the serials more generally. Ramayan's and Mahabharat's ability to enable darshan is presented as one of the primary reasons for their religious appeal and massive pop-cultural and political impact during and beyond their initial broadcast. Referring to this potency, Rajagopal describes Ramayan as a "congregational experience" (2001: 93), which he considers "the central selling point of Sagar's production" (ibid.: 116) ${ }^{116}$. According to the authors analyzing the serials' religiosity, the religious potential of Ramayan and Mahabharat is thus primarily, or even exclusively, mediated visually. Even though the devotional songs of the serials are

${ }^{116}$ Lutgendorf (1990) and Mankekar (1999) similarly emphasize the relevance of darshan for Ramayan's reception. 
occasionally mentioned in passing (for example by Mankekar 1999 and Rajagopal 2001), darshan as visual interaction is presented as the prime mode of evoking and expressing bhakti in the serials. While I do not deny the importance of darshan for mediating religious practices and feelings in Ramayan and Mahabharat, I consider this exclusively visual focus too one-sided. While bhakti prominently describes a feeling of "loving participation" (Wilke 2006: 17), a "mode of engagement and [...] a structure of feeling" (Mankekar 1999: $200)^{117}$, the phenomenon becomes tangible in the serials only through music and visuals, through camera positions and mise-en-scènes, and through song and singing. Bhakti and darshan are intangible modes of religious engagement, but I argue that their emotional dimension is an indication that they are not purely mediated through images, but that, instead, sound and music are an essential to affording their specific religious feelings. Sonic evocations of religious interaction and musical devotion can thus be understood as the aural, but in no way less important, equivalents to visual moments of devotion such as darshan.

In Ramayan and Mahabharat, Hindu religion is present foremost in the form of practices and rituals which are invariably infused with music. This emphasis on practices in the serials corresponds with anthropologist Birgit Meyer's definition of the concept of 'religion' as "particular, authorized, and transmitted sets of practices and ideas aimed at 'going beyond the ordinary', 'surpassing' or 'transcending' a limit” (Meyer 2014: 215), which I subscribe to in this thesis. An emphasis on practice as constitutive moment of religion implies the centrality of sensory experience to religion (see also Wilke 2006: 18). It thus makes sense to view Hindu religion as presented in the serials as a thoroughly ensounded set of practices; it becomes tangible and apprehensible through music and sound. In this sense, focusing on religion's aural dimension not only compensates for the sensory one-sidedness of previous research on the shows, it also adds a new dimension to this exploration of sound and music's narrative and atmospheric powers.

\footnotetext{
117 I will go into bhakti and its relevance for Hindu religious practice in more detail below.
} 


\section{Anthropology, Religion, and Mass Media}

Because the audiovisual mass mediation of Hindu religious practice was arguably vital to the serials' appeal and at the same time sparked both public and academic debates, I will now take a step back and briefly consider how the phenomenon of mass mediated religion is conceptualized in anthropological research.

Over roughly the past two decades, the study of mass mediated religion has gained growing relevance in ethnographic and anthropological studies, fueled by the increasing employment of electronic mass media by religious groups all over the world (Meyer and Moors 2006: 1). As anthropologists and religious studies scholars Annelies Moors and Birgit Meyer describe, the employment of mass media for mediating religious content and practice has spread over practically all medial channels available. This medial proliferation has resulted in the creation of new formats of religious communication and interaction - thus enabling new modes of experiencing and mediating religion - and has created (new) connections between religions, commerce, and consumerism (ibid.: 2).

This intersection of religion, commerce and consumerism is central in the case of Ramayan and Mahabharat as well. This is discussed in detail in the analyses of Mankekar (1999, 2002) and Rajagopal (2001), and is also evident in the continuing long-term commercial success of Hindu mythological serials in Indian television. The relevance of this intersection also implies that the mass mediation of religion entails a political dimension - as is emphasized in Mankekar's and Rajagopal's works. On one level this relates to the direct connection of some mass media to governmental structures, as is for instance commonly the case with television. On another level, mass media exert significant influence on the "politics of representation and visibility" (Meyer and Moors 2006: 16), which endows mass-mediated religions with the power to distribute political messages on very public platforms. The scope of medial outreach indicates that massmediated religions potentially possess the power to compete with governmental structures and institutions. As Eisenlohr puts it, "the use of new media technology" by religious groups contributes to "the creation of new publics and forms of religious authority" (2011: 43).

Evidently, mass-mediated religion has the potential to fuel powerful social dynamics, to mobilize people on a large scale and to lastingly influence discourses. In order for these dynamics to gain momentum, mediated religion is in part dependent on a highly 
individual dimension. Since religious sensations are a profoundly personal (visceral, emotional) experience, the representation of religion in a mass medium needs to afford such an individual engagement. The abundant instances and displays of bhakti and darshan in Ramayan and Mahabharat can accordingly be understood in this sense, since they afford and represent individual interactions between devotee and deity, thus also reinforcing the centrality of these two modes to Hindu religious practice. According to Meyer, "religion becomes concrete and palpable" through the study of religious practices - "concrete acts that involve people, their bodies, things, pictures, texts, and other media" (2014: 206).

\section{Sound and Music in Ritual: Yajna, Puja and Vedic Chant}

Sound and music are of utmost importance for Hindu religious practice and thought. Religious scholar Annette Wilke even asserts that in the cultural context of Hindu India, "the significance of religious music cannot be overestimated" (2006: 57). In ritual, sound not only structures actions, but fulfills crucial functions by providing "that necessary bond between myth (word) and action (ritual)" (Beck 2012: 17). Musicologist Selina Thielemann confirms that in "Hindu tradition, no ritual can be performed without the presence of sound in one form or another, and the spectrum of sound constructions ranges from the melodious recitation of sacred formulae (mantra) to the rendition of devotional songs" (2002: 2). This relevance of sound in Hindu religious practice has grown out of the vital role that has been attributed to it since the Vedic period. Sound is at the metaphysical heart of the Vedic understanding of the world. As "Sabda-Brahman", "the Supreme Absolute", it is considered to have "generated the universe" (Beck 2012: 25).

Wilke challenges the textual primacy of attributing sound's central role in Hindu practice to an alleged textual authorization in Vedic scriptures. Instead, she argues that sound's materiality - its ability to engage and make people resonate - is the source of its meaningfulness and importance in Hindu practice ${ }^{118}$. Its atmospheric powers, its

118 Understanding sound's materiality as constitutive for its significance in Hindu religious practice is also advocated by Beck (2012). 
potential emotional impact, enable specific - religious - structures of experience and feeling. As Wilke points out, in this sense "sound serves both to stimulate religious feelings and to give them a sensory form and embody them" (2006: 16). Sound as constitutive element of "Hindu sonic liturgy" affords a "participatory experience [...] in relationship with God or the numinous" (Beck 2012: 19).

Wilke also emphasizes this participatory component of sound and points out how, by virtue of its atmospheric materiality, sound takes hold of listeners, pervades them, makes them resonate, and thereby engages them emotionally and bodily ${ }^{119}$. As an atmospheric, immersive force that pervades listeners, sound connects on different levels: it creates community by connecting listeners and those producing sound, and it merges "things, humans and gods, the physical and the spiritual", thus serving as a "sensuous assessment of non-duality" (Wilke 2006: 34, see also Thielemann 2002: 3). Considering sound's capacity to connect devotees with the divine, the importance of sonic aesthetics beyond musical sound, including the sound of words (see Wilke 2006: 16), becomes apparent. Especially within bhakti traditions, sound and music are not only part of ritual, but can be understood as ritual themselves (Beck 2012: 21). Against this backdrop, it is evident how sound is a particularly powerful (and indispensable!) means of representing religious practice and interactions between humans and deities in the new medial setting of Mahabharat and Ramayan. Perpetuating the stories' Hindu religious dimension through sound is a powerful means of engaging the audience, of providing anchors for identification of (and potentially with) religious ideas, actions and places, and of stirring religious feelings through sonic emotional shortcuts. The specificities of religious ideas constructed in Ramayan and Mahabharat are thus also related through sound atmospherically and through immersion.

Both serials represent different modes of interacting with the divine and of Hindu/Vedic ritual. Beyond most of the interactions with Ram and Krishna, who are represented in their human forms in the serials, there are representations of worship ceremonies such as puja and arti, as well as life cycle rituals such as wedding ceremonies and yajnas - (fire) rituals of sacrifice - all of which are ensounded. This blend of practices from historically

\footnotetext{
${ }^{119}$ Such visceral, and as he frames it, even affective reactions to religious sound are analyzed in detail by Charles Hirschkind in his monograph The Ethical Soundscape: Cassette Sermons and Islamic Counterpublics (2006), which deals with (listening to) Islamic cassette sermons in Egypt. Hirschkind here describes how culturally learned modes of listening are deeply bodily, and join visceral and emotional reactions to sounds and words.
} 
different eras integrates the requirement to create a sense of the antiquity of the stories and at the same time provide anchors for modern audiences. In this, Ramayan and Mahabharat created an epochal synthesis that corresponded to the imagined ancient setting of the stories while at the same time evoking the audience's own (Hindu) religious experiences and their knowledge of Hindu religious practice.

A vital part of these televisual imaginations of the Vedic period was representations of yajnas, the central form of ritual of the Vedic age. They occur occasionally in the serials a lot more frequently in Ramayan than in Mahabharat - and sometimes even motivate the progression of the plot ${ }^{120}$. Without exception, these rituals are ensounded with mantras chanted on three alternating pitches, even though historically, as Beck explains, chanting was not the only aural or musical component of Vedic rituals (2012: 54). Not only does this employment of sound offer instant orientation and an atmospheric incentive to the audience, it also does justice to sound's relevance in Vedic rituals. Beck describes them as a "sonic liturgy" (ibid.: 40) in which music, beyond its symbolic potency, was regarded as "a kind of autonomous power substance" (ibid.: 55), vital for the successful outcome of a ritual.

In Ramayan, most of the yajnas are represented at least partially in a stylized aural aesthetic: usually the characters chant (sometimes cacophonously so) over a different, clearly audible background of pre-recorded chanting. The aesthetic of these underlying recordings with their sleek, hypnotic sound of the pre-recorded voices, endows the ritual scenes with an otherworldly, mystical atmosphere. In these pre-recorded chants, two or more male voices accurately and simultaneously intonate the notes, evenly revolving around three closely approximated pitches. The voices remain at the same dynamic level, have a nasal timbre and are heavily enhanced with reverberation, which creates a hypnotically monotonous sound that clearly sets the chanting apart from the intradiegetic music and diegetic voices. In Ramayan's fourth episode (example 4.4), sage Vishwamitra and other sages are shown performing a yajna in their ashram at nighttime, seated around a large ritual fire. One man loudly recites mantras in Sanskrit, to which the other men

120 Such as the rajasuya yajna that Yudhishthir performs after the Pandavas have installed their reign in Indraprasth in Mahabharat, or the sacrifices that are disturbed by the demons at the beginning of Ramayan. 
respond, pouring oblations into the fire and raising their hands. This recitation is only one of the two layers of sound heard in the scene; the diegetic voices are husky and just vaguely brush distinct pitches while the verses seem to be more shouted than recited. The second layer of sound is the hypnotic, reverberating chant from the recording mentioned above. While the first layer of chanting clearly emanates from within the diegesis, matching the sound quality of the diegesis and the characters' (lip-)movements, the entirely different aesthetic and texture of the pre-recorded chanting positions this recording in the intradiegetic narrative space. Resulting not only from their aesthetic differences, but also from the fact that different mantras are chanted in them, the two layers of chanting create a stark sonic clash, a jumbled sound carpet of mantras.

In some of the Vedic rituals shown in Ramayan, the pre-recorded chanting is enhanced by the drone of a tanpura and slowly ascending vibraphone scales, both matching the pitch and pace of the chanting. This contributes to the ethereal, wafting character of the recorded chanting, an impression that is increased by the fact that the sounds are never connected to any of the characters visible on screen. The recording is usually heard when none of the characters are moving their lips, and if they do move their lips, these movements match other sonic layers heard at the same time. The recorded chanting not only effectively establishes the context of the Vedic ritual, but also conveys a somewhat mysterious, sublime atmosphere. However, there are also representations of yajna rituals in Ramayan with only one layer of diegetic chanting (example 4.5). For instance, in episode 19, five rishis conduct a yajna in front of Ram's, Sita's and Lakshman's newly built hut in Chitrakut. Here, only a single layer of chanting is heard. The intonation of the chanting men, which is rather husk and rasping in contrast with the nasal, smooth, reverberating voices of the pre-recorded chanting in the previous example, matches the other sounds and voices of the setting.

Similar to this less stylized example, the yajnas represented in Mahabharat have a rawer aural aesthetic, but are no less identifiable as Vedic rituals. The chants are diegetic, coming from one, sometimes two male voice(s). Some of the yajnas are combined with intradiegetic music that does not match the style or 'melody' of the chanting, which curiously heightens the sense that the chanting is diegetic. An example of this effect is the rajasuya yajna that consecrates Yudhishtir as king of Indraprasth in Mahabharat's episode 43 (example 4.6). The Pandavas, a group of sage and other attendees are seated around a yajna fire. The first sounds that are heard are an 'Om'-chant followed by a few 138 
words in Sanskrit by a sage who then, speaking not chanting, instructs Yudhishtir to light the fire. Simultaneously, the sound of a sitar, tanpura and a pakhawaj playing one of the soft, slow-paced, meandering melodies so common in the show's intradiegetic instrumental music, is heard. Not at all adapted to match the sound of the chanting, this music continuously accompanies the entire scene. The diegetic chanting mainly remains on one pitch, which is accentuated rhythmically through the recited words, with occasional variations to a higher or a lower pitch. The sage's voice sounds raspy and untrained, slightly slurring off the pitches with a brittle timbre. This realistic representation of Vedic chant in a sense naturalizes it as an important part of the world that is narrated in the serials.

In Ramayan and Mahabharat, representations of Vedic yajnas are incorporated mostly as a means of locating the televisual narrations in the imagined historical period in which they are set. These representations of Vedic rituals reveal the vital importance of sound in the serials: there is not a single instance in which yajna is represented without the sound of mantra chanting. The chanting is a necessary indicator that enables the audience to instantly recognize the setting for what it is - a Vedic fire sacrifice. While it is represented in aesthetically different ways in the serials, ranging from otherworldly and ethereal to husky shouting, it powerfully affords a sense of age-old modes of interacting with the divine.

The other major group of rituals represented in Mahabharat and Ramayan are pujas and artis, modern Hindu rituals of worship, which Beck describes as "quintessential Hindu ritual[s]" (2012: 65). Different from the idea of antiquity afforded by the Vedic rituals of the serials, the artis (which are defined varyingly as either closing ceremonies of a puja, see Beck 2012: 66, or as the hymns that are sung to conclude a puja, see Manuel 1993: 108) and pujas in the serials are profoundly modern. Thus, they directly connect to the audience's own experiences, evoking everyday cultural knowledge and potentially embodied religious sensations. Moreover, these modern forms of ritual and worship represent an entirely different mode of religious practice, of interaction with the divine, than the Vedic yajna. Puja, as bhakti ritual (see below) is about "showing reverence to a god, a spirit or another aspect of the divine through invocations, prayers, offerings, songs, and rituals" (Beck 2012: 65). For this, it is vital to establish "a personal connection" (ibid.) 
between the devotee and the god. On a visual level, this contact is established through the image of the deity (murti) installed in the temple, which is the medium for darshan. On an aural and embodied level, sound and music are just as vital for establishing this ritual contact. Accordingly, in the serials, puja and arti are always also represented through sound, corresponding to the different steps of a ritual and the respective modes of sonic interaction with the divine. Chanting of Sanskrit mantras is therefore integrated into the serials' representations of pujas as are devotional songs or sung prayers.

In Ramayan, fragments of pujas are sometimes embedded into longer song sequences, or serve as the dramaturgical background of a song, as for example in episode 3 (example 4.7), where a song sequence of six minutes revolves around a puja for Shiva. The sequence integrates devotional singing, chanting of mantras and ringing of bells with visuals of a priest offering prasad to a Shiva lingam around which the congregation is seated, including Ram, who plays the veena, and his brothers. They all sing the song together ${ }^{121}$. The song combines the aesthetics of filmi Hindu devotional songs and congregational worship in a temple, with its polished sound, prominently tinkling manjiras, and elements of responsorial singing. A chanted Shiva-mantra aligns with the lyrics worshipping Shiva.

Similarly, in Ramayan's episode 53, devotional singing, chanting and the display of puja are integrated in a single sequence. In that episode, Ram and the army of monkeys have reached the ocean shore. In order to reach Lanka, the army builds a bridge across the water. In a sequence of six and a half minutes (example 4.8), the process of building and its finalization are narrated through a sequence of two sung passages of roughly one minute each, followed by a 20-second-display of puja to the sound of a chanted Vedic mantra. This is followed by a song of roughly three and a half minutes, which, in turn, is concluded with another chanted mantra. Visually, this is combined with the depiction of a Shiva puja. While the entire passage is sung by the same set of voices - Jain and a group of male responsorial voices - the instruments employed change occasionally and along with other structural parameters so that the musical sections are clearly distinct from each other. The first part is fast-paced, its sound dominated by a deep-pitched and dense layer of percussion which is heard throughout. At the very beginning of the section a layer of synthesizer sound introduces an equally fast-paced melodic pattern which is adopted

121 The song is also interspersed with displays of Shiva and Parvati sitting on mount Kailash, benignly observing the worship, which ultimately motivates Shiva to dance to the music played for him. The dancing Shiva is then projected onto the Shiva lingam in the temple. 
in a slightly modified way by Jain, who then comes in. From that point onward, the synthesizer layer is overlaid by the singing voices and the percussion. The sequence's high-pitched melody, sung at the top of the singers' voices and amplified by reverberation, creates an almost distorted sound. The lyrics describe the demanding process of building the bridge and the commitment and dedication of the soldiers in completing this task. The dense rhythmic frame created by the percussion, the accentuated melody and the swift pace make the passage highly dynamic. The corresponding images show the process of bridge-building by Sugriv's army in a montage sequence. This section is concluded by a descending synthesizer scale, which interrupts the music and transitions into the second section. This section is much slower than the first and has a distinct air of devotion: a sedate pace, structured prominently by the regular strikes of a manjira with its highpitched, piercing sound as well as a soft, barely audible percussion layer. A drone, a vibraphone and muted guitar strumming provide harmonies to the (reverberating) singing of Jain and the responsorial singers, which employs a different scale than in the first passage. Jain's voice starts softly at a lower register, then swells up in a highly ornamental passage, after which it descends again. The repeated chanting of the name Ram in this sequence strongly evokes the devotional song format of the nam-kirtan (see below). As in the previous section, the music is accompanied by a montage of images corresponding to the lyrics of the music, showing Hanuman writing Ram's name on the stones, bowing in reverence in front of them, after which he throws them into the water, where they float. This section is then interrupted by a cut in the visuals and a simultaneous abrupt change of the music: a close-up of an adorned Shiva lingam on which prasad is poured against the backdrop of a beach is shown. A long shot reveals that it is Ram who is pouring the prasad. He is surrounded by Lakshman and a number of sages, with whom he conducts the worship at the beach. The sound to these images is that of two male voices chanting the Vedic Mahamrityunjaya mantra (an invocation of Shiva). As in the yajna sequences, the voices sound polished, enhanced with reverb. Their chanting is evenly balanced among the three pitches employed, and is complemented by high-pitched, reverberating, hollow-sounding vibraphone tones which slowly play the pitches of the chant, stretched over two octaves. After roughly 20 seconds, the song begins. The scale employed here also includes the pitches of the previous chanting. Manjira, drums and 
vibraphone are complemented by sitar, a high-pitched flute and a swarmandal. The sound of the singing remains unchanged; a reverberating, at times booming Jain sings mostly alone and is supported by responsorial singers for parts of the mukhra. The music revolves at the sedate, regular pace so typical for devotional songs. The lyrics eulogize Ram's divine power that enables the utopian endeavor of building a bridge across the sea to Lanka, which is shown on the corresponding visual track and alternated with close-ups and long shots of Ram and the sages performing the ritual. The end of the song, which closes with images of the ritual, is immediately followed by another mantra. It is chanted by the same intradiegetic voices and employs the same pitches, but different instruments and includes the sound-effect of crashing waves.

Not only is this segment a good example of how the combination of different musical passages creates an emotional mosaic in the serials, highlighting the distinct parts and emotional implications of the events compressed in montage sequences. It also illustrates how the representation of Hindu ritual in the serials is saturated with music. The overall segment combines devotional singing as Hindu religious practice with the chanting of Sanskrit mantras, thus fusing the aesthetics of film aesthetic with those of congregational singing and Vedic ritual. This representation of puja ritual, entwined with devotional singing, not only emphasizes the relevance of sound in Hindu devotional practice, but also frames the devotional singing with a ritual backdrop. In addition, it normalizes the aesthetics of the musical worship through blending north Indian devotional styles with a stylized film musical aesthetic.

Puja rituals comprise several steps but only individual steps are represented in the serials. In Mahabharat, there are only a few representations of puja rituals. As in Ramayan, they are invariably ensounded. At times, it seems like the narrative setting and visual background of certain scenes are solely constructed to legitimize the insertion of devotional music and the sounds of ritual into the story. In Mahabharat's 28 $8^{\text {th }}$ episode, for instance, princess Rukmini conducts a ritual worshiping the goddess Parvati to pray for the success of her imminent abduction by Krishna (example 4.9). The scene of and around the ritual is a song sequence. Visuals of fragments of a puja are the backdrop against which an entire devotional song and an ensuing blessing sung by the deity are set. The song starts with an instrumental interlude and a panning long shot of Rukmini and two maids walking into a temple and to the shrine of a golden murti of Parvati holding Ganesha on her lap. Swarmandal, manjira, synthesizer, percussion, shenai and sitar introduce the 142 
melody that is then sung by a high-pitched intradiegetic female voice in the mukhra. The steady pace of the manjira as a staple of Hindu devotional music, and the lyrics, mostly a prayer to Parvati, but also addressing other gods, clearly position the song as a devotional interaction between deity and devotee. The rich instrumentation, the structure and the song's aesthetic, again reference film music. On the visual track, Rukmini is shown interacting with the murti, anointing it, offering prasad, waving lamps and taking darshan with her hands folded in reverence. As with Sita in the segment described at the beginning of this chapter, the song is sung from Rukmini's perspective but framed as an internal prayer as she does not move her lips. The song does not contribute to representing a puja ritual, but nevertheless effectively evokes a setting of devotion and interaction with the deity. By going into a different - albeit likewise devotional - direction than is suggested by the visual track, the song sequence expands the scene's expressive potential by the dimension of individual devotional connection between Rukmini and Parvati beyond the ritual context. This provides the audience with the possibility of a different emotional engagement than a realistic representation of the sounds of a puja would.

Another example of a fragmented representation of a worship ritual is the very brief arti scene of Mahabharat's episode 14 that was described in chapter 3 (example 4.10). Set to the intradiegetic sounds of the famous arti song122 'Om Jai Jagdish Hare', Krishna and his family are shown seated in front of a shrine with murtis of Ram and Sita. Nanda, Krishna's foster father, performs the arti ritual. Nanda waves a tray of lamps in front of the murtis and passes the lamps to his family members, who take the blessing by holding their hands over the flames and touching their faces with their fingertips. The intradiegetic music is the only sound heard in the sequence (after it ends, a slowly ascending passage of hazysounding synthesizer notes is heard briefly until a cut introduces the next scene). It begins with a brief and slow ascend-descend pattern played by a synthesizer with a metallic, santur-like sound and hazy timbre, accompanied on every note by the piercing strum of manjiras and bells. These are also the only instruments that accompany singer Mahendra Kapoor's voice at a slow, steady pace. Kapoor sings a few verses that in total complete one

\footnotetext{
122 Structurally, as it is employed throughout the entire serial, it is not a song but just a very brief sung passage. For the sake of readability, in what follows, I will refer to 'Om Jai Jagdish Hare' also as song or arti song. In order to avoid watering down the analytical category of 'song' as it is used in this thesis, I will use the term in this broadened sense only in reference to 'Om Jai Jagdish Hare', not to other sung passages.
} 
run of the melody. His voice is booming with reverb, sturdily singing the melody on relatively low pitches with only minor embellishments. Aurally, this rendition does not differ from the many other renditions of 'Om Jai Jagdish Hare' over the course of Mahabharat. This scene, however, is the only instance in the entire serial where 'Om Jai Jagdish Hare' ensounds an actual arti ritual. The lyrics, however, are more of a comment on the correct execution of devotional practice (see chapter 3) and might be understood as a metaphorical statement on the devotional and moral mindset that devotion or worship require. In this, this use of the 'Om Jai Jagdish Hare' melody is in line with the way it is employed throughout the serial. As described in chapter 2, the song is heard often (albeit irregularly) in Mahabharat, always with different lyrics matching the given situation, and thereby is one of Mahabharat's aural constants. It is inserted at selected points in the story as a brief aural moral-of-the-story, thus marking the given moments as crucial to the overall narrative. The frequent repetitions of the melody and sounds of the arti song establish 'Om Jai Jagdish Hare' as a serial constant in the overall narrative of Mahabharat, effectively evoking the Hindu religious context through the sounds' religiously charged background. The music's intricate connection with Hindu ritual is powerful enough to perpetually evoke the (north Indian, practicing) Hindu audience's embodied memories of the context of worship even without corresponding images or lyrics. Arguably, given the prominence of the song, it communicates the context of Hindu ritual worship it evokes also to non-Hindu audience members who are familiar with it, in these cases evoking a whole other set of sensations and feelings.

Overall, there are noticeably fewer representations of religious ritual in Mahabharat than in Ramayan, even though the show does exploit those parts of the story that lend themselves to incorporating rituals or being framed as bhakti (as elaborated below) ${ }^{123}$. Unlike Ramayan, interaction between humans and deities (other than Krishna) in Mahabharat is frequently represented as the summoning of a god through meditation and asceticism. Despite the lack of a conventionalized set of sonic practices (beyond mantrachanting, which is only included in some of the scenes), these scenes of meditation and interaction are also invariably ensounded, usually through thick layers of intradiegetic synthesizer sounds. For instance, in episode 71, right before the war in Kurukshetra

\footnotetext{
${ }^{123}$ Together with the fact that Mahabharat is not as heavily imbued with a bhakti aesthetic as Ramayan, this probably is the main reason why most of my interlocutors did not perceive Mahabharat as religious - in contrast to Ramayan. 
starts, Arjun summons the goddess Durga to ask her for her blessing in the upcoming battles (example 4.11). Arjun sits alone in the dark at the campsite, meditating with closed eyes. He is reciting barely audible mantras (on a single pitch, in a non-chanting way), of which only the syllable 'Om' is discernible. Intradiegetically, brassy, clattering long-held synthesizer sounds are heard. Even though they are placed irregularly, they form a continuous, dense layer of partially clustering and clashing sound. The sounds continue to maintain the thick, layered structure but shift in quality and texture when Durga appears, becoming strongly reminiscent of the sound of bells. As this scene, like a number of very similar scenes over the course of the serial, demonstrates, sound is a medium in which the interaction between humans and the divine takes place. Even though in this scene, sound is not part of a conventionalized, ritualized set of practices, it is indispensable part of Arjun's experience of interacting with the goddess and as such also a means of mediating this experience to the audience. The clouds of sharp, otherworldly sounds enable an immersive experience that leaves no doubt as to the celestial nature of the encounter.

In Ramayan and Mahabharat, the representation of (Hindu) religious practice is inseparably connected to music and sound, which is only logical given the crucial role of sound within Hindu understandings of the universe and its corresponding importance in religious practice. Sound, in this context, is a means of not only emotionally engaging participants in worship and framing the sequence of ritual events, but also establishing a connection between devotee and the divine. In the audiovisual setting of Mahabharat and Ramayan, the sounds of (ritual) religious practice are a powerful atmospheric, narrative means. Music furthermore immediately makes a scene as religious or endows it with an atmosphere of (regional) Hindu religiosity, be it through musical fragments such as 'Om Jai Jagdish Hare', through mantra chanting, or through the sound of manjiras. It affords religious feelings (at least for some of the audience) and narratively mobilizes cultural knowledge, therefore allowing for orientation, for instance regarding which kind of ritual is integrated in a given scene. This, in turn, offers another layer of context for interpreting a given scene. At the same time, the mostly stylized audiovisual aesthetics of the rituals in the serials significantly shape the overall representation of Hindu religious practice. Furthermore, these representations, including the ways in which they are ensounded, 
favor specific aesthetics and aural formats over others and embed them in widely known audiovisual narratives with a strong moral character. In this sense, they can also be understood as normative.

\section{Musical Devotion: Bhakti in Ramayan and Mahabharat}

As especially the scene of meditation and evocation of the goddess described above illustrates, the ritual context is far from the only setting in which Hindu religious practice is (musically) represented in Ramayan and Mahabharat. Beyond ritual elements, both of the serials are pervaded by bhakti, a mode of religious interaction I have previously mentioned in passing and which literally can be translated as "loving participation" (Wilke 2006: 17). Bhakti can best be described as a distinct Hindu religious mode, which, to simplify the complexity of this historical shift, originated as an anti-elitist reform movement around the $6^{\text {th }}$ century A.D. and subsequently spread throughout most of the South Asian Hindu congregations (see Manuel 1993: 107; Beck 2012: 107-110). As a vernacularizing countermovement that "gained wide adherence as a reaction against the perceived sterility and elitism of Brahminism" (Manuel 1993: 107), bhakti revolutionized the relation between deities and devotees, conceiving of it as personal and intimate, the believer surrendering to the deity in loving devotion (see Manuel 1993: 107; Thielemann 2002: 17-18; Beck 2012: 107). Against this backdrop, bhakti can also be understood as the above-mentioned “structure of feeling” (Mankekar 1999: 200).

This idea of the individual and emotional connection between devotee and deity also heavily shaped the forms of religious interaction arising from the movement. Music remained a vital component of ritual worship, or even gained in importance (see Beck 2012: 106; 131-32; Thielemann 2002: 20-21). Its functions shifted from summoning and communicating with the gods, as it was the case in Vedic ritual (Beck 2012), to praising them, expressing love and devotion, and thereby pleasing them. It is the emotional, atmospheric, even bodily intensity of music that makes it such a vital element of bhaktiwithin and beyond the ritual context of puja and arti (see also Wilke 2006). Accordingly, singing devotional songs, or even listening to them, is a "form of worship" in its own right, "a means of attaining direct communication and even mystical union with God" (Manuel 1993: 107). Independent of, but often also embedded in ritual practices, devotional songs embody the bhakti paradigms of parting from rigid and institutionalized structures of 
worship towards building an emotional relationship with the gods. Devotional songs are highly participatory, can be sung by anyone at any time, and by virtue of their musical materiality afford a high level of emotional engagement even when only listened to, thus highlighting the devotional act as "an aesthetic event" (Wilke 2006: 22). Music, through its power to emotionally engage people and allow them to establish a connection with the divine sphere, is thus an essential mode of Hindu bhakti religious practice. The Ramayana and Mahabharata stories themselves are central bhakti narratives, parts of a bigger corpus of narrative traditions centered on the lives and exploits of the avatars, mostly of Vishnu and Shiva. In this sense, Ramayan's continuous aural and visual devotional aesthetic and Mahabharat's inclusion of Krishna's childhood and the stretched out rendering of the Bhagavad Gita, can be understood as a logical consequence of narrating the stories ${ }^{124}$, or as a rationalization for the high density of (musical) bhakti in them. Against this backdrop, it becomes apparent how, the diverse and not necessarily ritualized forms of musical worship shaped the serials' religiosity to a much higher extent than the representations of ritual. Given that musical bhakti worship is unrestrained by ritual settings and a manifestation of a highly personal, emotional relationship with a deity, the forms, its structures and aesthetics are inconceivably diverse (although usually vocal music). Accordingly, devotional music and aural elements evoking a devotional setting in the two serials also come in a variety of forms.

The variety of vocal Hindu devotional music is generally covered by the umbrella terms of kirtan and bhajan. These terms refer to all the regional and transregional musical traditions or styles of singing in which stories from the lives of the deities or the personal relation to a god, ${ }^{125}$ in a given vernacular language, are fused, ranging from folk traditions, responsorial forms in temples, classical "thumri-style bhajan[s]" (Manuel 1993: 108, original emphasis), to aesthetically polished filmi versions of devotional songs. The two umbrella terms, while "often used interchangeably in common parlance" (Beck 2012: 133), actually capture different nuances of devotional music and are employed differently,

124 This does not mean that it is not possible or 'incorrect' to understand the stories from a non-religious perspective. As previously mentioned, a number of my informants did not conceive of the serials or the stories as Hindu religious and given the age of the stories and the vastness of their distribution, there are certainly versions of them that entirely lack this affiliation.

125 Beyond devotional songs praising specific deities, there is also the genre of nirgun bhajan, in which an abstract concept of divinity is praised. Nirgun is Hindi and means "'without form"' (Henry 1991: 221). 
varying from region to region (ibid.). The regional and formal differences between bhajan and kirtan are complicated and following up on them would go beyond the scope of this thesis, especially since, judging from the impression I got when talking with my interlocutors, the generic specificities of Hindu devotional music are barely relevant for the serials' audience. What can, however, be derived from this complexity is the fact that the forms of Hindu devotional songs are so varied that they are almost amorphous. Ramayan and Mahabharat make use of this amorphousness by incorporating different forms of devotional music to the shape the narrative context of a given scene as required. From brief repeated chants of a deity's name, to heavily rhythmical stotras (in Ramayan), responsorial structures that evoke the congregational singing in the temple, or extended songs with a film music aesthetic and mukhra-antara structure, the two serials flexibly fit musical expressions of devotion into the narratives.

Despite this diversity of structures and aesthetics, there are some similarities among the songs and sung passages which allow for establishing a Hindu religious frame or a devotional atmosphere through small musical details. For instance, the melodies of devotional songs are usually not too complexly embellished. One reason for this is that it allows devotees without musical training to sing the songs. Another reason is that, as Manuel points out, in devotional songs "abstract improvisations [as they would be common in the Hindustani classical context] should be kept to a discreet minimum, so as not to distract attention from the words" (1993: 113). Likewise, the intonation of a singer's voice or the pace of singing, need to be appropriate for the solemn devotional context, making them easily recognizable aesthetic markers. Especially in combination with other musical components, such as specific metrical structures or instruments that are usually employed in devotional songs, such as the manjira or the harmonium, a Hindu devotional musical atmosphere can be evoked through a few aural cues. This way, an air of bhakti can be subtly interwoven into the narrations, thereby framing and positioning them without the need for an elaborate song- or devotional sequence. As my previous descriptions of the aural worlds created in the serials have indicated, both serials made plenty of use of this significatory and atmospheric potency. Apart from combining devotional bhajans and polished film-song aesthetics with virtuoso instrumental performances and booming voices, this also manifests in the decidedly devotional sound of the singing narrator in Ramayan or the many instances of the 'Om Jai Jagdish Hare' melody in Mahabharat. The frequent employment of such musical fragments, as well as 
the integration of well-known devotional songs into the serial narratives, are effective means of endowing scenes in the serials with an atmosphere of Hindu devotion.

In the (academic) discourses on Ramayan and Mahabharat, authors have repeatedly commented on and analyzed the serials' strong bhakti character. Mentioning the sonic dimension of Hindu devotion only in passing, these analyses have mainly focused on the visual side of Hindu religious practice, such as darshan or the iconographic representation of characters. As I have demonstrated here by drawing on Thielemann, Manuel, Beck and Wilke, this visual bias ignores a crucial facet of Hindu religious thought and practice as well as a major aesthetic and narrative element of Ramayan and Mahabharat. Sound is an essential medium and mode of Hindu religious practice which allows devotees to get in touch with the divine, to participate in religious practice, and to emotionally engage with deities. The serials capitalize on this nexus of sound and devotion: they are thoroughly pervaded by sonic representations of Vedic and Hindu ritual practice, by devotional songs, and by aural elements that evoke a devotional setting on their own, such as the tinkling sound of hand cymbals. In this sense, sound serves as an effective cue that helps the audience to read a given scene that is infused with aural evocations of Hindu religious practice. Above that, sound and music create atmospheres of bhakti that can engage the audience emotionally, absorb them, afford a religious perception of the serial narratives, and spark visceral, embodied responses to the audiovisual complex of the serial.

The aural, or rather audiovisual representation of Hindu religious practice in Ramayan and Mahabharat is normative - for one because of its mass medial constitution that in the historical moment of the serials' broadcast implied an authoritative status, but also because of the claims to authority the serials themselves explicitly expressed. These claims then extend to what is represented in the serials, and since the representation of Hindu religious practice in Ramayan and Mahabharat occurs through specifically ensounded forms of ritual interaction and particular aural aesthetics, these aesthetics are then normalized within the audiovisual setting. Thus, on one level, a particular North Indian set of aesthetics and practices is normalized - through the language of the songs' lyrics and the styles of the devotional music, which, despite the pan-regional filmi aesthetic, differ from a range of devotional musics from other regions. This was asserted by one of my interlocutors, who grew up with Maharashtrian regional traditions of Hindu 
devotional music. She told me that to her, the structural elements of the serials' devotional musics - the intonation and techniques of singing and playing instruments, melodic structures, instrumentation and the like - differ from the bhakti in the South of India. She observed that the devotional music of Ramayan and Mahabharat created an entirely different "musical/aesthetic [ ] sensibility"126 from what she was familiar with from her own religious socialization. In Ramayan, there is one instance in which Ravan, Ram's antagonist from Lanka, sings the 'Shiva tandav stotram', a devotional song in praise of Shiva and his divine dance (tandav) (example 4.12). This sequence, which is a part of the long musical sequence that introduces Ravan to the story in episode 30, is insightful with regard to the moral framework of the story and the positioning of Ravan within it. Most interestingly, this sequence constructs Ravan as in a sense respectable because of his piousness, which he expresses through a musical devotional format that is typical for southern South Asia (see Wilke 2006: 35). With the lyrical complexity of its Sanskrit verses, this music highlights Ravan's scholarly prowess and represents a different approach to the relation with a deity than is represented by the 'simple', accessible music in the rest of the serial. In conjunction with the distinct aural aesthetic of the stotram with its fierce rhythmicality, the almost percussive, recitational vocal style, and the layers of percussion, the song contrasts heavily with the aesthetics of the music of bhakti and rituals that otherwise dominate the serial. On the one hand, this aesthetic contrast between the Ravan's musical mode of devotion and that of the other characters of the serial, including the acousmetric singing narrator, broadens the range of musical aesthetics represented in the serial. On the other hand, however, this representation reinforces the aural normativity of religious practice in Ramayan. After all, this specific musical aesthetic is employed to construct Ravan, perhaps not as an inherently immoral character, but still the serial's central villain. Because of this connection, and because it is an isolated exception to the musical rule, the stotram helps to normalize the North Indian and filmi aesthetics and devotional music formats in Ramayan, and to other Ram's opponents.

126 Interview DV, 8 Apr 2015. 


\subsection{Dharm-Adharm and Subtler Nuances: Creating Morality and Normativity through Sound}

While these musical representations of religious practice in Ramayan and Mahabharat constructe normative images of musical aesthetics and religious practice, the normative dimension of the serials as related through their sounds goes further than this. Beyond religious practice, which is always already infused with ideas of moral, the normative claims of Ramayan and Mahabharat relate to other aspects of social life as constructed in the serials. Based on the entanglement of religion and morality and the authority springing from this nexus, which is in turn interwoven with the stories' cultural value and their status as dharmic narrations, Ramayan and Mahabharat audio-visually outline morally justified guidelines for the social roles of woman, man, son, brother, daughter, mother, king, husband, wife or soldier. In conversations and interviews during my stays in India, I gained the impression that while only some of my interlocutors perceived the two serials as Hindu religious, Ramayan's and Mahabharat's claims to moral authority were not only more obvious, but also more widely perceived as preeminent.

As the serials' designation as 'dharmic' suggests, the concept of dharm is of major relevance in Ramayan and Mahabharat and serves to uphold the cultural status of the underlying narrative traditions as struggles between good and evil. While the concept of dharm is notoriously difficult to define due to its inherent complexity and is even untranslatable, as some commentators deem (see Das 2010: xlii), it may nevertheless be considered "perhaps the most important and ubiquitous concept in the history of South Asian religions" (Hudson 2013: 36). As this remark suggests, religion is an inherent element of the concept of dharm $^{127}$, even though it does not entirely capture its nuances. The difficulty of capturing the meanings of the term dharm as it is constructed in the Sanskrit epics is illustrated in its inconsistent use in the Mahabharata, where it is systematically confused and reconceptualized from changing perspectives (see Hudson 2013: 38-40) ${ }^{128}$ Beyond its religious connotations, it can, depending on the context, imply a multitude of semantic nuances, which Hudson outlines as "law, justice, custom, morality,

\footnotetext{
127 The way it is employed in Hindi, it is occasionally also translated simply as 'religion'.

128 See also Fitzgerald (2004) for a discussion of how the concept is constructed in the Sanskrit Mahabharata.
} 
ethics, religion, duty, nature, or virtue" (ibid.: 36). As John Brockington illustrates, in the Sanskrit Ramayana, most "occurrences" of the term "have the sense of either 'propriety' or 'morality'” (2004: 658). Furthermore, it is also employed in the sense of religious practice or in terms of "caste or personal duty" (ibid.). While it would be an error to equate the concept's semantic complexity in the Sanskrit epics with its meanings in the Hindi TVversions of the stories, this diversity does at least indicate the multiple ways in which 'dharm' may be understood in the context of the serials. Moreover, this semantic complexity offers another perspective on how strongly normativity, morality and religion are interlaced in the concepts of dharm and adharm (the opposite of dharm). The interlinked frameworks of religion and morality imply normativity with regard to behavior and social structures, and re-connect these to a legitimizing concept of morality. On the other hand, religion and ideals of behavior and social structure are often part of moral frameworks. The representations of religious practice in the serials, of morally approved behavior corresponding with appropriate social roles and religious practice, are equally inseparably bound up with normativity. The normative ideas communicated in the serials equally pertain to social structures, gendered behavior, cultural practices and the like, delineating what is appropriate according to the sets of values reinforced in the serials. As many of the practices framed this way are musical, an aesthetic normativity is implied in these dynamics.

The moral directives of Ramayan and Mahabharat relate to global questions of right and wrong in human interaction, thereby corresponding to the epic scale of the conflicts in the stories and their ultimate gory solutions. The serials' delineations of good and evil are straightforward ${ }^{129}$, which is probably owed to the demands of the televisual mass medium and the need to cater to a heterogeneous national audience. Chopra and Sagar broke down the ambiguity and complexity of moral questions negotiated in the epic stories and related their suggestions of how to understand these moral issues over the visual as well as the aural track. Visually, for instance, the iconography of the costumes the Pandavas wear white and silver, the Kauravas are dressed in black - obviously delineates the frontiers of right and wrong (Sengupta 2017: 155). Likewise, the visual representation of the demons in the serials makes an unmistakable distinction between those that have a modicum of morality, portrayed with a normal human appearance (for instance Vibhishan, Ravan and Meghnad in Ramayan or Hidimbi in Mahabharat), and

${ }^{129}$ And simplified in comparison to their epic counterparts. 
those that are entirely monstrous (such as Hidimba in Mahabharat or Tadaka in Ramayan). Aurally, the delineation of moral categories, affording an orientation within the moral universes narrated in the serials, is similarly straightforward. Intradiegetic as well as diegetic sounds construct and evaluate characters and situations along the lines of easily identifiable, culturally established, medial conventions of sound - of ambient, intradiegetic music, sound effects or voices. These, in turn, contribute to the shows' normative moral framework of human and divine (inter)action, making it accessible and emotionally comprehensible for the audience through sound's unique ability to create instant emotional relatability. Beyond the role of sound's aesthetics, styles and textures in shaping notions of morality and normativity, a structural dimension is also at play. The placement of sound in the narrative context, as well as the question of who is given a voice and what it sounds like, is relevant here. For instance, in Ramayan, barely any songs are sung from the perspective of Ravan, his family or ministers. Likewise, Ravan and other demons are often shouting in rage, which strongly contrasts with the unfailingly calm demeanor of Ram and Sita.

However, a character's voice is just one component of the aural construction of its morality and requires other aural elements to create a complete image. This is especially illustrative in the case of Shakuni, the main villain of Mahabharat. As already described in chapter 2, Shakuni is one of the few characters in Mahabharat (or in both serials for that matter, given that there is no character-bound music in Ramayan) with a distinct intradiegetic musical passage that is heard in almost every one of his appearances throughout the serial. This passage combines a pattern played by North Atlantic string instruments with different layers of synthesizer sound. A chromatic scale and a range of wavering timbres and clashing textures create a musical atmosphere that capitalizes on cinematic aural conventions of evoking eerie, ill-boding sensations (see example 2.2). The narrative-atmospheric impact of these sounds is absolutely vital for (aurally) constructing Shakuni as the villain in Mahabharat, since he barely raises his voice in the manner of the serial's other immoral characters and would otherwise appear harmless with his usual smug and sanctimonious smile. The voice, while indicating Shakuni's malevolence in the semantic meaning of his utterances, is not sufficient to create Shakuni as villain. It is the music that unambiguously makes him an evil character. In conjunction 
with visual and verbal means of narration, the sounds of the serials, such as voices and music, intertwine to symbiotically produce Ramayan's and Mahabharat's moral framework.

Often in the serials, dharm is represented more in the shape of an underlying comment than being at the center of a given sequence. In those instances, the sounds of a scene create a sense of moral judgment, an evaluation of a situation, of a character's actions in terms of his or her caste or gender, while the plot is moved forward with a different emphasis. In this sense, sound also shapes and relates normative ideas pertaining to a broad range of social parameters beyond the religious or devotional normativity discussed above. An example, is the way in which Gandhari is aurally framed in episode 7 of Mahabharat, where she is chosen - and chooses - to become the wife of Dhritarashtr, the blind prince of Hastinapur. This decision is the foundation of her brother Shakuni's never-ending wrath towards Bhishm. Her decision therefore initiates Shakuni's relentless attempts to secure a hegemonic position for his part of the clan by fighting Bhishm and the Pandavas, ultimately leading to the Kurukshetra war. Shakuni considers Dhritarashtr, who he thinks will never become king due to his blindness, an unworthy match for his sister Gandhari. The scene's central narrative purpose is to establish this central conflict that drives the plot of the serial, while Gandhari's (aural) framing as morally impeccable is relatively marginal. In the scene, Bhishm asks Shakuni and Gandhari's father to marry Gandhari to Dhritarashtr (example 4.13). Initially, before this proposal, the scene is ensounded by soft intradiegetic music. Played by a sitar, hand cymbals and a drum, regular, repetitive patterns create a mellow flow of sounds, thereby drawing on conventions of creating a pleasant, innocuous atmosphere. As a reaction to Bhishm's proposal, the soft music is abruptly replaced by a loud stinger, which is looped, repeated and combined with other layers of a brash, orchestral sound-wash playing diminished and augmented chords, as well as metallic-sounding plucked string instruments and a bell. The heavy sounds coincide with the outbursts of anger and disbelief by Shakuni and his father upon learning of Bhishm's proposal. The sounds fade out when the Gandhars hesitantly start to discuss the offer. Suddenly, Gandhari, who has been listening to the conversation from a different room, enters. Carried by a thick layer of intradiegetic orchestral string music, she declares Bhishm's proposal to be righteous and announces that she will accept the proposal and choose Dhritarashtr as her husband. In a monologue given in a calm, composed voice about her duty as a wife and her relation to her future 
husband, she blindfolds herself by tying a scarf around her head in order to restrict her vision to the same level as that of her future husband.

The intradiegetic music heard in the biggest part of the scene belongs to the musical staples of the serials. It starts with a layer of lower-pitched string instruments playing a melody that gradually shifts to higher pitches and splits into one higher-pitched and one lower-pitched layer after a few seconds. The sugary wash of string sounds is slow-paced, lacking accentuated rhythmic pattern, and revolves around smaller patterns of ascend and descend on a heptatonic scale corresponding to a minor scale in North Atlantic music. This music, with its large interval leaps and sudden accents in patterns, is replaced midascend by an equally sugary, but entirely different passage three minutes into the sequence. The new music, a bansuri alternating with a sitar, accompanied by a vibraphone and a barely audible swarmandal, is heard throughout the remainder of the scene. It contrasts with the filmi orchestral aesthetic of the previous music, employing a different scale and producing a different sonic texture. Overall, it generates more of a Hindustani classical aesthetic through structural parameters such as the instrumentation, the playing techniques, and the melodic contours. With their own distinct aesthetics - employing sweeping leaps, specific scales, abruptly swelling dynamics, a sedate pace or tender timbres - both of the intradiegetic passages create what I perceive to be a sense of pathos and grandeur. At the end of the scene, Shakuni and Gandhari's father are touched by Gandhari's ethos, even though Shakuni's acceptance does not last long and he will soon start scheming in search of revenge, thereby gradually paving the way to the apocalyptical Kurukshetra war.

Dramaturgically, this first encounter of Bhishm and Shakuni is vital for establishing a pivotal conflict of the story and also frames Gandhari as morally flawless woman fulfilling her dharm. By choosing Dhritarashtr as husband, and thereby restricting the ableness of her body to acknowledge her husband's superiority, Gandhari is presented as selfless and morally superior to her vain father and brother, who are insulted by Bhishm's proposal. This dharmic superiority, established in her first appearance, will remain a defining trait of Gandhari for the rest of the serial. Over the course of Mahabharat, she remains not only a loyal wife to Dhritarashtr, but also acts as his moral conscience throughout all of his questionable decisions. The music of this scene essentially contributes to framing 
Gandhari and her stance as morally superior. Drawing on conventions of creating pathos, for instance the music's sweeping leaps of melodic contour, or the textural softness and the slow pace of the passages - the sounds evaluate Gandhari's choices as admirable and touching. This positive sonic framing of Gandhari also contributes to the normative image of women's dharm in the serials. Furthermore, the placement of music in the scene affords an understanding of Gandhari as the Kurus' voice of reason as her appearance is synchronized with the start of the intradiegetic music that frames her monologue so sympathetically. She calms down the previous discordance between the three men, breaking the uneasy intradiegetic silence with the soft wash of sound that makes her entrance resonate. Thus, her role as the dignified, calming influence who sacrifices herself for the sake of a greater good - peace - is also positioned structurally in the musical framing of the scene.

This dharmically charged theme of self-sacrifice for a greater good, or out of respect for the orders of a senior (family member), pervades both of the serials. It is usually idealized, constructed as a desirable value by intradiegetic music in scenes across Ramayan and Mahabharat. Ram's reaction to his banishment into exile, for instance, is ensounded and (aurally) structured in a similar way as the scene featuring Gandhari described above (example 4.14). Ram's calm acceptance of the shocking order, his joy at fulfilling Kaikeyi's wish, is mediated through the intradiegetic sounds, which shift from the orchestral string music first heard in the scene to a scattered, softly plucked sitar. In Ramayan, the aural spectrum for distinguishing 'good' and 'evil' runs along the not-too-subtle distinction between 'Indian' instruments and musical structures, which create positive aural atmospheres, and filmi orchestral sounds, which are more connected to tragic and negative moments. Thus, the music of this scene unambiguously portrays Ram's reaction as positive and admirable to the audience (which is all the more important as the sparse facial expressivity of the actors does not really offer much of an anchor for interpretation).

An example of a slightly different aural approach to representing dharmically appropriate behavior is the story of Eklavya in episode 23 of Mahabharat (example 4.15). Eklavya, a young tribal prince, has been secretly observing Dron teaching the young Kaurava- and Pandava-princes. When Dron discovers him, he realizes that Eklavya has the potential to become the best archer. Because Dron wants this status reserved for his protégé and favorite student Arjun, he needs to manipulate Eklavya's abilities. Under the pretense of requesting a sacrifice from Eklavya to compensate for his transgression - studying from 156 
Dron without asking him, thereby violating the rules of the student-teacher-relationship - Dron secures Arjun's superiority as archer. In the scene, Dron and the princes discover Eklavya, who is practicing in hiding. As with most of the scenes in which Dron is teaching the princes, the scene has thus far been carried by a specific intradiegetic musical passage. Low-pitched, buzzing sounds of a single veena, backed up by a tanpura, playing an almost cyclical three-pitched pattern that sounds like Vedic chanting with the rhythm of its slow paced alternation of the low-pitched notes pervade the scene with a burring sound carpet, which is regularly interrupted by the metallic, pinging sound of a bell. As one interlocutor pointed out during an interview, this passage draws on conventions of representing conversations as serious, or of representing situations of teaching as grave and sublime. She traced this convention to the typical iconographic representation of Saraswati, the goddess of knowledge, with a veena in her hand ${ }^{130}$.

Over the course of the conversation between Eklavya and Dron, the music changes a little, the melody breaking the cyclical pattern by expanding into ascend-descend patterns over a pentatonic scale at a faster pace, complemented by a drum. When Dron asks Eklavya for an offering to prove his reverence towards his guru, a low-pitched, irregular synthetic beating sound with a rumbling texture comes in, layered over the veena-passage. Dron asks Eklavya to cut off his right thumb - a mutilation which will render Eklavya unable to operate bow and arrow. While reaction shots of the young princes at a medium close-up indicate that this demand is distressing, Eklavya - shown in a medium shot - only hesitates briefly before he agrees to the request, his hands folded in reverence. A shrieking, high-pitched string-stinger is heard, abruptly interrupting the previous music and standing in stark contrast to the unceremonious way in which Eklavya cuts off his thumb. The long-held shriek of the stinger, complemented by deep rumbling sounds as the camera closes up on the wound and the shocked faces of the boys, turns into a rapid descend pattern of the violins employing the same scale as the previous veena pattern. The veena pattern then picks up again with fast-paced ascends, rhythmically synchronized with the percussion. Eklavya, who has been firmly looking Dron in the eyes,

\footnotetext{
130 Interviews with DP, 5 Jul2015. While this remark by my interlocutor is not meant as a causally substantiated reason for the employment of these sounds in the scene, it is insightful to me in terms of the associations the serials' audience draws on in perceiving the serials' music.
} 
bows down and touches Dron's feet in reverence. Dron raises his hand in a blessing gesture with a mild look on his face, approving of Eklavya's obedience. While the shrieking stinger is a harsh interruption of the scene's sounds that viscerally relates the cruelty of Dron's request and the extremity of Eklavya's sacrifice, the immediate return to the prior veena pattern normalizes the mutilation and positions it as a restoration of a previously existing order.

As in the scenes of Gandhari and Ram's sacrifices described above, this sequence represents Eklavya's unhesitant self-sacrifice as commendable instance of a student's dharm towards his teacher, reinforcing a norm of unconditional obedience. However, the sounds of this sequence, with the heart-stopping, shrill stinger, and the shocked faces of the princes witnessing the scene imply that the sacrifices of such dharmic behavior can be dire. Even though overall, the fact that Eklavya immediately complies with Dron's request without questioning it is framed as positive, the sounds of the scene point toward the complexity of the concept of dharm by musically emphasizing the hardship that potentially goes along with such a level of obedience ${ }^{131}$.These three examples illustrate how Ramayan and Mahabharat construct self-sacrifice as a dharmic norm - as desirable and morally superior - and how music is an essential element in this process. Eklavya, Ram and Gandhari all make extreme sacrifices; the musical framing presents those of Ram and Gandhari as entirely positive and that of Eklavya as necessary despite its awfulness. Thereby, their sacrificial dharmic actions are simultaneously idealized and presented as a normative gauge to the audience.

As self-proclaimed stories about the struggle of justice against injustice, Mahabharat and Ramayan obviously also construct counter-images to the morally ideal characters described above. Here, too, sound is a vital means of framing actions and positioning them within the serials' spectrum of values. A good example of the aural co-construction of immoral behavior are Mahabharat's episodes 46 and 47, in which the infamous game of dice and Dushasan's assault on Draupadi, in which he disrobes her in front of Hastinapur's court assembly, are narrated. As a pivotal point in the narrative, this part of Mahabharat has received a lot of scholarly attention. It is illustrative of the complex dharmic fabric of the story, as it questions not only the actions of the obvious villains, but also of

\footnotetext{
131 The topic of the absolute fulfillment of duty pervades the entire serial and ultimately culminates in the in-depth exploration of dharm and the cost of adhering to one's dharm in the Bhagavad Gita (episodes 72 to 74). 
Yudhishthir, who stakes Draupadi in the game, of his brothers, Dhritarashtr and the court's elders, who passively witness Dushasan's assault without intervening. Despite these nuances of negotiating morality, the episodes clearly focus on representing the thorough immorality of Duryodhan, Shakuni, Dushasan and Karn ${ }^{132}$. The aural construction of their depravity mainly takes place through their voices.

The game of dice and the disrobing of Draupadi are narrated over the course of two entire episodes, in which not much else happens ${ }^{133}$. The slow narrative pace allows for pointedly evoking the scale of the disaster this incident represents for the Pandavas. The two episodes are carried by a constant carpet of intradiegetic sound. Mostly assembled from brash, clashingly layered synthesizer sounds resembling brass wind instruments and organ, the music consists of variations of the discordant synthesizer sounds employed so frequently throughout the serial. It combines brass and organ sounds with long-held layers of fuzzy-textured sounds, assembled in often looping and stretched-out patterns of a few pitches and interspersed with machinic sounds, which create a generally tense atmosphere over the course of the two episodes (example 4.18).

While the music engages the audience in the discomfort of the moment and the anguish and terror felt by the Pandavas, the voices of Duryodhan and his accomplices are the primary aural means that evoke their malevolence and make the scenes feel uncomfortable. The overwhelming sound of their voices forces their spite and aggression onto the audience, and thus positions the men unambiguously as morally corrupted. The vocal orientation of these episodes results from their overall audiovisual structure and narrative focus. The intradiegetic music here is more of a static sound carpet, which alternatingly swells and subsides throughout the episodes, shifting in texture with the progression of the narrative. Nevertheless, it does not command the audience's attention precisely because of its more static textures. Also, these sounds (and others that are stylistically close to them) are employed so habitually in Mahabharat that they are not

\footnotetext{
132 Karn is actually not that one-dimensional a character as it might seem here. Over the course of the serial, he is not solely represented as immoral or as a villain, but as a righteous victim of circumstances and as son of Kunti and deeply loyal friend to Duryodhan. While he demonstrates immoral behavior in the context of the game of dice and Draupadi's assault, he mostly tries to dissuade Duryodhan from his destructive schemes to extinguish the Pandavas.

133 The two episodes are included in the list of video examples (4.16 and 4.17) for a better comprehension of their atmospheric development as I am only including excerpts from them in the text here.
} 
specifically associated with any of the villainous characters of these two episodes but instead produce a nondescript tension. In addition, the visual-dramaturgical construction of these episodes makes the voices stand out as an aesthetic means to stage immorality. The narrative pace of the two episodes is slow, focusing exclusively on two connected incidents. Visually, the episodes are quite static: the incidents take place mostly in one room and the characters are generally seated and move very little (and if they do, it is generally only a couple of characters). Until Draupadi is dragged into the room of the game and assaulted by Dushasan, the visual track mainly consists of reaction shots between the participants and panning shots around the room. Alongside the steadiness of the narrative pace, visual layout and intradiegetic sounds, the voices particularly stand out. Beyond the two episodes' emphasis on dialogue, the textures of the voices aurally dominate the episodes, erupting irregularly, and consuming the space of the setting with their voluminous, booming sound.

Duryodhan and his allies repeatedly insult the Pandavas over the course of the match, commenting on the game and bursting into laughter with every move that brings them closer to winning. The tension of the situation and the torments of the losing party are continuously accentuated with each of these outburst of wooden, boisterous laughter. Over the course of the match, the insults and slander increase, as do the volume and intensity of the villains' voices. Duryodhan shouts with a coarse, husky, deep voice; his accomplices chime in to yell insults or the number the dice show, and fall into maniacal laughter. This contrasts with the paralyzed silence of the Pandavas and their occasional faint protests. The irregularly shouting and laughing voices of Duryodhan and his partners are enhanced with reverb, which makes especially their laughter stand out strongly, and melts the voices into one single rumbling, almost violent sound. The booming laughter erupts again and again, irregularly, unpredictably, and is so overpoweringly loud, so obtrusive, that it is impossible to ignore it (example 4.19). The laughter sounds exaggerated and stiff, which Mankekar describes as a "convention[...] borrowed" from "some forms of north Indian folk theater" (1999:229). Piyush Roy points out that this convention of representing the voice, and especially laughter, can be traced back to the Natyasastra, the Sanskrit treatise on the arts. Here, "boisterous laughter" - one of six "type[s] of laughter" - is reserved "for the loud and the demonic" (Roy 2015: 152). Against this backdrop of aesthetics and traditions, it is even more evident that the voices of Duryodhan, Dushasan, Shakuni and Karn are the means that unambiguously position 
them at the evil end of the moral spectrum, aurally separating them from their quiet opponents. The dharmic panorama outlined by the two episodes is complex, especially after Draupadi's insult has been passively accepted by the Pandavas and the Kuru elders, who have been constructed as upright and morally immaculate thus far in the serial. Even though the usually 'good' characters are now presented with more depth by questioning their morality, the two episodes instead emphasize the distinct, outstanding adharm of the Pandavas' opponents ${ }^{134}$.

In Ramayan, morally condemnable behavior is also framed as such through sound and music. Similar to Mahabharat, although less subtle, this is achieved by drawing on cinematic and folk conventions. Unlike Mahabharat, however, the aural construction of dharm and adharm is less targeted to specific characters, because the staple of intradiegetic instrumental sounds employed over the course of the serial is smaller than in Mahabharat. These aural fragments constructing dharm and adharm therefore not only repeat more frequently, but also in in more different contexts. One way of ensounding immorality in Ramayan is through intradiegetic orchestral music, which is usually very dramatic, either swirling and agitated, or with slow-paced, opulent string passages. In this capacity, it is equally connected to tragic and sad moments throughout the serial, as it is to situations in which characters act immorally. Sometimes, searing, wavering, pulsating synthesizer sounds are heard in scenes with evil or scary demonic characters, thus endowing the malice of their actions with the discomfort evoked by the clashing sounds. For example, Sita's abduction by Ravan is narrated through a blend of orchestral music and synthetic sounds, complemented by Sita's high pitched screams for help and Ravan's roaring laughter and shouting (example 4.20). While the distinction between moral and immoral acts or characters is occasionally blurred or complicated, especially in Mahabharat, overall both serials clearly outline straightforward, conservative and normative images of morality through the use of sounds and music by following cinematic and theatrical conventions. The atmospheric narrative impact of music and sounds afford

134 While I argue that it is mainly the vocal aesthetics that so obviously position Duryodhan and his allies as villains, the sounds also interlace with visuals and dialogue. For instance, as in the rest of the serial, Shakuni, Duryodhan, Dushasan and Karn wear dark colors that contrast with the light colors of the Pandavas and are an unambiguous comment on their moral condition. 
an emotional perception and evaluation of the scenes, thus creating and conveying the moral fabric of Ramayan and Mahabharat.

\subsection{The Sonic Coding of Gender}

As the preceding subchapters illustrate, morality, normativity and religious practice are closely intertwined and negotiated in musical representation. Beyond their inherent relation to each other, morals and norms are gendered - in this regard Mahabharat and Ramayan are no exception. Dharm is represented in both serials as dependent on social status and function, in this idealizing certain behaviors, positions and actions as related to specific characters. Every character's actions, abilities, desires and personalities are intricately linked to their gender. Therefore, examining how gender is constructed aurally - or rather audiovisually - and positioned morally allows to draw a more comprehensive picture of the framework of moral and social norms created in the serials.

Both of the serials strongly focus on masculinity, revolving around the demands towards kings, princes, warriors, and sages: in short, men in a range of social functions (but mostly in a narrow range of high castes). The dharmic challenges and demands of these social functions for men drive the plot and dominate most of the two narratives. As Andrea Custodi (2007: 208) points out with regard to the Sanskrit epic, masculinity is a central issue in the Mahabharata and is framed, normalized, and contested more than femininity is ${ }^{135}$. Likewise, Ramayan revolves around the construction of Ram as ideal man ('maryada purushottam'). Femininity, as well as other genders, serve more as a backdrop against which masculinity and male norms are positioned; they are understood primarily in relationship to, and serve to define, masculinity.

In the serials' marketing, the claim that they promoted women's rights occasionally emerged. This was sporadically echoed in the serials themselves, usually embedded in idealized representations of the ancient societies they attempted to re-create ${ }^{136}$. However, both serials actually create a reactionary image of gender roles, especially

\footnotetext{
135 This is not supposed to imply a binary and monolithic understanding of gender - I subscribe to a constructivist notion of gender as performed, constructed, fluid and diverse category of identification.

136 For instance, in Mahabharat, the right of the princesses to choose their own husband was emphasized and framed as an indicator for the progressiveness of the (imagined) long-gone past as it was represented in the serial.
} 
pertaining to the set of heavily patriarchal ideals they promote ${ }^{137}$. Male characters are at the center of the plot, combining action, the authority to explain events and their implications, and most of the strategizing in the two narratives. By contrast, the agency of the female characters is mostly tied to the male characters. However, the women of the story don't actually act that much anyway. They wish and hope, they obey or refuse, they react, demand or occasionally even strategize and steer, but beyond that they are mostly factors around which men act. Other genders, represented by the characters Brihannala and Shikhandi in Mahabharat, are likewise constructed in relation to, and delineation from, masculinity and are accordingly limited in their scope of action.

In the serials, normative masculinity is also produced through sound. One aural element through which gender and gendered norms are constructed is the voice, the material qualities of which indicate the gender of characters. Obviously, the relationship between a voice's sound and gender is not natural but depends on the specific historical and cultural location of a given setting. In addition, voice is easily manipulable. Nevertheless, in Ramayan and Mahabharat, the material qualities of voices still contribute to producing a distinction between male and female characters. As such, the sounds of voices in the two serials are part of delineating gendered norms: while the voices of the serials' male and female characters do not have a uniform sound, but cover a wide vocal range, there are characters that still do not match this spectrum of sounds. Coincidentally, these characters also do not conform to the gendered norms constructed in the serials. For instance, the voice of Brihannala, Arjun's transsexual alter ego during the Pandavas' last year of exile, sounds slightly different than that of Arjun's usual, hypermasculine self. Brihannala speaks at a barely higher pitch than Arjun, but forms the voice differently so that it has a softer, more hushed timbre. On the deeply embodied level of the voice, this subtle aural difference between Arjun's and Brihannala's appearance emphasizes that Brihannala differs from the 'real' man Arjun and represents Brihannala's transgression of gendered norms. Slightly differently, the voice of Tadaka, the first demoness Ram encounters and kills, can be understood as a negative counterpart of feminine norms (example 4.21). Her inarticulate roars and growls and rumbling laughter are mirrored in

137 See Mankekar (1999) and Krishnan (1990) for feminist perspectives and thorough analyses of the patriarchal social structures promoted in Mahabharat and Ramayan. 
her visual monstrosity. With her low-pitched, raucous and loud voice, her violation of gendered norms - as an aggressive woman - is expressed aurally, suggesting that she cannot possibly be perceived as a female.

Opposed to this, the sound of voices also affirms characters' adherence to gendered norms. While the characters' voices cover a wide aural range, stereotypically, the women's voices are higher pitched and have a softer texture than those of the male characters. Differences between the genders of characters are audible in the way voices are used: male and female voices differ in expressions such as screams, crying and laughter. Most female characters speak with a soft, restrained voice. Emotional outbursts of anger on the part of female characters are usually responses to attacks on their morality, as for instance Draupadi's accusations after her assaults, or Sita's reaction to Ravan's repeated advances after having abducted her. In situations of distress, the female characters' high-pitched screams contrast with the deep-pitched, coarse roars of the male characters, thus also reproducing norms about the genders' relations to violence (see chapter 5). Female voices not only speak calmly and softly or occasionally scream, but also, especially in Ramayan, cry ${ }^{138}$. While this is stylistically part and parcel of the serials' melodramatic setup and is not entirely confined to women (especially in Ramayan, male characters cry as well), it still aurally shapes how the serial's female characters - with their frequently trembling and breaking voices - sound. Overall, these aural characteristics contribute to positioning the female characters as inferior to male characters, ascribing authority and agency to male voices.

This distribution of aural authority also plays out on a structural level. In purely quantitative terms, the focus of the two narratives on quests faced by their male protagonists means that male voices are heard a lot more. Normative male, vocal authority is also embodied in the narrating voices of Ramayan and Mahabharat. As previously described, in each of the serials a disembodied male voice guides the audience through the respective story. In Ramayan, this instance narrates through singing; in Mahabharat, the narrator, conceptualized as time itself, speaks. Beyond the authority inherent in such (morally) superior characters as Krishna and Ram, the connection between authority and the male voice is established on another, overarching level through these narrators, who exercise control over the framing of the narrative.

138 One interlocutor told me how her perception of Sita was that of a constantly "miserable, whining woman" (interview with PK, 8 Apr 2015). 
Especially with their detached, omniscient perspectives on the narrative (after all, Mahabharat's narrator is time itself!), their voices become the ultimate source of authority. This status is also entangled with the voices' materialities: Harish Bhimani's (Samay's) always calm, slowly speaking, deep, booming, reverberating voice and Ravindra Jain's equally reverberating, but sleek, piercing vocal timbre, both voluminously fill the narrative space. This effect, their almost overwhelming presence, is enhanced by the way they are staged: both voices are the focus of the scenes in which they are heard, either because potential dialogues are muted (Ramayan) or because the setting in which the narrator is heard is also visually detached from the remainder of the narrative (Mahabharat).

The outlining of gendered norms through voices also extends to songs and sung passages in Mahabharat and Ramayan. Again, this manifests both on an aesthetic and a structural level. On the aesthetic level, the sounds of the female voices appear to be staged as an explicit opposite of the male singing voices: with one exception, the female voices sing in the extremely high-pitched register and intonation that was first popularized in Hindi cinema by Lata Mangeshkar. This style of singing was quickly established as not only an aural norm, but as the aesthetic ideal aspired to by striving new singers (see Jhingan 2013, Srivastava 2006). In employing this vocal aesthetic, Ramayan and Mahabharat again draw on the extremely popular cinematic convention. This vocal aesthetic contrasts not only with the timbre and texture of the voices of adult men, but also of speaking adult women. As Sanjay Srivastava (2006) argues, this adolescent, child-like voice, embodying the innocence and harmlessness of a girl, de-sexualizes the respective female character. This way, it defuses the threat of female sexuality, which becomes "domesticated through the timbre, tonality, and stylistic stricture" (ibid.: 130) of the vocal technique. Being tied to a film's heroine through song, this vocal aesthetic turns the heroine into a harmless character that functions as a canvas onto which the ideals of (Indian, Hindu) womanhood - chastity, demureness and inferiority compared to men - are projected (ibid). In this sense, the implications of this aesthetic match the image of morally idealized and normalized femininity promoted by Ramayan and Mahabharat. In the serials, however, this stylistic device is not systematically applied to the idealized or positively constructed female characters, as there are considerably fewer songs in the serials as there are in a 
mainstream Hindi film-melodrama. According to Srivastava, in its capacity as constructing an idealized type of femininity, this vocal aesthetic is also employed effectively in film to dissociate the heroine from the morally corrupted vamp. While this stereotype of a female character does not exist in the serials ${ }^{139}$, it is interesting that Draupadi's song to seduce Keechak (example 4.22) - the only song in either show in which a female character is represented as so erotically outgoing - is also the only song sung by a lower-pitched female voice. Srivastava positions the high-pitched, childlike vocal aesthetic in a broader political context, in which he understands it to contribute to an essentially modern - and Hinduized - image of the Indian woman. This notion seems accurate with regard to Ramayan and Mahabharat, where the construction of this nexus of moral, piousness and gendered norms intersects with the medial transition of the stories into the state-sponsored mass medium of television.

On a structural level, too, songs and singing reinforce male-centric nature of the narratives. One factor in this is the distribution of male and female voices: usually, songs representing or relating to a male or female character are sung by voices of their respective gender. Overall, male singing voices are heard more often than female voices. Beyond this aspect of placement, the narrative motivation behind songs from the perspective of a female character is always in a way related to a male character. Praying for a husband, adoring a male child, longing for the husband and so on, always revolve around the social position the female characters occupy with regard to men - as mothers, brides or future brides.

Singing is the form of musicking (Small 1998) with the most evident gendered bias and it enforces the male-centeredness of the two serial narratives. The chanting of Vedic mantras, represented solely as a ritual activity in Ramayan and Mahabharat, is exclusively done by male characters. By contrast, bhakti devotional songs - the other main aural religious practice in the two serials - are equally sung by female characters. The playing of instruments is rarely represented in the serials, and does not exhibit a clear gendered bias. While hypermasculine warriors such as Duryodhan, Bhim or Dron do not play instruments in Mahabharat, Krishna, at least the young Krishna, frequently plays the

\footnotetext{
${ }^{139}$ While it would be obsolete and beyond the point to compulsively draw parallels between the characters of the serials and the types of characters one typically encounters in a mainstream Hindi movie, for the sake of completeness it could be argued that Surpankha, Ravan's sister who harasses Ram and Lakshman, comes closest to the image of a vamp given her sexual aggression.

166
} 
flute ${ }^{140}$ and his masculinity is not contested. Arjun's/Brihannala's role as the princess's music and dance teacher at the court of Virat complicates the case for masculinity and musicking in Mahabharat even more. On the one hand, his masculinity is clearly constrained in the persona of Brihannala, and playing music is a kind of compensatory act when he is not able or allowed to engage in other clearly masculine-connoted behavior, such as violence (as I will analyze in more detail in chapter 5). On the other hand, the personality of Arjun, "this most virile of heroes" (Custodi 2007: 212) is not effaced with his transformation into Brihannala, which blurs a potentially gendered connotation of musical practice in Mahabharat. A closer look at the gendered representations of musicking in the serials reveals that while in Ramayan, male and female characters are equally singing and playing instruments, a gendered differentiation in both serials is, again, present on a structural level. Typically, musicking that is 'decorative' and entertaining, as opposed to purely devotional, especially in conjunction with dance (except the tandav, the divine dance of Shiva), is mostly connected to female characters, thereby asserting the conservative conceptions of gender in Mahabharat and Ramayan.

Both, Mahabharat and Ramayan construct conservative, normative images of gender through sound. The aural normalization of gender in the serials overlaps with the factors of morality and religious practice analyzed in the previous subchapters. The moral and social norms constructed and negotiated in the serials are always specifically adjusted to the social situatedness of a character. Consequently, the questions of moral and 'right' or 'wrong' actions, attitudes or aspirations are always represented as gendered, as is the case in religious practice. In Ramayan and Mahabharat, these norms are ensounded especially through the voice: through its material qualities as it is attached to characters, as well as structurally through the placement of voices in the narratives, in songs and throughout individual episodes. Overall, this structural and aesthetic setup attributes authority - not only, but also in terms of the process of narration - to male voices and male characters. The sonic coding of gender in Mahabharat and Ramayan, therefore, reinforces hegemonic reactionary norms.

140 Which is also one of his essential attributes in iconographic and other representations. 


\subsection{Concluding Thoughts}

Mahabharat and Ramayan are dharmic serials, narrating stories which address global questions of right and wrong with claims to universal validity. As stories that grew out of Vaishnavite bhakti traditions, they contain a religious dimension that, even though not unequivocally perceived as such by their entire audience, does shape their aesthetics as well as the alignment of the normative and moral ideas related in the serials. Overall, in Ramayan and Mahabharat these issues formed a complexly entangled nexus of normativity, morality and religion, which was substantially, even though not exclusively, related through sound.

Regardless of whether the audience perceives them as religious or not, in both serials the representation of religious practice is a formative element - though more so in Ramayan than in Mahabharat. Both serials combined representations of Vedic rituals with those of more modern, bhakti-infused Hindu rituals. As such, the sounds contributed to the construction of the imagined ancient era which they created as they narrated the stories. While this blend of ensounded modern and ancient rituals offered the audience an (aural) anchor for identification, it also normalized the specific north Indian set of practices, sounds and aesthetics that were part of these representations. This normalization not only pertained to the sounds of Hindu and Vedic rituals, but also to the sounds of other modes of devotional music, which pervade the serials (especially Ramayan) in the shape of different formats of singing and songs. As a mode of getting in touch with the divine, singing and listening to devotional music are a vital aspects of Hindu religious practice. Therefore, this exploration of the sounds of Hindu devotional practice in Ramayan and Mahabharat is an important step in balancing the previous visual bias of research on the shows, which neglected this essential sonic dimension entirely.

Beyond the representation of explicitly religious practices, sound and music in Mahabharat and Ramayan are crucial means of shaping the narrations' moral framework and communicating it to the audience. They do so through employing mainly conventional sounds to evaluate a scene or a character, to create atmospheres which, by cinematic convention, are easily accessible for the audience. Through their conventional aesthetics, these sounds - intradiegetic as well as diegetic - unambiguously instill impressions of 'good' or 'evil' and thus relate and emphasize the moral framework that holds the televisual re-tellings of the stories together. This aural moral guideline of the serials is in 
turn linked to and legitimized by religious ideas and practice. Likewise, the moralizing sounds of the serials have a normative effect that is saturated and intimately interlinked with Hindu religion and religious practice and norms. The normative effects of music and sound in the serials are also directed at the representation of gender. They limit and point out the ways in which, ideally, members of all genders are supposed to behave, as well as the requirements and expectations for fulfilling these ideals. In Ramayan and Mahabharat, this gendered normalization crucially happens through the voice - materially as well as through the question of whose voice is heard when.

In Ramayan and Mahabharat, sound and music are essential media in the construction and representation of normative images of gender, morality, and Hindu religious practice. Their atmospheric materiality and related capacity to engage audiences emotionally and viscerally -the way they make listeners resonate - make them so effective in this, interlacing the evocation of religious settings, senses of comfort or discomfort, emotional turmoil, excitement, and bliss. In research on the shows, Ramayan's and Mahabharat's unconcealed introduction of Hindu religious practice into India's state-run television has been discussed as a symptom of a gradual invasion and saturation of India's public space with symbols of Hindu religion in the greater context of resurgent Hindu nationalism (see for instance Rajagopal 2001, Ohm 2007). This pervasion of public space was understood as a continuing normalization of Hindu imagery and also of a normalized conflation of Hindu culture with Indian culture (see Mankekar 1999, 2002). In this sense, Ramayan and Mahabharat have mainly been conceived as making ideological and especially visual contributions to this process of normalization. Given the dense web of sounds in the serials - their subtle but visceral and emotionally intense effects, and their effective evocations of religious settings and normative images of morality, social roles and religious practice - I suggest including the sounds in this discussion around public space. In this sense, sound and music of the serials as further, vital elements of this normalization of Hindusim, which is so efficient precisely because of this atmospheric quality. The subliminal emotional impact of sound, I argue, functions like a cushion that constructs norms while at the same time dampening the audience's awareness of its normative claims, infusing the aural normalization of morality in Mahabharat and Ramayan with the unique, resonating pleasure of music. 


\section{Fighting, Roaring, Screaming: The Sounds of Violence}

In episode 42 of Mahabharat, Bhim fights and kills king Jarasandh of Magadh, who has 95 kings incarcerated with the plan to sacrifice them in a rajasuya yajna, which would expand his power. The Pandavas want to free the 95 kings to secure their loyalty and their acknowledgment of the Pandavas' superiority. This, in turn, will allow Yudhishthir to perform the rajasuya yajna himself, thereby confirming and reinforcing the Pandavas' hegemony.

The fighting scene opens the episode directly after Samay's introduction (example 5.1). Bhim and Jarasandh enter the ring that has been prepared for their wrestling match. Long to medium shots alternatingly show Bhim and Jarasandh slowly approaching each other, the spectators gathering around the ring, and Krishna and Arjun observing the setting. The scene is drowned in sound: long-held, pulsating synthesizer sounds slowly and irregularly shift to slightly higher or lower pitches without forming a melody. This layer of sound, with the hazy, overtone-rich timbre that is so common in the serial, is complemented by another layer of synthesized sound that irregularly breaks into the long-held tones of the first layer, interspersing them with buzzing, cracking sounds as the fighters circle each other. These sounds are heavily reverberating, augmenting its sharp, mechanic buzzing and its irregular, non-rhythm, thus enhancing its disruptive effect on the hazy sounds of the first layer. Against this aural backdrop, the two opponents circle each other slowly, maintaining tense eye contact in anticipation of the first attack. When they finally initiate this first attack (after roughly one minute), the intradiegetic aural layer is brought to a halt by a crashing, rumbling sound produced by the second layer of sound. This thunder-like sound is synchronized with the collision and magnifies this first physical crash. Bhim and Jarasandh lock hands, intensely staring at each other, their arms stretched out and their heads held close to each other, while trying to push their opponent off balance.

The initial minutes of the fight - which lasts 14 days in the epic - are shown in medium shots, long shots and close-ups which alternate at a moderate pace. The intradiegetic sounds gradually intensify. In addition to the percussive, rumbling sounds, first a pulsating buzzing synthesizer-sound with a static, hazy pitch is heard. Gradually, more layers of synthesized sound come in: a noisy drone and irregular swooshing sounds which percussively add rhythm and momentum to the sequence through sudden attacks. These sounds morph and change 
over the course of the sequence, individual layers fading out and others being added. Overall, the intradiegetic sounds create tension through their irregular intervallic shifts, the dense and jarring timbres, and through the pulsating, rumbling, texture of some of the layers. This musical backdrop lasts throughout the entire sequence and is complemented by the diegetic sounds of the fight and the opponents from the first attack onwards. Throughout the fight, strikes, kicks, falls and punches are sonically enhanced by loud clashing noises and bangs; the latter are high-pitched and explosively popping. Their exaggerated, unnatural quality is enhanced by the fact that occasionally they are not entirely synchronized with the visual track, making the sounds of punches and their visual representation a little off. Also, the same sounds are used indiscriminately for all kicks and punches. Falls are represented by blunt thuds. Beyond these sounds of forceful impact, the fighters' grunts and heavily reverberating roars and (muffled) yells are the only other diegetic sounds - the spectators remain an entirely silent mass that is only visually detectable.

Bhim and Jarasandh wrestle intensely; they punch and kick, choke and tackle each other. The pace of the cutting is moderate throughout the scene. However, the intensity of the fight seems to be increasing: the rate of the punching sounds and roars raises, the fighters' moves and attacks get more spectacular and daring, their bodies are covered in sweat and mud, their hair disheveled, their faces contorted from the strain of fighting. After roughly eight minutes of this sound carpet, of alternating perspectives of the wrestling and brief shots of the spectators, Krishna, standing next to the ring, makes eye contact with Bhim and rips a twig in half, its splintering being the only diegetic sound in the sequence beyond the sounds of the fight. Understanding the hint, Bhim, standing over Jarasandh, who is lying on his back, grabs Jarasandh's leg and tears the body apart from the bottom up. Jarasandh starts to scream loudly, his scream still reverberating when his body is already split. The tearing itself is heard as a loud, stretched out cracking sound, which turns into a brash rumbling when the gorily split body is shown in a long shot.

Bhim throws the body halves out of the ring, but since he throws the right half to his right side and the left half to his left side, the twitching pieces stop mid-air and magically merge back together as if they were magnetic. As soon as they have fused together again, a closeup shows Jarasandh's face on the ground, looking up at Bhim with eyes wide open, laughing maniacally. His laughter is heard over the continuing intradiegetic blend of flickering 
synthesizer layers. It is amplified and reverberating, thereby creating a massive wall of sound that also dominates the two following medium shots: showing confusion and disgust on the faces of Bhim and Jarasandh's son. This laughter seamlessly merges into a lowpitched, roaring scream when Bhim, shown in a long shot, moves to tear Jarasandh apart again. As soon as he actually starts to tear Jarasandh apart, the screaming stops and is replaced by the loud cracking sound of the first tearing. This sequence of shots is repeated again, slightly faster in succession: Bhim hurls the split halves of the body into the air; they stop mid-air and merge back together; his son looks shocked; Bhim looks confused; Jarasandh lies on the ground, his booming, reverberating laughter almost overpowering the flickering, sharp sounding intradiegetic synthesizer sounds. The laughter lasts throughout the ensuing shots of Krishna shaking his head, tearing apart another twig (which is illustrated again by the cracking sound) and throwing the pieces in opposite directions (the left half to his right, the right half to his left).

Ultimately, Bhim tears Jarasandh apart a third time. Against the backdrop of pulsating synthesizer sounds, Jarasandh's laughter turns into the roar heard before, which is muted as soon as his body starts to split, and is replaced by the loud and stretched-out cracking noise. The camera zooms out to a long shot when showing the ripping of the body, then returning to a position as if standing directly behind Krishna, whose profile and right shoulder fill a third of the screen. From this perspective, Bhim is shown hurling the body halves in opposite directions - Jarasandh's right side to his left and left side to his right. At this point, the intradiegetic sounds subtly start to change: softly, a slightly reverberating male singing voice comes in, vocalizing a slowly ascending passage on consisting of long-held notes and mingling with the flickering synthesizer. Upon flinging the halves of Jarasandh's body out of the ring, he roars loudly and deeply. His brawl is equally enhanced by reverb, thereby setting it apart from the intradiegetic sounds. The body parts hit the ground outside of the ring with voluminous, also reverbing smashing noises. Bhim throws his head back and softly laughs with relief.

Simultaneously, the intradiegetic sounds have continued to change. The percussive elements have faded out, the vocalizing voice has shifted to the aural foreground, carried by metallic sounding long-held synthesizer-sounds whose timbre strongly reminds of a santur, an aural staple of the serial. With their more melodic character and different textures, the sounds strongly contrast with the previous clashing, strumming intradiegetic sounds. Bhim walks towards Krishna and Arjun, the setting sun in the background. Lit by an aureole of sunlight, 172 
Bhim, Arjun and Krishna are shown in profile in a medium shot. Bhim bows down in front of Krishna, his hands folded in reverence, while Krishna raises his hands in a blessing gesture, a radiant smile on his face. Carried by the sound of the vocalizing voice and the santur-like synthesizer, the camera zooms through the group of characters on the sun until it fills the screen.

This sequence of Mahabharat evidently focuses on a detailed representation of an act of violence - the fight between Bhim and Jarasandh - which results in Jarasandh's death. A dense web of intradiegetic sounds shrouds the audience in a tense atmosphere; the sharp diegetic noises of the fight (and the fighters) pierce the setting and create not only a sense of the fight's intensity, but also its speed and course. Together with the visual track, the scene produces steadily increasing tension over a relatively large portion of the episode that puts an anticipatory and almost voyeuristic focus on the violent death of Jarasandh. The scene is explicitly framed as vital to the progression of the plot, thus legitimizing its lengthy, monolithic representation. The sequence is representative of the importance of violence in Ramayan and Mahabharat. Violence drives the plots of both shows, it paces the narratives, contributes to defining characters and their relations to each other, as well as to outlining social rules and moral frameworks. Quantitatively and structurally, the representation of battles and duels dominates a significant portion of many episodes. The intradiegetic and diegetic sounds are vital in each and every representation of violence in the serials. They are essential for the actual audiovisual construction of violent acts, for framing them, evaluating them, and for enabling the audience to feel along with the extremity and sheer physical force of the acts, and with the opponents' exertion, pain, anger, and fear. Therefore, exploring the sounds of violence in Ramayan and Mahabharat not only provides insight into how violence is framed in the serials, it is also vital for apprehending sound's impact and functions in the televisual narratives. While the sequence described above is representative of these aspects, it is also not entirely representative of how violence is represented (aurally) in Ramayan and Mahabharat because of the sheer quantity and different manifestations of violence portrayed in the serials. The aesthetic nuances of these various representations cannot possibly be captured in a single scene. 
As a complex social practice, violence, or rather representations of violence in their different manifestations, are closely interwoven with the moral frameworks in Ramayan and Mahabharat. Acts of violence are, without exception, judged explicitly or implicitly in terms of the moral standards of the serials - through sound, language and images. Likewise, the moral of segments, episodes and arcs of the serial's stories are often conveyed through plotlines pervaded by (audiovisual representations of) violence. In this sense, in Ramayan and Mahabharat, violence is employed as a practice for maintaining or changing the social fabric justified by morality. For instance, in the scene described above, Bhim kills Jarasandh brutally. Their violent encounter and its ending are, however, morally justified: First, the fight is a wrestling match and Jarasandh himself picked Bhim as an opponent. Second, Jarasandh is framed as an evil character who is planning to kill 95 kings in order to secure his own power, so that killing him is staged as an act of justice - even though the Pandavas only engage in this act because they, too, want to secure their power. Furthermore, Krishna steers the event by giving Bhim information on how to kill Jarasandh, which is the ultimate justification of this act. Jarasandh's death, as a punishment for his moral transgression, reinstates the social order. While a part of the positive framing of this violent act takes place throughout the sequence, its aural evaluation is concentrated at the end of the scene, where the intradiegetic sounds, the smiling characters and the modest laughter of Bhim instill a positive atmosphere.

As a social practice that is closely entwined with morality, violence in the serials is also strongly gendered. The masculinity of the serials' protagonists is, reflecting their uppercaste status as Kshatriyas, dependent on their martial prowess. Even though numerous positively constructed male characters in both serials suffer (a) defeat over the course of the narration, the ability to win a violent dispute, respond violently to provocation, and master different styles of fighting - and thus being able to physically dominate other men ${ }^{141}$ - is valorized in the serials. Control of not only one's own body but the bodies of others is a marker of superiority, but it doesn't entirely qualify a character as positive. There are brutal characters in both of the narratives that are constructed as morally corrupt through their penchant for violence.

As this brief outline shows, violence is a vital element in Ramayan and Mahabharat and is represented as the complex social practice and force that it is. Sound is of great

141 Violence against women is condemned as entirely immoral. 
importance in these representations. On one level, it works in conjunction with the images to make representations of violence intelligible: by ensounding actual impacts in a fight or the voices of the opponents, or through intradiegetic sounds. Because the latter are such an important element of communicating the overall moral framework in the serials (see chapter 4), they are essential for positioning acts of violence, indicating how to judge them. Furthermore, sound is crucial on an aesthetic level in the serials' representation of violence, engaging the audience emotionally by creating atmospheres of threat, aggression, and fear. As such, sound is uniquely capable of relating the extremity of the experience of violence to the audience. But in order to properly analyze the representation and moral evaluation of violence in the serials through sound, it is necessary to first examine the notion of violence itself.

Violence, "a human universal" (Abbink 2000: xi), comes in a plethora of forms and manifestations. In this study, I focus on physical violence and its (aural) representation in Ramayan and Mahabharat. Anthropologist David Riches proposes to understand physical violence as "the intentional rendering of physical hurt on another human being" (Riches 1986: 4). Usually, violence is the "'contested' use of damaging physical force against other humans" is "pre-emptive and aimed at gaining dominance over others", sometimes alongside "purposeful humiliation" (Abbink 2000: xi, original emphases) of its target. The fact that violence usually entails extreme physical consequences for one participating party explains its inherent factor of contestation, as well as its close entanglement with ideas of morality, justice, and dominance. What one person or instance deems a justified punishment for a transgression and a reinstatement of the social order might be perceived as the unleashing of chaos by the person(s) on the opposing side. As anthropologists Andrew Strathern and Pamela J. Stewart write, violence "pinpoints the differences between people's perceptions of what is proper and appropriate in different contexts of conflict" (Strathern and Stewart 2002: 3). Accordingly, violence is also culturally and historically contingent (see Riches 1986: 1) ${ }^{142}$. Riches views this contingency, this inherent contestation of its legitimacy, as the "core purpose" of violence (1986: 5). The contestation of violence is negotiated between the three functions or positions of

142 Which is the reason why I am mostly drawing on anthropological literature for the conceptualization of violence. 
performer, witness, and victim, who form the "basic triangle of violence" (Riches 1986: 8), and who assess an act differently depending on their position in this triangle. Victims and witnesses will probably conceive of an act of violence as unjust, while performers most likely will not, and might even be hesitant to refer to their acts as violence at all (see Riches 1986: 4; 8).

In the Mahabharat sequence described above, the fight is positioned as a means to reinstate order, legitimized by the Pandavas' moral superiority. The basic setup of the fight as a wrestling match - a regulated context for challenging Jarasandh - frames the encounter as fair, controlled by the physical equality of the opponents and their voluntary participation. The ending of the fight is extremely brutal, but since it is initiated by the divine character of Krishna, and Jarasandh is constructed as evil prior to the match, the audience is (also musically) steered towards the performer's perspective, in which killing Jarasandh is a legitimate means to overturn his reign of terror ${ }^{143}$.

In the two serials, the fictional representations of violence are employed for their symbolic functions (see Riches 1986, Aijmer 2000, Strathern and Stewart 2002), for “dramatizing the importance of key social ideas" (Riches 1986: 11), as they obviously cannot claim the expressive functions of actual violence in a factual setting. These aestheticized, idealized representations of violence are vital for constructing the serials' moral universe, relating ideas of right and wrong to concepts such as rulership, religion, and gender. Sound and music are vital means in this. Given the quantitative as well as qualitative relevance of the representations of violence in Mahabharat and Ramayan, their specific aesthetics have a great overall impact on the serials and in turn are insightful with regard to the portrayals of violence and the social dynamics they imply.

Analyzing the audiovisual representation of violence in Mahabharat and Ramayan is a first step in filling the yawning gap in research on the aesthetics of representations of violence in Indian cinema and television, on which, to my knowledge, no publications exist. In the context of Indian film and media studies, analyses of violence in films often have a distinctly political perspective, focusing, for instance, on the post-colonial nationstate as setting for filmic violence (see Nandi and Chatterjee 2012), or on negotiations of masculinity through violence (Nandi and Chatterjee 2012, Banerjea 2005, Mazumdar

\footnotetext{
143 Which is in a way paradoxical, since the Pandavas fight Jarasandh as a competitor of Yudhishthir, who wants to secure his supremacy by performing the exact same ritual that Jarasandh prepares to perform (albeit without sacrificing the other kings' lives). 
2000). Even beyond the study of Indian films and television shows, there are only few publications that explore the role of sound in creating audiovisual representations of violence (exceptions are Coulthard 2012, 2013 and Chion 1994) ${ }^{144}$. Given the inherent cultural and interpersonal contingency of violence, it is vital to consider the cultural specificities of (representations of) violence in Indian audiovisual media, the underlying notions and logics of violence that govern its placement in the narrative as well as the aesthetic and structural elements of its representation.

This notion of the cultural contingency of violence is supported by Vamsee Juluri (2008), who points out that even though violence is not necessarily depicted differently in terms of aesthetics in Indian films, it is governed by a culturally specific logic. He argues that violence in Indian films does not spring from the same cultural pre-dispositions as it does in North Atlantic films, but is instead embedded into moral frameworks that can be related to Gandhian notions of nonviolence. While I do not wish to reinforce a binary notion of 'West and Rest', Juluri's proposition sensibly points out that the rationalization and, similarly, the aesthetics of violence needs to be considered against the backdrop of the respective cultural premises in which a representation of violence is embedded. Juluri opposes a universalist "ideology of violence", according to which humans are inherently prone to violence and resort to it in cross-cultural conflicts (2008: 116-120). Instead, he suggests Gandhi's paradigm of nonviolence as a frame for conceptualizing the dynamics of violence in Indian films. Juluri warns against misunderstanding Gandhi's idea of nonviolence as the "simplistic cliché of [...] not hitting back if someone hits you" (ibid.: 120). Instead, Gandhi perceives violence as an inevitable part of human life which should, however, be kept to a minimum and resorted to only when there is absolutely no alternative. Not existing as an abstract concept but being bound to people or characters who perform it, violence is likewise embedded in a "relational matrix" (ibid.), the social network which integrates "human subjectivity [...] in a balance of duties and obligations" (ibid.). In this social web, peoples' "agency unfolds in their ability to recognize their debts to society, family, and nature" (ibid.). Violence, then, is likewise embedded in this matrix

\footnotetext{
144 The visual dimension of representations of violence in film has received a little more attention, especially with regard to the aesthetic of ultraviolence that first emerged in US-American films in the 1970s, see for instance Prince 2000.
} 
of relations, and is not performed as an end in itself, but as a last resort and as part of the performer's (and victim's) social relations. Given that Gandhi's philosophy in large part draws from the epics (see van der Veer 1995: 85-86) - which themselves revolve around and negotiate the question of the legitimacy of violence, (see Rambachan 2003: 116) Juluri's call to understand violence as part of a relational matrix makes sense.

Violence is complex not only in terms of its cultural and social implications, but also on a psychological level. Violence is an extreme human experience and needs to be conveyed as such through the limited means of two sensory channels in audiovisual representations. In turn, the aesthetic means through which this extremity is conveyed says a lot about the (culturally) specific ideas of violence that govern this representation. In this chapter, I explore the means by which violence is constructed audiovisually in Mahabharat and Ramayan from different perspectives, which correspond to the levels of music's effects and functions in the serials. In section 5.1, I focus on a structural dimension of violence's role in Ramayan and Mahabharat, exploring the embedding of audiovisual representations of violence in the serials' narratives and the ways that sounds of violent encounters shape the overall style and structural units of the serials. In section 5.2, I complement this perspective by aesthetic considerations and address the conventions of representing violence to which Ramayan and Mahabharat adhere. This perspective will then be narrowed to one specific feature of violence in sub-chapter 5.2.1, which centers on the aural creation of intensity. I will explore how the complex amalgam of deeply visceral sensations such as pain, rushes of adrenalin and stress, fear, anger and aggression, exhaustion, and extreme bodily movements is evoked and related through sound in Ramayan and Mahabharat. In section 5.3, I return to how the social dimension of violence, briefly touched upon at the beginning of this chapter, is constructed in the serials and ask how the aural representation of violence is bound up in the wider net of (moral) values established in the serials, especially with regard to the social category of gender. I explore how in Ramayan and Mahabharat, representations of violence are employed as a gauge within their moral frameworks. Violence, as a heavily morally charged social practice, is gendered in Mahabharat and Ramayan. Therefore, I will explore how masculinity, femininity and other genders are positioned through audiovisual representations of violence in the serials, thus linking back to my observations on sound and gender in Ramayan and Mahabharat from chapter 4.3. 


\subsection{The Sounds of Violence and the Rhythms of the Narratives}

As a theme, violence is not only important in those scenes in which it is actually represented through images and sound, but is also the topic of conversation, a motivator for characters' actions, a point of orientation, and a pivot for the course of the plots beyond actual scenes of violence. Scenes in which acts of violence are represented, are thus culminations of narrative arcs of suspense, which in turn deeply affect the remainder of the narratives. The specific filmic aesthetics of violent scenes - their look, speed, and sounds - shape the overall aesthetics of Mahabharat and Ramayan. Additionally, the factor of violence also impacts the setup of the serials, in which it has teleological status. Violence infuses the serial narratives as a latent shadow because the violent frames of the stories are present throughout. Against this backdrop, actual representations of violent acts are in a sense confirmations of this constant threat of violence, repeatedly and forcefully affirming its disruptive potential while altering the ongoing course of the stories.

However, the narrative and episodic structure of the serials is centered not on violence for its own sake, but instead, as previously explained, on well-known narrative fragments as they circulate in various traditions of narrating or performing the stories. Violence is framed teleologically in the serials, narratively aiming at the devastating wars that are fought towards their respective ends. In Ramayan, this teleological framing is not as central since the story's focus is more on the character of Ram as ideal man. By contrast in Mahabharat, violence is explicitly framed as the inevitable culmination of the story from its first episode onwards ${ }^{145}$. Given that the violent outcome of the story is positioned as so vital from early on, the entire serial feels like a colossal aggravation of aggression that inevitably has to lead to the excess of violence that is the battle of Kurukshetra. The violent atmosphere is furthermore foreshadowed and prepared through preceding outbursts of violence between the central opposing parties and other characters (many of which ultimately participate in the final war). In line with the complexity of the underlying story, the representations of violence in Mahabharat cover a broad spectrum of violent

\footnotetext{
145 Two of my interlocutors pointed in our interviews that this framing can also be drawn from the title sequence, not only from the visuals of the battlefield, but also from the music, which they perceived as sounding heroic or even aggressive (interviews with SK, 16 Feb 2016 and AK, 25 Feb 2016).
} 
forms, ranging from sexual assault over manslaughter, duels, wrestling matches with transgressive moments of escalation, to military conflict.

Representations of violence stand out in the serials because they condense a lot of action into a short timeframe, contrasting with the serials' otherwise moderate narrative pace and aesthetics. They are compressed, fundamental negotiations of the fictional social fabric of the serials, often with palpable and irreversible - potentially lethal - impact. This contrasts with the countless scenes of motionless dialogues and monologues, static tableaux-like arrangements of characters in religious bliss, or deeply meaningful (bodiless) interaction found in the serials. This contrast also involves the aural aesthetic of violent scenes, although only partially. It is mostly the diegetic sounds, the sound effects of a fight, the yells, punches, or flight of the arrows, which are specific to scenes of violence and aurally distinguish them from non-violent scenes, in which they talk with composed voices or sing. The intradiegetic sounds and music are not specific to violent scenes, but are assembled from the sample inventory of sounds and passages employed throughout the serials, which contributes to the stylistic coherence of the serials' music.

The teleological framing endows violence with the potency to drive the narratives and to impose a rhythm on them, with every representation of violence impacting the narrative in a specific way. The display of violent acts occurs in irregular clusters throughout the serials: for instance, there may be several episodes without any representations of violence followed by two or three episodes with multiple violent scenes. Occasionally, there are three or four episodes in a row with one violent scene each, followed by an episode without violent scenes, which is then again followed by one or two episodes with singular violent incidents. There is a total of 69 violent sequences of varying lengths in the 94 episodes of Mahabharat, with the vast blocks of battle scenes counted as one scene each. The representations of violence vary in length and in terms of their aesthetics, as different kinds of violence are represented differently visually as well as aurally - for example, a military conflict is represented differently than a duel or an assault. However, these variations are not extreme - there are standard camera angles (especially medium shots) and techniques (primarily reverse shots) employed in almost every fight or violent scene, and certain sets of sounds that are employed repeatedly throughout the serial. The differences between scenes of violence mainly result from the dramaturgic setting, such as the participating characters, and the aural specificities of a violent encounter. 
In Mahabharat, representations of violence are invariably rendered through a combination of diegetic sounds and sound effects as well as intradiegetic sounds. The diegetic sounds are not that widely varied, comprising of the clashing and banging and swooshing sounds for impact, as well as screaming, yelling or grunting voices. As such, diegetic sounds are vital for specifying the kind of violent encounter, the (number of) participants and their condition, as well as for conveying the course of the fight. The intradiegetic music and sounds, despite also being limited to a finite set of passages, cover a broader stylistic spectrum than the diegetic sounds and position the given violent encounter on the moral spectrum of the serial. These sounds and passages are not employed exclusively in connection with representations of violence. In fact, also emerging in the context of various seething conflicts in the serial from early episodes onwards, they efficiently link some acts of violence to the conflicts from which they have developed. The sounds of violent scenes thus produce their very own irregular rhythm in the serial, serving as a reminder of the inevitable war and smoldering conflict, as well as providing an internal frame of the serial.

The teleological framing of violence in Mahabharat is vital for the narrative dynamic of the serial: between scenes of violence, the story proceeds slowly, sometimes even appearing to stop. The threat of the next violent clash, which consistently looms in the background, imparts these passages with a momentum of tension. This way, violence creates a rhythm of inevitability in the serial - after each assault, the next outbreak of violence is only a matter of time. This teleological framework is established in the very beginning of the serial through Samay's introduction. From there on, scenes of violence occur in most of the first 17 episodes. Hereafter, they decline in frequency, and more episodes without any representations of violence are interspersed. This grows into the 'pattern' of irregular clustering, with periods of increased representations of violence alternating with periods without representations of violence. The suspense created through this pattern is fueled especially by the numerous dialogues about violence and the intradiegetic sounds related to the seething conflicts between the actual violent incidents. This dynamic is especially salient in the last half of Mahabharat: over the course of eight episodes between episode 51 and 61, repeated scenes of violence pervade the narrative. From episode 61 until episode 70 - which is close to the episode in which the 
Kurukshetra war finally starts (episode 75), after which violence dominates the narrative - not a single violent incident is narrated. The increasing tension between the opponents is portrayed in the clustering of violence between episode 51 and 61 . The lack of violence following this exacerbates the tension created by the previous harbinger of violence. This way, the outbreak of the long-announced war in episode 75 is both cathartic and the climax of the narration.

At one point in the narrative, this teleological framing of violence and the tension created before the outbreak of the war is even explicitly reinforced through a song (example 5.2). In episode 69, six episodes before the war actually starts, an extended song sequence of more than ten minutes narrates the preparations for the war, announcing it as 'great' and 'dharmic war'. The lyrics of the song frame the war not only as inevitable and apocalyptic, but simultaneously terrible and heroic (thus in a sense positive), introducing the warriors and the scale and magnitude of the upcoming escalation of violence, even though it ultimately still takes a number of episodes to reach this point. The music of the song powerfully creates a sense of the war's impending doom and the heroism of those involved. It is slowly paced, but heavily rhythmically accentuated by piercing and rumbling percussive layers. Equally accented are the melodic layers featuring, for instance, synthesizers that sound like tutaris, wind instruments employed for announcing the start of a battle. A single male voice sings most of the song, alternating in a responsorial structure with a reverb-enhanced group of male voices in the mukhras and antaras. For most of the song, the melody revolves almost statically around a few pitches close to each other. At some points, several verses are sung in an almost recitational style on a single pitch and overall the melody of the antaras and mukhras are similar. The singers intonate the melody boldly, even at the top of their voices, so that, in conjunction with the instruments, a voluminous cloud of sound is created. The visual backdrop of the song is a montage of alternating panorama shots of mustering princes, kings, and their armies. This is the only song in the entire serial that addresses the topic of violence. Given its position in the serial, as well as its aesthetics, extended structure and lyrics, it significantly contributes to the teleological framing of the war and to the positioning of military violence in the moral framework of Mahabharat. It stages the war as horrifying, but at the same time as a platform that emphasizes the stellar masculinity and heroism of its participants. 
Surprisingly, the war itself is not an excess of 45-minute stretches of violent images. Instead, the progress of the war is narrated over the course of 17 episodes in one to three sequences per episode, interlocked with scenes outside of the battlefield, where either the warriors themselves or their relatives process the events of the conflict. This way, the grandeur and momentousness of the single deaths and fights is highlighted. Furthermore, this narrative strategy allows the disproportionate extension of the narrated time of the battle: the 18 days of the battle are stretched over 17 episodes, while the Bhagavad Gita preceding it spans three episodes alone. By contrast, entire lifespans of characters or a decade of the Pandavas' exile are bypassed and lapsed in very few episodes. Thus, the constitutive violence of the war takes center stage for a considerable part of the serial. The breaks between the individual violent scenes during the narration of the war, in which preceding events are processed by the characters or strategies are planned, creates a distance from the violent scenes. This allows not only for an overall extended representation of the war, but also creates the impression that the violence continuously increases in intensity with every narrative return to the battlefield.

The punctuating, eruptive rhythm of the violent scenes in Mahabharat stands out from the overall narrative. One reason for this is the bodily extremity of these scenes, conveyed through both, the audio and the visual track, which builds a contrast to the otherwise mostly calm setting. Furthermore, the violent scenes are extreme in terms of the social negotiations taking place in them. In conjunction with the outstanding blend of images and sounds, this makes representations of violence narrative 'power plants' in Mahabharat: violence motivates strands of the plot of various scales, marks changes in the social constellation between the characters, and it is a frequent topic of conversation both before and after given incidents. Thus, many aspects of the serials revolve around violence, its imminence, or consequences: the (martial) rivalry of Duryodhan and the Pandavas starting in their childhoods, the humiliation of Draupadi in front of the court assembly, and ultimately the apocalyptic Kurukshetra war.

In Ramayan, violence is staged more as an inevitable means of reinstating social order, which is reserved for Kshatriyas, the caste of warriors and kings. While violence is condemned when exercised for the wrong reasons, Kshatriyas are expected to excel in military combat. In contrast to Mahabharat, Ramayan does not revolve around the many 
nuances of human conflict (mainly in terms of struggle for power) but around the character of Ram - around presenting his countless virtues as an ideal son, brother, husband, king, friend, man, warrior, and god. As a consequence, violence is framed in relation to Ram and therefore mainly in terms of the moral code of the Kshatriyas and its transgressions by his opponents. Thus, overall, there are fewer representations of violence in Ramayan than in Mahabharat.

In addition to the distinct framing of violence in Ramayan that differs from how it is valorized and embedded in the plot of Mahabharat, the aural and visual representations of violence in Ramayan are also slightly different. Beyond the diegetic sound of tutaris, which in the battle scenes, often frame or announce the fights, it is mostly the layers of intradiegetic sounds that are stylistically different from the sounds of Mahabharat and are assembled from a smaller range of passages. There are, for instance, swirling, clashing layers of synthetic sounds that occur in connection with fights against demons (example 5.3). These sounds are, however, an exception. Usually, in most violent scenes of Ramayan the intradiegetic music, interspersed with the diegetic sounds of the fights, is the highly agitated orchestral music that is also heard throughout the serial in various scenes of conflict and drama. Also, there are a few intradiegetic songs and sung passages in Ramayan that are layered over the respective battle scenes (examples 5.4 and 5.5). These songs, bleeding into the diegetic and the other intradiegetic sounds of the battle, endow the violence they accompany with a positive hue. Sounding similar to the war song in Mahabharat, these songs feature forcefully singing male voices arranged in responsorial structures and enhanced with reverberation, dense rhythmic patterns played by percussion instruments, mostly sparse melodic contours as well as lyrics praising the grandeur of the war and its participating warriors. Beyond their musical specificities, the mere fact that songs and representations of violence in Ramayan are combined in battle scenes points towards the moral valorization of these specific instances of violence, especially in terms of the fighters' heroism, which is clearly shown in a positive light.

Like Mahabharat, the representations of violence in Ramayan are distributed over the serial in irregular clusters, with extended stretches of entirely violence-free episodes in between. For instance, the first manifestation of violence takes place in episode four when an adolescent Ram kills the demoness Tadaka and fights other demons. After this, there is a stretch of 22 episodes without any violent scenes - although they are not without conflict. This violence-free part of Ramayan then focuses on displaying the various 184 
nuances of Ram's moral and divine superiority, and on negotiating questions of legitimate rule and moral conduct. This demonstrates how violence only motivates a part of the serial's plot; it is practically forced onto Ram by outside aggressors, or it is presented as a last resort to solve a situation.

In Ramayan, scenes of violence usually occur in clusters and rarely stand alone. After the initial long stretch of episodes without violence, Ram's helping the sages by killing the demons that harass them in episode 27 initiates a number of further violent scenes in the following four episodes, peaking in Sita's abduction. This clustered structure pervades the entire serial until it culminates in the 17 episodes that narrate the war between Ram and Ravan. Similar to Mahabharat, the representations of violence of the war are often distributed over the episodes in single sequences, which are embedded in non-violent negotiations of the violence's implications. This clustered structure of the representations of violence provides them with more narrative weight in the serial's slow-paced narrative and emphasizes their impact, even though they are not at all gory but represented in a very stylized fashion.

\subsection{Audio-Visual Conventions and Aesthetics of Violence in Mahabharat and Ramayan}

This stylized representation of violence in the serials, and specifically the visuals of the "polite" (Juluri 2008: 117) archery duels, has become a humorous trope among the former audiences of Ramayan and Mahabharat ${ }^{146}$ and, by extension, in Indian popular culture more broadly (see chapter 6). While these visuals are in fact characteristic of a large portion of the two serials' violent scenes - dominating the battle-scenes in the shows' wars as well as many of the fights against demons - there are various other ways in which violence is created through sounds and images in Mahabharat and Ramayan. I will now explore the filmic and aesthetic means through which violence is represented in the two serials and untangle them from the conventions of the performative traditions used by

146 Interviews DV and PK, 8 Apr 2015; SB 24 Apr 2015; LS and VR, 21 May 2015; and many informal conversations. 
the producers to assemble these aesthetics. Thereby, I will delineate how the syntheses of images and sounds are able to evoke multiple intense sensations that inevitably accompany and constitute violence. This perspective on the aesthetics of violence illuminates the particular notions of violence of the serials, and how violence is considered to interrelate with morality. Furthermore, it elucidates how exactly sound and images are able not only to communicate on-screen acts of violence to the audience, but convey the characters' experiences.

True to their amalgamated composition, Ramayan and Mahabharat both draw on two performative traditions to aurally and visually represent violence: Ramlila, the theatrical tradition of Ramcaritmanas performances in north India, and the mythological film. Combining these and adding a specific televisual flavor (mainly resulting from the conditions of the shows' production, such as time pressure and budgetary restrictions), the serials integrate a range of manifestations of violence into their narratives.

As previously mentioned, violence in military contexts - during battles, campaigns, and attacks - is the preeminent manifestation of violence in both serials. Many battles are presented in the form of stylized, disembodied archery duels. In these duels, which are invariably carried by a layer of agitated, often fast-paced intradiegetic music, the opponents are never shown in the same frame but exclusively through reverse shots that signal the distance between them. The opponents alternate shooting their arrow into the air in the direction of their adversary, sometimes pausing to pray before shooting in order to summon divine powers or weapons. This is more typical for Ramayan, where the representation of archery duels is much more fantastically embellished and abundantly displayed than in Mahabharat. Once the arrows are released, they are shown flying through the air towards their target, traversing the screen from left to right and right to left respectively. In Mahabharat, this is typically ensounded with a loud swooshing noise that evokes the arrows' speed and devastating impact, elevating it from the wash of tense, intradiegetic background music (example 5.6). In keeping with the slightly more realistic representation of such duels, the arrows are then shown colliding mid-air or hitting their target and wounding or killing the opponent. In Ramayan, too, the arrows' flight across the screen is ensounded as a swooshing noise that interlaces with the wildly twirling orchestral intradiegetic music. When the arrows collide mid-air, they sometimes spray sparks, or some other visual special effect conveys their supernatural, potentially even divine, powers. Aurally, the collision is often emphasized by the sound of a crash cymbal 186 
and a hazy synthesizer, which usually clashes with the loudly swirling intradiegetic music heard simultaneously. When the arrows collide sonorously, one of them usually disappears or falls down, which signals the respective opponent's defeat, typically emphasized by a reverse shot of his bewildered face (see example 5.3, 5.4). This way, the duels are continued until one of the adversaries is finally hit by an arrow and dies.

Beyond these stilted and distanced duels, battle scenes also depict other forms of combat. Often, in the background of the archery duels or as introductory shots of the battlefield, foot soldiers wielding swords and maces engage in battle in a noisy haze of metallic clattering sounds and clamor shrouded in the energetic atmospheres of (mostly thickly instrumented orchestral) intradiegetic music. On the battlefield, the protagonists, too, engage in fights other the duels described above. Combat with maces and swords (ensounded with loudly clanking sounds with every impact of the weapons), for instance, is a more confrontational, bodily form of fighting and is visually represented as such aurally, it is only their diegetic sounds that differ from the representations of other forms of battlefield violence. Unarmed combat is another form of violent confrontation of the serials, (aesthetically) exemplified by the fight between Bhim and Jarasandh described at the outset of this chapter. These more informal fights do not diverge significantly from the ways in which violent encounters are usually are represented in Ramayan and Mahabharat. Moderately paced cuts show the fighters' entanglement from different angles, the strain of the fight conveyed through grunting and the loud thumps of punches and kicks. Some violent encounters are even constructed with a tinge of humor, for instance when Hanuman fights Ravan's soldiers in a Lankan garden. Here, the humorous flavor is evoked not only by Hanuman's comical grimaces but also by the intradiegetic sounds, which replace the typical dramatic intradiegetic ascends and descends with quickly pulsating, meandering synthesizer noises that are reminiscent of sounds employed in slapstick films (example 5.7).

Finally, there are also, albeit significantly fewer, representations of violence against women and, in Mahabharat, representations violence of women against children ${ }^{147}$. Some of these incidents, too, are represented like the physical struggles of unarmed combat.

\footnotetext{
147 Ganga drowning her children and Putana poisoning the newborns in Vrindavan.
} 
Sita's abduction by Ravan, for instance, or the attacks on Draupadi, are represented with tense or agitated layers of intradiegetic sounds, along with equally intense diegetic screams of the women, raucous laughter of the attackers, and images of the women's struggle against the assault (example 5.8). With this attention-grabbing, dramatic representation, these violent incidents are positioned at the respective serial's narrative center stage, as (morally unambiguously staged) horrifying events that hereafter significantly shape the stories. An exceptional representation of an encounter that I classify as violent, but whose violence is more ambiguous, is the sequence in which Dhritarashtr, Pandu and Vidur are conceived. Sage Vyas is summoned by his mother Satyavati to procreate with the queens Ambika and Ambalika since their husband Vichitravirya, Satyavati's legitimate son, has died childless. As Wendy Doniger explains, this practice, called niyoga, "was legitimized and institutionalized" (Doniger 1995: 174) in Vedic times and thus can be understood as a customary solution to securing the continuation of the dynasty. However, in Mahabharat, the profound horror of the queens during this encounter is constitutive of the further course of the story: Ambika closes her eyes in shock during the act, which results in her son Dhritarashtr being born blind, Ambalika trembles with fear, so that her son Pandu is weak. Visually, however the actual act of rape is not even represented as violence and resembles the stylized, bodiless violence of the archery duels. Vyas stands opposite each woman in turn, without any physical contact. He stares at the woman, and she reacts with shock, which is shown in differently paced reaction shots. Thus, except for the women's reactions, the violence of the encounter is entirely erased from the visual track ${ }^{148}$. In the following section, I will go into the ways in which sound accounts for representing the violence of these scenes. For now, it suffices to state that these ambiguous encounters in Mahabharat are visually not clearly framed as violence and they aesthetically resemble the stylized representations of violence on the fictional battlefields of both serials.

The audiovisual representations of violence in Mahabharat and Ramayan draw on conventions from both film and performance traditions. Especially formative were the aesthetics of representing violence in mythological films. In fact, the depictions of "polite" duels with bow and arrow as well as the representation of hand-to-hand combat bear a striking resemblance to the representations of such fights in older mythological films,

\footnotetext{
148 Roshni Sengupta (2017: 155-56) also points out the ambiguity of this disembodied representation of sexual violence. 
among them earlier screen-adaptations of the serials' stories, such as Babubhai Mistri's Sampoorn Ramayan (1961) (example 5.9) and Mahabharat (1965) ${ }^{149}$. Likewise, the stylized representation of violence can be traced back to folk traditions of narrating the epics. For instance, Schechner and Hess describe the representation of demon king Ravan's killing during the Ramlila festival in the north Indian town of Ramnagar as a successive severing of limbs by Ram's arrows (1977: 62) ${ }^{150}$. There are demonic deaths which are represented exactly like this in Ramayan, while Ravan's death on the battlefield is a frenzy of booming, clashing sound effects and visual special effects (example 5.10)151. While the serials evidently aligned with visual conventions of representing violence, their specific aesthetic was noteworthy because they appeared outdated (at least to some viewers) in the decidedly modern context of India's 1980s television.

Unlike the constant visual quotation of these stylistic models, the aural aesthetics of representations of violence in Ramayan and Mahabharat are more diverse, relying on a wider range of references. The dense, fast-paced, loudly reeling orchestral intradiegetic sounds of many of Ramayan's (not so much Mahabharat's) violent scenes clearly exceed the intradiegetic music of the abovementioned 1960s mythological films in intensity. In this regard they are closer to the film musical conventions of their own time, aesthetically referencing the decade's popular Hindi action movies, such as Coolie (1983). In particular, the many samples and passages of synthesized sounds that play a crucial role in both intradiegetically and diegetically shaping representations of violence, especially in

\footnotetext{
149 In fact, Mistri even contributed to several episodes of Mahabharat as director of special effects.

${ }^{150}$ In her ethnographic study of families watching mythologicals in Southall, London (1995), Marie Gillespie points out the importance of such heavily stylized representations for a character's or a situation's recall value. Gillespie describes how Peter Brooks' theatrical adaptation of the Mahabharata was decidedly disliked by the family with whom she was watching because Brooks didn't represent the characters according to the established conventions of popular media such as calendar art, comics, and performative traditions. To the family she was watching with, this rendered the characters unrecognizable. Representing the battle scenes through this stylized aesthetic of mythological films and regional theatre, therefore, can be understood as providing an aesthetic point of orientation for the audience on behalf of Chopra and Sagar. 151 Just as dramaturgic elements, such as the exaggerated laughter of the villains, might be traced back to performative conventions formulated in scriptures such as the Natyasastra (see chapter 4.2), the representation of violent acts, too, might possibly be traced to traditions that have grown from these scriptures. The guidelines for representing emotions and feelings - and accordingly the dynamics between characters in situations as extreme as violence - as they were outlined in these art theoretic scriptures, were particularly important in mythological movies, as Piyush Roy points out (see 2015: 147). It can thus be assumed that these formulaic aesthetics, conventionalized as they were, also trickled down to the aesthetics of representing violence, or rather violently acting characters, in both Ramayan and Mahabharat.
} 
Mahabharat, clearly reveal the serials as product of the 1980s. Moreover, these sounds might even be understood as specific to an emerging televisual aesthetic, given that synthesizers were easily accessible and allowed not only a relatively uncomplicated production of music, but also provided a specific and particularly intense range of sounds ${ }^{152}$.

Overall, the audiovisual means through which violence was represented in Ramayan and Mahabharat created an aesthetic that was simultaneously traditional - even to the point of being outdated - and contemporary or modern. With their composition, especially the drawn-out battle and distant duel sequences, these scenes generated a kind of mix-andmatch aesthetic that emphasized their formulaic style. This aesthetic, probably also resulting at least in part from the conditions of production, such as time and budgetary restrictions, manifests in occasional asynchronicity between images and sounds. More prominent, however, are the sometimes clumsily combined repetitions of the same images (and often also sounds) in a loop so that the battle scene is stretched out, which contributes to the heavily stylization of the serials' aesthetics of violence. Contrasting with these abstract, often disembodied visualizations of violence, the ways in which Ramayan and Mahabharat employ sounds, reintroduce the body into the representations of violence.

\subsubsection{Intensity}

Violence is an utterly intense human experience, both emotionally and physically. As the images in Ramayan and Mahabharat's representations of violence frequently remove the body as site, executor and experiential node of violence, it is the sounds that create a sense of the intensity of experiencing violence. As atmospheres that make the audience resonate, they create a sense of the blend of shock and pain, the kinesthetic sensations of possible extreme body movements, the terror, fear and anger, and make the violence palpable. It is obviously impossible to represent to an audience exactly what it feels like to be a participant in a violent act. Nevertheless, representations of violence in audiovisual media usually aim at providing a virtual version of the characters' experience in such a

\footnotetext{
152 The intensity of the synthetic sounds was a major motivation for the extended employment of the synthesizer in the production of Mahabharat's music, as Surya Raj Kamal pointed out to me in our interview (17 Jun 2015). 
way that the audience emotionally, and even bodily, engage with fictional events and empathize with the characters.

As previously mentioned, the diegetic sounds are of violence are the most important aural element of representations of violence in Ramayan and Mahabharat; they not only provide information about the course of the fight, they also generate empathy through the sounds of impacts, pain and suffering that make the brutality of a fight palpable to the audience. Bangs and blunt thuds are heard throughout scenes of hand-to-hand combat, heavily amplifying (and, by virtue of their exaggerated artificiality, strongly aestheticizing) the sounds of bodies colliding and falling, and of weapons clashing. Yells, cries and grunts convey the physical exertions of a fight, of pain, and the impact of weapons or punches. These sounds are powerful mechanisms for providing points of attachment and connection and making the feelings and experiences of the characters accessible to the audience. The vocal utterances are particularly powerful because they are extreme, defining the situations of violence as extraordinary, and sensationally and emotionally devastating. The sounds of blows, unambiguous in what they represent, are vital in violent scenes for evoking "muscular sympathy" (Anderson 2001) - an embodied comprehension of their extreme impact - in the audience. They do so through the combined efficiency of cinematic conventions, within which the exaggerated banging noises unambiguously signify forceful impacts, and the immersive, resonating effects of sound, which engage the audience not only emotionally but viscerally.

On a structural level, the diegetic sounds of violence in Mahabharat and Ramayan generate sensations of intensity both through their materiality and their temporalization or temporal vectorization. Likewise, they convey the severity of these impacts. Beyond this function, the diegetic sounds are also vital for the audience's orientation in scenes of violence. Sequences of physical fights or struggle are often fast-paced. The jumble of rushed movements and tumbling bodies are difficult for the eye to follow and comprehend ${ }^{153}$. Therefore, the diegetic sounds of a fight, the bangs and clashes of impacts

\footnotetext{
153 In Ramayan and Mahabharat, the scenes of violent encounters are not as rapidly paced through editing as they are in many action movies or shows. While this makes the visual orientation in Ramayan's and Mahabharat's fighting scenes not as problematic as it is in other audiovisual narratives, such scenes are nevertheless visually muddled in the shows and require the sound track for orientation.
} 
and punches, as well as the swooshing, whipping sounds of flying arrows, are vital for structuring the course of an on-screen fight and making it comprehensible for the audience. As Michel Chion argues, the eye does not process impulses as quickly as the ear does (see 1994: 10). Thus, the diegetic sounds of a fight scene, which make audible the moments of impacts that influence the further course of a fight, render the scene intelligible and eliminate much of the ambiguity or unclarity of the visual track. Above that, the ways in which fights are ensounded by diegetic sounds also implies a hierarchization of the individual events that constitute the act of violence, emphasizing some movements or impacts over others, thereby conveying to the audience which punches or impacts are particularly severe, and which incidents influence the course of the struggle more than others.

While the diegetic sounds of violent scenes are very prominent in Mahabharat, the audiovisual representation of violence in Ramayan relies more on intradiegetic sounds (beyond shouting and screaming, that is). Similar to the diegetic sounds, the intradiegetic carpets of sound in Ramayan's violent scenes create a temporal dynamic. For instance, a rapidly-paced musical passage or a fast succession of stingers creates a sensation of pressure and speed, or of chaos, startling the audience with sudden aural eruptions. Both diegetic and intradiegetic sounds have the ability to evoke empathy and even a visceral co-sensation of the events represented, but they do so distinctly due to their particular material qualities and their implied position and structural function within the audiovisual narrative. The diegetic sounds in representations of violence, even though they are usually exaggerated compared to natural sounds, are the (aestheticized) actual sounds of the setting, representing the actual course of a scene's events. The intradiegetic sounds, in contrast, not bound to a requirement of realism, position violent scenes along the emotional (and the moral) spectrum of the respective serial, atmospherically guiding the audience into an understanding of the scenes. As atmospheres, the intradiegetic sounds of violent scenes can evoke senses of rush, suspense, and tension. Thereby they contribute this essential sensory-emotional dimension of thoroughly empathizing - of immersing in the scene - which is simply more than just an abstract feeling, but involves the entire, resonating body. Intradiegetic sounds in scenes of violent representations create the atmospheres that absorb the audience, at once exposing their fictionality through the 'unrealistic' carpet of sounds (see Anderson 2001, Bieger 2011, Abels 2015) while at the same time lowering the threshold of belief, to paraphrase Gorbman, and 
drawing the audience into the fictional events. Together, the combination of intradiegetic and diegetic sounds of many scenes of violence in Ramayan and Mahabharat is so potent that they alone would be sufficient to represent acts of violence without any images at all. In Ramayan, the intradiegetic music employed to co-create the intensity of violent scenes mostly consists of highly agitated passages of the orchestral-style music that is heard throughout the entire serial, not just in violent settings. At no point in the serial is violence represented by soft-sounding passages played by instruments such as the sitar, bansuri or santur. Instead, repetitive passages of densely textured orchestral music erupt frequently in scenes of violence, endowing them with urgent walls of sound assembled from stingers and rapid (often chromatic, often high-pitched) string-scales, large interval leaps, and tremoli. Often, these orchestral sounds are complemented by rumbling, pressing layers of percussion sounds, or even by the abovementioned songs in which the violent encounter is described from the singing narrator's detached perspective. These impenetrable walls of intradiegetic sound keep the audience alert with their density, their eruptive, fast-paced dynamics, and their loudness. Intensity here is created through the incessant stream of rapid, swirling, sometimes blaring or rumbling, impulses which evoke the disorienting bustle of a battlefield or of physical combat. Frequently, during fights against demons and monstrous evil creatures, there are also flickering, pulsating, distorted almost-machinic intradiegetic synthesizer sounds, which are usually combined with orchestral sounds (example 5.11). Together with the diegetic sounds of violent encounters, be it punches and thuds or the hazy swooshing synthesizer sounds of flying arrows, the intradiegetic sounds of violence in Ramayan build up and form a dense mixture of aesthetically clashing sounds that usually culminate - producing the peak of aural (micro)tonal tension - when a character is (fatally) shot or injured (see example 5.10). The intensity of violence is aurally created by the different dense and highly agitated layers of sound and by their (aesthetic) clashes, which heighten the impression of the characters' own agitation in the face of violence and afford an empathic perception of the scene. Overall, this does not really create subtle nuances of emotions, feelings and sensations - in fact, Ramayan is infamous for its cardboard-like interpretation of the characters and their action. 
In Mahabharat, overlaps of diegetic sound effects and intradiegetic sound in scenes of violence are also prevalent, especially in scenes of military or hand-to-hand combat. But since the range of sounds employed in scenes of violence is structurally and stylistically different than in Ramayan, these overlaps, although combining brash-sounding layers, do not seem quite as cacophonous and disorienting. As mentioned before, in Mahabharat too, the orchestral style of intradiegetic music is an aural component of violent scenes, but it is employed far less frequently and positioned less centrally than in Ramayan. More often, the intradiegetic sounds of violence in Mahabharat are synthesized, just as the diegetic sounds are. Especially in most of the battle scenes, the synthetic origin of the single layered intradiegetic sounds stands out with its unique texture and timbre, which could barely be any more different from the voluminous timbres of the swirling orchestral passages in Ramayan. At the same time, the intradiegetic synthesizer sounds heard in many of the battle scenes in Mahabharat appear to imitate parts of an orchestral sound (example 5.12). Playing quickly staggered repetitions of single chords and brief ascend patterns on four distinct pitches, these synthesizer sounds are reminiscent of fanfares and impose their strict, almost percussive rhythm on the battle scenes. Their hazy, slightly distorted timbre, which clearly identifies the sounds as synthetic, then melts together with the diegetic, equally synthesized sounds of flying arrows, without clashing as harshly as the combinations of entirely stylistically different layers of sound in Ramayan's violent scenes do. Here, the intensity of the battle - in Ramayan shaped by the swirling, colliding layers of sound - is largely produced by the pressing, percussive rhythms of the synthetic layers of sound.

The intensity generated by the juxtaposition of agitated, stylistically diverse musical passages is also prominent in a different context of violence in Mahabharat - in which a woman's acts of violence are represented. In the serial's first two episodes, the rivergoddess Ganga, the wife of Shantanu and mother of Devavrat/Bhishm, drowns her and Shantanu's first seven children. Before agreeing to marry, Ganga has made Shantanu promise to never question her actions. Therefore, she kills her sons openly; each scene depicts her calmly walking down to the river's shore with the respective newborn child in her arms before calmly dropping the child into the water. In each of the scenes, Shantanu, startled but bound by his promise, follows Ganga at a short distance, his hands reaching out to her in desperation as the children drown, his face contorted with pain. In the repetitions of these scenes, only slight variations on the visual and the aural track 
create some differentiation. The first of these scenes is the most aurally intense (example 5.13): Ganga's walk to the shore of the river is accompanied by tragically welling orchestral music, with lavish, leaping string movements over minor scales. The music is different from that heard in Ramayan's scenes of violence: it is not as hectic or eruptive and lacks agitated techniques such as tremolo that endow the music with a jittery texture. During this first instance of infanticide, the string music is suddenly interrupted by a shrill and wobbly sounding synthesizer stinger that is fused with an explosive chord played by orchestral instruments and synthetic swooshing bubbling sounds the moment the infant drowns. This stinger is enhanced by reverb and is looped and stretched out for a few seconds, during which the drowning child and Shantanu's horrified face are shown in alternating shots. This is followed by a reverberating high-pitched note with the poignant, but possibly synthetic timbre of a sarangi, which turns into a very slowly meandering melody as Ganga turns around and walks past Shantanu with a smile. Their dialogue, with his promise to her, is heard again, intradiegetically from the off and with reverb. The following varied repetitions of this scene are also ensounded by different musical passages, which change abruptly once the respective child is submerged in the water (but not as dramatically as in the first instances). Even though the scene sounds clearly different from Ramayan's battle scenes - not as tightly paced, the different styles of sound not clashingly layered - it is an example of how, in Mahabharat, stylistically contrasting musics are employed to create a sense of the (emotional) intensity of violent acts, in this case Ganga's infanticide. Because they are not layered but succeed each other, the sounds in this scene do not clash as heavily as they do in Ramayan. Nevertheless, they are vital for representing the scene's violence. Ganga remains entirely unemotional during the killings, and since there is no struggle and accordingly no corresponding diegetic sounds, the music alone - connecting vastly different sounds in fast succession - evokes the extremity of Ganga's transgression and the intensity of Shantanu's shock. The sounds of the scene are stylistically heavily mismatched, and their dramatic welling up, followed by an eruptive stinger and the piercing sound of the sarangi/synthesizer produce the intensity and discomfort of the violent situation, thereby affording empathy or horror in the audience through their play with conventions, and their joining of materially and aesthetically disparate sounds. 
Similarly, sound is essential in the niyoga-scenes in Mahabharat's episode 6 described earlier. Here, however, it is obvious that sound does more than 'merely' evoke (emotional) intensity. Rather, sound here provides this corporeal dimension. It compensates for the censored visual representation of violence by endowing these scenes with a dimension of intense viscerality and palpability. As described earlier, the scene does not actually depict any physical violence, but an intense eye-contact of Vyas and the respective princess. This contact, as the visual track unambiguously mediates, are a torture for the princesses. The extreme close-ups of their faces show Vyas's piercing stares and the princesses' agonized expressions. Still, the distance between the characters is not bridged at any time, which entirely erases the body from these violent encounters. Both scenes sound slightly different, but both evoke the maximum of intensity and horror the serial's sound world has to offer. The first scene (example 5.14) starts with a slowly stretched out string of synthesizer tones sounding like a blend of an electrified harpsichord and a santur, with a piercing, yet overtone-rich timbre and a rattling, reverberating texture. These sounds are combined with a medium shot of Vyas standing in a room of the palace, eyes closed in meditation, his back towards the door of the room. Ambika enters hesitantly and slowly approaches Vyas. She stops, maintaining a distance of about a meter between them, and bows in reverence. The rattling, metallic sounds now slowly repeat a low-pitched note. Vyas turns around and looks at Ambika; when she lifts her head and their eyes meet, she flinches. As Ambika starts lifting her head, the low-pitched synthesizer tone is replaced by the slowly, regularly and chromatically ascending string ostinato (always alternating at the interval of a fifth) that are otherwise exclusively heard in the passage connected to Shakuni. These string sounds are combined with hissing, rumbling, noisy, metallic and irregular lashes of synthesizer sound, which gradually increase in volume and speed, thereby corresponding with the visuals. As soon as the two characters make eye contact, the camera zooms in on extreme close-ups of their faces: Vyas piercingly stares at Ambika with his eyes wide open and an enigmatically blank facial expression, while she keeps her eyes closed, trembling, her face covered in sweat, the reverse shots between the extreme close-ups alternating increasingly rapidly. After a few seconds, the intensity of the sounds and the pace of the reverse shots decreases again until the scene ends abruptly in a cut. Vyas' second encounter with Ambalika is structured in the same way (example 5.15). It starts with a medium shot of Ambalika entering a room in the palace. The intradiegetic sounds of the previous scene - in which Vyas has told Satyavati that their plan did not 
work as intended - bleed into this scene and shape roughly the first five minutes. As in the scene with Ambika, a layer of synthesizer-santur/harpsichord plays a slow, successive string of tones that loosely form an unmetered, meandering melodic line. It comes to a halt on one repeatedly struck mid-frequency tone when Ambalika comes to a halt, leaving space between her and Vyas, who has his back turned towards her. Another repeatedly struck, halting tone consisting of two frequencies an octave apart sets in the moment that Vyas turns around to face Ambalika, who still has her head bowed down, his hand raised in blessing. The moment Ambalika lifts her gaze and looks at Vyas, these sounds are replaced by dense, lashing synthesizer noises, which sound slightly different from the previous scene. These noises are then complemented by further layers of synthesized sound, a polyphone clash of frequencies muddled together and combined with the stinging, metallic timbre of the first sound layer. The resulting wash of sound is extremely tense and abrasive, which is enhanced by the sounds' repeated crashing through a rapid sliding movement across an indiscernible scale. Similar to the encounter between Ambika and Vyas, the actual rape is 'shown' through gradually quickening reverse shots of extreme close-ups of Vyas' and Ambalika's faces. These shots are not perfectly synchronized with the intradiegetic noise, but still roughly correspond with each other. Ambalika, too, has an expression of terror on her face, which is covered in sweat and tears and takes on a greenish shade. Finally, the sounds crashingly settle on a low frequency, where they still continue to fluctuate and rattle for a time. Simultaneously, the pace of the reverse shots slows down significantly before the scene is again ended by an abrupt cut.

The ambiguity of this scene, caused by the fact that Vyas merely acts out of duty, but that the women still experience the encounter as violent, is created through the interplay of images and sound: the horror of the women and Vyas' calmness are visually displayed through facial expressions and make up. The camera angles and pacing of the shots convey the intensity and interpersonal nature of the encounter, but not the act of rape. This visual safe play is contradicted by the sounds, which, are the medium through which the physical violence is mediated. The progression of the sounds over the course of the scene - from the slow, unobtrusive metallic synthesizer at the beginning to the aural escalation of waves of ferocious noise - unambiguously constructs the scene as a moment of violence. The sounds combine all aural elements that constitute extreme sounds in the serial: 
microtonal tension; the combination of a number of clashing pitches and noise at once, often with a hazy, foggy timbre that blurs the perception of pitches; harsh, metallic textures; synthesizer sound; and a general sense of amorphous, overpowering sound. The rough, somewhat alien sounds of the synthesizer efficiently create disturbing and negative atmospheres.

In her essay “Dirty Sound: Haptic Noise in New Extremism” (2013), Lisa Coulthard focuses on this potentially haptic quality of noise in films. As Coulthard emphasizes, it is the raw, supposedly untamed and disturbing quality of noise - droning hums, ambient noises that endows it with the ability to work in potentially gut-wrenching ways. Noise, as she defines it, "is an all-encompassing category frequently used to describe acoustically undesired sounds" (2013: 116). It is the aesthetic of the "disturbance in otherwise peaceful [...] sonic environments", the fact that noises differ from "sounds organized" (ibid.) that makes them so powerful, not only in audiovisual media. While noise is clearly more than just unorganized sound (having enormous aesthetic potential) and, conversely, not all unorganized sounds are perceived as noise, Coulthard's definition this point highlights the underlying notion of disturbance that is fundamental to noise. In Mahabharat, such harsh intradiegetic sounds contrast with the sounds heard in those scenes where the world is properly ordered; athough not chaotic, but carefully orchestrated and placed, these synthesized sounds of violence nevertheless disrupt the impression of 'order' conveyed by pleasant sounds. With their decidedly unpleasant, tense, clashing qualities, they can be perceived as overwhelming, even assaulting. As dense, abrasive and unpleasant atmospheres, these sounds reach out from the narrative space, submerging the audience, pervading them with noise. With their lack of structure and the clashing combination of various unpleasant noises, the sounds trigger a bodily response to this aural stimulation of discomfort, a "psychoacoustical" (Coulthard 2013: $116)$ reaction to the disturbing sounds ${ }^{154}$.

Following theoretician Jacques Attali, the noisy aesthetics of Mahabharat's violent scenes (and of some violent encounters in Ramayan) are particularly apt for representing violence and its intensity due to the disruptive potential of noise. Noise, according to Attali, "is violence: it disturbs" (1985: 26, original emphases). Considering noise as violence means considering music, a channeling of noise, as a means of creating power; it

154 In fact, as Coulthard points out, these unpleasant psychoacoustical bodily effects of droning sounds on the body can even include senses of disorientation, nausea and anxiety (see 2013). 
claims power by forcing a focus and structure on the chaos of noise (ibid.). Even though there is a range of scenes, especially in Mahabharat in which sound does represent violence, it would be too simplistic to equate noise with violence in the two serials, as there are so many instances of violence which are not carried by noise - especially in Ramayan, where violent scenes are most often submerged in voluminous, but not abrasive and noisy, orchestral music. Furthermore, the connection of noise's disruptive force to violence in Mahabharat is complicated by the fact that over the course of the show, encounters of humans and benevolent deities are often drenched in noisy clouds of clattering intradiegetic sounds (example 5.16). In these scenes, the loud, dense, unstructured, metallic sounds are just as unpleasant and discomfort-evoking as they are in the scenes of sexual violence described above. This is the case even though their narrative context is positioned as a polar opposite of violence - if the encounter with a deity is understood as a blessing and positive ${ }^{155}$. On the other hand, these unpleasant noises of divine encounters could be understood as a means of instilling a palpable sense of the respective deities' awe-inspiring power via their overwhelming, noisy presence. In this sense, while sounds that point towards the abject evoke the explosive emotional and visceral amalgam that constitutes violence - the bubbling rage, the aggression, the sheer physical force and destruction (disruption, as Attali puts it) - and make it unpleasantly palpable to the audience, they are not the only ones to do so efficiently. Especially in Ramayan, scenes of violence are rarely unpleasantly noisy or repelling, but rather are ensounded within the 'normal' sound spectrum of the serial, although they are located at the extreme end of this spectrum. Despite not being sonically assaulting and abrasive, these sounds are highly dramatic due to their eruptiveness, their urging qualities, their dense, almost claustrophobic timbres, their rush of rapidly moving melodic lines, and their (tremolo-induced) shaking texture - all of which heavily contrast with the soft lull of flutes, sitar and veena constituting the serene and happy scenes.

\footnotetext{
155 However, it cannot be denied that the first encounter between Kunti and the sun god bears a violent dimension as well. Kunti had received a sacred mantra from her guru with which the god can be summoned as a reward for being a good student. When Kunti guilelessly recites the mantra out of curiosity, the sun god appears and claims to be unable to leave before he gives her "something", this something being a child. Kunti, unmarried, obviously, does not want that, and even though the god ensures her that she will remain a virgin, the encounter, drenched in abrasive metallic intradiegetic sounds, ultimately might also be understood as a violent one.
} 
Thus, beyond all the palpable moments of shock and unease that sounds generate in the serials' representations of violence, it is the intensity of rushing, voluminous, overwhelming, sometimes disturbing sounds that is vital in both serials to make the audience resonate and allow it to empathize with the extremeness of these moments.

\subsection{Aural Valorization of Violence: Norms, Moral and Gender}

As dharmic serials that narrate stories of the struggle of good versus evil, Ramayan and Mahabharat treat violence, too, as a heavily morally charged issue. As an extreme social practice and means of social regulation, violence is embedded in the moral framework of the stories. As such, they draw on and contribute to constructing norms about the legitimacy and illegitimacy of violence within a decidedly Hindu worldview. Given the close relation of morality to normativity and gender (see chapter 4), violence, as a social practice, is also represented as gendered in the serials, as a practice which conveys normative ideas of morality and gender.

The positioning of violence within the serials' moral spectrum draws on the framing of violence in (specific) Hindu scriptures. Here, Juluri's previously mentioned concept of the emotional/relational matrix, which draws on the prevalence of these Hindu concepts in Hindi film culture, is helpful. In both stories, violence is first and foremost framed as a means to (re-)instate social order and maintain power, thus distinguishing between rightful and wrongful violence. As Rambachan points out, such a distinction is already made in the Vedic scriptures, where violence is considered legitimate if certain premises are met. As discussed previously, in these scriptures, violence is only a legitimate social tool for the Kshatriya caste, the caste of kings and warriors, whose dharm it is to (violently) react to aggression in order to protect their people (Rambachan 2003: 116). The Kshatriyas are thus exempt from the basic imperative of ahimsa, of nonviolence. This basic concept of the role of violence within social structures is also prevalent in the epic stories, which grew from the historical-ideological context shaped by Vedic thought. It is also reproduced in the serials: in Mahabharat and Ramayan, violence is normatively organized along the lines of gender and caste, as well as the morally justified codes of conduct. Violence, as a dharmic duty of Kshatriyas and as a means to reinstate social order, is discussed in detail in the Bhagavad Gita. Parts of this discussion are obviously explicitly quoted in Mahabharat, but also beyond such quotations the wider concept of dharmic vs. 200 
adharmic violence lies at the heart of both serials. Corresponding to the Hindu ${ }^{156}$ context, they frame violence committed from greed or hunger for power as immoral, and violence in defense of righteousness, exercised according to a code of conduct, as justified. Because legitimate violence is therefore always a reaction to previous transgressions, it can be considered as embedded in Juluri's (2008) emotional-relational matrix. In the serials, it is entrenched in the characters' social relations also results from these relations.

While this underlying moral framework provides a straightforward guideline for assessing the validity of violent acts, the (intradiegetic and diegetic) sounds of violence do not always frame the serials' representations as unambiguously as this framework might suggest. At times, the aural ambiguity might spring from the fact that the representation of a given violent act is more focused on evoking the intensity of the encounter (see chapter 5.2.1), or on representing the involved characters as human and therefore inherently flawed, as is common in Mahabharat ${ }^{157}$. Likewise, the range of sounds through which violence is represented, especially in Ramayan, is more limited and thus has less scope to differentiate between 'righteous' and 'wrongful' acts. Explicit framing of violent acts in terms of morality in Ramayan often happens in songs or sung passages during battle scenes. The moral valence of act of violence is often conveyed not in the act itself but prior to the representation, during the act's preparation, or the confrontations that lead up to an outbreak of violence. Thus, it is not even always necessary to morally position a violent act during its occurrence because its moral value is evident from its (aural) framing in the narrative context. This way, the aural frames that are built around

\footnotetext{
156 I am here referring to the formative Hindu philosophy as it is expressed in the traditions around the underlying narratives of the two serials. The ideas about religiously motivated and legitimized violence had of course undergone significant shifts by the time the serials were produced and broadcast. Hindu nationalism, first emerging in the wake of anti-colonial activism in the late $19^{\text {th }}$ century and regaining strength in the 1980s, for instance, focused on defending India as a Hindu nation against what is perceived as alien influences, for instance Islam and Christianity (Rambachan 2003). The adaptation of discursive tropes of the newly rising Hindu nationalists occurs repeatedly throughout the serials (Mankekar 1999, Rajagopal 2001). While the serials were not produced as part of a Hindu nationalist agenda, the politization of Hindu philosophy and its employment for legitimizing violence did impact their production and the ways in which violence was framed.

157 In fact, during my stays in India many of my interlocutors emphasized that they preferred Mahabharat over Ramayan because they perceived Mahabharat's portrayal of its characters as more life-like, admitting to their inherent imperfection in contrast to Ramayan's focus on Ram's perfection.
} 
representations of violence in the serials also serve to position the characters and their actions on the moral compasses of Ramayan and Mahabharat.

The aural moral evaluation of the characters involved in a violent scene is accompanied by a normalizing aural construction of gender. Corresponding to the conservatism promoted by the serials, exerting violence is, with few exceptions, only socially acceptable for men of the Kshatriya caste. Women, by contrast, are only confronted with violence as victims or as relatives of men who are involved in violence. In fact, the two central female characters of the serials, Draupadi and Sita, are defined most strongly by their role as victims of male violence. Goddesses and demonesses are an exception to this female exclusion from violent behavior. In both serials, there are characters who challenge this basic setting of gendered violence and whose transgressions, marked as such by sound, refine this binary of violence.

For the central male characters of both stories, violence is part of their essential repertoire of action. 'Violence', in this case, refers to martial prowess, the ability to win a physical confrontation through the skillful use of weapons and force. Given the serials' focus on rulership and conflicts over territories, the importance for men of fighting - and winning - as a vital means of achieving and securing dominance is evident. Accordingly, in both serials the protagonists' rites de passage of becoming men are represented as extensive martial challenges: In episode 4 of Ramayan, Ram, who has just completed his education at an ashram, is called to help sage Vishwamitra by eradicating the plague of demons who are constantly attacking his ashram, thereby disturbing its inhabitants' pious lives. Ram and Lakshman follow Vishwamitra and encounter the terrible demoness Tadaka, who attacks them, but is immediately slain by Ram. The sequence introduces Ram as a fullgrown man who is able to defeat frightening, superhuman enemies. While this first violent scene of the serial is not constitutive for the further development of the plot, it is necessary for presenting Ram as the benevolent, dutiful warrior that he has grown into. However, the intradiegetic sounds employed to represent violence in the scene are unusual, consisting mostly of hissing, swooshing, and wafting synthesizer that contrast with the mostly swirling, melodic orchestral passages heard in most violent scenes in Ramayan. The diegetic sounds, however, are typical to how violence is aurally represented in the serial. 
In Mahabharat, the Kuru princes are also presented as grown-ups through a display of their martial abilities. In episode 24, the Kauravas and Pandavas, who have just completed their education by the warrior-sage Dron, demonstrate their martial skills to their parents, the court's elders, and the people of Hastinapur. The entire episode revolves around this demonstration of skill. In smaller groups of two to five, the princes spar with different weapons. Unlike Ramayan, both the intradiegetic and the diegetic sounds of this first demonstration of the protagonists' martial prowess are typical for the serials' aesthetics of conflict. In fact, many intradiegetic sounds are heard for the first time in this episode, thus in a sense introducing the aesthetic combining orchestral and noisy, machinic synthesizer sounds in one single intradiegetic passage - an aesthetic that has been employed, albeit sparsely, in previous episodes (example 5.17). This way, this demonstration of the princes' masculinity also establishes an aesthetic that provides aural continuity for the remainder of the serial.

These early sequences of violence link the adult versions of their protagonists - or rather the instant of their growing up - to their ability to exert violence, as if their masculinity could only be confirmed through their skills in battle. This explicitly positive staging of the princes' martial skills does not produce a homogenous masculine identity, but implies a casteist exclusionary mechanism, which, in Mahabharat, becomes evident in the examples of Karn, who, as a foundling of secretly noble birth has to cheat his way into military education, and Eklavya, whose caste status ultimately costs him his thumb and keeps him from becoming an archer. As analyzed above, in the case of Eklavya, the extreme punishment he receives for his transgression is normalized by the calm intradiegetic sounds that surround the actual representation of his self-mutilation.

The normative framing of masculinity through the (aural) representation of violence also extends to the normative image of femininity by positioning female characters in relation to violence. As previously mentioned, the idealized female characters of Draupadi and Sita relate to violence as victims: Sita is abducted by Ravan and Draupadi is repeatedly assaulted by the Kauravas and other kings. Their status as victims of violence, and the violent acts themselves, are powerful catalysts of the two serials' plots. The two women deal with this status differently. Draupadi's active and continuous demands for revenge by her husbands point towards another role that women can occupy with regard to 
violence: that of the instigator ${ }^{158}$. Draupadi's refusal to suffer in silence is also portrayed as problematic in the serial. Occasionally, the narrator Samay declares it to be one of the reasons for the apocalyptic war of Kurukshetra, and at one point her actions are explicitly reprehended by Krishna (episode 78). This indicates the limits of morally justifiable female participation in violence as presented in the serials. Sita, in contrast, suffers passively, weeping and crying for Ram to save her. Getting little musical attention over the course of the serial, barely being involved in representations of violence at all, Sita is representative of most female characters, who are barely accounted for aurally in scenes of violence beyond the sounds of their screams. Apart from such diegetic and intradiegetic sounds (such as those in the niyoga sequence) that can be attributed to their experiences of violence, women are almost muted in the context of violence.

In both serials, the rare exceptions of women who are aggressive or actively exert violence are either goddesses or demonesses - extremes that are clearly beyond the norms pertaining to the 'ordinary' human woman. And even in these extreme cases, violence is different than that exerted by men: Ganga's infanticide, carried by lavish orchestral passages accompany her walking to the riverside. The moment she drops the respective child into the water, this music is replaced by either an explosive, bubbling stinger, an intradiegetic rendition of the arti 'Om Jai Jagdish Hare' or a single layer of reverberating, slightly squeaking synthesizer-sound that sounds like a shenai, playing a slowly meandering melody with a piercing timbre. Ganga's repeated acts of violence are thus musically positioned as tragic occurrences. While Ganga's violence is aurally rendered differently than most male violence in the serial, it is within the conventional range of sounds employed in Mahabharat to create an air of tragedy and sadness, thereby aurally setting Ganga's violence apart from other violent acts in the serial. Furthermore, it clearly positions the acts not as abhorrent violation of social rules, as violence is often framed in other parts of the serial. Instead, Ganga's killings of her children, motivated and legitimized as we later learn, by the fact that she releases them from a curse, sound entirely differently from Kansa's killings of his sisters' children (example 5.18). The murders committed by Kansa, ensounded by the reverberating screams of his sister and the low-pitched, rumbling intradiegetic synthesizer sound that is continuously connected

\footnotetext{
${ }^{158}$ In this, she clearly contrasts with Gandhari, who ardently tries to maintain the peace between the rival parties. 
to him, are solely motivated by his hunger for power. Accordingly, they are aurally positioned as immoral atrocities.

Beyond the distinct motivations behind these characters' acts, their different aural valorization and the different ensounding of their acts of violence also contain a gendered dimension - while Kansa is without exception portrayed and aurally constructed as an aggressor, Ganga's act is aurally positioned as the selfless deed of a mother wanting to protect her children. Elsewhere, she is not aggressive or violent at all, but instead presented as a benevolent, calming, omniscient character in the background. As the only other character besides Shakuni and Kansa, her appearances throughout the serial are constantly connected to a specific passage of intradiegetic music ${ }^{159}$, featuring voices singing a slowly ascending pattern (intonating 'a') with soft, voluminous voices. These are combined with toned down strings duplicating and continuing the ascending melody, with temple bells, flute, soft drums and a drone, all playing at a calm pace (example 5.19). This continuous musical framing of her character indicates her exceptionality among the female characters in the serial, positioning her, the goddess, at an end of the moral spectrum that is unattainable for mortal female characters. The other violent female characters of the two serials are the exact opposite of Ganga: they are evil demonesses. In Ramayan, Sita is guarded and occasionally harassed by armed demonesses (although one of them, Trijata, is friendly to Sita, frequently consoles her and provides her with information on Ram). Shurpanka, Ravan's sister, initiates the entire plot around Sita's abduction by aggressively expressing her desire of Ram and Lakshman and threatening Sita in the same course of events. Overall, the ways in which violence is related to female characters constructs a morally charged image with normative implications: women are not supposed to be aggressive, but bear violence passively, ensounded through desperate weeping and intradiegetic sounds of tragedy.

In Ramayan, the already mentioned demoness Tadaka is represented as a giant monster without any of the pleasing visual attributes of the serial's beautiful queens and princesses

159 There are also passages of intradiegetic music that are, for instance, frequently heard in connection to Duryodhan, Krishna and Arjun, but these passages are only connected to phases of their lives or specific situations, so that they are only heard in individual scenes and not throughout these characters' appearances over the course of the serial. 
(or men, for that matter): dark-skinned, hairy, cross-eyed, with displaced teeth and a necklace of human skulls, she makes several attempts to kill Ravan, Vishwamitra and Lakshman with her magical weapons. The sounds employed in this scene (see example 5.20) equally construct her as monstrous: the dense, machinic intradiegetic synthesizer sounds as well as her deep, booming, raucous voice, with which she only laughs, grunts and screams but does not articulate any words, create an uncomfortable setting and leave no doubt about the intended negative image of Tadaka. In the $12^{\text {th }}$ episode of Mahabharat, the evil Kansa instructs the demoness Putana to kill all newborn children in Krishna's village to make sure that Krishna, who is threatening to Kansa's tyranny, is eliminated. Putana assumes the form of a young human woman with a ravanhatta (a bowed string instrument) which is heard intradiegetically, reverberating, alternating with scattered, equally reverberating drum beats, over the course of the episode when families are shown mourning their deceased babies. While these sounds surround Putana's acts of violence, being heard before they take place and after their discovery, another layer of intradiegetic sounds is heard when Putana sneaks up on, abducts, and tries to poison the baby Krishna. Irregularly wafting, bubbling synthesizer noises are heard in the background, while Putana's raucous, booming laughter dominates the diegetic soundscape as she attempts to kill the baby (example 5.21). Putana has now assumed her demonic form, which resembles Tadaka's representation. This disturbing appearance emphasizes the sense of threat and horror created by the intradiegetic and diegetic sounds uttered by and surrounding the two demonesses. Tadaka and Putana, as rare examples of aggressive, violent female characters are constructed as transgressing any social norm and as defining the negative end of the serials' moral spectrum. Barely constructed as characters with an autonomous motivation or personality, they are merely portrayed as frightful examples of thoroughly depraved monsters whose danger is essentially constructed through sound. As violent, immoral female characters, they are, in the truest sense of the term, demonized.

In Mahabharat, there are two characters in particular whose ensounding exposes the connection of violence with gendered norms and morality. Brihannala, who is barely a distinct character, and Shikhandi each have small storylines in the serial in which their respective gender identities are directly connected to violent acts and music, each in distinct ways. Shikhandi, the brother of Draupadi, participates in the battle of Kurukshetra on the Pandavas' side. Not only was Shikhandi born as a woman: in an earlier life, he was 
Amba, one of the princesses who were abducted by Bhishm during their swayamvar to be married to Vichitravirya, Hastinapur's heir to the throne. When Amba refuses to marry Vichitravirya and is subsequently rejected first by the prince of Halwa, then by Bhishm, she swears to avenge her mistreatment by punishing Bhishm. After her rebirth as Shikhandini, she gains her sex change as a boon for strict penance. But even though Shikhandi is now a man, he is not perceived as an equal by the other male characters, his past as a woman denying him the social value of a 'real' man. This lower status, resulting from his transgression of gendered norms, is aurally outlined by intradiegetic sounds, by the demeaning ways in which the other characters treat him, and by the fact that he is employed by the Pandavas in a ruse to kill Bhishm in the Kurukshetra war. Bhishm, who once was granted the boon to choose the moment of his own death and who is an outstanding warrior, cannot be eliminated by 'regular' fighting in the battle of Kurukshetra. Thus, as a ploy to defeat Bhishm, Krishna proposes to let Shikhandi take his place as Arjun's charioteer for a day: since Bhishm won't raise his weapons against a woman, which he apparently still considers Shikhandi to be, Arjun will have free access to a more or less helpless Bhishm and will be able to take him down. The plan works as intended. Bhishm is wounded by Arjun and spends the remaining days of the battle laying on the bed of arrows that pierce his body until he eventually decides to die. Shikhandi has thus been a vital figure or strategy in eliminating Bhishm and thereby for the Pandavas' victory in the battle.

The episodes that include Shikhandi's storyline and the development and execution of the plan to defeat Bhishm (episodes 78 and 79) feature an unusually vast array of new intradiegetic musical passages that create dense, uncomfortable, nightmarish atmospheres in the respective segments. Over the course of these episodes, various layers of synthesizer with textures including hazy, machinic, hissing, swirling, clashing, and belllike sounds, are combined with acoustic instruments (mostly strings). The slow pace of most of these passages, their often unmetered irregularity and timbral fragmentation, and the range of scales and tones create unsettling aural tensions. These clearly contrast with the softer, more homogeneous musical passages associated with morally immaculate characters, or with positively tragic situations, such as those that characterize the story of Bhishm. In episode 78, Bhishm has a final encounter with his mother Ganga. This 
sequence of roughly three minutes is entirely carried by the intradiegetic passage connected to Ganga (see example 5.19) and extensions of this passage in the form of brief aural fragments played (alternatingly) by bells, tanpura, swarmandal, sitar, vibraphone and flute. Played at a sedate pace in hushed, smooth and hazy timbres and textures and lacking any harsh attacks, a calming, feelgood atmosphere is stretched over the entire sequence and reinforces Bhishm's moral superiority one last time. The aural contrast of the different passages in the two episodes locates the sounds, and thus the events and characters they co-narrate, at opposing ends of Mahabharat's moral spectrum. This is especially salient in the following sequence of scenes: After Bhishm has talked to Ganga, he releases his slaves into freedom in a scene that features no other sounds apart from the diegetic dialogue, the rustling of fabric, and the clinking of jewelry. The scene concludes with an intradiegetic rendition of 'Om Jai Jagdish Hare', the reverberating vibraphone barely fading out before a sudden cut to Shikhandi in his tent, preparing for battle (example 5.22). The aural cut, perfectly synchronized with the visual one, is almost shocking in its abruptness. An extended drum roll rumbles loudly over a brief scale of very deep frequencies and combines with a hissing synthesizer sound - like radio interference - that rapidly moves from mid to high pitch and then back to a lower pitch. This section of mismatched, colliding sounds repeats before being replaced by other aural fragments as the sequence unfolds: Arjun enters the tent and a conversation between the two men starts. During the conversation, the intradiegetic montage of musical fragments that form a mosaic of clashing aural elements, some of them with negative connotations in the context of the serial, continues. Distorted, noisy synthesizer sounds combine with looped, low-pitched string fragments with jittery timbres; they circle around a brief minor-scale melody before becoming an ascending passage. When Arjun speaks, the sounds shift: they now consist of voices intonating on 'a' and metallic, distorted synthesizer-sounds, thereby referencing previous scenes dealing with his moral struggle during the Kurukshetra war. During the last seconds of the scene, coinciding with Shikhandi's response, fragments of Shakuni's characteristic passage are employed. Deconstructed and spread out, they are interlinked with other sounds. The descending melodic fragment which is played by a high-pitched synthesizer in Shakuni's passage is now played by a lower pitched, muffledsounding brass wind-like synthesizer over a low, rumbling synthetic drone. The sounds of this sequence, specifically those that are unambiguously linked to Shikhandi, are outstandingly harsh and tense due to the clashing combinations of mismatching musical 
elements. Shikhandi falls outside of the gendered norms and challenges the gendered rules that control violence as a social practice. As Andrea Custodi points out, it is the direction of Shikhandi's gender transition, from female to male, which makes him such a problematic character: "A woman who wants to become a man [...] constitutes a direct challenge to the social and political status quo, and her sexual transformation thus must be allayed, undermined, inauthenticated, made only temporary, or outright denied" (2007: 217). Bhishm's refusal to acknowledge Shikhandi's masculinity is such an undermining, and it directly leads to Bhishm's defeat.

Even though he is merely a pawn in Krishna's ruse, Shikhandi is judged through the intradiegetic sounds of the serial. In particular, his challenging of the norms of gender identity and violence as they are represented in Mahabharat are singled out and constructed as thoroughly negative through intradiegetic sound. Not only is the montage of musical fragments heard in the scenes in which he appears disturbingly harsh, clashing and noisy, it also singles him out: the music heard during Shikhandi's screen time is unique to this character and is employed nowhere else in the serial. This example offers another perspective on how morality, gender, and violence are interlaced by (aurally) constructing Shikandi's transgression of gender norms as fatal to one of the story's major benevolent characters. As Custodi points out:

"As fluid as sexual characteristics and gender may be among deities and in mythological escapades, however, dharma as it structures and orders this-worldly affairs revolves around a firm conception of the two genders, and is very much based upon their clear distinction and eternal stability. In the Mahābhārata a lack of clear distinction between the sexes has inauspicious resonances" (2007: 209-10)

Another character who challenges gender norms, but who is contained by them with respect to violence, is Brihannala. The Pandavas have to spend their last year of exile in public, but unrecognized. They decide to hide at the court of King Virat: Draupadi works as a maid, Bhim as a cook, Yudhishthir as a courtier to the king, and Nakul and Sahadev work in the stables. Arjun, the virile, outstanding warrior, assumes the disguise of 
Brihannala, a transsexual/transvestite ${ }^{160}$, who teaches singing and dancing to princess Uttara. This disguise poses the starkest contrast possible to the 'regular' character of Arjun. In his choice of this disguise, Arjun cleverly makes use of the fact that he has been cursed to a year of impotence in an earlier encounter with a goddess. Confirming Custodi's thesis that male-to-female gender-bending or transition is socially more acceptable than the other way around, Brihannala is not portrayed negatively in Mahabharat, at least not through music. Instead, she is portrayed through musicking, which goes along with her function as dance teacher at Virat's court. In Mahabharat, men neither sing, dance, nor with the notable exception of Krishna ${ }^{161}$ - play instruments. Arjun's adoption of music and dance as Brihannala thus can also be understood as a comment on his (temporary) gender identity. In one extended sequence in particular, the entanglement of norms associated with music, gender, violence comes to the fore when, in episode 58, Draupadi (disguised as the Queen's maid) is assaulted by the Queen's brother Keechak in front of the entire court assembly. The incident tragically repeats the Kauravas' assault in Dhritarashtr's court as culmination of the game of dice. Again, Draupadi demands that her husbands avenge her humiliation. Yudhishtir, in another parallel to the assault in Hastinapur, witnesses the incident and is unable to intervene because that would risk disclosing his true identity. Therefore, Draupadi turns to Bhim with her demand for revenge. Bhim agrees and they develop a plan to lure Keechak into a trap. Later at night, thinking that he will meet Draupadi there, Keechak goes into the palace's dance hall where Bhim awaits and finally kills him with his bare hands (see chapter 2; an excerpt of only the fight is example 5.23). The extended fight scene alternatingly shows Bhim and Keechak struggling from different camera angles, as well as Draupadi delightedly peeking at the scene from behind a pillar. Brihannala, as husband of Draupadi, is the third element that is alternatingly shown in the scene. Starting with Bhim's first punch of the fight, the scene is delivered through a web of three different layers of sounds: an intradiegetic layer of synthesizer sound that morphs in texture - broad, hazy, overtone-rich - while staying roughly on the same range of pitches, a diegetic layer of stylized fighting sounds and grunts, and finally, a diegetic (enhanced, reverberating) layer of drumming. Alternating with the images of the fight and of Draupadi observing it, medium and close-up shots of

\footnotetext{
160 I am hesitant to speak of a gender transition in the case of Brihannala, because in the serial as well as in the epic (see Custodi 2007) it is not clear whether Arjun only crossdresses or actually assumes a different gender and sexual identity.

161 And even Krishna does not play the flute anymore as a grown man. 210
} 
Brihannala playing a pakhawaj are shown. While it is not clear whether or not Brihannala is sitting in the room in which the fight takes place, it is evident that the loud, dense and rapid sounds of her drumming are supposed to obscure the noises of the fight. Blankly staring straight ahead, her face increasingly covered in sweat, Brihannala intensely plays the pakhawaj over the course of the entire fight. At the end of the scene, her playing already wild and loud due to the ever-increasing noise of the fight, she smashes the drumhead a final time, her hands covered in blood. The symbolism of these final images is not too subtle: Brihannala literally has blood on her hands because her playing allowed Bhim to kill their wife's assailant. Thus, while on the one hand Arjun fulfills his duty as a husband to protect his wife, on the other hand, due to his ambiguous gender at the time of the fight, he does not or cannot actually participate in the fight. Located at a physical distance from the setting of the fight (even if he is in the same room, the two fighters do not get close to him), he contributes in a way that stands in stark contrast to the repertoire of actions that corresponds to his usual "hypermasculinity" (Custodi 2007: 212) as a warrior. He is excluded from the 'properly' masculine way of handling the situation and displayed participating in it in a way that is reserved - with the exception of Krishna - for female characters in the serial. As an incomplete man, the social norm prevents Brihannala from joining a thoroughly masculine means of social interaction, of assertion of dominance and control.

Norms of violence, morality, and gender are complexly entwined with sound in Mahabharat and Ramayan. Norms - here specifically gendered norms - govern violence as a social practice in the serials. These norms are closely connected to the spectrum of morals that is constructed in the stories. Violence is legitimized or condemned in terms of this moral spectrum. Likewise, the characters' genders contribute to positioning acts of violence on the stories' moral spectrum, and in turn are defined by their position towards violence. Sound is a vital element of this process of normalization, legitimization, and moral validation because it atmospherically positions situations and characters along the intersecting lines of norms and morals. 


\subsection{Concluding Thoughts}

Violence is a social practice through which dominance is negotiated. Therefore, it is a vital factor in fundamental dynamics of rulership, authority, and (the outlining and maintenance of) morals. Given the central focus of both Ramayan and Mahabharat on power struggles and questions of legitimate rule, this close relationship between violence and power is of utmost importance. Violence motivates major elements of the serials' plots, it is a pivot for narrative developments, and it is a means for defining both the characters as well as the moral framework in which they act. In Ramayan and Mahabharat, sound is an indispensable medium for conveying violent acts, differentiating between them, and positioning them within moral frameworks. I have focused on outlining the four constitutive pillars of the aural representation of violence in Ramayan and Mahabharat: the distribution of representations of violence over the serial narratives, the aesthetics and conventions of representing violence, the creation of intensity and moral positioning of violence through sound, and the corresponding aural normalization of gender.

Both Ramayan and Mahabharat culminate in extended wars - in Mahabharat, this martial climax is framed teleologically from the first episode onwards. Beyond these destructive wars, representations of violence are distributed irregularly over both of the narratives, often occurring in clusters, thereby imposing an erratic rhythm of audiovisually dense scenes of violence over the narratives. The clustered scenes of violence are points of dramatic density that dramatically pivot and expedite its plot. Every instance of violence contributes to increasing the tension among the characters involved, thereby foreshadowing the ultimate, inevitable, apocalyptic violent clashes that lead the two narratives to their ends. In both serials, aural representations of violence are not ends in themselves; they are not included for the sake of spectacle alone but are instead deployed to construct moral frameworks and to position characters and their actions within them.

Visually, representations of violence in Mahabharat and Ramayan are governed by conventions established in performative traditions such as Ramlila and mythological films, while film music is the most prominent aural influence. The audiovisual blends that create representations of violence in the two serials thus balance the aesthetics of regional theatrical formats with demonstratively modern ones. Especially the extensive use of decidedly modern synthesizers - mostly for diegetic sounds in Ramayan and for the 
tense, wafting intradiegetic soundscapes in Mahabharat - can be understood as the establishment of a specific televisual aural aesthetic of violence.

The visual aesthetics of many of the instances of violence are heavily stylized. In particular, military combat is depicted as entirely disembodied, creating an abstract, incorporeal image of violence (even a censored image in the instances of sexual violence in the narratives). In these scenes, it is sound that brings back the body and the inevitable intensity of physical violence into these representations. The dense layers of intradiegetic and diegetic sounds create atmospheres of tension and rush. They evoke the physical intensity of a fight by allowing the audience to empathize with the characters' raw utterances of exhaustion and aggression. The highly exaggerated sounds of punches and impacts of weapons are vital for creating a sense of the physical and psychological intensity of the violent acts, serving as a bridge between the disembodied visualization of violence and the audience. The swirling, agitated or seething, uncomfortable intradiegetic layers of sound evoke the tension, frenzy or horror of violence, which, drawing on Attali and Coulthard, are rooted in the unpleasant and therefore in themselves violent textures of noise. Beyond these immersive capacities, the diegetic sounds in particular are also vital for structuring - and thereby rendering intelligible - a scene of violence by punctuating its visual rush and highlighting impacts, falls and the like.

Sounds are essential for positioning the narratives' representations of violence within the moral frameworks of the shows. In Ramayan and Mahabharat, violence illustrates moral ideas by clearly distinguishing between legitimate and reprehensible acts. By employing cinematic aural conventions that atmospherically resonated with the audience, the serials effectively position acts of violence as right or wrong.

The audiovisual representation of violence in Mahabharat and Ramayan could be understood as an attempt to amalgamate modernity and ancient morals, to modernize the partially reactionary values they convey by blending dated theatrical and cinematic modes of visually representing violence with modern sounds. The synthesized sounds of Ramayan's and Mahabharat's violent outbreaks are an emblematic of the 1980s televisual aesthetic zeitgeist - at least of the numerous international programs that were also shown on Doordarshan during the time that the two mythologicals aired. Combining these 
futuristic sounds with the traditional, polite visuals and sounds of violent encounters updates the stories and extends their claims to timeless universality to the modern age of television. It also endows their televisual narrations with the intense expressive potential of the synthesizer to stage and evoke the extremity of violence.

As most of my interlocutors during my stays in India pointed out to me, the aesthetics of Ramayan's and Mahabharat's representations of violence were often amusing rather than emotionally stirring to their young, urban audience. Nevertheless, or perhaps because of this, the violent scenes of Ramayan and Mahabharat are still a much-loved point of reference in Indian popular culture. The enduring popular cultural relevance of Mahabharat and Ramayan has grown out of the serials' extraordinary impact on India's mediascape during their initial broadcast - a topic that still shapes the discourse on the serials 30 years after Ramayan was first aired. 


\section{Epic Television: TV-Frenzy, Legends, and Nostalgia}

"I think for me [...] it is like the memory of - people flocking our house on Sunday morning. Like, there were neighbors who did not have televisions [...]. So they would come and sit in our house and watch Ramayan with us [...]. We're a Christian family and yet, like, you know, both the serials were so central to our Sunday ritual." (PK, 8 Apr 2015)

"And I remember that the Mahabharat at [...] the peak of its craze, I think it was telecast at 10 a.m. on Sunday mornings, at that time there were [...] news-stories about how if you went out on the roads at 10 or 10.30 in the morning on Sunday you would not see a soul. Anywhere." (KT, 25 Apr 2015)

"My first memory for instance just now is seeing arrows. Flying through the air." (RB, 24 Apr 2015)

"Everybody watched it! The whole country watched it! [...] Sunday morning nine o' clock, if you're standing on the street you will not see anybody outside." (LS, 21 May 2015)

"We didn't have choices. [Ramayan] was the only one that was available so you [...] adapt to it." (TL, 7 Jun 2015)

"The theme song [...] (sings) 'atha shri Mahabharat katha' [...] this is [...] the music[al] attraction where the people used to [...]put on the TV, they used to wait for half an hour, [...] as soon as this music used to start, it the streets were empty, the roads used to be totally finished and they [...] were all attentive. In fact, there was a total strike like thing, [...] whole cities, entire India used to be totally closed." (SP, 26 May 2015)

"People [...] like my grandmother. Every time Krishna's character would come on, she would start praying to the TV." (BA, 18 Jun 2015)

"K: So that timeslot became sacred, you know?

B: $m h-h m$

K: Like people just stopped everything and like housewives would finish their cooking [...], and everybody else would kind of, you know, sit in front of the TV, waiting for the serial. [...] B: [...] I can imagine. Do you still remember the music of the serials? That is something that I have to ask of course (laughs).

K: (sings) Mahaabharaaaat!” (KR, 15 Jun 2015)

"The title songs have been drilled in! [...] I don't remember any other songs, [but] the title songs are drilled in. The there's no way I can forget them. [...] that voice in the opening. 'Mai samay hu'. That. All of these are so iconic." (SK, 16 Feb 2016) 
These excerpts from interviews I conducted during my stays in India illustrate the range of reactions, or rather the range of aspects addressed, when I would ask my interlocutors for their spontaneous or most salient memories of (watching) Ramayan and Mahabharat. Also, beyond my formal interviews, people I met and talked to about the topic of my research would often start recounting their memories. Here, too, they would most often talk about collective viewing, about relatives praying in front the television, about empty streets during the broadcast, and some of them would even burst into the drawn-out "Mahabharat" exclamation of the show's title sequence. With these accounts and anecdotes, my interlocutors reinforced some of the most prevalent topics that I had noticed in my previous reading on Ramayan and Mahabharat during the initial phases of my research.

The similarities of many of these accounts indicate how strongly the collective memories of the two serials are shaped by a small number of topoi. These independent perpetuations of similar or even the same themes constitute the consensus of what was formative and essential about Mahabharat and Ramayan, and mainly revolve around the audience's reactions, the practices of viewing, and the aesthetics of 1980s Indian television (particularly, of course, of Mahabharat and Ramayan themselves). In turn, scholarly studies of the development of Indian television, of the Indian public sphere in the wake of liberalization, the rise of Hindu nationalism and communal violence, or even of the newer trends in the traditions of narrating and performing epic stories, cannot avoid to at least mention Ramayan and Mahabharat. These repetitions of discursive fragments in accounts of watching the serials create selective images and establish hierarchies of what is considered most salient and important about the two shows. As such, these discourses significantly shaped my research, my approach to and understanding of the serials and their musics. Therefore, in this chapter I address the continuing perpetuation of these discourses and the images they (retrospectively) create of Mahabharat and Ramayan. I analyze the ways in which the serials' aesthetics are now an anchor of nostalgic, embodied memories for some of their audience and thus how they are still potent points of reference in contemporary India's popular culture.

I conducted my research in India in 2015 and 2016, almost 30 years after Ramayan first aired (January 1987). Obviously, the memories of my interlocutors of how they perceived 
the serials during their initial broadcast can in no way paint a picture of an alleged past 'reality'. However, at no point of my research was it my goal to reconstruct my interlocutors' actual feelings when they first experienced the serials. Rather, I was interested in how my interlocutors remembered and reacted to the serials now, decades later, in order to gain insights into how they perceived and understood TV-serial music. I was interested in how this perception of the serials' music fed into their memories of Mahabharat and Ramayan and how these memories of the serials continued to affect current understandings of the stories and popular culture.

Over the course of my research I barely read a text or had a conversation about Mahabharat and Ramayan without reading or hearing about the outstanding impact of the serials' broadcast, either in terms of the sheer magnitude of their audiences, or with regard to the ways in which people engaged with the serials. Engaging with, or drawing on these discourses appears to be an indispensable element of writing and talking about Ramayan and Mahabharat. I am aware that by retracing them, I also reproduce them. However, I consider engaging with these discourses important not only because they shape the memories of people's experience with the stories and with the medium of television more generally, but also because these discourses are vital to the founding narrative of Indian television and the self-image of India's (televisual) popular culture. In engaging with the ways in which my interlocutors remember the serials and how authors talk about them, I aim to provide an overview of how, by whom, and to what ends the audience's responses to the serials were described, and to which other discourses - for example, Hindu religion, popular culture, the televisual medium, and India's postcolonial society - these responses were connected.

\subsection{Perspectives on Mahabharat and Ramayan - Now and Then}

During my research, it struck me how the accounts of people's experiences with the serials and of the phenomenal manifestations of the audience's response were not just similar but also remarkably durable. Individual details notwithstanding, newspaper articles from the time of the serials' broadcast, scholarly articles published in the decades after the broadcast, and the recollections of my interlocutors in 2015 and 2016 constitute a very 
consistent common thread. Often, I would encounter the same stories I read in a newspaper article from 1988 in interviews I conducted in 2015. Combined, these stories create the impression that during the almost three years in which Ramayan and Mahabharat were first broadcast, there was practically no way to avoid engaging with them in one way or another. Even those of my acquaintances in India who had not watched the serials had done so not because they hadn't heard of them, but because they had consciously decided to not watch them. Thus, even avoiding the serials was a way of intentionally engaging with them.

Mahabharat and Ramayan, so the tenor of all the accounts, caused a run on television that had been unprecedented and unpredicted in India. Many of the journalistic and scholarly texts on the shows support these abstract statements with numbers, citing (estimated) audience ratings which reached unprecedented heights during the serials' broadcasts ${ }^{162}$. Interestingly, however, these ratings are rather inconsistent. A brief review of the figures cited for Mahabharat reveals that estimations of viewership ranged from 74\% (Iyengar 1989), over 80\% (Krishnan 1990: 115 FN 6), to 92\% (Mitra 1993: 90, FN 1; Hegarty 2012: 192). Others give concrete - but varying - numbers, ranging from 80-100 million according to Cusack (2012: 279) and Rajagopal (2001: 84), up to 200 million according to Mankekar (1999: 224). Others refrain from citing actual figures and instead simply imply a (miraculously) high quantity of viewers (Ninan 1995: 35; Singh 1988). Beyond their inconsistencies, these numbers allow authors to convey a more concrete sense of the abstract enormity of the serials' audience as well as a way to legitimize Ramayan and Mahabharat as landmarks of Indian television. The numbers set the two serials apart from the rest of the programming as they illustrate that the frenzy Ramayan and Mahabharat caused - and the overwhelming mass of people they mobilized and mesmerized - far exceeded the success of every previous show. Other successful Indian-produced serials from the 1980s that are often mentioned alongside Ramayan and Mahabharat, such as Nukkad, Buniyaad or Hum Log, are never connected to such legendary accounts of an enormous mass audience.

The allegedly immense revenues the two shows yielded for Doordarshan and the production companies Sagar Arts and BR Films are also occasionally brought up in texts on the serials, both in the press coverage (Vaid-Fera 1987; The Illustrated Weekly of India

162 References to audience ratings were also emphasized by those of my interlocutors who were parts of the serials' production teams. 
8 Nov 1987) and in academic publications (Lutgendorf 1990: 135-36; Mankekar 1999: 374 FN 2) ${ }^{163}$. The commercial potential of the medium of television was already foreshadowed by the success of the first commercially sponsored serial, Hum Log, and the rise in advertising revenues it generated. Apparently, however, the extreme popularity of Ramayan and Mahabharat propelled these revenues into new dimensions (Ninan 1995: 147-48; Mankekar 1999: 80-81).

Overall, the accounts - written and verbal - of the ways in which the audience responded to the serials' broadcast, almost always featured elements that conveyed the exceptionality of Mahabharat's and Ramayan's impact. Generally, such accounts would feature either one or both of the most prevalent topics: descriptions of the impact of the broadcast on social life and people's various efforts to catch the latest episode, and/or the particular religious mode of the audience's interaction with the programs ${ }^{164}$.

Both authors and my interlocutors illustrated the outstanding popularity of Ramayan and Mahabharat by describing the great lengths people would go through to watch the shows and the dramatic changes of social life and public space during their Sunday morning time slots. In his 1990 article, Lutgendorf describes the impact of Ramayan's broadcast as follows:

"Visible manifestations of the serial's popularity included the cancellation of Sunday morning shows in cinema halls for lack of audiences, the delaying of weddings and funerals to allow participants to view the series, and the eerily quiet look of many cities and towns, especially in the North, during screenings." (1990: 136-37)

Accounts of deserted streets and villages (Gupta 1998: 47) are complemented by stories of the limited access of most people to televisions, so that masses of the serials' audience would watch the shows "at the homes of relatives or at local tea shops" (Richman 1991: 3, cf. Rajagopal 2001: 94-95)165. Other stories, for instance of train conductors stopping (and staying) in stations with a television set in order to watch the show (see Rajagopal

\footnotetext{
163 Concrete numbers are rarely mentioned, however, and if they are, they are derived from the advertising revenues which increased dramatically during the broadcast of Ramayan.

164 In fact, the particular audiovisual aesthetics and narrative form of the two serials were just as prominent in written and oral accounts of the serials, and were even hotly debated. However, since they do not directly relate to the dynamics of the audience's interaction with the serials, I do not deal with these formal aspects here.

165 While I only reference here the texts in which such accounts are featured, these anecdotal fragments occurred in almost every one of the roughly 45 interviews I conducted.
} 
2001: 84; Dwyer 2006: 52), or the postponing political rallies and the like, emphasized just how enthralled masses of people were with the two shows and how their broadcast abruptly altered the rules, dynamics and priorities of social life.

In addition to narrations of the sheer extent of the serials' popularity, accounts also highlight the specific - religious - media practices afforded by Ramayan and Mahabharat. For many pious Hindu viewers - in the accounts of my interlocutors mostly elderly family members - the serials' broadcast was an opportunity to worship the gods that appeared on the small screen. They would take a purifying bath before the broadcast, garland their television set, bow in reverence to the gods on screen, or perform devotional rituals before or during the broadcast. Newspapers and magazines published prominent features and articles addressing the craze the shows caused in the Indian public (see Illustrated Weekly of India, 8 Nov 1987; Bhargava 1987; Vaid-Fera 1987; Bajpai 1988; Lutgendorf 1990: 137; Gillespie 1995; Rajagopal 2001: 93-94; Mankekar 2002: 137; Cusack 2012: 279). While this sort of reaction to the serials was observed with interest by journalist and academics alike, the academic literature incorporated it into the analysis of broader issues of the serials' religiosity and the political implications of their broadcast on the country's only network - which was directly governed by India's decidedly secular government. The most prominent aspects analyzed in this context was the role of the serials in the wider televisual project of nation-building, and the rise of Hindu right-wing ideology in the public sphere (see Mankekar 1993, 1999 and 2002; Rajagopal 2001; Roy 2005). Considering the discourses on the serials' reception as acts of framing in Mieke Bal's sense of the term - as an active process that "produces an event" (2002: 135) - it becomes evident how the reiterations of the discourses set them apart from the rest of the programming, not only with regard to the late 1980s, but from everything that has been broadcast on Indian television before and since ${ }^{166}$. Framing Ramayan and Mahabharat in terms of the outstanding responses to them has itself played a role in making them the popular cultural legends that they are today.

166 Ramayan and Mahabharat are not the only shows that have a benchmark-status in Indian Hindi television. In our interviews, my interlocutors - mostly those working in the television industry or as television critics - would also mention the family-drama serial Kyunki Saas Bhi Kabhi Bahu Thi ('Because the Mother-in-Law Once Also was the Daughter-in-Law'), which aired between 2000 and 2008, and the franchised game-show Kaun Banega Crorepati (known as 'Who Wants To Be A Millionaire' in Anglophone countries) hosted by actor Amitabh Bachchan. Even though these shows, too, have received a lot of attention in Indian Television Studies, to my knowledge, none of them is similarly framed as cultural phenomenon Ramayan and Mahabharat are. 


\section{Nostalgia, Distance, and Embodied Memory: The Generation-Group}

While almost all of my interlocutors gave accounts of people's engagement with Ramayan and Mahabharat, over the course of my stays in India it became increasingly apparent that one group of my interlocutors had a distinct perspective on the serials. These were young adults from their late 20 s to late 30 s, who had watched the serials as children. I watched at least one episode of Ramayan or Mahabharat with many of them. Overall, members of this group recounted similar memories of experiencing the shows, framing them similarly in many respects, but with differing opinions on individual aspects. Even though Ramayan and Mahabharat were neither the first nor the only shows my interlocutors had watched on TV, they stood out to them. The almost ritualized instances of watching the single episodes - every Sunday morning, often with the entire family - and the fact the serials frequently served as a topic of exchange with peers and friends in school, made a strong impression on the children. The serials had a higher relevance in their lifeworlds than was the case for those of my informants who had watched the serials as adults. For many young viewers, Ramayan and Mahabharat evoked amazement and enchantment, and sometimes rejection - but whatever their nature these memories were intense enough to be vividly recalled almost three decades later.

For the child viewers, as probably for the majority of the other viewers, too, the experience of watching Ramayan and Mahabharat entailed a dimension of collectivity. Even if the watching itself was not a regular family event, the exchange with friends or siblings, or even the conscious avoidance of watching, would position viewers in relation to the shows and thereby in relationship to a larger collective. For the sake of simplicity, and lacking a more creative term, I am calling this group of interlocutors the 'generationgroup'.

For many of this group's members, recalling their experience of viewing Ramayan and Mahabharat evoked not only elicited opinions and perspectives but also evoked nostalgia and stirred embodied memories, sometimes producing somatic reactions to the sounds and images of the serials. Given the many similarities among the group's perceptions of Ramayan and Mahabharat, I suggest conceiving of the serials as 'generational objects'. 
This term, coined by psychoanalyst Christopher Bollas, designates cultural objects (also immaterial ones, such as songs) that are endowed with particular sets of meanings and functions by one generation. For this generation, these object(s) "serve as [...] formative matrix" with regard to their "vision of social reality" (1992: 255-56) - or for instance their perspective of popular culture - even though the objects "may also have been used by preceding generations" (ibid.: 255). Generational objects emerge out of age-related commonalities in the perception of these objects and the positions they occupy in people's lives. They are associated with particular, often similar sets of meanings through which they contribute to forming "a sense of generational identity" (ibid.). This does not mean that the countless different ways of making sense of the serials are less intense or important for audience members of other generations. On the contrary, the passions involved in the religious and political perception of Ramayan and Mahabharat are of a different nature and exceed the intensity than my informants' childhood fascinations ${ }^{167}$. Still, for this group, watching the serials as children was a formative experience, especially with regards to their understanding and perspectives on media and on the serials' stories.

When I watched episodes with interviewees, they would often joke, laugh at the serials and demonstrate an ironic distance to them. One oft-recurring remark in this context related to the state of the institution of television in the late 1980s: some of my interlocutors emphasized that their regular watching of Ramayan and/or Mahabharat was due to the lack of alternatives - other than not watching television at all - due to Doordarshan's monopoly at that time (interviews with DV, 8 Apr 2015, KT, 25 Apr 2015, LS and VR 21 May 2015, with TL, 7 Jun 2015, SN, 7 Jul 2015, and SK, 16 Feb2016). In this regard, they appeared to be retrospectively downplaying the mesmerizing power that the serials held over them, or they were perhaps justifying joining the hype. Nevertheless, their childhood fascination for the two serials shone through their accounts (except for those who fiercely disliked them), and their descriptions of the viewing contexts and their viewing experiences were vivid. My interlocutors retrospectively described their enthusiasm, their feelings towards the shows and their memories of the overall television programming in the 1980s. As such, they put the serials in relation to the status of the medium and its further developments, and sometimes also to their current usage of

\footnotetext{
167 Even though my interlocutors were highly educated and many of them ardently political, none of them were aware of the heavily politicized - and mostly academic - discourses around the serials' instrumentalization by Hindu nationalism, and Ramayan's and Mahabharat's discrepancy with the government's secularism.
} 
media. Many of the interviewees recalled already making fun of the shows during the initial broadcast, for example ridiculing their sanskritized Hindi at school by inventing mocking rhymes in the same style. Others remembered being absolutely smitten by the shows. For example, KT recounted that upon watching Mahabharat he was so inspired by its stylized displays of ancient warfare that he immediately downgraded his brand new He-Man action figures that he had bought in the UK the previous summer - until then his favorite toys - by using them as targets for the bows and arrows with which he and his friends would play (interview KT, 25 Apr 2015).

When interviewees and I watched an episode of Ramayan or Mahabharat together, the serials' aesthetics, closely entwined with recollections of the context of viewing the serials in the 1980s, were a central topic of conversation. The sounds and images of these reencounters with Mahabharat or Ramayan occasionally sparked selective, embodied memories of the modes of first experiencing the shows. Many of my interviewees nostalgically recounted the weekly get-togethers in front of the screen with their family, their parents' employees, or neighbors. Some elaborated on the adaptations to their routines to incorporate the collective watching of Ramayan or Mahabharat: having breakfast earlier, hurrying home from Sunday school, or discussing the just-watched episode with relatives who happened to be there. PK told me how our joint serialwatching reminded her of her family's activities and how she felt just after a Mahabharat/Ramayan episode ended:

"You [are] just just feeling this, everybody will stand up, stretch, relax, and I remember that once the episode was over, my uncles and my father would be like ok, now we've got to go for our weekly - whatever. Shopping of vegetables and uhm, ok, I'm going to go and get the meat, my mother would be ok, let's start doing lunch and I would be like shit, I've to finish [...] pending homework and like, Sunday's coming to an end, how terrible. But in those five minutes after the serial ended. And I remember feeling - you know, I would feel with trepidation [...] how the holiday's coming to an end, [...] so I would almost like hang on to those moments where people would stand up and then like there would be a buzz about what happened and what's going to happen next." (PK, 8 Apr 2015)

Bollas describes these kinds of memories "as an inner psychic constellation laden with images, feelings and bodily acuities" that feel "almost as if we can reach through the past and touch the essence of a distant self experience" (1992: 3). The nostalgia of these moments is heavily charged with embodied, emotional memories. Nostalgia, a longing for 
something that is irretrievably lost (Angé and Berliner 2015: 2), describes specific dynamics and textures of memories. As literary scholars Nadia Atia and Jeremy Davies argue, nostalgia "serves as a negotiation between continuity and discontinuity: it insists on the bond between our present selves and a certain fragment of the past, but also on the force of our separation from what we have lost" (2010: 184). This visceral feature of nostalgia, according to Atia and Davies "gives sensory depth to our awareness of the other places, times and possibilities that are at once integral to who we are and definitely alien to us" (ibid.). In its sensory capacities, nostalgia can be triggered by music and other types of sound, which can be objects of nostalgia. Accordingly, the sounds and images of the serials evoked nostalgic memories and feelings by atmospherically re-creating the textures of past experiences.

This sensory, embodied dimension of nostalgia and musical memory manifested particularly noticeably when a few of my interlocutors sang along to the title tracks of the serials, delighted that they still remembered the lyrics after all the years that had passed since the original broadcast ${ }^{168}$. While it was only some of my interlocutors who felt - or gave in to - the urge to sing along to the well-known songs, many others had a similarly embodied musical memory. As previously mentioned, many of my interlocutors would jokingly burst out into the famous "Mahabharat" exclamation from the beginning of the serial's title track, either when I mentioned my research topic or when I asked about their most salient sonic association with the serials. Remembering the serials, so it seemed, linked back to sounds that made their bodies resonate (Abels 2015: 64) and called for such a somatic response. As Abels writes, "hearing can temporarily put us in touch with ourselves" (ibid.: 63), which makes music such an intense trigger of memory and nostalgia.

DV, with whom I watched several full episodes and snippets from the serials over the course of a few weeks during my stay in Delhi, was very open about her intense reactions to the serials' music (all while maintaining her rather ironic distance to the shows), which manifested multiple times. She would laugh out loudly, voice her dislike, or marvel at the representations of miracles performed by gods, shuddering and rubbing their arms upon the sounds and visual effects in these scenes.

\footnotetext{
168 Some interviewees from the episode group, though, did not perceive the music of the serials as something memorable (the title tracks being an exception) and did not have specific musical memories of the shows. 
On one occasion, we were watching episode 3 of Mahabharat together, in which Devavrat renounces his father's throne and takes an oath to never marry and remain childless. This oath not only earns him the name Bhishm ${ }^{169}$, but also the blessing of being able to choose the time of his own death. The scene is pivotal for the further development of the plot. The oath is first announced before Devavrat actually takes it, in a brief scene that is not particularly emphasized in the course of the episode; in fact, it almost vanishes within the narrative flow (example 6.1). At first, DV mistook this for the actual oath and was disappointed with the way the moment was staged. When the actual oath finally ensued (example 6.2), DV excitedly expressed how content she was with the way the scene was staged, with its rumbling thunder effects, booming voices amplified by reverb, special effects and the piercing sound of the immediately ensuing summarizing musical lesson closing the episode:

(clapping her hands) "Whoa! Oh my lord. Ja, that's more like it! (laughing) [...] Mahendra Kapoor [playback singer, B.L.] has to come! - Yes! [...] Oh, I'm getting goosebumps." (DV, interview 24.4.2015).

Her disappointment with what she initially took to be the representation of the actual oath was directed at its staid display and lack of visual and aural emphasis, which strongly mismatched her expectations of the exuberant sound and visual effects typical of the serial, and once her expectations were met in the actual scene, her excitement, triggered by the combination of blasting sounds and flashy images, manifested in a somatic response $\mathrm{e}^{170}$. DV's reactions to the scenes combined her familiarity with the stories and awareness of the gravity of these moments with the impact of the sonic atmospheres and her knowledge of the conventions governing them. She expected the sounds to be intense enough to create a sense of the moment's grandeur, and the subdued sounds of the first

\footnotetext{
169 The name refers to this oath.

170 The correlation of anticipation and embodied responses is a focus in social anthropologist Charles Hirschkind's monograph The Ethical Soundscape: Cassette Sermons and Islamic Counterpublics (2006) on sermon listening in Egypt. Hirschkind explains how an empathic listening mode that involves sensory responses from the entire body is vital for these sermons. The somatic responses are learned along with the process of socialization with this format. The sermons are usually interspersed with narrative elements "from the common stock of cultural wisdom" (2006: 86), so that "the listening pleasure found in such narratives does not reside in the presentation of something entirely new but in the effective and stirring performance of a known account" (ibid.). It is this familiarity that evokes a "sensory responsiveness" (ibid.: 101), or a bodily resonance as Abels would put it, often involving the whole body.
} 
did not meet her expectations. Only when the actual scene of the oath is dramatically staged with its overwhelming washes of music, rumbling layers of sound and Bhishm's roaring voice, was it intense enough for DV to indulge in the resonance of the moment's drama. Her expectations of this scene were fundamentally sonic in nature. Similarly, the tendency of some of my interlocutors to sing along enthusiastically with the title songs can be understood as a somatic indulging in nostalgia triggered by music. In singing along, they succumbed to the nostalgic urge to palpably connect with the music - and the associated "distant self experience" (Bollas 1992: 3) of voicing the web of "idiomatic significance" (ibid.) the serials held for them - while maintaining the ironic distance required by their distinguished adult taste in culture.

\section{The Pop Cultural Legacy of Two Epic Mythologicals}

During my stays in India and the countless conversations with people who had watched the serials as children, I repeatedly encountered examples of the serials' continuing resonance in Indian (metropolitan) popular culture. While 25 years after the end of their broadcast (the last episode of Mahabharat aired in July 1990), Ramayan and Mahabharat were far from omnipresent and had been relegated to pop culture's second tier, the longevity of their impact was evident. Fragments such as the title sequences, the stilted, sanskritized dialogues, the stylized images of clashing arrows, and the craze around their Sunday morning timeslot have become cultural points of reference for at least one generation and continue to surface in various contexts. Such referencing continues to nurture the serials' image as iconic landmarks in India's television history.

One of my interlocutors, journalist and author Akshay Manwani (who had watched the serials as a child) contributed to maintaining the serials' cult status in his writing on popular culture and cinema. On the occasion of the $25^{\text {th }}$ anniversary of the first broadcast of Mahabharat, he wrote an extensive feature on the show for the cultural online magazine Caravan ${ }^{171}$. In it, Manwani emphasizes the serial's production: he traces the process of initiating and conceptualizing Mahabharat as a show on Doordarshan, as well as of the process of assembling the cast and crew. In addition to highlighting the perspective of the production crew, Manwani targets his readers' nostalgia by adding the

\footnotetext{
171 "The Show of Shows", 1 Apr 2013, http://www.caravanmagazine.in/reviews-and-essays/show-shows [view date 18 Nov 2016]. 
backstories to popular and memorable details of Mahabharat, such as Harish Bhimani's iconic voice of Samay. Manwani illustrates failed attempts to capitalize on the success of the show by producing a remake, thus reinforcing the extraordinary nature of the shows' success. The article accords Mahabharat an outstanding position in the history of Indian television, arguing that the primary reason for its prominence was not only the specific historical moment of its broadcast (although this is acknowledged) but also the quality of the conversion of the complex epic narrative into the small screen's serial format. Locating his piece firmly within the usual legendary discourses of deserted streets, Manwani emphasizes the show's impact, even from a contemporary perspective:

"what remains unparalleled is the scale at which Mahabharat was made, and the impact it had on its audience. Watched by almost a quarter of the Indian population, which was on the cusp of the wide-ranging political and economic changes that the early 1990s would bring, this monumental television adaption of a relatively unpopular epic became one of the most important cultural signposts of independent India." (Manwani 2013)

Manwani underlines the significance of this serial in India's popular culture, not only as co-initiator of the genre of the mythological serial, but as televisual role model, point of reference, and anchor of nostalgic memories for those who experienced them as a vibrant spectacle.

Months before my first trip to India, I coincidentally came across a different Ramayan and Mahabharat reference in the shape of three five-minute YouTube videos entitled Metal Bharat (examples 6.3-6.5) ${ }^{172}$. When I followed up on these videos during my first stay in Mumbai, I learned that they were promotional videos advertising a collaborative concert of Indian Metal bands at the 2012 NH7 Bacardi Weekender-festival, issued and produced by the agency that organized the festival. The videos humorously employed the imagery and aural style of the two mythologicals to promote the concert. They alluded to Mahabharat's prominent theme of fraternal rivalry through their story of two opposing parties learning how to be a proper metalhead. The direct references to Mahabharat occurred on more than one level - the names of the videos evidently being one of them. Furthermore, the brief title sequences imitated the emblematic "Mahabharat" call that was followed by a deep Death Metal growl. In this way, they replicated not only the

172https://www.youtube.com/watch?v=mYxK9jroi]c, https://www.youtube.com/watch?v=kXJUs4Chwcw, https://www.youtube.com/watch?v=QuBipOhbGQk, [view date 18 Nov 2017]. 
aesthetics but also the structure of this segment of the title song. Parts two and three of the videos are modeled on episodes and (iconic) narrative sections of Mahabharat ${ }^{173}$, such as the game of dice, the education of the princes, or the final battle. Moreover, emblematic figures from the cast of Mahabharat serve as model for the characters starring in the promo videos, such as Drona, Bhishm, Duryodhan and Yudhishthir ("Dudhishthir"). The emblematic sonic and visual markers seem to be as important in signifying the videos as a parody of Mahabharat: shiny costumes, special effects such as the clashing arrows, the imitation of the show's title sequence as well as the background music, which sounds very much like the synthesizer-heavy background music heard in a large portion of Mahabharat ${ }^{174}$. These blatant references are combined with an eclectic mix of references from metal culture, be it the band T-shirts the characters wear, the songs they sing, the cast members assembled from Indian metal bands, or the intradiegetic and diegetic music. The two opposing parties learn headbanging in an ashram, unleash their dueling arrows through guitar solos, and fight their Kurukshetra war in a mosh pit.

Using the mythologicals as a template for the videos was the result of a brainstorming session, as two staff members of the agency which organizes the festival and initated and produced the videos, recalled when we met ${ }^{175}$. Given the serials' high aesthetic recall value and their popularity, especially among people above the age of 30, parodying Mahabharat was guaranteed to be a safe hit. In an interview, one of the videos' cast members told me about the thoroughly positive feedback the videos received from those who knew the serials from their childhoods. He told me that because of the story's prevalence, younger fans, too, liked the videos even though they had not watched the serials $^{176}$.

The "Metal Bharat" videos are not the only reference to the serials' aesthetics within Indian popular music. There is, for instance, a mashup-video of an excerpt of a track of EDM-producer Nucleya and rapper Divine ("Scene Kya Hai"), which combines the rapidly

\footnotetext{
${ }^{173}$ Many elements could just as easily be modeled on Ramayan, such as the scenes of dual combat with their depiction of the clashing arrows.

${ }^{174}$ In fact, this music is extracted from the children cartoon serial He-Man, which aired on Indian television before the mythologicals (interviews with the director of the videos, 18 Jun 2015, email conversation with VJ).

175 Interview with LS and VR, 21 May 2015. Trying to find a deeper meaning behind the idea, VR suggested that within the context of Indian Metal, Mahabharat would occupy a position similar to mythological stories and figures in sub-genres like Viking or Pagan Metal, which draw heavily on northern European mythology. 176 Interview with KS, 24 May 2015.
} 
paced music with manipulated images of Ram's and Ravan's final battle (example 6.6)177. Uploaded to YouTube in October 2016, the video indicates how deeply, even decades after their broadcast, the aesthetics of the serials are entrenched in India's popular culture where even fragments effectively function as references, satiric or otherwise ${ }^{178}$.

Possibly the most obvious long-term effect of Ramayan and Mahabharat was their establishment of an entire genre: the mythological serial, which is now a staple constituent of India's television program. Their first spin-off was Luv Kush, the continuation of Ramayan's story. It narrated the last book of the Sanskrit epic, which was omitted in the original serial, and aired shortly after Ramayan. Subsequently, spurred by the liberalization of the television market in the early 1990s, the mythological genre burgeoned - in contrast to the mythological film genre's steady descent into (commercial) irrelevance since the 1970s. There was a remake of Mahabharat with the same cast as Chopra's original version a few years after the show aired (Manwani 2013), and numerous shows have been produced about individual characters from the serials, such as Krishna (Shri Krishna, Sagar Arts; 1993, Doordarshan, 1999, Zee TV, 2001, Sony TV)179, Hanuman (Jai Hanuman, 1997-2000, Doordarshan, Sony Entertainment) ${ }^{180}$ or Karna (Suryaputra Karn, Swastik Productions; 2015 - present, Sony TV). There have been remakes of both stories (Ramayan, Sagar Arts; 2008-2009, NDTV Imagine181, Kahani Hamari Mahabharat Ki, Balaji Telefilms, 2008, 9X TV182, or Mahabharat, Swastik Productions; 2013-2014, Star Plus) ${ }^{183}$ and there have been stories about other deities and mythological characters from entirely different sources (such as Devon Ke Dev... Mahadev, 2011-2014, Life $\mathrm{OK}^{184}$ ) -only some of the serials that were produced in Hindi. The genre diversified in terms of the length of episodes, the overall length of the serials' runs, the

\footnotetext{
177 https://www.youtube.com/watch?v=BQ cojh1 9A [view date 18 Nov 2017].

178 As Manuel (1993: 116-120) points out, recordings of Hindu devotional musics have been widely included in temple worship or other devotional contexts. Given that the serials' soundtracks were also marketed separately, it is safe to assume that the songs of Ramayan and Mahabharat also found their way into the formats of performing or telling the epic stories.

179 http://www.sagartv.com/krishna.htm [view date 17 May 2016]

$180 \mathrm{http://www.imdb.com/title/tt2452062/} \mathrm{[view} \mathrm{date} 18$ Nov 2017]

181 http://www.sagartv.com/ramayan-new.htm [view date 17 May 2016]

$182 \mathrm{http}: / /$ balajitelefilms.com/serial.php?id=65 [view date 18 Nov 2017]

$183 \mathrm{http://swastikproductions.com/work-2/ \# .VzreAvmLTIU} \mathrm{[view} \mathrm{date} 18$ Nov 2017]

184 http://www.hotstar.com/tv/devon-ke-dev-mahadev/12 [view date 18 Nov 2017]
} regular Hindu religious practices of their audience, and probably also had an effect on popular religious 
frequency of airing - from daily to weekly formats - and so on. The continuous diversification of the market meant that no subsequent mythological received nearly as much attention as Ramayan or Mahabharat. Nevertheless, the mythological genre continues to be a seemingly sure formula for success in India's competitive television landscape ${ }^{185}$.

Ramayan and Mahabharat not only established mythological stories in Indian television, they also broke with the sparse aesthetics of previous realist televisual dramas and introduced the era of booming, swirling, dramatic sound and bright, shiny visuals in Indian television. This particular audiovisual aesthetic also shaped the mythologicals of the 1990s. These serials, too, drew on a range of performative traditions, especially the genre of the mythological film, and combined orchestral sounds, soft sitars and bansuri with synthesized sound effects in ways similar to Ramayan and Mahabharat ${ }^{186}$. In addition, the sounds of mythological television gradually changed due to technological advancements in film and music production, the continuously and rapidly evolving television industry in India, and general shifts in audiovisual aesthetics. As Indian television increasingly developed its distinctive voice, the sounds of mythologicals and of other televisual genres started to gradually become more similar to each other.

Today, television serials in India narrate through "carpet music", as two of my interlocutors from the television industry put it ${ }^{187}$ - through continuous streams of intradiegetic scoring that almost entirely covers the episodes. Combined with highly polished visual aesthetics, the sounds of Indian (mythological) TV serials today create a constant mode of high drama in their narratives. The use of reverberation effects on voices and (intradiegetic) sounds makes them larger than life. Synthetic droning, stringlike sounds are rhythmized by scattered and rapid percussive patterns and stingers. This not only intensely and relentlessly produces atmospheres of threat or suspense, but also of highly emotional drama188. Despite this rather homogenous aural televisual

\footnotetext{
185 As some flops, such as the Balaji Telefilm's version of Mahabharat, Kahani Hamari Mahabharat Ki (2008) demonstrate, the genre alone is not always entirely enough for a serial's success.

186 These similarities are not too surprising given not only the success of Ramayan and Mahabharat, but also the fact that Sagar Arts, the Sagar family's production company, as well as Ravindra Jain, kept producing mythological serials in the decades after Ramayan.

187 Interviews with BG (1 Jul 2015), and with SK (4 Jul 2015).

188 Furthermore, as one informant pointed out to me, this continuous stream of intradiegetic sounds makes the more time-consuming and elaborate production of sound design obsolete (interview SK, 4 Jul 2015). 230
} 
aesthetic $^{189}$, there are however some differences that aurally set mythologicals apart from other genres of serial, for example by using chanting (of mantras) or the sounds of temple bells and conches to highlight their Hindu religious background.

Even though today's mythologicals have a highly polished audiovisual aesthetic that barely resembles the first versions of Ramayan and Mahabharat, these two shows were formative, revealing the genre's potential for India's television market and introducing lavish audiovisual aesthetics to the medium. And while music directors of today's mythological serials orient their work towards contemporary aesthetics, some of those with whom I talked valued Rajkamal's and Ravindra Jain's music as setting a benchmark for ensounding mythological stories.

Ramayan and Mahabharat have acquired an emblematic status in Indian popular culture that is so potent that even individual fragments are sufficient for evoking the discourses and memories of the exceptional social dynamics that surrounded their initial broadcast. The range of reactions of their audience and the Indian public notwithstanding, the broadcast and (commercial) success of Mahabharat and Ramayan made one thing unmistakably clear: the mythological was here to stay.

\subsection{Concluding Thoughts}

Ramayan and Mahabharat received an enormous amount of attention during and even after their broadcast, attracting not only masses of viewers on a weekly basis but also sparking decades of debate. The spectacle of the serials' broadcast generated extended discussions, and these in turn contributed to framing the serials as spectacles. These discussions spread from public conversations into academia, where the serials were generally analyzed in terms of their political impact. Ramayan and Mahabharat owed their now legendary success to their specific position as mythological serials at a historical

\footnotetext{
189 This homogeneity is closely related to the overall dynamics of the television industry today: due to its thorough commercialization and the highly competitive environment this has created, the development and creation of shows today is strictly organized along market research and specific targeting of programs. This also means that, unlike three decades ago, composers must now adhere to strict guidelines set by the channels or production companies (this was the tenor of several interviews I conducted with informants currently working in the television industry).
} 
juncture of India's television. Broadcast before the medium's liberalization and corresponding diversification, but at a time when TV was already accessible for large parts of the population, allowed them to generate maximum attention. This way, Ramayan and Mahabharat made a mark on India's popular culture that continues to be felt today. This was probably largely due to the fact that a significant number of the serials' original audience were children; the serials, and the music that was an indispensable part of them, were objects of nostalgia for many of my interlocutors. In my conversations I learned that this music could be a medium of, and a trigger for, embodied memories. Regardless of how they are treated - sometimes humorously inserted into other contexts or parodied, sometimes earnestly discussed as exceptional phenomena in the history of Indian television - the serials as and their aural and visual aesthetics represent an important milestone in Indian popular culture. 


\section{7 ... The End? - Concluding Thoughts}

What is it that music does in television serials? How can we understand its multiple effects in the audiovisual narrative - gripping us, exciting us, soothing us, making us feel the gravitas of a situation or the villainy of a character, or making our eyes well up with tears? In this thesis, I have approached this question by exploring the music of the first two Indian mythological television serials Ramayan (1987-1988) and Mahabharat (19881990). In their capacity as first mythological serials on Indian television, Ramayan and Mahabharat not only attracted an unprecedented mass audience but also a great deal of academic attention. In addition, the sounds of the two serials are exemplary of how Indian television as medium of entertainment developed its own voice, and a distinct aesthetic demarcated from film.

In this thesis, I have argued that music is an essential narrative element of television serials which shapes televisual storytelling through its atmospheric materiality. As such, it has unique capacities to engage the audience in ways that differ from images and language. I approached the serials through a combination of ethnographic methods and close readings of the audiovisual material. During two research stays in Delhi and Mumbai, India, I conducted mostly semi-structured and conversational interviews and watched episodes or clips of the serials with my interlocutors - who had watched the serials as children, who had been involved in their music production, or who had observed and commented on the serials as cultural critics. Based on these interviews, I reapproached Ramayan and Mahabharat and analyzed the particularities and effects of their sounds, not only within the serial narratives, but as sounds of serials. Within the field of television music studies, this thesis is the first study of Indian television serial music, and the first that explores the sounds of serials outside of North America or Europe.

In my thesis, I sought to outline how sound and music narrate in the medial setting of the two serials studied, and in which ways the multiple effects of music and sound in the audiovisual narrative are particular to sound. I furthermore sought to illustrate the specific styles and aesthetics of Mahabharat's and Ramayan's sounds, thereby highlighting how these aural characteristics interact with and shape the serials' content. Therefore, beyond the chapters in which I focus on the structural characteristics of sound 
and its impact, I approach the sounds of the two serials in terms of key topics - their amalgamated aesthetics, religion, morality, violence, pop-culture - that particularly shape the shows.

I started my study by fleshing out the main concept underlying my argument about music's functions and effects in audiovisual narratives. Based on the assumption that music and sound are narrative agents in Ramayan and Mahabharat, I first explored the concept of narrative, and focused on Marie-Laure Ryan's and Werner Wolf's notion that narrative is a cognitive scheme that can be evoked in and by different media, as well as Peter Verstraten's model of filmic narration. Against the backdrop of these approaches, I argued that music and sound possess narrativity: they are able to evoke narrative scripts and, in the audiovisual context of television (as in film), constitute the narrative in conjunction with images and language. Inquiring further into how sounds, which obviously lack the explicit denotational qualities of words, are able to narrate in television's audiovisual setting, I argued that the core of sound's narrative capacity is its specific materiality, which pervades the audience and evokes often visceral responses, and by which it is also able to signify. I proposed to employ the concept of atmospheres to grasp the quality and effects of sound's materiality. As atmospheres, sounds are not just heard, but felt. They pervade the audience, make the audience resonate as they fill space - both the fictional narrative space as well as the actual physical space of viewing and listening. Aural atmospheres mobilize cultural knowledge and thus can evoke deepseated, visceral responses. As such, they are an element of sound's signifying processes that are a vital part of relating the audiovisual narratives, the course of the stories as well as the implied (and subjective) emotional dimensions. The reactions to musical atmospheres are culturally learned, which is why I argued that in the audiovisual setting their narrative capacities can also be understood as functioning through signification. Conceiving of sounds as icons, indices and, given the thorough conventionalization of their employment in audiovisual media, even as symbols in Peirce's sense, allows us to understand how even tiny, abstract fragments of sound can enable a particular understanding of a scene. The quality of these effects, however, is better understood in terms of its atmospheric impact.

Against this conceptual backdrop, I outlined the structural and stylistic characteristics of music in Ramayan and Mahabharat and provided an overview of the range of formats, narrative functions and formal effects of music and sound in the two serials. Sound and 234 
music frame and structure episodes, they evoke settings and create the magic of gods and demons, they judge and comment on situations, characters, and reactions. They create moods, evoke emotions and sensations, impart images with a temporal dimension and causality, and they provide orientation within the serial narrative as a sort of aural longterm memory.

As narrative agents, music and sound are crucial to telling the serials' stories, powerfully shaping the particular readings the serials promote and the values implied in them. Sound and music effectively position the serials within the rich traditions of the stories they narrate. By highlighting particular aesthetics over others, for instance, they essentially contribute to producing a particular version of their respective story. In this case, they constituted hegemonic versions of two morality stories, which were then broadcast on a state-controlled medium to a mass audience unprecedented in its scope. Therefore, in the third chapter, I inquired into how the music of the serials impacted the particular readings of the stories and focused on which musical aesthetics and traditions are amalgamated. In so doing, I addressed a prevalent topic in the academic discourse on the two shows, but in which, as with most other topics, the aural dimension has so far been ignored. I pointed out how Ramayan and Mahabharat heavily draw on cinematic aural aesthetics as well as a number of North Indian performance and narrative traditions. To exemplify the serials' amalgamated textures, I analyzed their title sequences, showing that they draw on various traditions of narrating the stories themselves and are therefore illustrative of the serials' overall eclecticism. Furthermore, these sequences, as central structural elements of the shows that frame the narratives and are vital constituents of their seriality, also reveal the particular interpretation of the stories that is promoted in the serials - ones that focus on the religious dimension of the stories, and, in the case of Mahabharat, revolve around the war that ends the story.

Further probing beyond the purely structural qualities of sound, in the following two chapters I focused on how music and sound shape two complexes that are central in both serials: religion, morality, normativity, and violence. The representation of these particular aspects, too, is a crucial element in positioning the serials among the re-tellings that affirm hegemonic versions of the stories. 
In chapter four, I focused on the ways in which sound and music construct and represent the cluster of morality, normativity and religion in Ramayan and Mahabharat - another topic that strongly shapes the academic discourse on the shows. Contrary to the academic positions on the topic, the sum of my interlocutors had mixed opinions about whether or not the serials were religious shows. Nevertheless, representations of Hindu religious practice and religiously legitimized moral claims pervade the serials. I therefore explored how music not only evokes Hindu religious settings and ritual contexts, but also functions as Hindu devotional practice itself. As atmospheric means of narration, sound and music create a web of religious references in Mahabharat and Ramayan, which highlights the historical background of the stories as bhakti-narratives. More so, as forms of worship in themselves, the devotional songs and sonic representations of rituals can powerfully mediate religious feelings. At the same time, the aural representation of religious practice promotes particular (regional) forms and aesthetics of worship. Likewise, sound crucially co-constructs the moral frameworks of the serials. By intradiegetically commenting on characters and situations, or rather, by almost constantly providing clouds of sound that create emotionally engaging sensations of comfort, threat, grandeur or sadness, the music paints a clear picture of good and bad, of dharm and adharm. By this same dynamic, morally and religiously legitimized norms are conveyed through sound. I explored this aural creation of normativity mostly in terms of gender. Characters that deviate from social norms are sonically created as transgressive and potentially problematic. Gendered and morally or religiously legitimized normativity also manifests subtly, for instance through the sounds of voices, or the gendering of musical practices and representation. Here, it is particularly salient that the male voice is constructed as the sole bearer of (narrative) authority in Mahabharat and Ramayan.

I extended this thematic approach in chapter five by focusing on the audiovisual representation of violence in Mahabharat and Ramayan. Violence, too, as the teleologically framed climax of both narratives, is entangled with morality, normativity, and particular gender dynamics. The role of sound in representing violence in audiovisual narratives, however, has generally barely been researched. I explored how the (aural) representations of violence are distributed over the serial narratives in irregular clusters. I analyzed the audiovisual aesthetics of representing violence, which are further examples for Mahabharat's and Ramayan's amalgamated textures because they fuse the cinematic aesthetics of the mythological genre with the technical specificities afforded by the new 
televisual medium. The use of synthesizers - easily accessible and not requiring huge amounts of resources - here serves to modernize the stylized visuals of many of the scenes of violence and evokes the often supernatural qualities of the adversaries. I then focused on how sounds are crucial for introducing a bodily dimension into the often very stylized, disembodied visual representations of violence. Sound and music, here, are indispensable for framing the visuals as acts of violence, as they structure the images and create intensity. It is the sounds that create atmospheres of threat, tension or fear, and which evoke a sense of the physical force, and the strain and pain of the violent encounters. As such, they are vital for engaging the audience, making them empathize with the characters' unease or aggression, or palpably feel the rush of the violent encounter. I furthermore explored the gendered dynamics of the audiovisual representations of violence in the serials, which also intersect with Ramayan's and Mahabharat's implicit claims to normativity. I pointed out the close connection between violence and the norms and ideas of masculinity as conveyed in the serials, as masculinity is dependent on exerting violence, at the same time legitimized and restricted by the moral frameworks of the shows. This, in turn, the distinction between 'right' and 'wrong' violence (and masculine conduct) is strongly shaped by sound.

In chapter six, I focused on the necessarily retrospective character of my study, conducted decades after the serials were first broadcast. I looked more closely at the ways in which the serials were remembered by their former audience, and the pop-cultural echoes they produced. I outlined how the dynamics and particularities of the audience's response to the serials during the first broadcast shaped the discourses about Ramayan and Mahabharat, not only during their broadcast, but also in the years to follow, and how I still encountered these anecdotes during my research. Drawing on encounters during my research stays in India, I described how the serials' music functions as an anchor for the embodied memory of members of their former audience. For this group - who were children when they first watched the shows - the serials are a generational object, a collective pop-cultural landmark. As a result, this generation keeps incorporating references to Ramayan and Mahabharat into their current cultural work, where fragments of the serial serve as points for identification. 
Ramayan and Mahabharat were the first serials to introduce Hindu mythological content to Indian television. While there had been popular, Indian-produced television serials before them, the two mythologicals were not only milestones in terms of their popularity, they also brought a new aesthetic to Indian television. Beyond these aesthetic innovations, so far Ramayan and Mahabharat have mainly been analyzed from highly political perspectives. While my thesis mainly revolved around the aural aesthetics, the structural particularities of sound in the two shows, my study however does complement these perspectives. For instance, as mentioned earlier in this study, the serials have been understood as contributing to the increasing pervasiveness of Hindu symbolism in India's public space, which has been implicated in the rise of the Hindu right (Mankekar 1999, 2002; Rajagopal 2001; Ohm 2007; Sinha 2014). In the light of my analyses of the sonic representation of Hindu religious practice in Ramayan and Mahabharat, this phenomenon also has an aural dimension: the thorough pervasiveness of Hindu religious songs and singing in the serials, likewise contributes to normalizing the aural presence of Hindu devotion in public space. On one level, this pertains to the medial context of these sounds: they were disseminated on a state-controlled mass medium (by a decidedly secular government) and explicitly marketed as universal and pan-Indian. On another level, this normalization pertains to the density with which sounds of Hindu devotion, particularly through song and singing, were incorporated in the narratives. In Ramayan, passages of devotional singing were particularly prevalent, strongly shaping the narrative mode of the entire serial. In Mahabharat, the religious aural framing of the story, while less frequent, had a more subtle quality: the multiple renditions of the 'Om Jai Jagdish Hare' melody with lyrics relating to the respective narrative setting continuously evoked the devotional Hindu backdrop without making it explicit. Yet, these sounds subliminally framed the serial as unmistakably Hindu, thus demonstrating similar slippages between Indian and Hindu culture that Mankekar (1999) points out in the serials' dialogues and voice-over narration. While this aural religious framing might indeed be so subliminal that it has been routinely overlooked in analyses of the shows, it is all the more efficient. Just as images in a given (public) space, but more subtly, the religious sounds of the serials pervade the space in which they are heard, and claim it, suffusing it with markers and sonic evocations of Hindu devotion. Likewise, the music of Ramayan and Mahabharat might be understood as a material manifestation of the particular post-colonial dynamics of modernity in India. The dynamics of this particular Indian modernity, described by 
Chatterjee (1999) as heterogeneous, are analyzed in their relation to Ramayan and Mahabharat by Mankekar (1999) and Rajagopal (2001). They point out how the heterogeneous coexistence of different temporalities particular to this modernity is exemplified in the serials, which construct "an idealized past that showed the symptoms of modernity long before its time" (Rajagopal 2001: 25) in the thoroughly modern medium of television. The sounds of the serials, amalgamating futuristic synthesizer sounds with the imagined music of antiquity, do exactly this: they generate a sonic heterogeneity that allows the representation of gods, monsters and miracles to seem thoroughly modern while at the same time legitimizing the modern medium with 'traditional' aesthetics.

Beyond this, my study has pointed towards further fields of possible research. My initial exploration of television serial music beyond the North Atlantic axis is only the beginning, as there are entire worlds of televisual aural narration and other dynamics of sound in the medium that have yet to be explored in academic research. Beyond political or aesthetic questions, the dynamics of how sounds and the televisual formats in which they are heard, reciprocally influence each other - how sound shapes the format and how the formats shape sound, is a promising and so far only scarcely researched field. In my study, I only fleetingly touched upon the ways in which the Indian television market and its sounds, especially in the mythological genre, further developed after Ramayan and Mahabharat. Exploring the shifts and developments of aesthetics and inquiring into the changing paradigms of aural narration would also be a fruitful line of inquiry. Likewise, my chapters on the aural representation of violence and of mediating religion in Mahabharat and Ramayan shine a light on the aesthetics of two essential social practices, which have so far not received a lot of attention in academic research.

My study of Ramayan's and Mahabharat's music is the first to comprehensively engage with the sounds of non-European or American televisual formats. In it, I proposed to understand music and sound as narrative agents of television serials whose efficiency and particularly intense emotional-visceral effects on the audience can be linked to its atmospheric materiality. I showed how the sounds of Mahabharat and Ramayan were essential in structuring, framing and relating the shows' stories, in evoking social and religious practices, abstract ideas of good and bad, and in thoroughly engaging the 
audience. Hopefully, my contribution to the study of television music is an incentive for other researchers to pick up this thread and take it further. 


\section{Filmography}

B.R. Chopra, Ravi Chopra. Mahabharat. DVD Set, Arrow Films 2009.

Ramanand Sagar, Ramayan. DVD Set Vol. 1-16, Digital Version in Hindi with English SubTitles, Asian Video Movie.

\section{Bibliography}

Abbink, Jon. 2000. "Preface: Violation and Violence as Cultural Phenomena." In Meanings of Violence: A Cross Cultural Perspective, edited by Göran Aijmer and Jon Abbink, xi-xvii. Oxford: Berg.

Abbott, H. Porter. 2011. "Narrativity." In The Living Handbook of Narratology, ed. Peter Hühn et al. Hamburg: Hamburg University, URL = http://www.lhn.uni-hamburg.de/ [view date: 26 Nov 2017].

Abels, Birgit. 2015. "Emotional Ecologies and Musical First Aid at the Edge of Reason (Mind You: Baby, This Is Serious." In "Rage, Anger and other Don'ts," edited by Regina Bendix, special issue, Ethnologia Europaea 45, no.2: 61-66.

Abels, Birgit. 2013 "Hörgemeinschaften. Eine musikwissenschaftliche Annäherung an die Atmosphärenforschung." Die Musikforschung 66: 220-231.

Abels, Birgit. (Forthcoming.) "Musical Atmospheres and Sea-Nomadic Movement Among the Sama Dilaut: Sounding Out a Mobile World." Mobile Culture Studies 3.

Abels, Birgit. 2016. "Restless, Risky, Dirty (An Introduction)." In Embracing Restlessness: Cultural Musicology, ed. Birgit Abels, 1-15. Hildesheim: Olms.

Aijmer, Göran and Jon Abbink, eds. 2000. Meanings of Violence: A Cross Cultural Perspective. Oxford: Berg.

Akass, Kim and Janet McCabe, ed. 2005. Reading Six Feet Under: TV to Die For. London, New York: I.B. Tauris.

Allrath, Gaby, Marion Gymnich, Carola Surkamp. 2005. "Introduction: Towards a Narratology of TV Series." In Narrative Strategies in Television Series, edited by Gaby Allrath and Marion Gymnich, 1-43. Basingstoke, New York: Palgrave Macmillan.

Almén, Byron. 2008. A Theory of Musical Narrative. Bloomington, Indianapolis: Indiana University Press.

Altman, Rick. 1986 “Television/Sound.” In Studies in Entertainment: Critical Approaches to Mass Culture, edited by Tania Modleski, 39-54. Bloomington, Indianapolis: Indiana University Press. 
Anderson, Aaron. 2001. "Violent Dances in Martial Arts Films." Jump Cut: A Review of Contemporary Media 44, URL https://www.ejumpcut.org/archive/ic44.2001/aarona/aaron1.html [view date: 26 Nov 2017].

Anderson, Ben. 2009. “Affective Atmospheres.” Emotion, Space and Society 2: 77-81.

Angé, Olivia and David Berliner. 2015. "Introduction: Anthropology of Nostalgia Anthropology as Nostalgia." In Anthropology and Nostalgia, edited by Olivia Angé and David Berliner, 1-15. New York: Berghahn.

Arnold, Alison. 1992. "Aspects of Production and Consumption in the Popular Hindi Film Song Industry." Asian Music 24, no.1: 122-136.

Aslinger, Ben. 2013. "Nip/Tuck: Popular Music.” In How to Watch Television, edited by Ethan Thompson and Jason Mittell, 47-55. New York: New York University Press.

Atia, Nadia and Jeremy Davies. 2010. "Nostalgia and the Shapes of History." Memory Studies 3, no.3: 181-186.

Attali, Jacques. 1985. Noise: The Political Economy of Music. Minneapolis: University of Minnesota Press.

Attinello, Paul, Janet K. Halfyard and Vanessa Knights, eds. 2010. Music, Sound, and Silence in "Buffy the Vampire Slayer". Farnham: Ashgate.

Bajpai, Shailaja. 1988. “Is there Life After Ramayana?” Indian Express Magazine, August 7.

Bal, Mieke. 1997. Narratology: Introduction to the Theory of Narrative. $2^{\text {nd }}$ ed. Toronto: University of Toronto Press.

Bal, Mieke. 2002. Traveling Concepts in the Humanities: A Rough Guide. Toronto: University of Toronto Press.

Banerjea, Koushik. 2005. "Fight Club': Aesthetics, Hybridisation and the Construction of Rogue Masculinities in Sholay and Deewaar." In Bollyworld: Popular Indian Cinema Through a Transnational Lens, edited by Raminder Kaur and Ajay J. Sinha, 163-185. New Delhi: Sage.

Beaster-Jones, Jayson. 2015. Bollywood Sounds: The Cosmopolitan Mediations of Hindi Film Song. Oxford: Oxford University Press.

Beck, Guy L. 2012. Sonic Liturgy: Ritual and Music in Hindu Tradition. Columbia: The University of South Carolina Press.

Bhargava, Simran. 1987. “Divine Sensation.” India Today, April 30, 70-71.

Bieger, Laura. 2011. “Ästhetik der Immersion: Wenn Räume wollen. Immersives Erleben als Raumerleben." In Raum und Gefühl: Der Spatial Turn und die neue Emotionsforschung, ed. Gertrud Lehnert, 75-95. Bielefeld: transcript.

Böhme, Gernot. 2000. "Acoustic Atmospheres: A Contribution to the Study of Ecological Aesthetics.” Soundscape: The Journal of Acoustic Ecology 1, no.1: 14-18. 
Bollas, Christopher. 1992. Being a Character: Psychoanalysis and Self Experience. London: Routledge.

Bolter, Jay David and Richard Grusin. 1999. Remediation: Understanding New Media. Cambridge: MIT Press.

Booth, Gregory. 2008a. Behind the Curtain: Making Music in Mumbai's Film Studios. Oxford: Oxford University Press.

Booth, Gregory. 2000. "Religion, Gossip, Narrative Conventions and the Construction of Meaning in Hindi Film Songs." Popular Music 19, no. 2: 125-145.

Booth, Gregory. 2008b. “That Bollywood Sound.” In Global Soundtracks: Worlds of Film Music, ed. Mark Slobin, 85-113. Middletown: Wesleyan University Press.

Booth, Gregory. 1995. "Traditional Content and Narrative Structure in the Hindi Commercial Cinema." Asian Folklore Studies 45, no. 2: 169-190.

Bor, Joep, ed. 1999. The Raga Guide: A Survey of 74 Hindustani Ragas. Rotterdam: Nimbus Records.

Brockington, John. 2004. "The Concept of Dharma in the Rāmāyaṇa." Journal of Indian Philosophy 32, no. 5-6: 655-670.

Brown, Royal S. 1994. Overtones and Undertones: Reading Film Music. Berkeley: University of California Press.

Brownrigg, Mark and Peter Meech. 2002. "From Fanfare to Funfair: The Changing Sound World of UK Television Idents." In "Music and Television", edited by Keith Negus and John Street, special issue, Popular Music 21, no. 3: 345-355.

Bryant, Edwin Frances. 2007. "Krishna in the Tenth Book of the Bhagavata Purana." In Krishna: A Sourcebook, edited by Edwin Frances Bryant, 111-137. Oxford: Oxford University Press.

Chatterjee, Partha. 1999. "Anderson's Utopia." In "Grounds of Comparison: Around the Work of Benedict Anderson", edited by Pheng Cheah, special issue, Diacritics 29, no.4: 128-134.

Cheng, William. 2013. "Monstrous Noise: "Silent Hill" and the Aesthetic Economies of Fear." In The Oxford Handbook of Sound and Image in Digital Media, edited by Carol Vernallis, Amy Herzog and John Richardson, 173-190. New York: Oxford University Press.

Chion, Michel. 1994. Audio-Vision: Sound on Screen. New York: Columbia University Press. Chion, Michel. 1999. The Voice in Cinema. New York: Columbia University Press. 
Coulthard, Lisa. 2013. "Dirty Sound: Haptic Noise in New Extremism." In The Oxford Handbook of Sound and Image in Digital Media, edited by Carol Vernallis, Amy Herzog and John Richardson, 115-126. New York: Oxford University Press.

Coulthard, Lisa. 2012. "The Attractions of Repetition: Tarantino's Sonic Style.” In Music, Sound, and Filmmakers: Sonic Style in Cinema, edited by James Wierzbicki, 165-173. New York: Routledge.

Cusack, Carole. 2012. “The Gods on Television: Ramanand Sagar's Ramayan, Politics and Popular Piety in Late Twentieth-Century India." In Handbook of Hyper-Real Religions, edited by Adam Possamai, 279-297. Leiden: Brill, 2012.

Custodi, Andrea. 2007. "'Show You Are a Man!' Transsexuality and Gender Bending in the Characters of Arjuna/Bṛhannaḍā and Ambā/Śikhaṇdin(ī)." In Gender and Narrative in the Mahābhārata, edited by Simon Brodbeck and Brian Black, 208-229. London, New York: Routledge.

Das, Gurcharan. 2010. The Difficulty of Being Good: On the Subtle Art of Dharma. New York: Oxford University Press.

Davison, Annette. 2013. "Title Sequences for Contemporary Television Serials." In The Oxford Handbook of New Audiovisual Aesthetics, edited by John Richardson, Claudia Gorbman and Carol Vernallis, 146-167. Oxford, New York: Oxford University Press.

Deaville, James. 2011b. "A Discipline Emerges: Reading Writing about Listening to Television." In Music in Television: Channels of Listening, edited by James Deaville, 7-33. New York: Routledge.

Deaville, James, ed. 2011a. Music in Television: Channels of Listening. New York: Routledge.

Desai, M.S.M and Premnath Nair. 1988. “How Will Mahabharat Fare?” Indian Express, New Delhi, October 23.

Deshpande, G.P. 1988. “The Riddle of the Sagar Ramayan” Economic and Political Weekly, October 22, 2215-2216.

Devadas, Vijay and Chris Prentice. 2011. “Introduction: Postcolonial Popular Cultures.” In "Postcolonial Popular Cultures", edited by Vijay Devadas and Chris Prentice, special issue, Continuum: Journal of Media and Cultural Studies 25, no. 5: 687-693.

Doniger, Wendy. 1995. "Begetting on Margin: Adultery and Surrogate Pseudomarriage in Hinduism." In From the Margins of Hindu Marriage: Essays on Gender, Religion, and Culture, edited by Lindsey Harlan, Paul Courtright, 160-183. Oxford: Oxford University Press.

Donnelly, K.J. 2005. The Spectre of Sound: Music in Film and Television. London: British Film Institute Publishing.

Donnelly, K.J. 2002. “Tracking British Television: Pop Music as Stock Soundtrack to the Small Screen." In "Music and Television", edited by Keith Negus and John Street, special issue, Popular Music 21, no. 3: 331-343. 
Donnelly, K.J. and Philip Hayward, ed. 2013. Music in Science Fiction Television: Tuned to the Future. New York: Routledge.

Dwyer, Rachel. 2006. Filming the Gods: Religion and Indian Cinema. London, New York: Routledge.

Eisenlohr, Patrick. 2011a. "Introduction: What Is a Medium? Theologies, Technologies and Aspirations." In "What Is a Medium? Theologies, Technologies and Aspirations", edited by Patrick Eisenlohr, special issue, Social Anthropology/Anthropologie Sociale 19, no.1 (2011a): 1-5.

Eisenlohr, Patrick. Forthcoming. Sounding Islam: Voice, Media, and Sonic Atmospheres in an Indian Ocean World. Oakland: University of California Press.

Eisenlohr, Patrick. 2011b. "The Anthropology of Media and the Question of Ethnic and Religious Pluralism." In "What Is a Medium? Theologies, Technologies and Aspirations", edited by Patrick Eisenlohr, special issue, Social Anthropology/Anthropologie Sociale 19, no.1 (2011a): 40-55

Fairchild, Charles. 2011. "Flow amid Flux: The Evolving Uses of Music in Evening Television Drama." Television \& New Media 12, no.6: 491-512.

Fitzgerald, James L. 2004. "Dharma and its Translation in the Mahabharata." Journal of Indian Philosophy 32, no. 5-6: 671-685.

Frith, Simon. 2002. "Look! Hear! The Uneasy Relationship of Music and Television." In "Music and Television", ed. Keith Negus and John Street, special issue, Popular Music 21, no. 3: 277-290.

Fuller, Christopher. 2004. The Camphor Flame: Popular Hinduism and Society in India. Rev. ed. Princeton: Princeton University Press.

Ganti, Tejaswini. 2004. Bollywood: A Guidebook to Popular Hindi Cinema. New York: Routledge.

Ganti, Tejaswini. 2012. Producing Bollywood: Inside the Contemporary Hindi Film Industry. New Delhi: Orient Black Swan.

Gillespie, Marie. 1995. "Sacred Serials, Devotional Viewing, and Domestic Worship: A Case-Study in the Interpretation of Two TV Versions of the Mahabharata in a Hindu Family in West London." In To Be Continued... Soap Operas Around the World, edited by Robert C. Allen, 354-380. London, New York: Routledge.

Goldmark, Daniel, Lawrence Kramer and Richard Leppert. 2007. "Introduction. Phonoplay: Recasting Film Music." In Beyond the Soundtrack: Representing Music in Cinema, edited by Daniel Goldmark, Lawrence Kramer and Richard Leppert, 1-9. Berkeley: University of California Press.

Gorbman, Claudia. 1980. "Narrative Film Music." In "Cinema/Sound", special issue, Yale French Studies 60: 183-203. 
Gorbman, Claudia. 1987. Unheard Melodies: Narrative Film Music. Bloomington, Indianapolis: Indiana University Press.

Gupta, Nilanjana. 1998. Switching Channels: Ideologies of Television in India. Delhi: Oxford University Press.

Hegarty, James. 2012. Religion, Narrative and Public Imagination in South Asia: Past and Place in the Sanskrit Mahābhärata. London, New York: Routledge.

Heldt, Guido. 2013. "Schizophrenic Chords and Warm Shivers in the Stomach: The "New Astronautic Sound" of Raumpatrouille." In Music in Science Fiction Television: Tuned to the Future, edited by K. J. Donnelly and Philip Hayward, 87-110. New York: Routledge.

Helmreich, Stefan. 2010. “Listening Against Soundscapes” Anthropology News, Dec.: 10.

Henry, Edward 0. 1991. "Jogīs and Nirgun Bhajans in Bhojpuri-Speaking India: IntraGenre Heterogeneity, Adaptation, and Functional Shift.” Ethnomusicology 35, no.2: 221242.

Hirschkind, Charles. 2006. The Ethical Soundscape: Cassette Sermons and Islamic Counterpublics. New York: Columbia University Press.

Hudson, Emily T. 2013. Disorienting Dharma: Ethics and the Aesthetics of Suffering in the Mahābhārata. Oxford: Oxford University Press.

Hume, Lynne and Jane Mulcock. 2004. "Introduction: Awkward Spaces, Productive Places." In Anthropologists in the Field: Cases in Participant Observation, edited by Lynne Hume and Jane Mulcock, xi-xxvii. New York: Columbia University Press, 2004.

Illustrated Weekly of India. The Ramayan: Has the Idiot Box Failed to Capture the Spirit of the Great Epic? November 8, 1987.

Iyengar, Jayanthi. 1989. "Scoring On Serials." Times of India, Saturday Times, Section 1, April 22.

Jhingan, Shikha. 2013. "Lata Mangeshkar's Voice in the Age of Cassette Reproduction." BioScope 4, no.2: 97-114.

Jhingan, Shikha. 2011. "Re-Embodying the "Classical": The Bombay Film Song in the 1950s." BioScope 2, no.2: 157-179.

Juluri, Vamsee. 2008. "Our Violence, Their Violence: Exploring the Emotional and Relational Matrix of Terrorist Cinema." In Global Bollywood, edited by Anandam P. Kavoori and Ashwin Punathambekar, 117-130. New York: New York University Press.

Kalinak, Kathryn. 2010. Film Music: A Very Short Introduction. Oxford: Oxford University Press.

Kalinak, Kathryn. 1992. Settling the Score. Madison: University of Wisconsin Press.

Kassabian, Anahid. 2001. Hearing Film: Tracking Identifications in Contemporary Hollywood Film Music. New York, London: Routledge. 
Kaye, Peter. 2005. “I'm Dead, Wow, Cool: The Music of Six Feet Under." In Reading Six Feet Under: TV to Die For, edited by Kim Akass and Janet McCabe, 192-206. London, New York: I.B. Tauris.

Kelleter, Frank. 2012. "Populäre Serialität: Eine Einführung." In Populäre Serialität: Narration - Evolution - Distinktion, edited by Frank Kelleter, 11-46. Bielefeld: transcript.

Kozloff, Sarah. 1988. Invisible Storytellers: Voice-Over Narration in American Fiction Film. Berkeley: University of California Press.

Kramer, Lawrence. 1991. "Musical Narratology: A Theoretical Outline." Indiana Theory Review 12: 141-162.

Krishnan, Prabha. 1990. "In the Idiom of Loss: Ideology of Motherhood in Television Serials." Economic and Political Weekly, October 20-27, 103-116.

Kumar, Shanti. 2006. Gandhi Meets Primetime: Globalization and Nationalism in Indian Television. Urbana, Chicago: University of Illinois Press.

Lerner, Neil, ed. Routledge Screen and Media Series. New York: Routledge.

Levinson, Jerrold. 1996. "Film Music and Narrative Agency." In Post-Theory: Reconstructing Film Studies, edited by David Bordwell and Noël Carroll, 248-282. Madison: University of Wisconsin Press.

Lury, Karen. 2002. "Chewing Gum for the Ears: Children's Television and Popular Music.” In "Music and Television", edited by. Keith Negus and John Street, special issue, Popular Music 21, no. 3: 291-305.

Lutgendorf, Philip. 1990. “Ramayan: The Video.” The Drama Review 34, no.2: 127-176.

Lutgendorf, Philip. 1989. The Life of a Text: Performing the Rāmcaritmānas of Tulsidas. Berkeley: University of California Press.

Mankekar, Purnima. 2002. "Epic Contests: Television and Religious Identity in India." In Media Worlds: Anthropology on New Terrain, edited by Faye D. Ginsburgh, Lila AbuLughod and Brian Larkin, 134-151. Berkeley: University of California Press.

Mankekar, Purnima. 1993. "National Texts and Gendered Lives: An Ethnography of Television Viewers in a North Indian City." American Ethnologist 20, no.3: 543-563.

Mankekar, Purnima. 1999. Screening Culture, Viewing Politics: An Ethnography of Television, Womanhood, and Nation in Postcolonial India. Durham, London: Duke University Press.

Manuel, Peter. 1993. Cassette Culture: Popular Music and Technology in North India. Chicago, London: University of Chicago Press. 
Manwani, Akshay. 2013. "The Show of Shows." Caravan, April 1, http://www.caravanmagazine.in/reviews-and-essays/show-shows

Maus, Fred Everett. 2005. "Classical Instrumental Music and Narrative." In A Companion to Narrative Theory, edited by James Phelan and Peter J. Rabinowitz, 466-483. Malden: Blackwell Publishing.

Mazumdar, Ranjani. 2007. Bombay Cinema: An Archive of the City. Minneapolis, London: University of Minnesota Press.

Meyer, Birgit. 2014. “Around Birgit Meyer's 'Mediation and the Genesis of Presence: Toward a Material Approach to Religion'” Religion and Society: Advances in Research 5: 205-254.

Meyer, Birgit and Annelies Moors, ed. 2006. Religion, Media, and the Public Sphere. Bloomington and Indianapolis: Indiana University Press.

Mitra, Ananda. 1993. Television and Popular Culture in India: A Study of the Mahabharat. New Delhi: Sage.

Moormann, Peter, ed. 2010. Musik im Fernsehen: Sendeformen und Gestaltungsprinzipien. Wiesbaden: VS Verlag für Sozialwissenschaften.

Morcom, Anna. 2007. Hindi Film Songs and the Cinema. Farnham, Burlington: Ashgate.

Nandi, Swaralipi and Esha Chatterjee, ed. 2012. Spectactles of Blood: A Study of Masculinity and Violence in Postcolonial Films. New Delhi: Zubaan.

Negus, Keith and John Street. 2002. "Introduction to 'Music and Television' Special Issue." In "Music and Television", edited by Keith Negus and John Street, special issue, Popular Music 21, no. 3: 245-248.

Negus, Keith and John Street, ed. 2002. "Music and Television", special issue, Popular Music 21, no. 3: 245-388.

Newman, Michael Z. 2006. "From Beats to Arcs: Towards a Poetics of Television Narrative." The Velvet Light Trap 58: 16-28.

Ninan, Sevanti. 1995. Through the Magic Window: Television and Change in India. New Delhi: Penguin.

Ohm, Britta. 2007. "The Televised Community: Culture, Politics, and the Market of Visual Representation in India." PhD diss., University of Frankfurt/Oder.

Peirce, Charles Sanders. 1955. "Logic as Semiotic: The Theory of Signs.” In Philosophical Writings of Peirce, ed. Julius Bucher, 98-119. New York: Dover.

Prince, Gerald. 2005. "On a Postcolonial Narratology." In A Companion to Narrative Theory, edited by James Phelan and Peter J. Rabinowitz, 372-380. Malden: Blackwell Publishing.

Prince, Stephen, ed. 2000. Screening Violence. London: The Athlone Press. 
Raghavendra, M.K. 2006. "Structure and Form in Indian Popular Film Narrative." In Fingerprinting Popular Culture: The Mythic and the Iconic in Indian Cinema, edited by Vinay Lal and Ashis Nandy, 24-50. New Delhi: Oxford University Press.

Rajagopal, Arvind. 2001. Politics after Television: Religious Nationalism and the Reshaping of the Indian Public. Cambridge: Cambridge University Press.

Rajagopal, Arvind. 1993. "The Rise of National Programming: The Case of Indian Television." Media, Culture and Society 15: 91-111.

Rambachan, Anantanand. 2003. "The Co-Existence of Violence and Non-Violence in Hinduism." The Ecumenical Review 55, no. 2: 115-121.

Ranade, Ashok Da. 2006. Hindi Film Song: Music Beyond Boundaries. New Delhi: Promilla.

Reyland, Nicholas. 2014. "Narrative." In Aesthetics of Music: Musicological Perspectives, edited by Stephen Downes, 203-223.New York: Routledge.

Reyland, Nicholas. 2012. "The Beginnings of a Beautiful Friendship? Music Narratology and Screen Music Studies." Music, Sound, and the Moving Image 6, no.1: 55-71.

Richardson, John. 2016. "Ecological Close Reading of Music in Digital Culture." In Embracing Restlessness: Cultural Musicology, edited by Birgit Abels, 111-142. Hildesheim: Olms.

Richardson, John and Claudia Gorbman. 2013. "Introduction." In The Oxford Handbook of New Audiovisual Aesthetics, edited by John Richardson, Claudia Gorbman and Carol Vernallis, 3-35. Oxford: Oxford University Press.

Richardson, John, Claudia Gorbman and Carol Vernallis, ed. 2013. The Oxford Handbook of New Audiovisual Aesthetics. Oxford: Oxford University Press.

Riches, David. 1986 “The Phenomenon of Violence." In The Anthropology of Violence, edited by David Riches, 1-27. Oxford: Basil Blackwell.

Richman, Paula. 1991. "Introduction: The Diversity of the Rāmāyaṇa Tradition.” In Many Rāmāyanas: The Diversity of a Narrative Tradition in South Asia, edited by Paula Richman, 3-21. Berkeley: University of California Press.

Richman, Paula. 2001. "Questioning and Multiplicity Within the Ramayana Tradition." In Questioning Ramayanas: A South Asian Tradition, edited by Paula Richman, 1-23. Berkeley: University of California Press.

Rodman, Ron. 2010. Tuning In: American Narrative Television Music. Oxford: Oxford University Press.

Roy, Abhijit. 2008. "Bringing Up TV: Popular Culture and the Developmental Modern in India." South Asian Popular Culture 6, no. 1: 29-43. 
Roy, Abhijit. 2005. “The Apparatus and its Constituencies: On India's Encounters With Television." Journal of the Moving Image 4.

Roy, Piyush. 2015. "Gendered Bhavas: Perpetuating Notions of "Ideal” Male and Female Behaviour Through Specific Emotions Highlighted in Acting in Mayabazaar." In Transcultural Negotiations of Gender: Studies in (Be)longing, edited by Saugata Bhaduri, Indrani Mukherjee, 145-158. New Delhi: Springer.

Ryan, Marie-Laure. 2010. "Introduction." In Narrative Across Media: The Languages of Storytelling, edited by Marie-Laure Ryan, 1-40. Lincoln: University of Nebraska Press.

Scharff, Christina. 2010. “Silencing Differences: The 'Unspoken' Dimensions of 'Speaking for Others'." In Secrecy and Silence in the Research Process: Feminist Reflections, edited by Róisín Ryan-Flood and Rosalind Gill, 83-95. London, New York: Routledge.

Schechner, Richard and Linda Hess. 1977. "The Ramlila of Ramnagar [India].” The Drama Review 21, no. 3: 51-82.

Scheffel, Michael, Antonius Weixler and Lukas Werner. 2014. “Time." In The Living Handbook of Narratology, ed. Peter Hühn, Peter et al. Hamburg: Hamburg University. URL = http://www.lhn.uni-hamburg.de/article/time [view date: 26 Nov 2017].

Sen, Biswarup and Abhijit Roy. 2014. "Introduction." In Channeling Cultures: Television Studies from India, edited by Biswarup Sen and Abhijit Roy 1-16. New Delhi: Oxford University Press.

Sen Gupta, Suddhabrata. 1991. "Sexual Politics of Television Mythology." Economic and Political Weekly, November 9: 2558-2560.

Sengupta, Roshni. 2017. "Iconography of Violence in Televised Hinduism: The Politics of Images in the Mahabharata." Continuum 31, no. 1: 150-161.

Singh, Kushwant. 1988. "Squeezing the Ramayan Dry.” The Telegraph, August 22.

Sinha, Dipankar. 2014. "From Clients to Consumers: The Missing Citizens Among the Indian Television Audience." In Channeling Cultures: Television Studies from India, edited by Biswarup Sen and Abhijit Roy, 104-128. New Delhi: Oxford University Press.

Small, Christopher. 1998. Musicking: The Meanings of Performing and Listening. Middletown: Wesleyan University Press.

Srivastava, Sanjay. 2006. "The Voice of the Nation and the Five-Year Plan Hero: Speculations on Gender, Space, and Popular Culture." In Fingerprinting Popular Culture: The Mythic and the Iconic in Indian Cinema, edited by Vinay Lal and Ashis Nandy, 122155. New Delhi: Oxford University Press.

Stahl, Matthew. 2002. "Authentic Boy Bands on TV? Performers and Impresarios in The Monkees and Making the Band." In "Music and Television", edited by Keith Negus and John Street, special issue, Popular Music 21, no. 3: 307-329.

Stilwell, Robynn J. 2011. “"Bad Wolf”: Leitmotif in Dr. Who (2005).” In Music in Television: Channels of Listening, edited by James Deaville, 119-141. New York: Routledge. 
Stilwell, Robynn J. 2003a. "It May Look Like a Living Room...: The Musical Number and the Sitcom." ECHO: A Music-Centered Journal 5, no. 1: 1-27.

Stilwell, Robynn J. 2003b. “The Sound is 'Out There': Score, Sound Design and Exoticism in The X-Files." In Analyzing Popular Music, edited by Allan Moore, 60- 79. Cambridge: Cambridge University Press.

Strathern, Pamela and Andrew Stewart. 2002. Violence: Theory and Ethnography. London: Continuum.

Swann, Darius L. 1993. "Rās Līlā." In Indian Theatre: Traditions of Performance, edited by Farley P. Richmond, Darius L. Swann and Phillip B. Zarrili, 177-214. Honolulu: University of Hawaii Press.

Tagg, Philip. 1979. "Kojak: 50 Seconds of Television Music: Toward the Analysis of Affect in Popular Music.” PhD diss., University of Göteborg.

Thielemann, Selina. 2002. Singing the Praises Divine: Music in the Hindu Tradition. New Delhi: A.P.H Publishing.

Thompson, Ethan and Jason Mittell, ed. 2013. How To Watch Television. New York: New York University Press.

Turino, Thomas. 1999. "Signs of Imagination, Identity, and Experience: A Peircean Semiotic Theory for Music." Ethnomusicology 43, no.2: 221-255.

Vaid-Fera, Minnie. 1987. “Hare Rama, Hare Sagar!” Imprint, October, 6-17.

van der Veer, Peter. 1995. "Radical Hinduism and Modernity." In The Limits of Pluralism: Proceedings of the Erasmus Ascension Conference, 83-91. URL: = http://www.mmg.mpg.de/departments/religious-diversity/scientific-staff/prof-drpeter-van-der-veer/\#c3912.

van Straaten, Eva-Maria. 2017. "Listening Out for Sangit Encounters: Dynamics of Knowledge and Power in Hindustani Classical Instrumental Music." PhD diss., University of Göttingen.

Vasudevan, Ravi. 2011. The Melodramatic Public: Film Form and Spectatorship in Indian Cinema. New York: Palgrave Macmillan.

Weber, Tanja and Christian Junklewitz. 2008. "Das Gesetz der Serie - Ansätze zur Definition und Analyse." MEDIENwissenschaft 7, no.1: 13-31.

Weidman, Amanda. 2014 “Anthropology and Voice." Annual Review of Anthropology 43: 37-51.

Wilke, Annette. 2006. "Sound and Sense: Sonic Perception in Hindu India." In Religion and Music: Proceedings of the Interdisciplinary Workshop at the Institute for Scientific Studies of Religions, Freie Universität Berlin, May 2006, ed. Lidia Guzy, 15-59. Berlin: Weißensee Verlag. 
Winters, Ben. 2012. "Musical Wallpaper? Towards an Appreciation of Non-Narrating Music in Film." Music, Sound, and the Moving Image 6, no.1: 39-54.

Winters, Ben. 2010. “The Non-Diegetic Fallacy: Film, Music, and Narrative Space.” Music and Letters 91, no. 2: 224-244.

Wolf, Werner. 2002. "Das Problem der Narrativität in Literatur, Bildender Kunst und Musik: Ein Beitrag zu Einer Intermedialen Erzähltheorie." In Erzähltheorie Trangenerisch, Intermedial, Transdisziplinär, edited by Vera Nünning and Ansgar Nünning, 23-104. Trier: Wissenschaftlicher Verlag Trier.

Woods, Faye. 2013. "Storytelling in Song: Television Music, Narrative and Allusion in The O.C." In Television Aesthetics and Style, edited by Jason Jacobs and Steven Peacock, 199208. New York: Bloomsbury.

\section{Online Sources}

Balaji Telefilms, Kahani Hamari Mahabharat Ki

http://balajitelefilms.com/serial.php?id=65 [view date 18 Nov 2017]

Hotstar, Devon Ke Dev... Mahadev, http://www.hotstar.com/tv/devon-ke-devmahadev/12 [view date 18 Nov 2017]

Internet Movie Database, Jai Hanuman, http://www.imdb.com/title/tt2452062/ [view date 18 Nov 2017]

Sagar Arts, Ramayan (2008) http://www.sagartv.com/ramayan-new.htm [view date 17 May 2016; site no longer available]

Sagar Arts, Shri Krishna, http://www.sagartv.com/krishna.htm [view date 17 May 2016; site no longer available]

Swastik Productions, Mahabharat (2013) http://swastikproductions.com/work2/\#.VzreAvmLTIU [view date 18 Nov 2017]

YouTube, Babubhai Mistri. Mahabharat (1965) https://www.youtube.com/watch?v=pwcExIbNw [view date 2 Dec 2017]

YouTube, Babubhai Mistri. Sampoorn Ramayan (1961)

https://www.youtube.com/watch?v=iU2 KY7RxUM [view date 2 Dec 2017)

YouTube, Dipraj Jadhav, Mashup of Nucleya feat. Diving, Scene Kya Hai, https://www.youtube.com/watch?v=BQ cojh1 9A [view date 18 Nov 2017]

YouTube, Metal Bharat 1, https://www.youtube.com/watch?v=mYxK9jroi]c [view date 18 Nov 2017] 
YouTube, Metal Bharat 2, https://www.youtube.com/watch?v=kX]Us4Chwcw [view date 18 Nov 2017]

YouTube, Metal Bharat 3, https://www.youtube.com/watch?v=QuBipOhbGQk [view date 18 Nov 2017]

YouTube, Ramayan title sequence https://www.youtube.com/watch?v=R9g7kiK cCg [last accessed 30 Nov2017] 